\title{
ANTI-INFLAMMATORY PROPERTIES OF COWPEA PHENOTYPES WITH DIFFERENT PHENOLIC PROFILES
}

\author{
A Dissertation \\ by \\ LEONNARD ODHIAMBO OJWANG
}

Submitted to the Office of Graduate Studies of

Texas A\&M University

in partial fulfillment of the requirements for the degree of

DOCTOR OF PHILOSOPHY

May 2012

Major Subject: Food Science and Technology 
Anti-Inflammatory Properties of Cowpea Phenotypes with Different Phenolic Profiles Copyright 2012 Leonnard Odhiambo Ojwang 


\title{
ANTI-INFLAMMATORY PROPERTIES OF COWPEA PHENOTYPES WITH DIFFERENT PHENOLIC PROFILES
}

\author{
A Dissertation \\ by \\ LEONNARD ODHIAMBO OJWANG
}

\begin{abstract}
Submitted to the Office of Graduate Studies of
Texas A\&M University

in partial fulfillment of the requirements for the degree of

DOCTOR OF PHILOSOPHY
\end{abstract}

Approved by:

Co-Chairs of Committee, Joseph M. Awika Susanne M. Talcott

Committee Members, Lloyd W. Rooney

Bhimanagouda S. Patil

Chair of

Interdisciplinary Faculty, Alejandro Castillo

May 2012

Major Subject: Food Science and Technology 


\begin{abstract}
Anti-inflammatory Properties of Cowpea Phenotypes with Different Phenolic Profiles.

(May 2012)

Leonnard Odhiambo Ojwang, B.S., Egerton University, Kenya;

M.S., University of Missouri, Columbia

Co-Chairs of Advisory Committee: Dr. Joseph M. Awika

Dr. Susanne M. Talcott
\end{abstract}

Cowpea (Vigna unguiculata) is a highly nutritious, drought tolerant crop with several agronomic advantages over other legumes. This study demonstrated the association of different cowpea phenotypes with specific phenolic profiles, antioxidants activity, anti-inflammatory properties on non-malignant colonic (CCD18co) cells challenged with a lipopolysaccharide (LPS), and the effect of boiling on their individual and total flavonoid content.

Only the black and green phenotypes had detectable anthocyanins; and their levels were highest in the black IT95K-1105-5 variety. The red cowpea phenotypes had the highest level of flavonols (858 - $941 \mu \mathrm{g} / \mathrm{g}$ cowpea flour) and white Early Acre variety had the least. Quercetin derivatives were the major flavonols detected, followed by myricetin derivatives. Monomeric, dimeric and polymeric procyanidins also made up a large proportion of cowpea phenolics. The light brown 09FCV-CC27M cowpea variety had the highest average flavan-3-ol content (13,464 $\mu \mathrm{g} / \mathrm{g}$ cowpea flour); whereas white 
and green varieties did not contain detectable levels of flavan-3-ols. Thus, seed-coat color was a good indicator of the accumulation of specific flavonoids in cowpeas.

The black, red and light-brown cowpeas had the highest antioxidant activity measured by ORAC and ABTS methods, correlating with their higher total phenol content (TPC) and condensed tannin content (CTC); whereas the white and green varieties had the least. Boiling significantly affected the phenolic profiles, TPC and CTC of all cowpea varieties studied, as well as the antioxidant activity associated with these compounds. The net reduction in antioxidant activity after boiling was less than the net TPC reduction, indicating that the heat-induced phenolic products may still have radical scavenging capacity.

Overall, proinflammatory genes regulation, intracellular ROS inhibition, and modulation of miR-126 and its target gene VCAM-1 by cowpea were found to be dependent on cowpea variety, phenolic composition and concentrations. The underlying mechanism by which cowpea induced miR-126 may be associated with inhibition of ROS and down-regulation of transcription factor NF- $\mathrm{B}$. These results emphasize the importance of the cancer inhibitory potential of phenolic compounds from cowpea and their possible role in preventing anti-inflammatory disorders. Further in vivo studies with cowpea diets are required to validate their clinical relevance to human health. 


\section{DEDICATION}

To my Mum Claris Martha A. Ojwang and Dad John W. O. Ojwang.

Your constant reminder of nothingness of my yesterday and abundance of today keeps urging me to pursue greater heights. I was fortunate to have been born to the two of you. 


\section{ACKNOWLEDGEMENTS}

My special heartfelt gratitude goes to Dr. Joseph M. Awika for championing my dreams through my entire graduate school. I also wish to thank my committee members Dr. Lloyd W. Rooney, Dr. Susanne M. Talcott and Dr. Bhimanagouda S. Patil for the counsel, honest assessment, encouragement, time and guidance. You offered the critique that strengthened this work.

I wish to thank Dr. Linda Dykes for helping with UPLC/MS analysis and interpretation of the data; you are uniquely talented. Thanks to Dr. Giuliana D. Noratto, Dr. Gabriela Angel-Morales and Nivedita Banerjee for all the patience and help in making me understand molecular biology and cell culture protocols; you are very good teachers. Thanks are also extended to Ms. Shirley Arbizu for her generosity when I really needed CCD18Co cells to enable me finish my experiments.

Thanks to Ms. Twambo Hachibamba of University of Zambia, Lusaka, Zambia, for helping with lab work as well as carefully editing, critiquing this dissertation and her attention to finer details; you improved this work a whole lot. I will always remember the tough times at Centeq and your unwavering support, friendly presence and for preventing several potential nervous breakdowns.

Special thanks to Ms. Antonia Violet Achieng - I enjoy the humor of life because you have always given me your very best - all the way. You are my personal hero. Thanks for being so laid-back. You always make the differences in life so visible to me. 
And to Yvonne T. Akinyi - your thought process mirror mine when I was your age. I hope this work will challenge you to become even better.

I would also like to thank undergraduate student workers Alexandria Bass for her kind help with media preparation, taking care of cells, RNA extractions and real time PCR analysis; Julia D. Nelson for helping with media preparation and facilitating purchasing of reagents and other lab supplies; and Andrea Roque-Andrade for the Western Blot analysis for the cell culture studies. I would like to thank Liyi Yang, Archana Gawde and Karla P. Siska from the Soil and Crop Sciences Department for offering assistance and encouragement during the entire research work. Thanks are also extended to Victor Taleon Alban and Frederico Barros for the healthy exchange of research ideas and for their support.

Special thanks to Dr. B. B. Singh and Mr. David Verbree of Texas A\&M University; as well as Dr. Jeff Ehlers of University of California-Riverside for providing the samples for this research. I highly value the contributions of Dr. Bhimalingeswarappa Geera for his technical support, as well as providing helpful and stimulating scientific discussions.

My sincere gratitude also goes to Dr. Carmen d'Assomption Tekwe, a Biostastistician and a good friend, for helping with the statistical analysis of the data. You are smart.

Thanks to Pamela Littlejohn for everything she represents to Soil and Crop Sciences Department; and to the Cereal Quality Laboratory 2011 team for the encouragement. Your critique helped me win $1^{\text {st }}$ Place in the 2011 AACC International 
Best Student Research Paper Competition during the 2011 AACCInt. Annual Meeting in Palm Springs, CA.

Thanks to my uncles and aunts for their prayers and encouragement and for getting me through the bumps in my childhood and throughout my high school education. Thanks to all my nieces and nephews for modeling me into a good role model. Thanks to all my cousins for all the good wishes - I love you.

I am particularly indebted to my brothers: Evans, Julius and Dickson and my sisters: Rose and Hellen Night for their outstanding love and support. You are a constant reminder of what I have got and how lucky I am.

Special thanks to my Mum Claris Martha A. and Dad John W. O. Ojwang who have encouraged every step of my journey. You are the ultimate reason I did this; each and every day you endured and struggled to give me a decent upbringing in the midst of emptiness and to make my education so possible, so irreplaceable, so unique and so focused. I did this on your behalves. I love you!

All in all, Glory be to God the Father, the Son and the Holy Spirit for driving my academic progress and facilitating EVERYTHING in my life. 


\section{TABLE OF CONTENTS}

Page

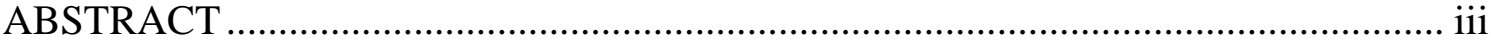

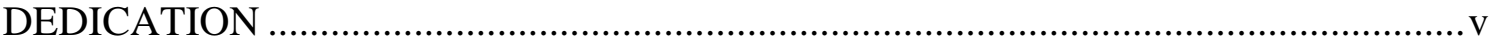

ACKNOWLEDGEMENTS ..............................................................................

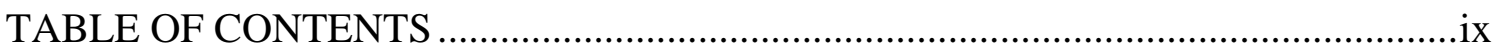

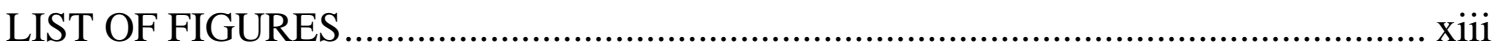

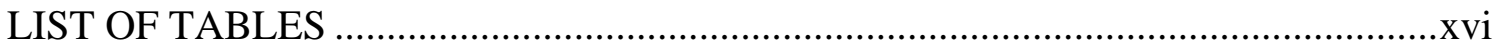

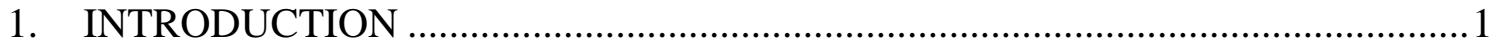

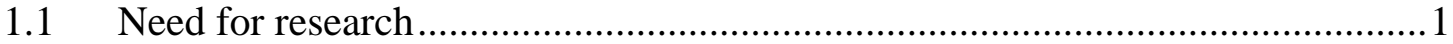

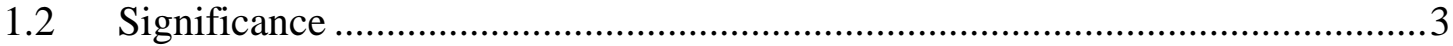

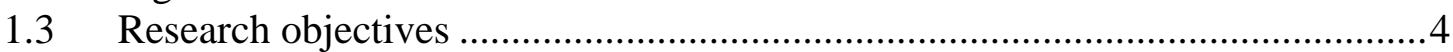

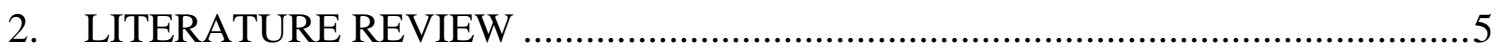

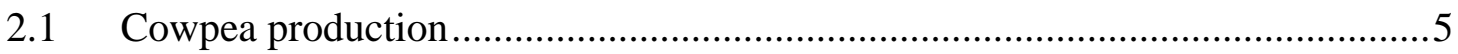

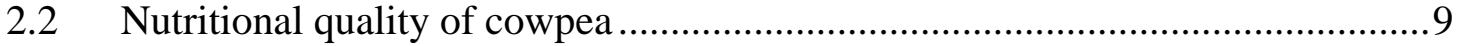

2.3 Utilization of cowpea for human food........................................................... 11

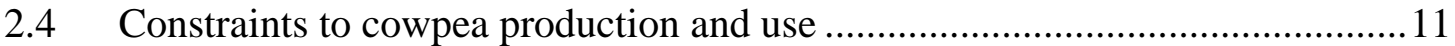

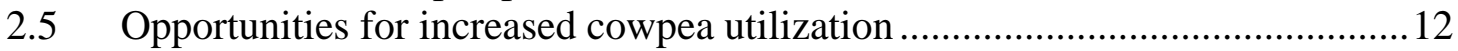

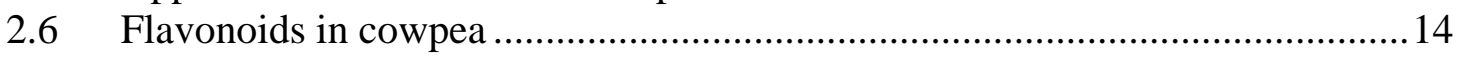

2.7 Importance of legume flavonoids as antioxidants .........................................17

2.8 Effect of thermal processing on phenol content and antioxidant activity of

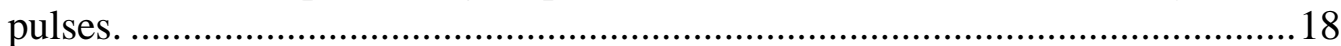

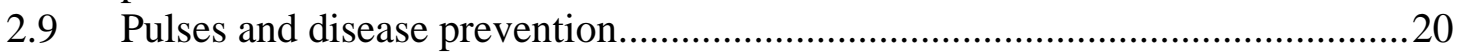

2.9.1 Pulses in prevention of cardiovascular disease ........................................20

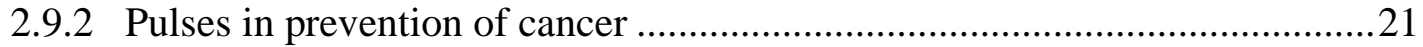

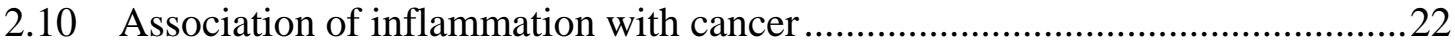

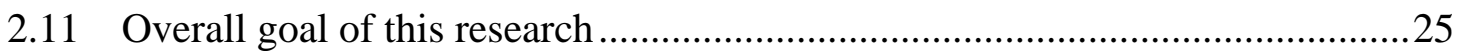

2.12 Potential impact of this research................................................................26 


\section{PHYTOCHEMICAL PROFILES OF DIFFERENT COWPEA PHENOTYPES} AND THEIR LEVELS BEFORE AND AFTER THERMAL PROCESSING ........27

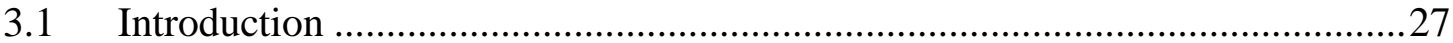

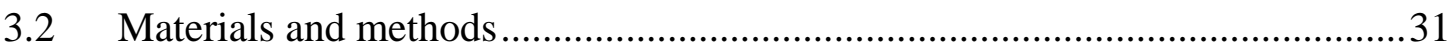

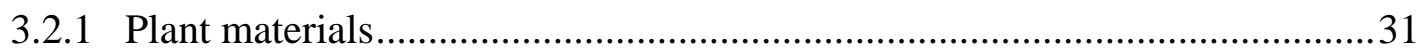

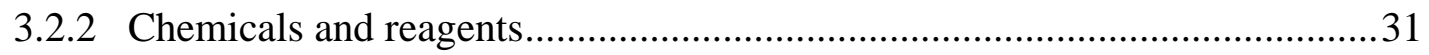

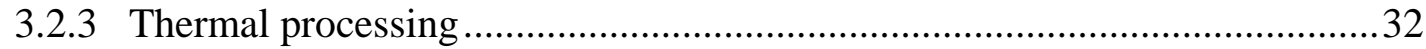

3.2.4 Extraction of polyphenols for HPLC and mass spectrometry analysis...........33

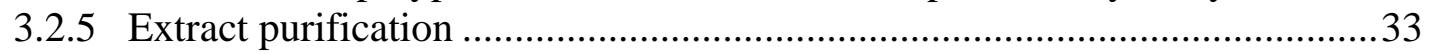

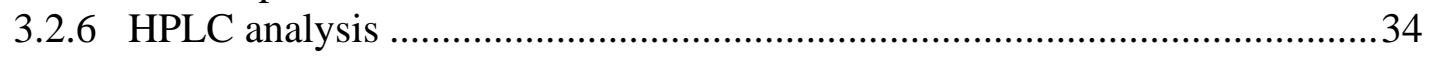

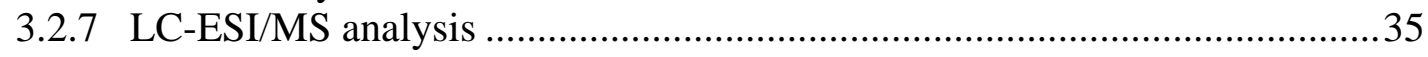

3.2.8 Quantification of anthocyanins, flavonols and flavan-3-ols .........................37

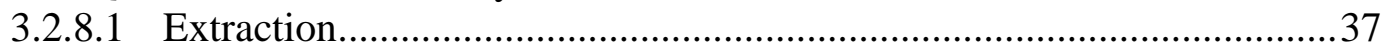

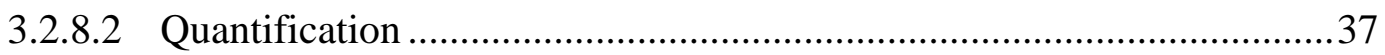

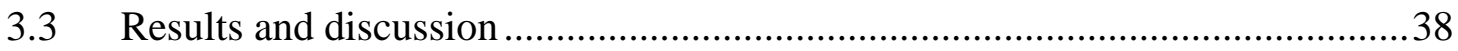

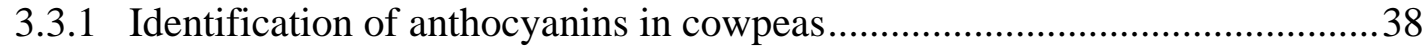

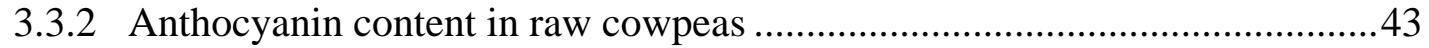

3.3.3 Effect of boiling on anthocyanin content in cowpea ...................................46

3.4 Flavonoids in the methanolic fractions.......................................................48

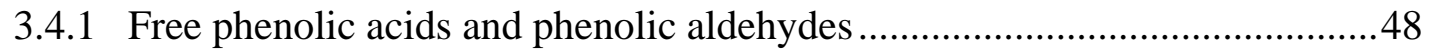

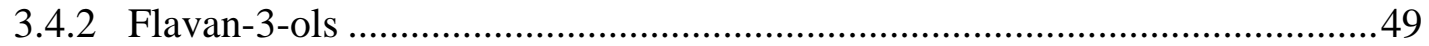

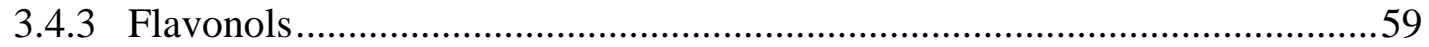

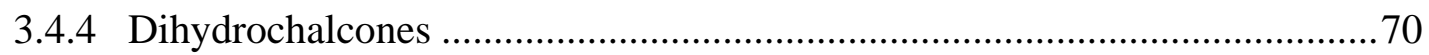

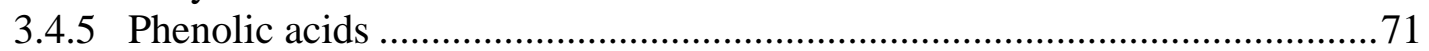

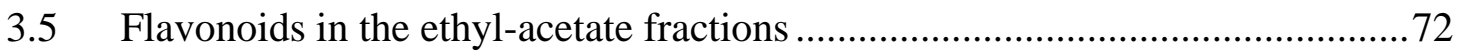

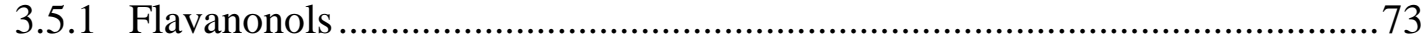

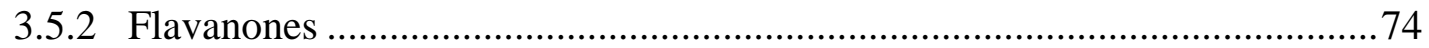

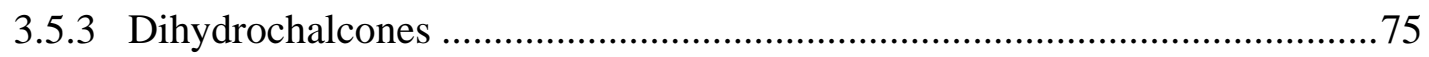

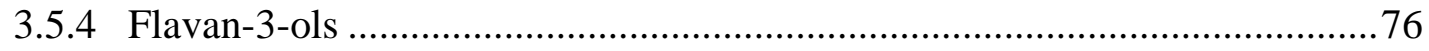

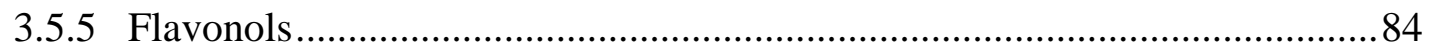

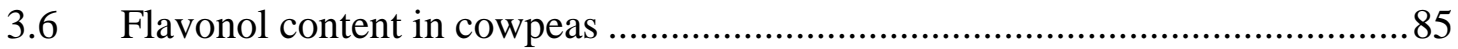

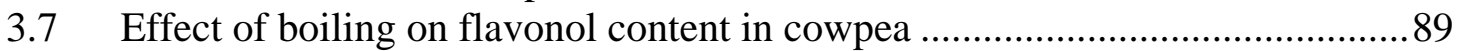

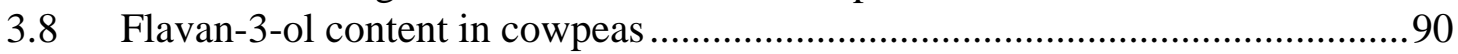

3.9 Effect of boiling on flavan-3-ol content in cowpea......................................94

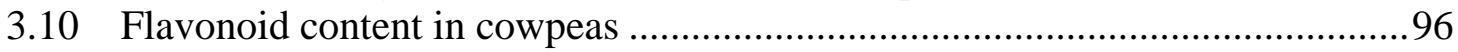

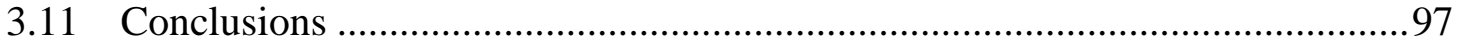


4. EFFECT OF BOILING ON THE ANTIOXIDANT PROPERTIES OF DIFFERENT COWPEA PHENOTYPES .............................................................101

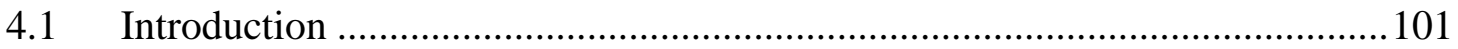

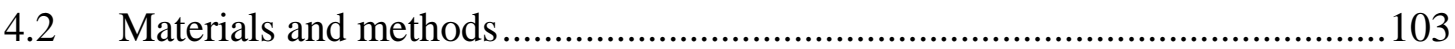

4.2.1 Cowpea samples...................................................................................103

4.2.2 Chemicals and reagents............................................................................104

4.2.3 Determination of total phenols content (TPC)............................................104

4.2.4 Determination of condensed tannins content (CTC) ....................................105

4.2.5 Determination of scavenging activity on 2,2'-azino-bis(3ethylbenzothiazoline-6-sulphonic acid) radical cation $\left(\mathrm{ABTS}^{\circ+}\right)$..............................105

4.2.6 Oxygen Radical Absorbing Capacity (ORAC) Assay …………………........106

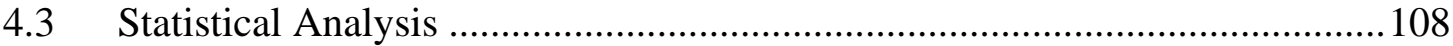

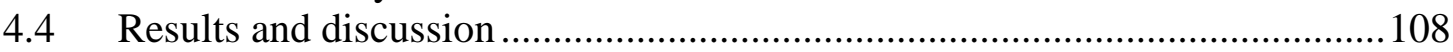

4.4.1 Effect of seed coat color on total phenolic composition of cowpea .............108

4.4.2 Effects of boiling on total phenolic composition of cowpeas........................110

4.4.3 Antioxidant capacity of cowpeas with different seed coat colors.................112

4.4.4 Effect of boiling on antioxidant activities of cowpeas.................................115

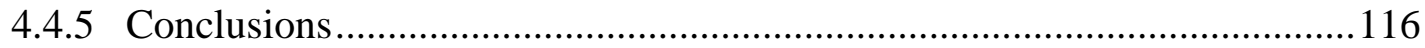

5. ANTI-INFLAMMATORY PROPERTIES OF COWPEA PHENOTYPES

WITH DIFFERENT PHENOLIC PROFILES IN INTESTINAL

MYOFIBROBLAST CCD18Co CELLS ……………….....................................117

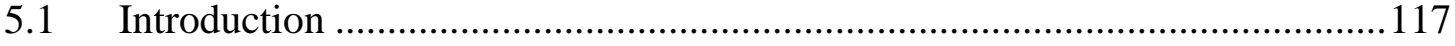

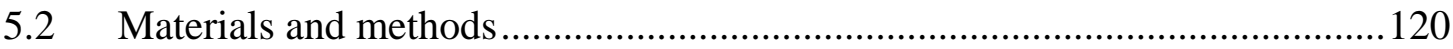

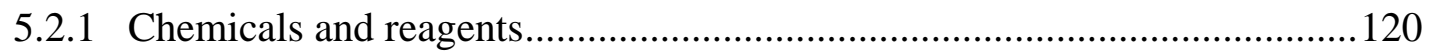

5.2.2 Plant materials and extraction ....................................................................120

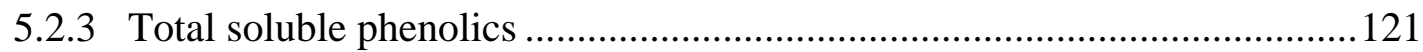

5.2.4 Cell culture assays..................................................................................121

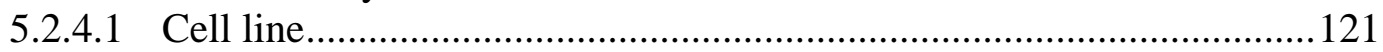

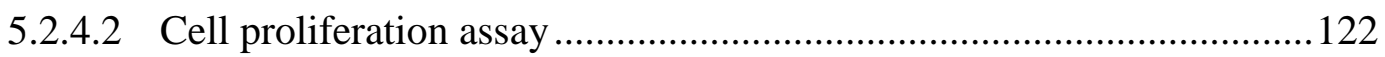

5.2.4.3 Generation of reactive oxygen species (ROS) assay ..............................122

5.2.4.4 LPS-induced inflammation assay ..........................................................123

5.2.4.5 RNA extraction and real-time PCR analysis of mRNAs and miRNAs 123

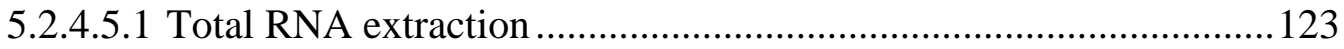

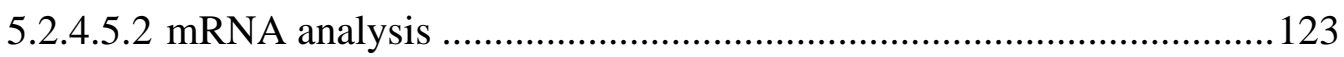

5.2.4.5.3 Primer sequences used for mRNA analysis .......................................124

5.2.4.5.4 miRNA analysis ...........................................................................124

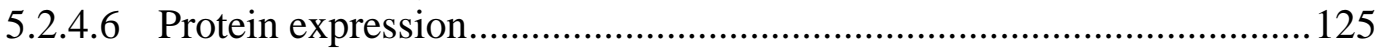

5.2.4.6.1 Enzyme-Linked Immunosorbent Assay (ELISA) ..............................125

5.2.4.6.2 Transfection assay ............................................................................... 125 


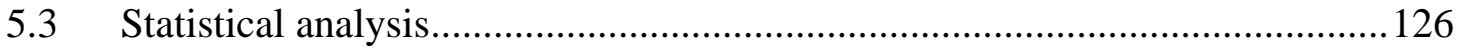

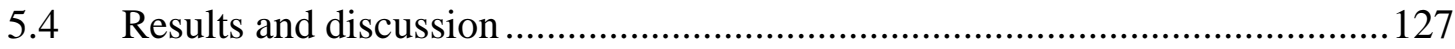

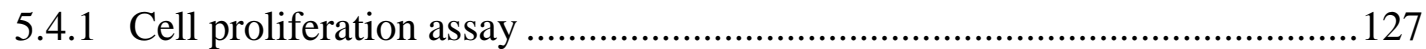

5.4.2 Cell protection against production of reactive oxygen species.....................128

5.4.3 Effects of cowpea extracts on proinflammatory cytokines............................130

5.4.4 Effect of cowpea extracts on lipopolysaccharide-induced vascular inflammation ...........................................................................................139

5.4.5 Effect of cowpea extracts on miR-126 ....................................................144

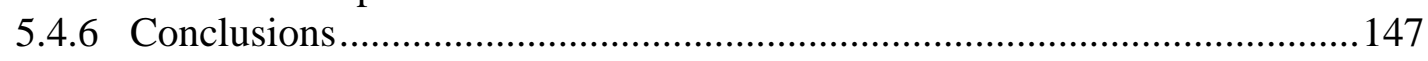

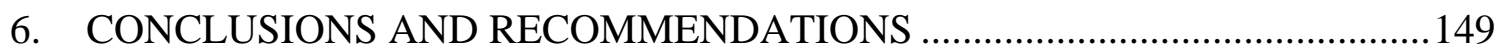

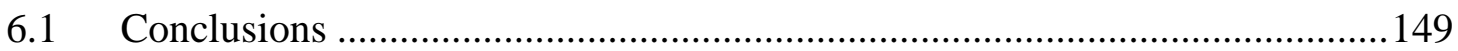

6.2 Recommendations for further research.............................................................150

LITERATURE CITED …………………………………………………………....151

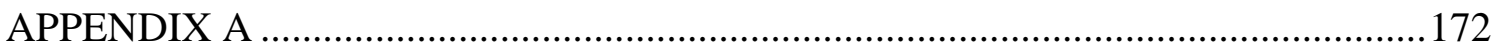

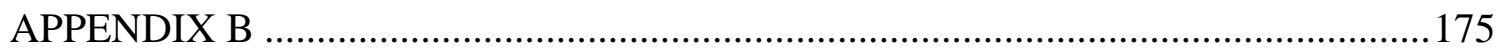

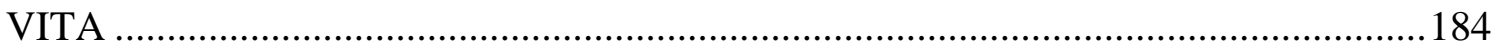




\section{LIST OF FIGURES}

Page

Figure 1 Representative UPLC chromatogram of anthocyanins found in the methanolic fractions from black IT95K-1105-5 cowpea variety monitored at $520 \mathrm{~nm}$. The black IT98K-1092-1 and green TX20281-3-1 varieties also had similar profile.

Figure 2 Chemical structures of the eight anthocyanins found in cowpeas.

Figure 3 Reverse-phase UPLC chromatogram of phenolic extracts from methanol fractions of red cowpea varieties; IT97K-1042-3 at $280 \mathrm{~nm}$ (A-1) and $360 \mathrm{~nm}$ (A-2); and IT82D-889 at $280 \mathrm{~nm}$ (B-1) and 360 $\mathrm{nm}(\mathrm{B}-2)$.

Figure 4 Chemical structures of flavonols and their glycosyl and acyl derivatives, (A); and flavanonol (taxifolin), flavanone (eriodictyol), protocatechuic acid and protocatechuic aldehyde identified in cowpea seeds (B).

Figure 5 Reverse-phase UPLC chromatogram of phenolic extracts from methanol fractions of golden brown cowpea varieties; IT84S-2246 at $280 \mathrm{~nm}(\mathrm{~A}-1)$ and $360 \mathrm{~nm}(\mathrm{~A}-2)$; and Ife Brown at $280 \mathrm{~nm}(\mathrm{~B}-1)$ and $360 \mathrm{~nm}(\mathrm{~B}-2)$.

Figure 6 Chemical structures of the most common flavanol monomers, procyanidin dimers and trimers identified in cowpea. .55

Figure $7 \quad$ General schematic diagram showing fragmentation of dimeric procyanidins in negative mode.

Figure 8 Reverse-phase UPLC chromatogram of phenolic extracts from methanol fractions of light brown cowpea varieties; 09FCV-CC27M at $280 \mathrm{~nm}(\mathrm{~A}-1)$ and $360 \mathrm{~nm}(\mathrm{~A}-2)$; and IAR-48 at $280 \mathrm{~nm}(\mathrm{~B}-1)$ and $360 \mathrm{~nm}(\mathrm{~B}-2)$.

Figure 9 Reverse-phase UPLC chromatogram of phenolic extracts from methanol fractions of black cowpea varieties at $360 \mathrm{~nm}$; IT95K1105-5 (A); and IT98K-1092-1 (B).. 
Figure 10 Reverse-phase UPLC chromatogram of phenolic extracts from methanol fraction of white cowpea variety, Early Acre at $280 \mathrm{~nm}$ (A) and $360 \mathrm{~nm}$ (B).

Figure 11 Reverse-phase UPLC chromatogram of phenolic extracts from methanol fraction of green cowpea variety, TX2028-1-3-1 at $280 \mathrm{~nm}$ (A) and $360 \mathrm{~nm}(\mathrm{~B})$.

Figure 12 Representative aldaric acid derivatives. .72

Figure 13 Hydroxychalcones identified in cowpea. Phloretin, (A); phlorizin, (B), and phlorizin dimer, (C). .76

Figure 14 Reverse-phase UPLC chromatogram of phenolic extracts from ethylacetate fractions of red cowpea varieties; IT97K-1042-3 at $280 \mathrm{~nm}$ (A-1) and $360 \mathrm{~nm}$ (A-2); and IT82D-889 at $280 \mathrm{~nm}$ (B-1) and 360 nm (B-2).

Figure 15 Reverse-phase UPLC chromatogram of phenolic extracts from ethylacetate fractions of golden brown cowpea varieties; IT84S-2246 at $280 \mathrm{~nm}(\mathrm{~A}-1)$ and $360 \mathrm{~nm}(\mathrm{~A}-2)$; and Ife Brown at $280 \mathrm{~nm}$ (B-1) and $360 \mathrm{~nm}(\mathrm{~B}-2)$.

Figure 16 Fragmentation mechanism of flavanol-flavan-3-ol dimer found in cowpea (in negative mode)

Figure 17 Reverse-phase UPLC chromatogram of phenolic extracts from ethylacetate fractions of light brown cowpea varieties; 09FCV-CC27M at $280 \mathrm{~nm}(\mathrm{~A}-1)$ and $360 \mathrm{~nm}(\mathrm{~A}-2)$; and IAR-48 at $280 \mathrm{~nm}$ (B-1) and $360 \mathrm{~nm}(\mathrm{~B}-2)$.

Figure 18 Reverse-phase UPLC chromatogram of phenolic extracts from ethylacetate fractions of white cowpea variety, Early Acre at $280 \mathrm{~nm}$ (A) and $360 \mathrm{~nm}(\mathrm{~B})$.

Figure 19 Reverse-phase UPLC chromatogram of phenolic extracts from ethylacetate fractions of black cowpea varieties; IT95K-1105-5 at $280 \mathrm{~nm}$ (A-1) and $360 \mathrm{~nm}$ (A-2); and IT98K-1092-1 at $280 \mathrm{~nm}$ (B-1) and $360 \mathrm{~nm}(\mathrm{~B}-2)$. 
Figure 20 Reverse-phase UPLC chromatogram of phenolic extracts from ethylacetate fractions of green cowpea variety, TX2028-1-3-1 at $280 \mathrm{~nm}$ (A) and $360 \mathrm{~nm}(\mathrm{~B})$.

Figure 21 Antioxidant activities of various raw and cooked cowpeas varieties:

ORAC values, A; and ABTS values, B.

Figure 22 Cell proliferation assay on CCD18Co cells treated with various concentrations of extracts from different cowpea varieties; and assessed after 48 hrs incubation.

Figure 23 Effect of cowpea extracts on generation of ROS after LPS-induced oxidative damage in non-cancer CCD-18Co cells.

Figure 24 CCD-18Co gene expression of IL-8.

Figure 25 CCD-18Co gene expression of TNF- $\alpha$.

Figure 26 CCD-18Co gene expression of NF-кB.............................................136

Figure 27 CCD-18Co gene expression of VCAM-1.........................................138

Figure 28 Relative amount of VCAM-1 protein excreted to culture media..............142

Figure 29 Modulation of miR-126 by cowpea extracts on LPS-challenged CCD18Co cells

Figure 30 Effect of $10 \mathrm{mg}$ GAE/L polyphenolic extracts from black IT95K1105-5 cowpea variety on VCAM-1 mRNA levels on LPS-treated transfected cells (A); miR-126 levels on transfected cells (B); and miR-126 levels on LPS-treated transfected cells (C). 


\section{LIST OF TABLES}

Page

Table 1 Proximate composition, mineral content and amino acid profile of selected grain legumes

Table 2 Description of cowpea cultivars selected for the study.....

Table 3 Identification of anthocyanins in IT95K-1105-5 (black), IT98K1092-1 (black) and TX2028-1-3-1 (green) cowpea varieties based on UPLC retention time $\left(\mathrm{t}_{\mathrm{r}}\right)$, UV-vis spectroscopic characteristics $\left(\lambda_{\max }\right)$, MS and MS/MS spectroscopic pattern.

Table 4 Contents of anthocyanins in raw and boiled black (IT95K-1105-5 and IT98K-1092-1) cowpea varieties as determined by HPLC-UVvis $^{a}$

Table 5 Contents of anthocyanins in raw and boiled green (TX2028-1-3-1) cowpea variety as determined by HPLC-UV-vis ${ }^{a}$....

Table 6 Identification of phenolic acids and phenolic aldehydes monitored at 280 and $330 \mathrm{~nm}$ in methanolic fraction of 10 cowpea varieties based on UPLC retention time $\left(\mathrm{t}_{\mathrm{r}}\right)$, UV-vis spectroscopic characteristics $\left(\lambda_{\max }\right)$, and MS-MS/MS spectroscopic pattern.....

Table 7 Identification of flavan-3-ols monitored at $280 \mathrm{~nm}$ in methanolic fraction of 10 cowpea varieties based on UPLC retention time $\left(\mathrm{t}_{\mathrm{r}}\right)$, $\mathrm{UV}$-vis spectroscopic characteristics $\left(\lambda_{\max }\right)$, and MS - MS/MS spectroscopic pattern.

Table 8 Identification of dihydrochalcones (at $320 \mathrm{~nm}$ ) and flavonols (at 360 $\mathrm{nm}$ ) in methanolic fraction of 10 cowpea varieties based on UPLC retention time $\left(\mathrm{t}_{\mathrm{r}}\right)$, UV-vis spectroscopic characteristics $\left(\lambda_{\max }\right)$, and MS-MS/MS spectroscopic pattern.

Table 9 Identification of flavonoids in ethyl-acetate fraction of 10 cowpea varieties based on UPLC retention time $\left(\mathrm{t}_{\mathrm{r}}\right)$, UV-vis spectroscopic characteristics $\left(\lambda_{\max }\right)$, and MS-MS/MS spectroscopic pattern. Ionization was performed in the negative mode.

Table 10 Compositions ( $\mu \mathrm{g} / \mathrm{g}$ of cowpea flour) and effect of boiling on flavonols and flavan-3-ols in black cowpea varieties ${ }^{a}$ 
Table 11 Compositions ( $\mu \mathrm{g} / \mathrm{g}$ of cowpea flour) and effect of boiling on flavonols and flavan-3-ols in red cowpea varieties ${ }^{a}$

Table 12 Compositions ( $\mu \mathrm{g} / \mathrm{g}$ of cowpea flour) and effect of boiling on flavonols and flavan-3-ols in light brown cowpea varieties ${ }^{a}$.....

Table 13 Compositions ( $\mu \mathrm{g} / \mathrm{g}$ of cowpea flour) and effect of boiling on flavonols and flavan-3-ols in golden brown cowpea varieties ${ }^{a}$.....

Table 14 Compositions ( $\mu \mathrm{g} / \mathrm{g}$ of cowpea flour) and effect of boiling on flavonols in green (TX2028-1-3-1) and white (Early Acre) cowpea varieties $^{a}$...... .95

Table 15 Flavonoid content of raw cowpea samples. ................................................97

Table 16 Levels of Total Phenolic Content (TPC) and Condensed Tannin Content (CTC) of raw and boiled cowpeas. 109 


\section{INTRODUCTION}

\section{$1.1 \quad$ Need for research}

Epidemiologic evidence show that regular consumption of products containing grain legumes reduce the risk of cancer (colon, breast, prostrate) (1), cardiovascular diseases (2) and diabetes (3). For example, consumption of pinto beans has been shown to decrease levels of LDL-cholesterol (4) by partially interrupting the enterohepatic circulation of bile acids (5). Anthocyanidins from black soybean seed coat were found to suppress cyclooxygenase-2 (COX-2) and inducible nitric oxide synthase (iNOS) mRNAs in tissue plasminogen activator (TPA) stimulated HT-29 cells (6). Phenolic compounds, like anthocyanins, exert a strong antioxidant activity and are thereby able to protect cells against reactive oxygen species (ROS). ROS act as mitogens to stimulate COX-2 expression via nuclear factor карра B (NF-kB) activation, thereby inducing inflammatory responses (7). NF- $\kappa \mathrm{B}$ is the main molecular link between inflammation and inflammatory-linked diseases. Therefore, plant compounds that can effectively

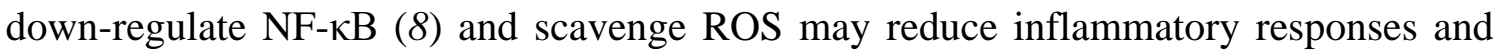
alleviate the related pathological conditions.

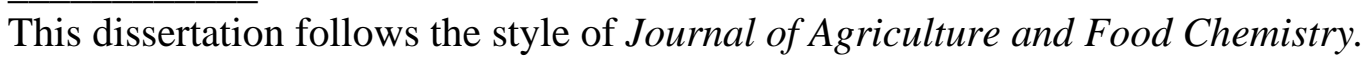


Cowpea (Vigna unguiculata L. (Walp)) is a highly nutritious crop that can be grown in places not suitable for the growth of most food legumes because of its heat and drought tolerance. It is cultivated for its immature pods, mature seeds and fodder, which are rich in lysine and tryptophan - limiting amino acids in cereals.

Cowpea is considered a low glycemic index (GI) food (9), a good source of proteins and other nutrients and is especially consumed in developing countries (10). Low GI foods have been shown to reduce post-prandial blood glucose and insulin responses in normal and diabetic patients (11). Cowpea is also important for the rural farmers who cannot afford fertilizers since it fixes nitrogen into the soil thus improves soil fertility. Cowpea has good quality proteins, carbohydrates, phytochemicals, and calorically compares favorably with soybean, chickpea and kidney-beans. It is cheaper than other protein sources such as meat, milk and fish. This makes production of cowpea more viable for regions pressed by social, cultural, religious and economic issues.

Cowpeas also contain significant quantities of polyphenols such as simple phenols, flavonoids and tannins (12), which could act as inflammatory modulators. Inflammatory reaction occurs in response to infection, irritation, trauma, noxious stimuli or other injury that provoke an immune reaction. These conditions may be caused by bacterial, viral, parasitic and chemical agents (13). These responses are necessary so that the body can eliminate viral infections, repair tissue injury, and suppress tumorigenesis (14). Polyphenols have been proposed to exert their anti-inflammatory property through various mechanisms such as inhibition of ROS and modulation of cytokines/chemokines (15). However, no studies have been performed on the potential of cowpea polyphenols 
to prevent or delay the onset of inflammatory-linked diseases. Thus, the polyphenolic and physiological properties of different cowpea varieties increases the need for research on the bioactive compounds present in cowpeas that could be exploited for improved human health.

An expanding body of research suggests a connection between consumption of flavonoids, down-regulation of inflammatory mediators and prevention of inflammatorylinked diseases. When NF-kB is activated, it regulates inflammatory responses of many cell types by activating production of pro-inflammatory cytokines, cell adhesion molecules and chemokines (7). These inflammatory mediators are important inflammatory markers involved in several chronic inflammatory conditions, which could be alleviated by plant polyphenols. Cowpea flavonoids and their potential to reduce risk of inflammatory-linked chronic diseases should be investigated. The association between the antioxidant activity of cowpea polyphenolics with their anti-inflammatory potential and prevention of chronic diseases is still unknown.

\subsection{Significance}

Cowpea is an inexpensive source of protein, dietary fiber and minerals (Table 1), which are required for good health but are often inadequate in our everyday diets. However, many consumers still view cowpea as a 'poor man's food,' since its production and consumption is mostly associated with the rural farmers in poor and drier regions of developing countries. Thus, increased scientific information on potential health benefits of cowpea consumption is critical in promoting cowpeas to the urban- 
middle class, who still do not appreciate the potential value of cowpea in human nutrition. Due to the rising health concerns in the urban demographic, the potential to serve this segment of population with functional foods is no longer a niche market. Thus, by establishing association between seed coat color and bioactive properties of cowpeas we may improve the understanding of healthy varieties that could be bred for improved nutritional properties. Additionally, information about the health properties of cowpeas will equip breeders with more parameters to select for and will contribute to cowpea improvement and greater economic returns to the farmers.

\subsection{Research objectives}

Three research objectives were established to test this hypothesis

1. Determine the phenolic composition of cowpea as influenced by seed coat color

2. Determine effect of boiling on the phenolic profiles of cowpeas

3. Investigate anti-inflammatory and antioxidant properties of the cowpea varieties, and correlate these properties to phenolic composition 


\section{LITERATURE REVIEW}

\subsection{Cowpea production}

The Leguminosae (or Fabaceae) is the second largest family of flowering plants containing some of the most biologically active phytochemicals known to improve human health and prevent various diseases. This family comprises of beans, peas, cowpeas, peanuts, soybeans, lentils, etc. Among the grain legumes, cowpea is one of the most important food legumes of Africa, Asia and South America (16). Its origin and domestication is disputed in literature but has been associated with pearl millet and sorghum in Africa (17). In the US, cowpea is commonly called crowder pea, black-eyed pea or southern pea; while in some parts of the world, it has several names including kunde (Swahili), coupe and niebe (French), or frijoles (Spanish).

The world's largest production and consumption of cowpea is in West Africa (Nigeria and Niger). In 2009, Nigeria produced 2.4 million tons of the total world production of 4.5 million tons (18). In Nigeria, two out of every three children feed on cowpeas as a source of protein. Brazil, India, Myanmar, Sri Lanka, Haiti, Senegal, Cameron, Burkina Faso, Australia and the U.S. also produce significant quantities (18, 19).

In the U.S., the total production of cowpeas is estimated at 60,000 to 80,000 acres, of which the largest market classes are black-eyed pea and pink-eyed southern pea, which are usually harvested for their leafy greens, green pods, fresh shelled green 
seeds, and shelled dried seeds (20). In the US, Georgia, Arkansas, California and Texas are the leading producers, accounting for about $60 \%$ of the total production (19).

Cowpea is a heat and drought tolerant crop that requires little agronomic incentives in terms of fertilizer. Maximum yields are obtained at $27 / 22^{\circ} \mathrm{C}$ (day/night) temperatures (21). Cowpea is able to survive under arid or semi arid soil conditions, since they are morphologically and physiologically able to reduce transpiration (22). Some varieties also grow a deep root system, and may have smaller leaf size with thicker cuticles to reduce rate of water loss, which increases their drought tolerance (22).

Cowpea is adapted to a wide range of soils, and can survive in sandy, clay and acid soils which support the presence of nitrogen fixing bacteria and good drainage. Good yields are obtained around $\mathrm{pH}$ 6, especially in the Oxisol of central Brazil (23). Poor soils produce little forage, but generally produce good yield of seed (24). No other legumes has been reported as widely adaptable to various soil and climate conditions as cowpea (24).

These cowpea's unique traits and low agronomical input requirement are favorable to the poor and low income farmers. The lower income populations are particularly vulnerable to malnutrition because the usual protein sources (meat and milk) are beyond their purchasing ability. Malnutrition, especially during childhood, has been linked to various chronic diseases in adulthood, including diabetes, obesity and cancer, especially in developing countries (25). Childhood malnutrition is also closely associated with food insecurity, particularly in developing countries (25). Nutritious, less costly, 
easily accessible plant protein sources such as pulses (e.g. cowpea) can be used to improve the nutritional status of these low-income populations.

Unfortunately, most rural poor primarily obtain their food energy from cereals (poor sources of lysine, tryptophan and niacin) and starchy tubers. These foods are generally deficient in good quality proteins as well as health-promoting phytochemicals. The increase in consumption of staple diets such as cereal grains in these rapidly growing populations has led to a steady rise in chronic malnutrition and infant mortality and morbidity (26). For example, one in three school age Kenyan children are currently stunted from chronic malnutrition which impairs growth, causes poor performance in schools, and increases morbidity and mortality (27). From 2005 - 2007, chronic diseases contributed over half of the top twenty causes of morbidity and mortality in Kenya (28). In Zimbabwe, acute child malnutrition has increased by almost 75\% since 2007, and more than $50 \%$ of the population needs humanitarian assistance (29). In eastern Congo, the World Vision estimates the number of children under the age of 5 suffering from malnutrition has increased more than ten-fold since 2008 because of poverty and conflict (30). Thus, most developing nations are faced with an impending epidemic of chronic diseases.

On the other hand, chronic diseases such as obesity, diabetes mellitus, CVDs and cancers are becoming increasingly significant causes of premature deaths worldwide, placing additional burdens on already overtaxed national health budgets (31). Since cowpea may be a "climate-change crop" due to its wide adaptability in several 
environmental conditions and soils, it should be exploited for its potential to contribute to prevention of chronic diseases.

Table 1. Proximate composition, mineral content and amino acid profile of selected grain legumes*

\begin{tabular}{lllll}
\hline Nutrients (g/100 g) & Cowpea & Chickpea & Lentil & Green pea \\
\hline Crude protein & $24.7 \pm 0.10$ & $24.0 \pm 0.30$ & $26.1 \pm 0.09$ & $24.9 \pm 0.03$ \\
Crude fat & $4.8 \pm 0.07$ & $5.2 \pm 0.01$ & $3.2 \pm 0.06$ & $1.5 \pm 0.04$ \\
Ash & $4.2 \pm 0.05$ & $3.6 \pm 0.04$ & $2.8 \pm 0.06$ & $3.6 \pm 0.04$ \\
\hline Minerals (mg/100 g) & & & & \\
\hline Sodium & $102 \pm 5.29$ & $101 \pm 3.51$ & $79 \pm 2.65$ & $111 \pm 2.65$ \\
Potassium & $1280 \pm 8.62$ & $1155 \pm 5.00$ & $874 \pm 6.43$ & $1021 \pm 12.49$ \\
Phosphorus & $303 \pm 7.94$ & $251 \pm 6.11$ & $294 \pm 3.61$ & $283 \pm 3.00$ \\
Calcium & $176 \pm 4.58$ & $197 \pm 3.61$ & $120 \pm 6.24$ & $110 \pm 3.61$ \\
Copper & $9.7 \pm 0.20$ & $11.6 \pm 0.20$ & $9.9 \pm 0.10$ & $10.0 \pm 0.40$ \\
Zinc & $5.1 \pm 0.20$ & $6.8 \pm 0.26$ & $4.4 \pm 0.20$ & $3.2 \pm 0.56$ \\
Magnesium & $4.8 \pm 0.10$ & $4.6 \pm 0.04$ & $4.5 \pm 0.04$ & $4.2 \pm 0.04$ \\
Manganese & $1.7 \pm 0.04$ & $1.9 \pm 0.10$ & $1.6 \pm 0.03$ & $2.2 \pm 0.02$ \\
Iron & $2.6 \pm 0.20$ & $3.0 \pm 0.20$ & $3.1 \pm 0.26$ & $2.3 \pm 0.56$ \\
\hline Amino acids (\% of protein) & & & & \\
\hline Arginine & $7.5 \pm 0.04$ & $8.3 \pm 0.21$ & $7.8 \pm 0.03$ & $7.2 \pm 0.04$ \\
Leucine & $7.7 \pm 0.08$ & $8.7 \pm 0.03$ & $7.8 \pm 0.05$ & $7.4 \pm 0.05$ \\
Lysine & $7.5 \pm 0.04$ & $7.2 \pm 0.03$ & $7.0 \pm 0.03$ & $8.1 \pm 0.07$ \\
Methionine & $2.2 \pm 0.04$ & $1.1 \pm 0.04$ & $0.8 \pm 0.02$ & $1.1 \pm 0.03$ \\
Phenylalanine & $7.5 \pm 0.06$ & $5.5 \pm 0.04$ & $5.0 \pm 0.12$ & $5.2 \pm 0.04$ \\
Tryptophan & $0.7 \pm 0.02$ & $0.9 \pm 0.02$ & $0.7 \pm 0.03$ & $0.8 \pm 0.02$ \\
Valine & $5.0 \pm 0.06$ & $4.6 \pm 0.03$ & $5.0 \pm 0.05$ & $5.0 \pm 0.09$ \\
Histidine & $3.1 \pm 0.03$ & $3.0 \pm 0.03$ & $2.2 \pm 0.05$ & $2.4 \pm 0.05$ \\
Isoleucine & $4.5 \pm 0.03$ & $4.8 \pm 0.03$ & $4.1 \pm 0.05$ & $4.5 \pm 0.06$ \\
Leucine & $7.7 \pm 0.08$ & $8.7 \pm 0.03$ & $7.8 \pm 0.05$ & $7.4 \pm 0.05$ \\
Alanine & $4.2 \pm 0.03$ & $4.97 \pm 0.03$ & $4.2 \pm 0.04$ & $5.2 \pm 0.04$ \\
Aspartic acid & $10.8 \pm 0.08$ & $11.0 \pm 0.04$ & $11.8 \pm 0.08$ & $11.0 \pm 0.06$ \\
Glutamic acid & $17.2 \pm 0.06$ & $17.3 \pm 0.08$ & $21.5 \pm 0.07$ & $17.5 \pm 0.06$ \\
Proline & $4.0 \pm 0.13$ & $3.8 \pm 0.05$ & $3.5 \pm 0.03$ & $3.8 \pm 0.03$ \\
\hline Adapted from & & & &
\end{tabular}

*Adapted from Iqbal et al. (32). Data are presented as means \pm SD. 


\subsection{Nutritional quality of cowpea}

Cowpea has a number of attributes that make it valuable in human nutrition. The chemical composition of cowpea seeds vary depending on the genetic origin, as well as the climate, season, soil type and other agronomic practices. Table 1 provides the comparison of proximate composition, mineral content and amino acid profiles between cowpea and selected common pulses.

Starch is the most abundant form of carbohydrate found in cowpea. Significant quantities of stachyose $(2.0-3.6 \%)$, verbascose $(0.6-3.1 \%)$ and raffinose $(0.4-1.2 \%)$ exist in cowpea. These oligosaccharides are known to cause flatulence (33).

Cowpea also contains anti-nutritional factors like trypsin, chymotrypsin, subtilisin and protease inhibitors $(34,35)$. These classes of inhibitors are thermo-labile, thus are eliminated after proper heat processing. Tannins are particularly high in cowpeas having colored seed coat. Legume tannins complex with dietary proteins, decreasing protein digestibility and efficiency ratio (36). The presence of phytic acid (the storage form of phosphorus) in legumes decreases the bioavailability of essential minerals such as calcium and iron by making them insoluble; and may also complex with proteins or protein-mineral complexes. The interaction between phytic acid, proteins and starch also causes the "hard-to-cook" phenomenon of legumes seeds (37).

The need to improve human health through diet has motivated researchers to examine not only the levels of essential and non-essential nutrients in crop plants (e.g. grains, oilseeds and legumes) but also the contribution of plant components such as phenolic compounds with potential health attributes (e.g. antioxidant activity). Not only 
are the antioxidant compounds able to protect cells and organs, as well as food systems, against oxidative damage caused by superoxide, hydroxyl and peroxyl radicals, but they also provide other health benefits such as lowering risk of several diseases. The challenge, therefore, is for breeders to design approaches for improving the "total nutritional quality" and appealing visual properties of popular grains commonly cultivated and consumed by the rural-poor (e.g. cowpea) to provide acceptable, sustainable and inexpensive complements to medical and social programs that are striving to prevent human diseases.

The diets in most poor communities consist mainly of starchy cereals (sorghum, millet, corn, rice, etc.), tubers (cassava, potatoes, etc.) and plantains. Cereal proteins, as well as cassava proteins, are deficient in lysine, in which legumes are much richer. Cereals provide $70-85 \%$ of total calories, and are usually prepared in the form of "porridge." The practice, commonly used in many rural areas in Africa, of mixing cassava flour with cereal flour to make a staple food, in the form of stiff porridge, and eating this porridge with legume-based soups provides relatively cheap, nutritious diets which would be beneficial even for the urban dwellers. Therefore, increased production and improvement of familiar legumes such as cowpeas, better storage practices to eradicate weevils, increased scientific information on their health benefits, and new industrial methods of processing, should be given high priority. 


\subsection{Utilization of cowpea for human food}

Cowpea is widely utilized in a variety of food preparations, and is mostly consumed as a boiled, steamed, fermented or fried vegetable (38). The traditional foods utilizing recipes of cowpea like ewa (boiled whole bean), akara (deep-fried dehulled cowpea paste), seke-sin (fried cowpea cakes with green onions), gbegiri (cowpea soup) and moin-moin (steamed cakes) are commonplace in West Africa (39). In India, it is consumed as cooked whole seed, or cooked green immature pods in the form of curry in conjunction with certain cereals (40). In southern US, it is canned and consumed as boiled beans (41). In some parts of the world, the young shoots are often consumed as spinach in fresh form (42). Cowpeas thus play a vital role in many traditional diets of several regions throughout the world by providing the major proportion of essential nutrients and energy to these populations. Thus, the use of cowpea in both infant and adult foods is recommended since it improves the nutritional balance of the diet in order to reverse the perennial problems of malnutrition in developing countries.

\subsection{Constraints to cowpea production and use}

Physical degradation and nutrient depletion of soil is a perennial problem for the rural-poor farmers in developing countries, where much grain-legume production and consumption occurs. Many of these farmers cannot afford to use fertilizers, thus limiting their productivity. Diseases, pathogens and pests also affect legume production, especially in tropical and subtropical regions of Africa (43). Crop losses occurring as a

result of these factors are huge and several strategies to reduce productivity losses have 
been proposed, including biological control of diseases, chemical application and use of molecular markers in disease resistance breeding in bean and cowpea (43, 44). Unfortunately, the rural-poor and subsistence farmers cannot afford to utilize many of these expensive measures.

Inclusion of legumes in human diet is also problematic due to lack of compelling benefits to consumers, beany flavor, longer preparation time, and the presence of antinutritional factors which dampens demand and economic value. Protein content in legume seeds range from $20-30 \%$, and are rich in lysine, complementing the low levels in starchy cereals and tubers in the diet. However, legumes contain low levels of sulfur amino acids and are usually hard to cook. Consumer preferences for particular grains or seed colors also affect marketability and acceptance. Compelling evidence on health effects of grain-legume consumption may promote acceptability among the urban-rich who are looking for healthy foods.

\subsection{Opportunities for increased cowpea utilization}

By 2030, the rapidly expanding water-stressed areas of the world is likely to worsen the drought problems for legumes (45). Therefore, there is increasing need to increase drought and salinity tolerance in legumes in many areas, especially in the face of climate change. The drought-tolerant legumes, such as cowpea may be a good "climate-change crop" candidate due to its wide adaptability to various environments. 
Cowpea contains flavonoids such as anthocyanins; glycosides of flavonols (i.e. kaempferol, quercetin and myricetin), isoflavones (i.e. daidzein and genistein), phenolic acids and tannins $(46,47)$. Reports show that these flavonoids have strong anticancer and anti-inflammatory activities $(48,49)$. Thus, cowpea may provide significant health benefits which would be appealing to the urban-rich who are looking for healthier lifestyles.

Unfortunately, legumes seeds, particularly cowpea are still regarded as "poor man's meat”, a stigma that undermines these valuable protein sources. From a nutritional standpoint, the high protein (18 - 35\%), carbohydrate (50 - 65\%) and amino acid profile of cowpea complement that of cereal grains and starchy tubers. However, in general, the use of cowpea in many foods is limited due to the beany flavor. If appropriate and inexpensive technologies can be developed for converting cowpea into nutritious food ingredients and products, it would be appealing to the urban-rich who presently subsist on nutritionally deficient diets. Presently, food applications utilizing cowpea flour include baby/weaning foods, chips, papad (thin-wafer like tortillas), cinnamon sweet rolls, cookies, doughnuts, muffins, biscuits, Chinese type noodles, moin-moin and akara (50). The beany aroma is acceptable in certain cowpea products such as moin-moin, but not in the noodles, baked and snack food products. Thus, further improvement in cowpea flour research to eliminate the beany aroma would enhance its acceptance and economic value.

Cowpea phenotypes are diverse. Such genetic variation helps in the development of improved cultivars. Each cowpea phenotype has seeds with distinctive appearance 
and flavor, which can be used as an alternative to common beans (less drought tolerant legume).

Unfortunately, with increasing population growth in many developing countries, as well as natural calamities such as famine, there is reduced availability of food to match the demand of the growing populations. Cowpea could play an important role in reducing hunger and prevention of such diseases associated with protein-calorie intake.

\subsection{Flavonoids in cowpea}

Cowpea contains phenolic acids in free and bound forms (47), as well as other flavonoids, mainly anthocyanins (46), flavonols and flavan-3-ols derivatives (51). Cai et al. (47) reported that in cowpea, protocatechuic acid is the major phenolic acid present in esterified forms, ranging from 9.3 to $92.7 \mathrm{mg} / 100 \mathrm{~g}$ of flour. Trace amounts of six other phenolic acids (at $<7 \mathrm{mg} / 100 \mathrm{~g}$ of flour), namely, $p$-hydroxybenzoic acid, caffeic acid, $p$ coumaric acid, ferulic acid, 2,4-dimethoxybenzoic acid, and cinnamic acid, were also identified, mainly in free forms. Total phenolic contents determined using FolinCiocalteu's reagent ranged from 34.6 to $376.6 \mathrm{mg} / 100 \mathrm{~g}$ of flour. On the other hand, the phenolic acids content of common bean (Phaseolus vulgaris L.) reportedly ranged from 19.1 to $48.3 \mathrm{mg} / 100 \mathrm{~g}$ of flour (52). Ferulic acid was reportedly the most abundant, whereas $p$-coumaric and sinapic acids were present in moderate amounts in all the samples studied. However, no literature is available correlating cowpea phenolic acids with specific phenotypes and/or variety. 
Anthocyanins are responsible for the red, blue, purple colors of many fruits, leaves, stems, roots, flowers and cereal grains. They are odorless and nearly flavorless, and are probably the most important subclass of visible plant pigments in nature. Anthocyanins are not commonly present in most legume seeds. However, anthocyanins have been identified in Beluga Black lentils (53) and Hakmeitau beans - a black seed cultivar of cowpea (54). In cowpea, seven anthocyanins have been reported, namely, delphinidin-3-O-galactoside, delphinidin-3-O-glucoside, cyanidin-3-O-galactoside, cyanidin-3-O-glucoside, petunidin-3-O-glucoside, peonidin-3-O-glucoside, and malvidin-3-O-glucoside (46). However, their levels are unknown. Since anthocyanins are increasingly becoming important as antioxidants, information on anthocyanin content in cowpea would provide evidence on potential health effects associated with ability to reduce oxidative stress.

In legumes, flavonols (e.g. kaempferol, myricetin and quercetin) and isoflavones (e.g. daidzein and genistein) are usually present in their glycosylated forms, often associated with glucose or rhamnose sugar moieties (55). Isoflavones have pseudohormonal properties, as such are classified as phytoestrogens.

Compared to other legumes, black seed coat cowpea has higher amounts of quercetin (214 - $280 \mu \mathrm{g} / \mathrm{g})$, but limited amounts of daidzein, genistein and kaempferol (56). Other pulses, for example mung bean contain about 17.6 to $22.0 \mu \mathrm{g} / \mathrm{g}$ of myricetin, and limited amounts of daidzein and kaempferol (56); while chickpeas contain approximately $0.4 \mu \mathrm{g} / \mathrm{g}$ daidzein, $0.6 \mu \mathrm{g} / \mathrm{g}$ genistein, $1.4 \mu \mathrm{g} / \mathrm{g}$ formononetin and $0.2 \mu \mathrm{g} / \mathrm{g}$ 
biochanin A (12). However, how seed coat color influences types and levels of flavonols in cowpea is still unknown.

Procyanidins (i.e. condensed tannins) are the predominant phenolic compounds found in legume seeds, and consist of two main monomers, namely (+)-catechin and (-)epicatechin. They are located mainly in the seed coats and play an important role in the defense system of seeds against many oxidative insults from the environment. Tannins are known to lower protein digestibility thus reduce nutritional quality of tannin-rich diets. Among legumes, lentils, red bean, adzuki bean, pigeon peas and black gram contain significant levels of tannins $(57,58)$; while chick peas and mung beans contain no detectable levels of tannins (59). Tannin concentration in cowpea range from 0 $0.7 \%$, a level that may be nutritionally important (59).

How phenotype/variety affects the types and levels of procyanidin compounds in cowpea is unknown. Other pulses such as lentils reportedly contain procyanidin B2, B3, and procyanidin tetramer ranging from 0.1 to $0.5 \mathrm{mg} / 100 \mathrm{~g}$ dry weight, $\mathrm{db}(60)$; while adzuki bean contain procyanidin dimers and trimers ranging from 15.9 to $213 \mathrm{mg} / \mathrm{g}$ (61). Additionally, procyanidin B2, C1, and C2 have been identified in the hulls of red, brown, and black beans (62). These compounds play a critical role in the sensory properties and biological quality of foods $(63,64)$.

Seed-coat color influences levels of flavonoids in legume seeds (56). Literature reports on the differences in flavonoid compositions among legume genotypes suggest that no single legume is a good source of all flavonoids. However, how cowpea seed coat color affects flavonoid composition is unknown. Association between seed coat 
color and individual flavonoid content may be an indicator of accumulation of particular flavonoids and the potential ability of specific cowpea phenotypes to prevent chronic disease.

\subsection{Importance of legume flavonoids as antioxidants}

Several studies have been conducted to screen for antioxidant activity levels in various legumes. Black and red pigmented cowpeas were reported to have the highest antioxidant activity, followed by the pinkeye and black-eye types. The cream types had the lowest antioxidant capacity (65). This suggested that compounds responsible for cowpea seed coat color were involved in antioxidant activity. The antioxidant activity of red and black varieties of common bean was found to be higher than those of their white counterparts, and was attributed to the presence of anthocyanins in the seed coats of the colored types (66).

Siddhuraju and Becker (67) also screened raw and dry-heated seed extracts from two cowpea varieties for their potential antioxidant activities using DPPH, ABTS, FRAP, linoleic acid emulsion and $\beta$-carotene-linoleic acid assays in vitro and reported that all extracts exhibited good antioxidant activity against the linoleic acid emulsion system. Thus, cowpea could contribute significantly in prevention of degenerative diseases associated with free radical damage.

$\mathrm{Xu}$ et al. (68) showed that black beans (Phaseolus vulgaris L.), lentils (Lens culinaris), red kidney beans (Phaseolus vulgaris L.) and pinto beans exhibited higher antioxidant capacities (5.7 to $6.4 \mu \mathrm{mol} \mathrm{TE} / \mathrm{g}$ ), than yellow peas, green peas and chickpea 
(2.1 to $2.4 \mu \mathrm{mol} \mathrm{TE} / \mathrm{g}$ ) in both LDL-conjugated dienes (CD-Trolox) assay and LDLthiobarbituric acid reactive substances (TBARS) assay. The antioxidant activities of these legumes against human LDL-cholesterol oxidation were found to correlate significantly $(p<0.01)$ with their phenolic content, DPPH radical scavenging activity and ORAC values in vitro (68). These results indicate that intake of legumes such as black beans, lentils and red kidney beans may have great potential in inhibiting LDLoxidation thus promoting cardiovascular health.

With vast differences in cowpea genotypes, we believe elucidating the chemical composition and antioxidant properties of cowpea as influenced by seed coat color could increase public recognition of the health benefits (such as antioxidant activity and ability to lower inflammatory-linked conditions) of consuming specific cowpea phenotypes, which could increase demand for food uses of cowpea.

\subsection{Effect of thermal processing on phenol content and antioxidant activity of pulses}

Most legume seeds must be thermally processed before consumption. Severe heating, for example, pressure cooking (i.e. $121^{\circ} \mathrm{C}$; $103.421 \mathrm{kPa} ; 60 \mathrm{~min}$ ) reportedly reduced the phenolic content in common bean seed coats by approximately $90 \%$ (69). Cooking (i.e. boiling for $5 \mathrm{~min}$, microwave cooking for $1 \mathrm{~min}$ or steaming for $7.5 \mathrm{~min}$ ) has also been shown to significantly $(p<0.05)$ reduce phenolic content in peas $(70)$. Among the cool season food legumes, the boiling process has been reported to reduce 40 
- $60 \%$ of total phenol content in green peas, yellow peas and chickpeas; and $60 \%$ in lentils (71). Thus, in general, thermal treatment is detrimental to the phenolic composition of legumes. Presently, effect of heat on phenol content of different cowpea phenotypes/varieties is unknown.

Reduction of phenolic content as a result of thermal treatment correlates with reduced antioxidant activity of legumes compared to their raw counterparts. For example, boiling process reportedly decreased ferric reducing antioxidant power (FRAP) values of green pea, yellow pea, chickpea and lentils by 58.5 - 64, 57 - 60, 44 64 and $68-70 \%$, respectively (71). Similar trends were obtained using oxygen radical absorbing capacity (ORAC), DPPH radical scavenging activity (72) and Trolox equivalent antioxidant capacity (TEAC) on thermally processed cool-season food legumes (73). Thus, thermal processing reduces antioxidant properties of legumes, possibly through leaching of the water-soluble antioxidants (74) and degradation of phenolic compounds (75). Low antioxidant activity of thermally processed legumes reportedly reduces their antiproliferation activities compared to the raw samples (71).

How thermal processing impacts antioxidant capacity, antiproliferation activity and anticancer properties of cowpeas is unknown. These could be critical information because the hypothesized potential modes of actions against cancer proliferation are assumed to involve antioxidant capacity, especially after thermal processing. Thus, in terms of human health, the properties of cowpea phenolics after thermal treatment are important. 


\subsection{Pulses and disease prevention}

\subsubsection{Pulses in prevention of cardiovascular disease}

Cardiovascular disease (CVD) remains the leading cause of death and disability in North America (76). Most CVDs are preventable through life-style measures such as diet and exercise.

Consumption of pulses has been shown to effectively manage hypercholesterolemia, a major risk factor for CVD. The hypocholesterolaemic effects of pulses is related to the presence of dietary components such as soluble dietary fiber, vegetable protein, oligosaccharides, isoflavones, phospholipids and fatty acids, phytosterols, as well as saponins $(77,78)$. Consumption of common beans has been shown to decrease serum LDL-cholesterol by $7 \%$ and serum triacylglycerols by more than $10 \%$, without significantly affecting serum HDL-cholesterol values (79). Increased bile acid binding and decreased re-absorption of bile acids may also play a significant role in the hypocholesterolaemic effects of pulses (5).

Common beans are also relatively good sources of folic acid and thiamine vitamins known to lower serum homocysteine concentrations (79). Pulses supply essential minerals that may lower the risk for hypertension and stroke (80). Isoflavones from pulses have also been reported to improve serum lipoproteins, antithrombotic effects and anti-inflammatory activity (81).

Epidemiological evidence show that consumption of legumes (more than 4 times per week compared with less than once a week) reduced risk of coronary heart disease (CHD) and CVD by 22 and 11\%, respectively (82). No epidemiological data exists on 
how cowpea consumption may reduce total cholesterol, LDL (important CVD risk factor) and HDL levels. Cowpea's nutritional profile is comparable to that of common beans. Thus, cowpea may have important metabolic and/or physiological effects on reducing CVD risk. Further research is needed to determine how cowpea can reduce CHD and CVD risk factors such as intracellular reactive oxygen species (ROS), which correlates with prevention of inflammatory related diseases.

\subsubsection{Pulses in prevention of cancer}

Several epidemiologic studies show inverse correlation between intake of plantbased foods and protective effects certain cancers. For example, in a large prospective cohort study a reduced postmenopausal breast cancer risk was associated with higher intake of pulses (e.g. common beans) (83). A comparative study of lifestyles in Jiangsu Province, China, found that people living in a low-risk area for gastric cancer consumed kidney beans and soya products more frequently than those in a high-risk area (84). In Europe, a case control study showed protection against colorectal cancer by most vegetables, including pulses such as beans (85). In the Netherlands, a large cohort study revealed that consumption of pulses such as French beans and broad beans was associated with reduced risk of prostate cancer (86). In the United States, a cohort study of non-Hispanic white California Seventh-day Adventists showed that individuals who consumed red meat had significant protection against colon and pancreatic cancers if they also consumed legumes frequently (87). Other studies have also shown that 
consumption of pulses such as dried beans, split peas, or lentils reduced risk of colorectal adenoma (88).

No epidemiological evidence exists on consumption of cowpea and reduced risk of cancers. Since cowpea contains flavonoids that can enhance the body's immune system against inflammatory-linked diseases, potential of cowpea to contribute to cancer prevention should be investigated. How heterogeneity in types and levels of polyphenolics from different cowpea phenotypes could affect ability of cowpea against cancer initiation should be established. This information could form the basis for quantitative measures of intakes for specific cowpea varieties or for pulses in general.

\subsection{Association of inflammation with cancer}

Inflammation process produces reactive oxygen species (ROS) and reactive nitrogen species (RNS). ROS significantly impact etiology of several non-communicable diseases, including cancer (89), by causing oxidative damage and DNA mutations (90). RNS leads to nitration of DNA bases, which increases the risk of DNA mutation and hence cancer (91). ROS include singlet molecular oxygen $\left(-\mathrm{O}_{2}\right)$, peroxide $(\mathrm{O}-\mathrm{O}-\mathrm{H})$ and lipid peroxides (LOO), while free radicals include superoxide (-O), hydroxyl (OH), Fe, $\mathrm{Cu}$, nitric acid and ozone. It is thought that inflammation may contribute to tumor initiation through excessive generation of ROS and RNS (92).

Characteristics of inflammation include redness, swelling and pain. These conditions may be caused by bacterial, viral, parasitic and chemical agents. Gram- 
negative bacteria produce a lethal endotoxin known as lipopolysaccharide (LPS) which functions as an effective stimulus in activation of macrophages to release proinflammatory cytokines such as interleukins (IL-6 and IL-8) and TNF- $\alpha$, as well as other inflammatory mediators such as prostaglandins, nitric oxide and cyclooxygenase enzymes (COX) (93). In general, cytokines are a group of substances produced by resident or migrating cells (e.g. mast cells, macrophages and neutrophils), and function at many steps of the inflammatory response to heal wounds and stimulate epithelial cell proliferation (94).

Nuclear factor- $\kappa \mathrm{B}(\mathrm{NF}-\kappa \mathrm{B})$ is a transcription factor that plays a major role in the immune, stress, proliferative, apoptotic and inflammatory response (95). NF- $\mathrm{B}$ is sequestered in the cytoplasm, where it is held inactive in a non-DNA-binding form by

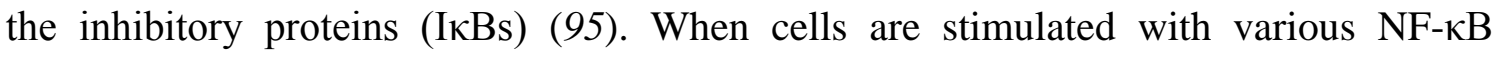

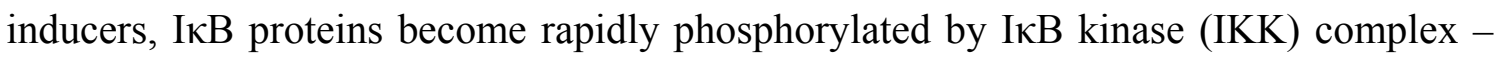
an inhibitor of NF- $\kappa \mathrm{B}$ kinase. Thus, inhibition of $\mathrm{NF}-\kappa \mathrm{B}$ is regarded as a useful strategy for treatment of inflammatory disorders (96).

The cytokine response related to transduction signaling, cellular differentiation and disease can be regulated by microRNAs (miRs; small portent non-coding RNA that post-transcriptionally regulate target genes). miRs can modulate anti-inflammatory mechanisms associated with NF- $\mathrm{B}$ activation by inducing mRNA degradation or blocking translation, as well as regulating vascular inflammation (97). For example, endogenous miR-126 has been demonstrated to regulate leukocyte adherence to endothelial cells usually associated with tumor development (97). It is likely that the 
involvement of plant phenolic compounds in regulation of the cytokine system may also affect expression of mRNAs and activity of miRs during immune response. Therefore, further insight into the effect of phenolic compounds on regulation of cytokine signaling by miRs may help design new strategies to modulate inflammation in a clinical context.

Recent data suggest that some phenolic compounds can exert their antiinflammatory activity by regulating NF-kB activation, as well as acting on multiple steps of NF-kB activation cascade and consequently on downstream effectors (98). For example, quercetin may potentially control intestinal inflammation in celiac disease by preventing the activation of NF- $\mathrm{kB}$ and mitogen activated protein kinases (MAPK) pathways (99); consequently counteracting the expression of cytokines and inducible nitric oxide synthase (iNOS) (100). Anthocyanins have also been shown to inhibit TNF$\alpha$-induced endothelial leukocyte adhesion molecule-1 (ELAM-1) and intercellular adhesion molecule-1 (ICAM-1) expression in cultured human umbilical vein endothelial cells (HUVEC) (101). Cell adhesion molecules play a key role in monocyte recruitment and thus promote tumor development. Phenolic compounds are therefore important metabolic modulators of cellular pathways and molecules. Therefore, their regulatory action on NF- $\mathrm{kB}$ pathways and inhibitory property on NF- $\mathrm{KB}$ activation cascade is a critical part in the mechanisms associated with anti-inflammatory effects of dietary plant phenolic compounds.

Majority of studies on legumes and their relationship to prevention of chronic diseases focus on specific nutritional components and not the total dietary intake of legumes. Therefore, legumes have been understudied in their relationship to CHD, CVD 
and cancers. The ability of cowpea phenolics to prevent or delay the onset of inflammatory-linked diseases is unknown. Research is needed on possible health promoting effects of cowpea which might help promote its consumption. This study, therefore, aims to demonstrate the anti-inflammatory potential of cowpea polyphenols using nonmalignant colon cells with relevance to colorectal cancer prevention.

\subsection{Overall goal of this research}

For some dietary polyphenols, certain beneficial effects on cell functions (e.g. ability to prevent cancer and cardiovascular disease risks) are suggested by epidemiological studies, some are supported by in vivo studies, and others are extrapolated from in vitro systems. However, to our knowledge, no literature exists on how cowpea polyphenols may offer a direct or indirect protection on cell functions such as activation of endogenous defense systems or modulation of cellular signaling processes such as NF- $\mathrm{B}$ activation, which may prevent pathogenesis of inflammatory diseases. We hypothesize that cowpea polyphenols may protect cells against oxidative stress by scavenging ROS or blocking ROS production intracellularly. The ability of cowpea phenolic to inhibition ROS could be pivotal in the cellular defense mechanisms against oxidative and xenobiotic stresses, thus inhibiting NF- $\mathrm{B}$ transactivation critical in the prevention of inflammatory-linked diseases such as cancer. Different cowpea phenotypes would have different phenolic profiles which may affect their antiinflammatory property. Thus, the overall goal of this research is to identify cowpea phenotypes with best potential to prevent chronic disease. 


\subsection{Potential impact of this research}

The ability of cowpea flavonoids to prevent chronic diseases is unknown. Since significant differences may exist in levels of flavonoids (flavonols, isoflavonols, anthocyanins, proanthocyanidins and phenolic acids) present in different cowpea phenotypes/varieties, information about the health properties of cowpeas will: (a) help identify phenotypes/varieties with best potential to prevent chronic disease, (b) provide compelling evidence on health benefits of cowpea consumption to consumers, (c) equip breeders with more parameters for crop improvement, and (d) increase demand and economic value of cowpea to farmers. 


\section{PHYTOCHEMICAL PROFILES OF DIFFERENT COWPEA PHENOTYPES AND THEIR LEVELS BEFORE AND AFTER THERMAL PROCESSING}

\subsection{Introduction}

Cowpea (Vigna unguiculata) is an important part of human diet in many countries around the world, especially in developing countries (102). Apart from its traditional role of supplying good quality proteins (25\%) essential in preventing protein malnutrition, cowpea is also a low glycemic index food high in carbohydrates (60\%), dietary fiber and minerals (e.g. K, Mg, Ca, P, Na, and Fe) $(103,104)$. Cowpea seed and cowpea protein isolates have been reported to lower plasma total cholesterol and increase high density lipoproteins (HDL) (105). Antioxidant activities and phenolic constituents in raw cowpeas have also been reported $(47,51,56,106,107)$.

Phenolic constituents of 17 cowpea varieties were reported to be dominated by protocatechuic acid in esterified forms (from 9.3 to $92.7 \mathrm{mg} / 100 \mathrm{~g}$ of flour) (47). Six other phenolic acids were reportedly present in small quantities, including $p$ hydroxybenzoic acid, caffeic acid, p-coumaric acid, ferulic acid, 2,4-dimethoxybenzoic acid, and cinnamic acid; which may be free, esterified or bound to other non-phenolic compounds (47). The chromatograms of the phenolic constituents in the 17 cowpea flours before acid hydrolysis showed significant differences in the number of peaks and peak distribution. This evidence suggests that chromatograms of intact phenolic compounds better described the distributions of polyphenolic compounds and identities of the individual cowpea phenotypes or varieties. 
Anthocyanins, such as 3-O-glycosides of delphinidin, cyanidin, petunidin, peonidin and malvidin have also been reported in raw cowpea seed coats (46). Anthocyanins are known to have anti-inflammatory property (108), selective growth inhibitory activity of cancer cells (109), as well as ability to reduce risk of coronary heart disease (110). How cowpea seed coat color influence anthocyanin composition is unknown.

Apart from phenolic acids and anthocyanins, cowpeas also contains significant amounts of proanthocyanidins (i.e. condensed tannins), flavan-3-ols (e.g. catechin, epicatechin), flavonols (i.e. quercetin, myricetin and kaempferol), and isoflavones (i.e. daidzein and genistein) (56). For example, cowpea reportedly contains relatively high amounts of myricetin and quercetin especially in the dark colored varieties, but limited amounts of genistein and kaempferol (56). However, since identification and quantification was performed after acid hydrolysis, the study never considered the fact that these flavonoids may be associated with other non-phenolic materials such as glycosides or acyl groups, and thus failed to provide the structural properties of the flavonols and isoflavones in cowpea.

Proanthocyanidins (i.e. condensed tannins), consist primarily of catechin and epicatechin units, and are considered antinutritional compounds since they precipitate proteins and complex with iron in the lumen, thus reducing the absorption, digestibility and availability of these nutrients (111). Most investigations on condensed tannins in legumes have always focused on herbaceous forage legume species rather than the seeds useful in human nutrition (112). Elias et al. (113) showed that the content of tannins in 
legume seeds varied with the color of seed coats, with the white varieties containing lower tannin concentrations than the red, black or bronze seed coats. Tannin-rich extracts from legumes with colored seed coat (i.e pea, faba bean, lentil and broad bean) were reported to possess stronger antioxidant activity measured by the oxidation rate of phosphatidyl choline in the liposome system, than legumes with white seed coats (i.e. bean, pea and everlasting pea) $(114,115)$. The presence of higher levels of tannins in the seed coat apparently correlates with the antioxidant activity of legume seeds.

Cowpea polyphenolics are located mainly in the seed coats. Cowpea seed-coat color, hue and intensity vary greatly among varieties, and has been established to strongly correlate with antioxidant activity and total phenol content (65). Therefore, it is reasonable to suspect that seed-coat color might influence the flavonoid composition and content in cowpea seeds, and that their antioxidant activities would be phenotype dependent.

Cowpea seeds must be processed before consumption, thus, information on the composition and health promoting properties of boiled samples are more relevant from nutritional point of view. Processing methods include soaking and thermal treatment, as well as fermentation or milling into flour to make other food products $(116,117)$. Thermal processes improve flavor and palatability of cowpeas, and increase the bioavailability of nutrients by eliminating or inactivating antinutritional factors (e.g. trypsin inhibitor, saponins, agglutinins, lectins, flatulence causing oligosaccharides, etc) (118-120). Thermal processing may also lead to complex changes in the phenolic composition of legumes, as well as degradation of polyphenols. Rocha-Guzmán et al. 
(69) reported that severe heating, for example, pressure cooking (i.e. $121^{\circ} \mathrm{C} ; 103.421$ $\mathrm{kPa} ; 60 \mathrm{~min}$ ) drastically reduced the phenolic content in common beans seed coats by approximately 90\%. However, since polyphenolic compositions of cowpea may be phenotype dependent, effect of thermal treatment on the polyphenolic profiles of cowpea may be phenotype dependent as well. Information on the degree of retention of specific phytochemicals and possible formation of polyphenolic-derivatives following thermal treatment would be essential in providing insight into levels and heat stability of individual cowpea polyphenolic compounds and possible recommendations on strategies to enhance their stability during processing.

At present, no information is available on how seed coat color influences types and levels of flavonoid compounds in cowpea grains. Moreover, no information exists on the effect of thermal treatment on retention and/or transformation of polyphenolic compounds in cowpeas. In order to associate flavonoid profiles of different cowpea varieties with health promoting potential, it is important to first identify and quantify the individual polyphenols present in cowpea, and establish how seed coat color and thermal treatment influence their composition. Thus the objectives of this study were to; (1) elucidate the flavonoid profile of distinct phenotypes of cowpea seeds; (2) demonstrate the association of cowpea phenotype with major flavonoid levels; and (3) characterize the effect of thermal treatment on those flavonoids. 


\subsection{Materials and methods}

\subsubsection{Plant materials}

Dry cowpea seeds within six phenotypes (black, red, green, white, light brown and golden brown) were collected at maturity in late July 2010 at university experimental station in College Station, Texas, and UC-Riverside, California. The cowpea varieties, seed-coat color, texture and size, and origin or collection sites are listed in Table 2. Broken and damaged seeds, as well as foreign materials were removed prior to use. The seeds were ground using a coffee grinder (Cuisinart, Model DCG-20N series) to pass through a 60 -mesh sieve. The powders were then stored at $4^{\circ} \mathrm{C}$ until used. To determine the moisture content, triplicate samples of the ground powders were dried in an air circulated oven at $110^{\circ} \mathrm{C}$ until a constant weight was obtained (121). All calculations for flavanoid content, total phenol content, condensed tannin content and antioxidant capacity were on a dry weight basis.

\subsubsection{Chemicals and reagents}

All reagents were analytical grade. Kaempferol, quercetin, quercetin-3-Orutinoside (rutin), procyanidin dimer B2, taxifolin, phloretin, phloretin-2'-glucoside (phlorizin) and (+)-catechin were purchased from Sigma-Aldrich Chemicals, St. Louis, MO; protocatechuic acid was obtained from MP Biomedicals, LLC, Solon, OH; myricetin was obtained from ACROS Organics, New Jersey, USA. Delphinidin-3-Oglucoside, cyanidin chloride, cyanidin-3-O-glucoside, malvidin-3-O-glucoside, 
eriodictyol, eriodictyol-7-O-glucoside and quercetin-3-O-glucopyranoside were purchased from Extrasynthese Natural Products, Genay Cedex, France.

Table 2. Description of cowpea cultivars selected for the study. See appendix $\boldsymbol{A}$ for photos of cowpea phenotypes investigated in this study.

\begin{tabular}{llll}
\hline Variety & $\begin{array}{l}\text { Seed weight }^{\dagger} \\
\text { (g/100 seeds) }\end{array}$ & Seed coat property & Origin $^{\ddagger}$ \\
\hline IT95K-1105-5 & $23.4 \pm 0.37$ & Black, smooth & Riverside, CA \\
IT98K-1092-1 & $11.6 \pm 035$ & Black, smooth & College station, TX \\
IT82D-889 & $11.3 \pm 0.17$ & Red, smooth & College station, TX \\
IT97K-1042-3 & $13.1 \pm 0.20$ & Red, smooth & College station, TX \\
TX2028-1-3-1 & $21.6 \pm 0.45$ & Green, freckled, black-eye & College station, TX \\
IAR-48 & $22.6 \pm 0.22$ & Light brown, rough & College station, TX \\
09FCV-CC-27M & $14.9 \pm 0.40$ & Light brown, smooth & Riverside, CA \\
IFE BROWN & $15.8 \pm 0.16$ & Golden brown, rough & College station, TX \\
IT84S-2246 & $17.5 \pm 0.08$ & Golden brown, smooth & Riverside, CA \\
EARLY ACRE & $11.6 \pm 0.16$ & White, freckled, brown eye & College station, TX \\
\hline
\end{tabular}

${ }^{\dagger}$ Seed weight expressed as mean \pm SD of triplicate weights of 100 seeds. ${ }^{\ddagger}$ Samples were grown in university test plots in CA or TX in 2010.

\subsubsection{Thermal processing}

Triplicate amounts (100 g each) of the whole cowpea seeds from each variety were separately soaked in 450 g distilled water for 12 hours, and were then boiled in beakers at atmospheric pressure for $15 \mathrm{~min}$ [the average time adequate tactile texture (resistance to pressure between the fingers) was achieved] (122). Cooking time commenced when the cook-water started boiling. The cooked seeds (including the soups) were immediately transferred into $50 \mathrm{~mL}$ falcon tubes, and cooled in a chilling water bath. Subsequently, these samples were frozen to $-80^{\circ} \mathrm{C}$, freeze-dried and ground to pass through 60 -mesh screen. The powders were then stored at $4^{\circ} \mathrm{C}$ until used. 


\subsubsection{Extraction of polyphenols for HPLC and mass spectrometry analysis}

Approximately 5 grams of raw and cooked ground cowpeas were separately weighed into capped polypropylene centrifuge tubes and soaked in $15 \mathrm{~mL}$ of $70 \%$ acetone acidified with $1 \%$ formic acid for 12 hours at $4^{\circ} \mathrm{C}$. Then, the mixtures were shaken intermittently for 4 hours in a shaking water bath set at $37^{\circ} \mathrm{C}$ (Blue M, Blue Island Electrical Company, IL, USA). The extracts were centrifuged (10,000 $g$-force for 10 min) using a Heraeus Megafuge 11R Centrifuge (Thermo Fisher Scientific, Asheville, NC) at $4^{\circ} \mathrm{C}$ and the supernatants were transferred into new falcon tubes. The solid residues were washed twice with $10 \mathrm{~mL}$ of the extraction solvent and further centrifuged. The supernatants were then combined and concentrated under reduced pressure (Buchmann R110 Rotavapor, Westbury, NY).

\subsubsection{Extract purification}

The cowpea extracts were fractionated on a Sep-Pak Solid Phase Octadecylsilane (C18) cartridges (Sigma, USA) following methods described by Prior et al. (123) and Monagas et al. (124) but with some modifications. Briefly, the C18 cartridges were preconditioned with $25 \mathrm{~mL}$ methanol:water (1:1) for $1 \mathrm{hr}$ and washed with $50 \mathrm{~mL}$ distilled water. At least $5 \mathrm{~mL}$ of the concentrated extracts were deposited into the cartridges and washed with $5 \mathrm{~mL}$ distilled water to remove the sugars. Then, catechins, oligomeric proanthocyanins (PA) and other small phenolic molecules were eluted with $15 \mathrm{~mL}$ ethyl acetate. The ethyl acetate fraction was taken to dryness under vacuum, and re-dissolved in $3 \mathrm{~mL}$ of methanol:water (50:50) containing $0.05 \%$ formic acid. The 
flavonols, isoflavonols and anthocyanin pigments were then eluted with $15 \mathrm{~mL}$ methanol acidified with $0.1 \%$ formic acid, followed by elution of polymeric proanthocyanidins with $10 \mathrm{~mL}$ 100\% methanol. The sequential elution procedure was chosen to reduce the number of compounds in each fraction injected into the mass spectrometer, thus enabling proper characterization. The prepared pigments were stored at $4^{\circ} \mathrm{C}$ until analyzed.

\subsubsection{HPLC analysis}

Aliquots of the purified extracts $(400 \mu \mathrm{L})$ were each separately mixed with 400 $\mu \mathrm{L}$ of methanol acidified with $0.05 \%$ formic acid and filtered through a syringe with a $0.2 \mu \mathrm{m}$ polytetrafluoroethylene (PTFE) membrane filter prior to injection into an HPLC system. The HPLC analysis was conducted using an Agilent 1200 series LC system, equipped with a G1322A vacuum degasser, a G1311A quaternary pump, G1364C analytical auto-sampler, G1316B thermostated column compartment, and a G1315C Diode Array and Multiple Wavelength Detector (Agilent Technologies, Palo Alto, CA, USA). Chromatographic separation was performed on a ZORBAX Stable Bond Eclipse XDB-C18 column (4.6 × 150 mm, $5 \mu \mathrm{m}, 100$ A; Agilent Technologies, MD, USA), with a guard column $(4.6 \times 12.5 \mathrm{~mm}, 5 \mu \mathrm{m})$. The mobile phase consisted of aqueous $2 \% \mathrm{v} / \mathrm{v}$ formic acid solution (A) and acetonitrile:methanol (50:50) acidified with $2 \%$ formic acid (B). Using an injection volume of $5 \mu \mathrm{L}$ in each analysis, the elution gradient was carried out at a flow rate of $1.0 \mathrm{~mL} / \mathrm{min}$ with the column temperature thermostated at $40^{\circ} \mathrm{C}$. The gradient profile was programmed at $0 \% \mathrm{~B}$ from $0-2 \mathrm{~min}, 0-10 \% \mathrm{~B}$ from $2-8 \mathrm{~min}, 10$ - 20\% B from 8 - 15 min, 20 - 50\% B from 15 - 30 min, 50 - 80\% B from 30 - 35 min, 
$80-100 \%$ B from 35 - 40 min, followed by 5 min of isocratic elution at $100 \%$ B. A 2min post time was allowed for a system equilibration before each sequential injection. The spectra were monitored at $280 \mathrm{~nm}$ for phenolic acids and flavanols; at $360 \mathrm{~nm}$ for flavonols and isoflavonoids; and at $520 \mathrm{~nm}$ for anthocyanins.

\subsubsection{LC-ESI/MS analysis}

A Waters - ACQUITY UPLC/MS system (Waters Corp., Milford, MA) was used. The UPLC was equipped with a binary solvent manager, sample manager, column heater; and Photodiode array e $\lambda$ detector and interfaced with a Mass Spectrometer equipped with a tandem quadrupole (TQD) electrospray ionization (ESI) detector. Anthocyanins were monitored at $520 \mathrm{~nm}$, while other phenolics were at 280 and $360 \mathrm{~nm}$. The column used was a Kinetex C18 column, $150 \times 2.10 \mathrm{~mm}$, ำ6 (Phenomenex, Torrance, CA). The column temperature for anthocyanins and other phenolics was thermostated at 50 and $40^{\circ} \mathrm{C}$, respectively. Mass spectrometric data of the eluted compounds from the column were acquired in positive mode for anthocyanins and negative mode for flavonol glycosides and catechins. Data acquisition and processing were performed using Empower 2 software (Waters Corp., Milford, MA). The MS scan were recorded in the range of 100 - 1000 Da for anthocyanins, and 100 - 1500 Da for other phenolics. Nitrogen was used both as a drying gas and as nebulizing gas, while argon was used as the collision gas (AOC, Bryan, TX). The nitrogen gas flow conditions were 800 and $50 \mathrm{~L} / \mathrm{hr}$ for desolvation and at the cone, respectively. Source block temperature and desolvation temperature were set at 150 and $400^{\circ} \mathrm{C}$, respectively. 
Optimization of ionization conditions was based on the intensity of the mass signals of protonated/deprotonated molecules and aglycones fragments, and was performed for each individual peak/compound detected. Mass parameters were optimized as follows: capillary voltage, 3.5/3.0 kV; and cone voltage, $40 / 30 \mathrm{~V}$ for positive/negative ionization, respectively. The MS/MS scan was optimized as follows: cone voltage, 40/30-55 V; and collision energy, 20/15-40 V for anthocyanins/other phenolics, respectively. The purified phenolic extracts described above (see extract purification) were dissolved in methanol/water (50:50) acidified with $0.05 \%$ formic acid. The solution was filtered by a syringe filter with a $0.2 \mu \mathrm{m}$ PTFE membrane, and $1 \mu \mathrm{L}$ was injected onto the LC column for UPLC-UV and UPLC-ESI-MS analyses.

The solvents were $2 \%$ formic acid in $\mathrm{H}_{2} \mathrm{O}$ (solvent A) and acetonitrile (solvent B) for anthocyanin analysis; and $0.05 \%$ formic acid in $\mathrm{H}_{2} \mathrm{O}$ (solvent A) and acetonitrile (solvent B) for other phenolics. A high level of formic acid was required to modify the $\mathrm{pH}$ of the mobile phase for proper analysis of anthocyanins (125). The gradient was $5 \%$ B from 0 - 2 min, 5 - 75\% B from 2 - 27 min, $75 \%$ B isocratic from 27 - 30 min, 75 $5 \%$ B from $30-31 \mathrm{~min}$, followed by $5 \%$ B isocratic for 5 min to allow for column equilibration before the next injection; at a flow rate of $0.4 \mathrm{~mL} / \mathrm{min}$. 


\subsubsection{Quantification of anthocyanins, flavonols and flavan-3-ols}

\subsubsection{Extraction}

Approximately $5.0 \mathrm{~g}$ of raw and cooked cowpea flour were separately extracted in $15 \mathrm{~mL}$ of $1 \% \mathrm{HCl}$ in methanol for 2 hours at room temperature with continuous shaking. The extracts were centrifuged (10000 $\mathrm{g}$-force for $10 \mathrm{~min}$ ) using a Heraeus Megafuge 11R Centrifuge (Thermo Fisher Scientific, Asheville, NC) at $4^{\circ} \mathrm{C}$ and the supernatants were transferred into $50 \mathrm{~mL}$ falcon tubes. The solid residues were washed twice with $5 \mathrm{~mL}$ of the extraction solvent, further centrifuged, and the supernatants combined with the previously collected supernatants from corresponding samples. An aliquot from these mixtures were filtered using a syringe filter with a $0.2 \mu \mathrm{m}$ PTFE membrane, and $5 \mu \mathrm{L}$ was injected onto the LC column for HPLC analyses.

\subsubsection{Quantification}

The assumption made for quantification of anthocyanins, flavonols and flavan-3ols derivatives with no standards was that their molar absorptivity was similar to those of their aglycones or mono-glycosides. Thus, concentrations of the identified compounds in cowpea were calculated from the HPLC standard curves of pure standards; and were expressed as micrograms per gram $(\mu \mathrm{g} / \mathrm{g})$ of dry seed on a dry weight basis. 


\subsection{Results and discussion}

\subsubsection{Identification of anthocyanins in cowpeas}

Naturally, anthocyanins generally occur as O-glycosides. During MS/MS fragmentation, the glycosidic bond is cleaved with concomitant proton rearrangement which leads to elimination of the sugar moiety. Typical losses include 162 amu (hexose; glucose or galactose), 146 amu (deoxyhexose; rhamnose), 132 amu (pentose; xylose or arabinose), and 176 amu (glucuronic acid). The most abundant and common glycosyl moiety in most anthocyanins and other pigments is glucose. Glycosylation mostly occurs at position C-3 (126). In this study, designation of sugar moieties was mostly achieved based on the MS spectra obtained as well as using literature evidence.

In the UPLC chromatograms acquired at $520 \mathrm{~nm}$, eight distinct anthocyanin peaks (compounds 1a - 8a) were detected in only the black (IT95K-1105-5 and IT98K1092-1) and green (TX2028-1-3-1) cowpea phenotypes (Figure 1; Table 3). Their structures are presented in Figure 2. All the other phenotypes did not contain detectable levels of anthocyanins. Identification was achieved by elution profile, comparison to pure standards, UV-vis spectra and comparing the molecular ions and product ions of these anthocyanin compounds with those available in the literature. The molecular ions and product ions of anthocyanins in the three cowpea varieties are summarized in Table 3. 


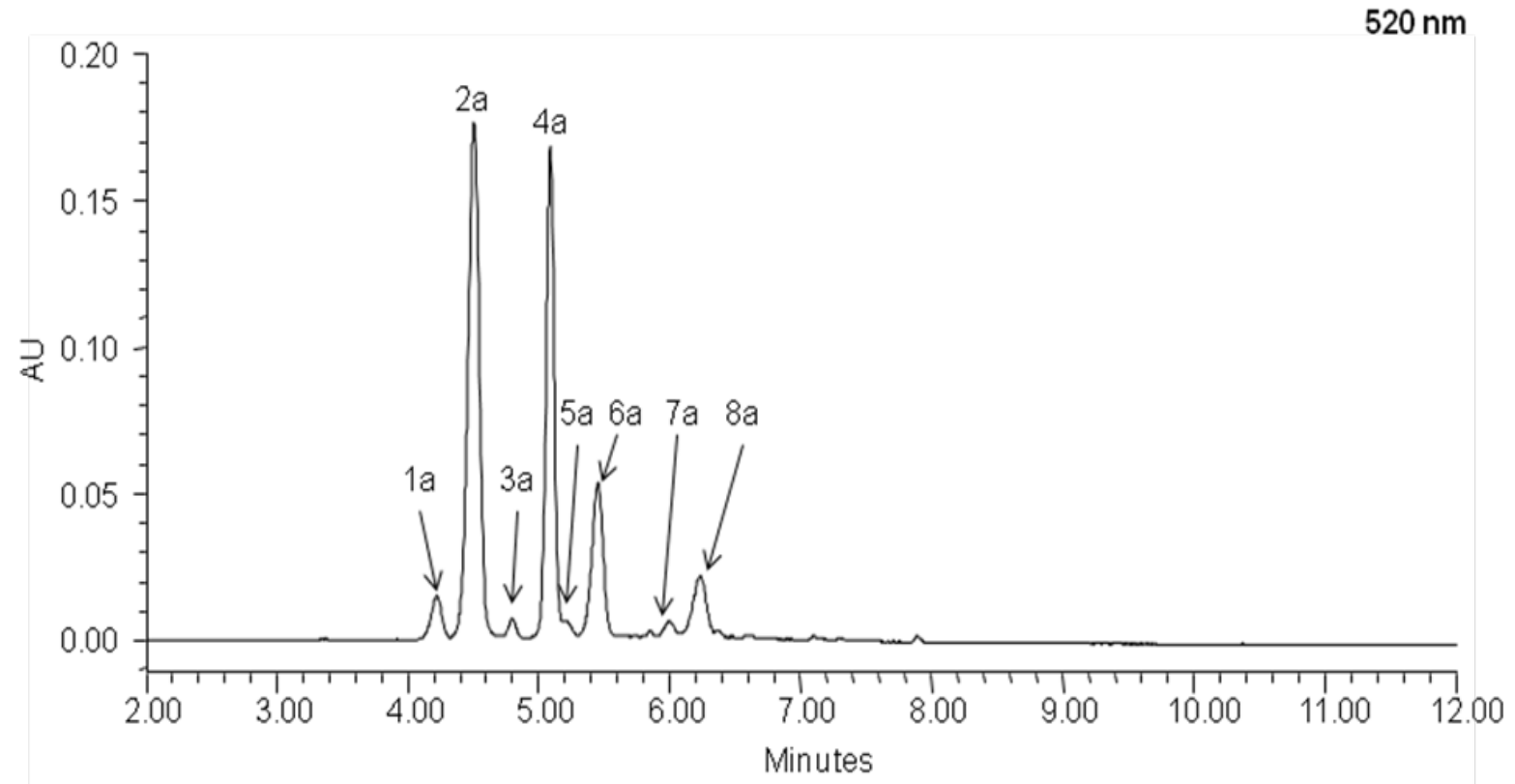

Figure 1. Representative UPLC chromatogram of anthocyanins found in the methanolic fractions from black IT95K-1105-5 cowpea variety monitored at $520 \mathrm{~nm}$. The black IT98K1092-1 and green TX2028-1-3-1 varieties also had similar profile. See Table 3 for peak identities and Figure 2 for structures.

The MS spectrum of peak $1 a\left(t_{\mathrm{R}}=4.22 \mathrm{~min}\right)$ and $2 a\left(t_{\mathrm{R}}=4.50 \mathrm{~min}\right)$ showed that the peaks had similar molecular ion $[\mathrm{M}+\mathrm{H}]^{+}$at $\mathrm{m} / \mathrm{z} 465$, and the MS/MS spectrum showed that the ions at $m / z 465$ had the same fragmentation patterns $(m / z$ 303: [M - 162 amu]) which corresponded to the loss of a hexose. The MS/MS fragment at $\mathrm{m} / \mathrm{z} 303$ corresponded to a delphinidin aglycone. Since peaks $1 a$ and $2 a$ differ only by retention time (Table 3), peak $1 a$ was established as delphinidin-3-O-galactoside, on the basis of its shorter retention time; whereas peak $2 a$ was elucidated as delphinidin-3-O-glucoside, and corroborated by literature data (46). The nature of the glycosyl group apparently has 
no influence on $\lambda_{\max }$; however, galactosyl units increases polarity of the pigments through the C18 column than glucosyl units, thus the galactosides elute before glucosides $(46,127)$.

Peaks $3 a\left(t_{\mathrm{R}}=4.79 \mathrm{~min}\right)$ and $4 a\left(t_{\mathrm{R}}=5.08 \mathrm{~min}\right)$ showed a molecular ion $[\mathrm{M}+\mathrm{H}]^{+}$ at $m / z 449$ that, when fragmented, gave an ion at $m / z 287$, corresponding to the loss of a hexose molecule ( $-162 a m u$ ). These 2 peaks ( $3 a$ and $4 a$ ) also differed by retention time (Table 3). Thus, based on UV-vis, MS data, retention time and literature evidence, peak $3 a$ was identified as cyanidin-3-O-galactoside, while peak $4 a$ as cyanidin-3-O-glucoside (46).

Table 3. Identification of anthocyanins in IT95K-1105-5 (black), IT98K-1092-1 (black) and TX2028-1-3-1 (green) cowpea varieties based on UPLC retention time $\left(t_{R}\right)$, UV-vis spectroscopic characteristics $\left(\lambda_{\max }\right)$, MS and MS/MS spectroscopic pattern. Peak numbers are referenced to Figure 1. The structures of the peaks are reference to Figure 2.

\begin{tabular}{cccccl}
\hline $\begin{array}{c}\text { Peak } \\
\text { no. }\end{array}$ & $\begin{array}{c}\boldsymbol{t}_{\boldsymbol{R}} \\
(\mathbf{m i n})\end{array}$ & $\boldsymbol{\lambda}_{\max } \mathbf{( n m )}$ & $\begin{array}{c}\mathbf{M S} \\
{[\mathbf{M}+\mathbf{H}]^{+}}\end{array}$ & $\begin{array}{c}\text { MS/MS } \\
{[\mathbf{M}+} \\
\mathbf{H}]^{+}\end{array}$ & Proposed structure \\
\hline 1a & 4.22 & 524 & 465 & 303 & Delphinidin-3-O-galactoside \\
$\mathbf{2 a}$ & 4.50 & 524 & 465 & 303 & Delphinidin-3-O-glucoside \\
3a & 4.79 & 517 & 449 & 287 & Cyanidin-3-O-galactoside \\
$\mathbf{4 a}$ & 5.08 & 517 & 449 & 287 & Cyanidin-3-O-glucoside \\
$\mathbf{5 a}$ & 5.20 & 526 & 479 & 317 & Petunidin-3-O-galactoside \\
$\mathbf{6 a}$ & 5.45 & 526 & 479 & 317 & Petunidin-3-O-glucoside \\
$\mathbf{7 a}$ & 5.99 & 516 & 463 & 301 & Peonidin-3-O-glucoside \\
$\mathbf{8 a}$ & 6.23 & 526 & 493 & 331 & Malvidin-3-O-glucoside \\
\hline
\end{tabular}


Similarly, peaks $5 a\left(t_{\mathrm{R}}=5.20 \mathrm{~min}\right)$ and $6 a\left(t_{\mathrm{R}}=5.45 \mathrm{~min}\right)$, having a molecular ion at $\mathrm{m} / \mathrm{z} 479$ from the MS spectrum and one product ion at $m / z 317$ ([M - 162 amu]) from the MS/MS spectrum, indicated that the compounds are glucosides of petunidin (Table 3). Peak $6 a$ was identified as petunidin-3-O-glucoside (46), while peak $5 a$ was identified as petunidin-3-O-galactoside based on its shorter retention time relative to its glucosidic analog. This is the first time this pigment is reported in cowpea. In this study, petunidin-3-O-galactoside was identified in all three cowpea varieties that contained anthocyanins (black and green). However, since the level of petunidin-3-O-galactoside (peak 5a) was low (Figure 1), a high sensitive LC-MS system is critical in ensuring that the compound is detectable. In this analysis, the UPLC-MS provided exceptional sensitivity due to high LC pressure and greater specificity since the detector could be programmed to select specific ions to fragment with no interferences or ion suppression.

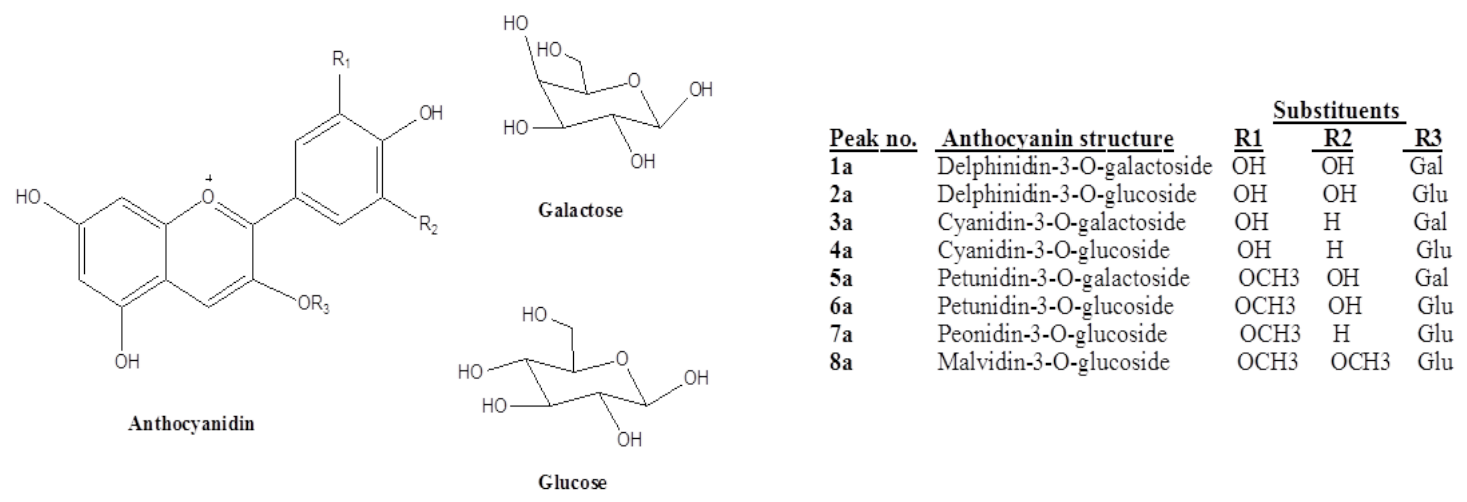

Figure 2. Chemical structures of the eight anthocyanins found in cowpeas. See Table $\mathbf{3}$ for molecular masses, maximum absorption wavelengths and peak retention times. 
The MS spectrum of peak $7 a\left(t_{\mathrm{R}}=5.99 \mathrm{~min}\right)$ indicated that the peak had $\mathrm{m} / \mathrm{z} 463$, and the MS/MS spectrum showed it fragmented to $\mathrm{m} / \mathrm{z} 301$, corresponding to the molecular ion of peonidin aglycone and a loss of a hexose moiety ([M - 162 amu $]$ ). This compound was identified as peonidin-3-O-glucoside. Peak $8 a\left(t_{\mathrm{R}}=6.23 \mathrm{~min}\right)$ was identified as malvidin-3-O-glucoside based on MS spectrum molecular ion at $m / z$ 493, UV-vis spectra and MS/MS fragment at $\mathrm{m} / \mathrm{z}$ 331, corresponding to loss of hexose moiety. Both compounds had previously been identified in cowpea (46).

We did not detect anthocyanins in the red, light brown, golden brown and white cowpea varieties studied. Additionally, there are no reports in the literature regarding the anthocyanin profile in green cowpea phenotype. In particular, TX2028-1-3-1 is a variety of cowpea with a green seed coat and a black eye and can be used as a vegetable in many diets such as gravies since it has an appealing look.

The three cowpea (black and green) varieties which contained anthocyanins exhibited similarities in their anthocyanin profiles, suggesting phenotype did not influence the nature of anthocyanins detected. Since the black IT95K-1105-5 variety was grown in UCR while the black IT98K-1092-1 and green TX2028-1-3-1 varieties were grown in College Station, TX, this study provide evidence that genes, light, temperature and agronomic factors do not impact the nature of anthocyanins forms identified in cowpea. 


\subsubsection{Anthocyanin content in raw cowpeas}

On average, the black IT95K-1105-5 and green TX2028-1-3-1 cowpea varieties had the highest seed weight (21.6 - 23.4 g/100 seeds), compared to that of black IT98K1092-1 variety (11.6 g/100 seeds) (Table 2).

Anthocyanin content varied significantly between the three varieties (Tables 4 and 5). Among the black phenotypes, the IT95K-1105-5 cowpea variety had the highest average anthocyanin content (2095 $\pm 35.6 \mu \mathrm{g} / \mathrm{g})$ despite its larger size, than the smaller seeded black IT98K-1092-1 (1676 $\pm 33.9 \mu \mathrm{g} / \mathrm{g})$ suggesting varietal effect (Table 4). It is not clear how growth environment influenced anthocyanin content. The IT95K-1105-5 was from UCR while IT98K-1092-1 was from College Station. The green TX2028-1-3-1 cowpea variety had (876 $\pm 28.4 \mu \mathrm{g} / \mathrm{g})$ (Table 5).

In all the three varieties, the most dominant pigment was delphinidin-3-Oglucoside, followed by cyanidin-3-O-glucoside and then petunidin-3-O-glucoside. Petunidin-3-O-galactoside, a new compound first reported in cowpeas in this study, was the least. The average amounts of delphinidin-3-O-glucoside in the raw IT95K-1105-5, IT98K-1092-1 and TX2028-1-3-1 cowpeas were 681, 508 and $231 \mu \mathrm{g} / \mathrm{g}$, respectively; while those of cyanidin-3-O-glucoside were 549, 444 and $209 \mu \mathrm{g} / \mathrm{g}$, respectively (Tables 4 and 5).

The literature on anthocyanin content in cowpeas is very limited. Chang and Wong (54) reported higher contents of delphinidin-3-O-glucoside (1,450 $\mu \mathrm{g} / \mathrm{g})$ and cyanidin-3-O-glucoside $(1,030 \mu \mathrm{g} / \mathrm{g})$ in the flour of Hakmeitau beans, a black cowpea cultivar. This is in contrast to investigations by Ha et al. (46), who showed that area 
percent of cyanidin-3-O-glucoside (58.1\%) in the seed coat was much greater than that of delphinidin-3-O-glucoside (22.0\%). These differences could be attributed to differences in extractions methods, varieties and environment.

Table 4. Contents of anthocyanins in raw and boiled black (IT95K-1105-5 and IT98K-1092-1) cowpea varieties as determined by HPLC-UV-vis ${ }^{a}$

\begin{tabular}{|c|c|c|c|c|c|c|}
\hline \multirow[b]{4}{*}{ Compound } & \multicolumn{6}{|c|}{ Black cowpea varieties } \\
\hline & \multicolumn{3}{|c|}{$\underline{\text { IT95K-1105-5 }}$} & \multicolumn{3}{|c|}{$\underline{\text { IT98K-1092-1 }}$} \\
\hline & \multicolumn{6}{|c|}{ Anthocyanin content ( $\mu \mathrm{g} / \mathrm{g}$ cowpea flour) } \\
\hline & Raw & Boiled & $\begin{array}{c}\% \\
\text { change }\end{array}$ & Raw & Boiled & $\begin{array}{c}\% \\
\text { change }\end{array}$ \\
\hline Delphinidin-3-O-galactoside & $169 \pm 5.2^{6}$ & $103 \pm 1.7^{b}$ & 38.9 & $143 \pm 2.4^{b}$ & $105 \pm 2.5^{b}$ & 26.7 \\
\hline Delphinidin-3-O-glucoside & $681 \pm 5.3$ & $115 \pm 8.2$ & 83.1 & $508 \pm 6.4$ & $68.2 \pm 3.41$ & 86.6 \\
\hline Cyanidin-3-O-galactoside & $152 \pm 4.9^{c}$ & $\mathrm{ND}^{e}$ & - & $142 \pm 3.2^{c}$ & ND & - \\
\hline Cyanidin-3-O-glucoside & $549 \pm 8.5$ & $89.2 \pm 3.1$ & 83.8 & $444 \pm 6.0$ & $53.5 \pm 2.83$ & 87.9 \\
\hline Petunidin-3-O-galactoside & $35.2 \pm 1.12^{d}$ & ND & - & $24.1 \pm 3.03^{d}$ & ND & - \\
\hline Petunidin-3-O-glucoside & $265 \pm 3.6^{d}$ & $143 \pm 4.0^{d}$ & 46.3 & $202 \pm 3.5^{d}$ & $90.6 \pm 3.81^{d}$ & 55.3 \\
\hline Peonidin-3-O-glucoside & $41.1 \pm 2.11^{d}$ & ND & - & $38.4 \pm 1.09^{d}$ & ND & - \\
\hline Malvidin-3-O-glucoside & $202 \pm 4.8$ & $60.3 \pm 1.0$ & 70.2 & $174 \pm 2.2$ & $41.0 \pm 2.01$ & 76.5 \\
\hline $\begin{array}{l}\text { Total monomeric } \\
\text { anthocyanins }\end{array}$ & $2094 \pm 35.5$ & $511 \pm 18.0$ & 75.6 & $1676 \pm 27.8$ & $358 \pm 14.6$ & 78.6 \\
\hline
\end{tabular}


Table 5. Contents of anthocyanins in raw and boiled green (TX2028-1-3-1) cowpea variety as determined by HPLC-UV-vis ${ }^{a}$

\begin{tabular}{lccc}
\hline & TX2028-1-3-1 (green) variety & \\
\hline Compound & Anthocyanin content $(\boldsymbol{\mu}$ g/g cowpea flour) \\
\hline Delphinidin-3-O-galactoside & $98.7 \pm 0.80^{6}$ & $32.6 \pm 1.67^{b}$ & 67.0 \\
Delphinidin-3-O-glucoside & $231 \pm 8.3$ & $73.9 \pm 2.02$ & 68.0 \\
Cyanidin-3-O-galactoside & $62.2 \pm 3.33^{c}$ & $\mathrm{ND}^{e}$ & - \\
Cyanidin-3-O-glucoside & $209 \pm 4.4$ & $43.9 \pm 1.02$ & 79.1 \\
Petunidin-3-O-galactoside & $15.7 \pm 2.30^{d}$ & $\mathrm{ND}$ & - \\
Petunidin-3-O-glucoside & $119 \pm 4.4^{d}$ & $37.7 \pm 1.62^{d}$ & 68.4 \\
Peonidin-3-O-glucoside & $29.3 \pm 3.02^{d}$ & $\mathrm{ND}$ & - \\
Malvidin-3-O-glucoside & $110 \pm 1.9$ & $32.7 \pm 2.12$ & 70.2 \\
\hline Total monomeric anthocyanins & $\mathbf{8 7 5} \pm \mathbf{2 8 . 5}$ & $\mathbf{2 2 1} \pm \mathbf{8 . 5}$ & $\mathbf{7 4 . 8}$ \\
\hline
\end{tabular}

${ }^{a}$ All values are expressed as mean \pm SD of triplicates on a dry weight basis. ${ }^{b}$ Expressed as delphinidin-3-O-glucoside equivalent. ${ }^{c}$ Expressed as cyanidin-3-O-glucoside equivalent. ${ }^{d}$ Expressed as malvidin-3-O-glucoside equivalent. ${ }^{e} \mathrm{ND}=$ not detectable.

In this study, the levels of galactosyl-derivatives of anthocyanins were lower than their glucosyl-derivatives. For instance, the average amounts of delphinidin-3-Ogalactoside in the raw IT95K-1105-5, IT98K-1092-1 and TX2028-1-3-1 cowpeas were 169, 143 and $98.7 \mu \mathrm{g} / \mathrm{g}$, respectively; while those of cyanidin-3-O-galactoside were 152, 142 and $62.2 \mu \mathrm{g} / \mathrm{g}$, respectively (Tables 4 and 5). Similar trends were also reported in levels of anthocyanins in Hakmeitau beans (54).

In summary, the levels of the anthocyanins identified in the raw black and green cowpea varieties were in the following descending order: delphinidin-3-O-glucoside, cyanidin-3-O-glucoside, petunidin-3-O-glucoside, malvidin-3-O-glucoside, delphinidin3-O-galactoside, cyanidin-3-O-galactoside, peonidin-3-O-glucoside and finally petunidin-3-O-galactoside (Figure 1; Table 3). These findings are in agreement with 
those of Ha et al. (46) who reported that cyanidin-3-O-glucoside, delphinidin-3-Oglucoside, petunidin-3-O-glucoside, and malvidin-3-O-glucoside were the major anthocyanins in a black seeded cowpea. Other authors $(128,129)$ reported delphinidin-3O-glucoside, petunidin-3-O-glucoside and malvidin-3-O-glucoside as the major anthocyanins in black common beans. However, black common beans reportedly contained much higher anthocyanin content compared to the cowpeas used in our study. For example, Xu and Chang (130) reported that black beans contained higher levels of delphidin-3-O-glucoside (2197 $\mu \mathrm{g} / \mathrm{g}$ ), followed by petunidin-3-O-glucoside (838 $\mu \mathrm{g} / \mathrm{g}$ ).

\subsubsection{Effect of boiling on anthocyanin content in cowpea}

Levels of monomeric anthocyanins were significantly reduced by boiling in all three cowpea varieties (Tables 4 and 5). In comparison to other anthocyanins, boiling reduced cyanidin-3-O-galactoside, petunidin-3-O-galactoside and peonidin-3-Oglucoside in all the varieties to undetectable levels (Tables 4 and 5).

In the case of the black varieties, the most impacted pigments as a result of boiling were delphinidin-3-O-glucoside and cyanidin-3-O-glucoside $(83.1$ - 87.9\% reduction), and the least was delphinidin-3-O-galactoside (26.7 - 38.9\% reduction) (Table 4). A similar trend was also observed for the green TX2028-1-3-1 variety due to boiling (Table 5). Xu and Chang (130) reported that on average, thermal processing reduced levels of anthocyanins by $>90 \%$ in black beans (Phaseolus vulgaris). Similar trends have also been reported in thermally processed soybean (131). 
In general, the black and green cowpea varieties lost on average $75-79 \%$ of their average monomeric anthocyanin content (measured by HLPC) as a result of boiling (Tables 4 and 5). The loss of anthocyanins might be attributed to degradation or decomposition of anthocyanins upon boiling. Thermal degradation of anthocyanins has been reported to follow first-order reaction kinetics, that is, anthocyanins content in foods decrease with increase in temperature (132). The decrease in anthocyanin content after boiling may also occur through the formation of less soluble polymerized complexes with other cellular components such as aldehydes, proteins and tannins.

Our results show that monomeric anthocyanins, especially the non-acylated forms found in cowpeas, are highly unstable during processing, and are easily degraded upon heating. Heat-induced degradation of anthocyanins is initiated by opening of the pyrylium ring, leading to formation of their thermolabile chalcone derivatives. This may be followed by degradation of the A-ring to phloroglucinaldehyde; and B-ring to protocatechuic acid or 4-hydroxybenzoic acid as the terminal degradation products (133). These colorless phenolics generated upon heating also contribute to the total antioxidant capacity. Phloroglucinaldehyde ( $m / z$ 155), protocatechuic acid $(m / z ~ 155)$ and 4-hydroxybenzoic acid ( $\mathrm{m} / \mathrm{z} 139)$ in the boiled samples can be detected by comparing their fragmentation data with typical fragmentation patterns of commercial references using LC/MS. 


\subsection{Flavonoids in the methanolic fractions}

\subsubsection{Free phenolic acids and phenolic aldehydes}

Peak $1\left(\mathrm{t}_{\mathrm{R}}=2.56 \mathrm{~min}, \lambda_{\max }=294 \mathrm{~nm}\right)$ had a $[\mathrm{M}-\mathrm{H}]^{-}$at $\mathrm{m} / \mathrm{z} 153$. The major MS/MS ions produced were at $\mathrm{m} / \mathrm{z} 109\left(\mathrm{M}-44 \mathrm{amu}\right.$, loss of $\left.\mathrm{CO}_{2}\right)$, the basis of which the peak was identified as protocatechuic acid. Among the samples investigated, only the red IT97K-1042-3 cowpea variety had detectable levels of protocatechuic acid (Table 6; Figure 3A-1; Figure 4B). Protocatechuic acid has been reported in some cowpea varieties (51).

Peak $5\left(\mathrm{t}_{\mathrm{R}}=3.85 \mathrm{~min}, \lambda_{\max }=281 \mathrm{~nm}\right)$ had a $[\mathrm{M}-\mathrm{H}]^{-}$at $\mathrm{m} / \mathrm{z} 137$, was identified as protocatechuic aldehyde (Figure 4B) since its MS and MS/MS ions were similar to those previously reported in literature (134). In the MS/MS spectrum, it had strong signals at $\mathrm{m} / \mathrm{z}$ 53, 81, 91, 109 and 119 (Table 6). Some leguminous seeds have been reported to contain protocatechuic aldehyde (135), however, to our knowledge, this is the first report of protocatechuic aldehyde in cowpeas. Among the varieties studied, protocatechuic aldehyde was only found in the red IT82D-889 variety (Figure 3B-1).

Table 6. Identification of phenolic acids and phenolic aldehydes monitored at 280 and $330 \mathrm{~nm}$ in methanolic fraction of 10 cowpea varieties based on UPLC retention time $\left(t_{R}\right)$, UV-vis spectroscopic characteristics ( $\left.\lambda_{\max }\right)$, and MS-MS/MS spectroscopic pattern. Ionization was performed in the negative mode.

\begin{tabular}{llllll}
\hline $\begin{array}{l}\text { Peak } \\
\text { no. }\end{array}$ & $\begin{array}{l}\mathbf{t}_{\mathbf{R}} \\
(\mathbf{m i n})\end{array}$ & $\begin{array}{l}\boldsymbol{\lambda}_{\max } \\
(\mathbf{n m})\end{array}$ & Proposed identifications & $\begin{array}{l}{[\mathbf{M}-\mathbf{H}]^{-}} \\
(\mathbf{m} / \mathbf{z})\end{array}$ & MS/MS fragments $(\mathbf{m} / \mathbf{z})$ \\
\hline $\mathbf{1}$ & 2.56 & 294 & Protocatechuic acid & 153 & 109,107 \\
$\mathbf{5}$ & 3.85 & 281 & Protocatechuic aldehyde & 137 & $119,109,91,81,53$ \\
$\mathbf{9}$ & 4.58 & 322 & trans-Feruloylaldaric acid & 385 & 209,191 \\
\hline
\end{tabular}


Peak $9\left(\mathrm{t}_{\mathrm{R}}=4.58 \mathrm{~min}, \lambda_{\max }=322 \mathrm{~nm}\right)$, which had a $[\mathrm{M}-\mathrm{H}]^{-}$at $\mathrm{m} / \mathrm{z} 385$ (Table 6) was elucidated as trans-feruloylaldaric acid based on matching UV-vis spectrum and MS data with literature data (51). The MS/MS spectrum indicated that the ion at $\mathrm{m} / \mathrm{z} 209$ (M - $176 a m u)$, occurred after cleavage of a glucuronic (aldaric) acid group. The fragment at $\mathrm{m} / \mathrm{z} 191(\mathrm{M}-176-18 \mathrm{amu})$ indicated a further loss of water molecule (Table 6). In this study, trans-feruloylaldaric acid was found in the red IT97K-1092-2 sample (Figure 3A-1), the golden brown (IT84S-2246 and Ife Brown) and white cowpea varieties. The presence of trans-feruloylaldaric acid has been reported in some cowpea varieties (51).

\subsubsection{Flavan-3-ols}

Peak $3\left(\mathrm{t}_{\mathrm{R}}=3.06 \mathrm{~min}, \lambda_{\max }=278 \mathrm{~nm}\right)$ had a $[\mathrm{M}-\mathrm{H}]^{-}$at $\mathrm{m} / \mathrm{z} 451$; its $\mathrm{MS} / \mathrm{MS}$ showed a major ion at $\mathrm{m} / \mathrm{z} 289$ (M - $162 \mathrm{amu}$, loss of a hexose unit). Other ions included m/z 151 and 179 which matches fragmentation pattern of catechin molecule (Table 7). Thus, peak 3 was identified as catechin-3-O-glucoside, a compound which has been identified in lentils (136). We found catechin-3-O-glucoside in all the varieties studied except in the IT82D-889 (red), TX2028-1-3-1 (green) and Early Acre (white) cowpea phenotypes. This is the first report of glycosyl derivative of flavan-3-ols in cowpea. 
Table 7. Identification of flavan-3-ols monitored at $280 \mathrm{~nm}$ in methanolic fraction of 10 cowpea varieties based on UPLC retention time $\left(\mathrm{t}_{\mathrm{r}}\right)$, UV-vis spectroscopic characteristics $\left(\lambda_{\max }\right)$, and MS - MS/MS spectroscopic pattern. Ionization was performed in the negative mode. Peaks marked (*) were unidentified.

\begin{tabular}{|c|c|c|c|c|c|}
\hline $\begin{array}{l}\text { Peak } \\
\text { no. }\end{array}$ & $\begin{array}{l}\mathbf{t}_{\mathrm{R}} \\
(\mathrm{min})\end{array}$ & $\begin{array}{l}\lambda_{\max } \\
(\mathrm{nm})\end{array}$ & Proposed identifications & $\begin{array}{l}{[\mathrm{M}-\mathrm{H}]^{-}} \\
(\mathrm{m} / \mathrm{z})\end{array}$ & MS/MS fragments $(m / z)$ \\
\hline $2 *$ & 2.85 & 278 & Unknown & 203 & $186,159,142,116,74$ \\
\hline 3 & 3.06 & 278 & Catechin-3-O-glucoside & 451 & $289,179,165,151$ \\
\hline 4 & 3.36 & 278 & $\begin{array}{l}\text { Procyanidin dimer-3-O-diglucoside- } \\
\text { 7-O-glucoside }\end{array}$ & 901 & 739, 577, 393, 269 \\
\hline $6^{*}$ & 4.19 & 279 & Unknown & 885 & $723,435,423$ \\
\hline $7^{*}$ & 4.45 & 271 & Unknown & 508 & $328,258,145,127,119$ \\
\hline 8 & 4.49 & 278 & Procyanidin dimer B-type & 577 & $425,407,289,125$ \\
\hline 10 & 4.82 & 279 & Catechin or epicatechin & 289 & $245,205,187,151,109$ \\
\hline 11 & 5.29 & 279 & Procyanidin trimer $\mathrm{T} 2$ & 865 & 713, 577, 451, 289, 287 \\
\hline $12^{*}$ & 5.36 & 279 & Unknown & 885 & 723, 435, 423, 125 \\
\hline 13 & 5.46 & 278 & Procyanidin tetramer A-type & 1154 & $821,803,575,287$ \\
\hline $15 *$ & 5.85 & 278 & Unknown & 387 & 207, 89, 59 \\
\hline $16^{*}$ & 6.03 & 279 & Unknown & 721 & 697, 407, 289, 195 \\
\hline $18^{*}$ & 6.16 & 279 & Unknown & 885 & 723, 587, 560, 241, 229 \\
\hline $20 *$ & 6.36 & 294 & Unknown & 317 & $255,191,179,163,153,150$ \\
\hline 21 & 6.39 & 279 & Procyanidin trimer C1 & 865 & $713,577,425,407,289,287$ \\
\hline $31 *$ & 7.48 & 290 & Unknown & 349 & $331,300,271,255,179,151$ \\
\hline $35 *$ & 7.73 & 278 & Unknown & 723 & $435,395,287,273,161,125$ \\
\hline $44^{*}$ & 8.40 & 279 & Unknown & 809 & 595, 435, 391, 272, 161 \\
\hline
\end{tabular}



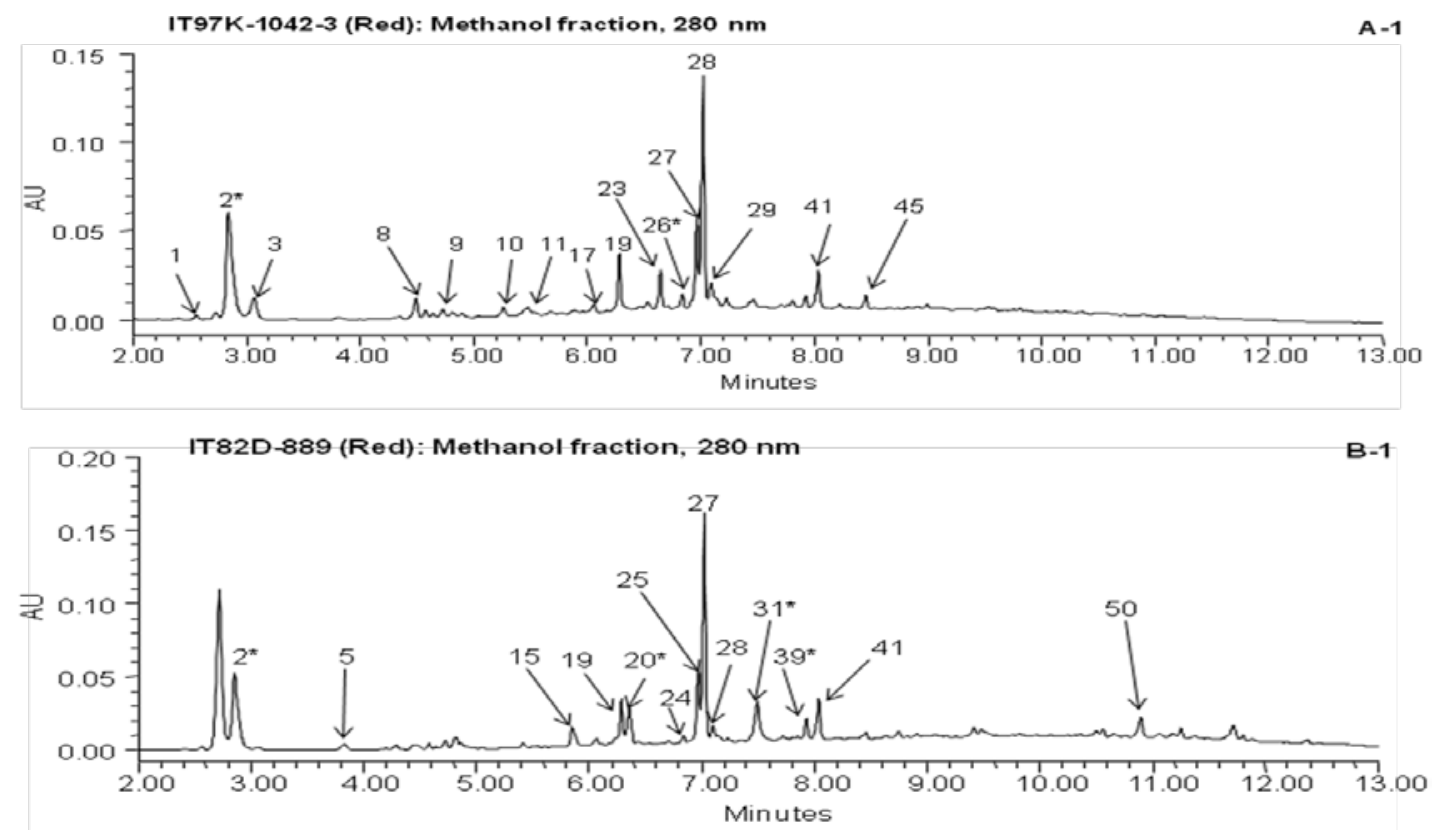

IT97K-1042-3 (Red): Methanol fraction, $360 \mathrm{~nm}$

A-2
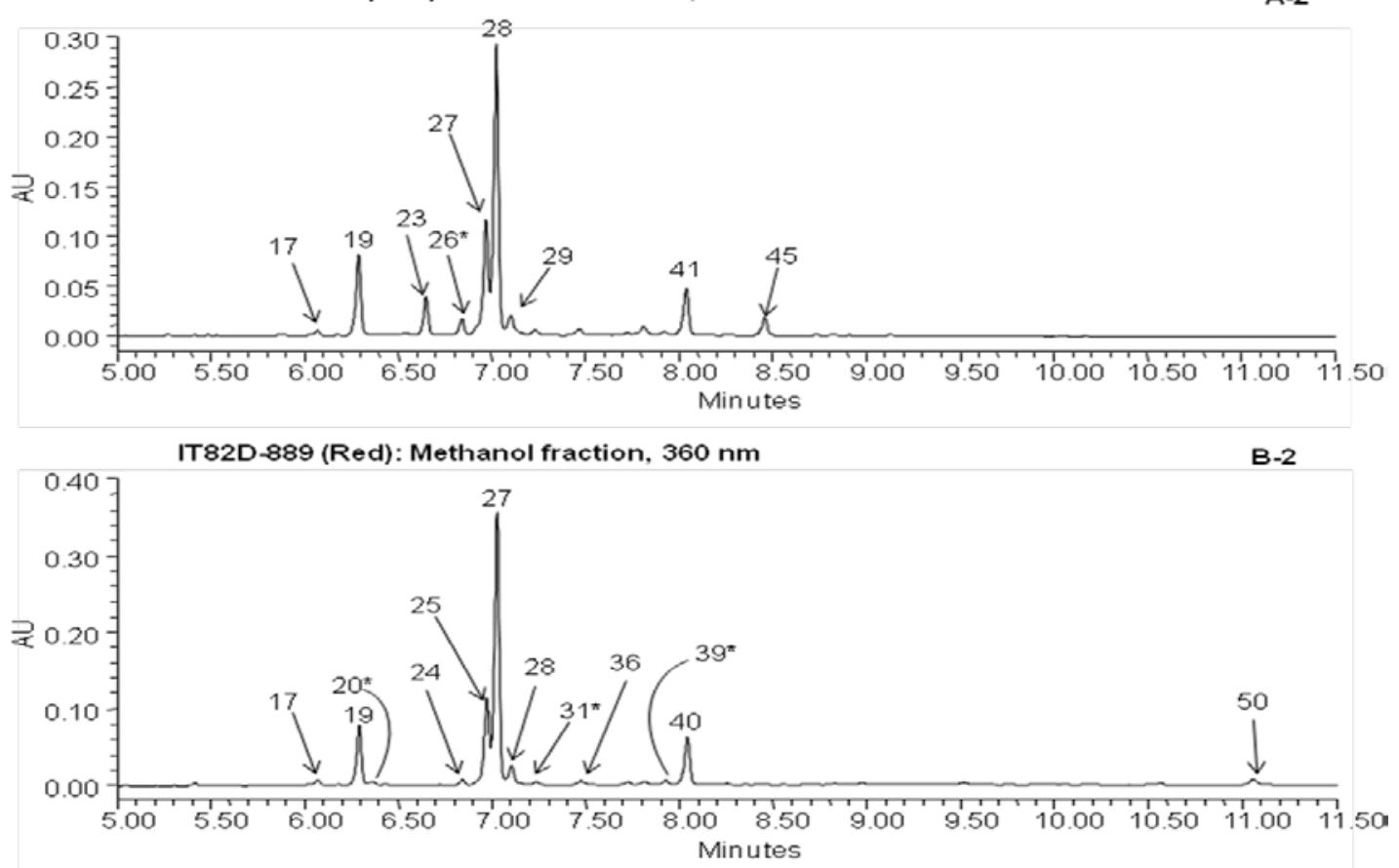

Figure 3. Reverse-phase UPLC chromatogram of phenolic extracts from methanol fractions of red cowpea varieties; IT97K-1042-3 at $280 \mathrm{~nm}$ (A-1) and $360 \mathrm{~nm}$ (A-2); and IT82D-889 at 280 nm (B-1) and $360 \mathrm{~nm}$ (B-2). Peaks marked (*) are unidentified. Peak numbers are referenced to Tables 6 - 8. 
Peak $4\left(\mathrm{t}_{\mathrm{R}}=3.36 \mathrm{~min}, \lambda_{\max }=278 \mathrm{~nm}\right)$ had a $[\mathrm{M}-\mathrm{H}]^{-}$at $\mathrm{m} / \mathrm{z}$ 901, and the MS/MS spectrum had fragments at $\mathrm{m} / \mathrm{z} 739$ (M - $162 \mathrm{amu}$, loss of one hexose unit) and $\mathrm{m} / \mathrm{z} 577$ ( $\mathrm{M}-324 \mathrm{amu}$, loss of two hexose units), an indication of 2 glucose moieties attached at 2 different positions on a procyanidin dimer molecule (Table 6). Two common positions for the conjugation with sugars are C-3 and C-7 (137). Thus, on this basis, peak 4 is identified as a B-type procyanidin dimer-3-O-diglucoside-7-O-glucoside, and was only detected in the Ife Brown (golden brown) cowpea variety (Figure 5B-1). This is the first report of glycosylated derivatives of proanthocyanidin compounds in cowpeas.

Peak $8\left(\mathrm{t}_{\mathrm{R}}=4.49 \mathrm{~min}, \lambda_{\max }=278 \mathrm{~nm}\right)$ was identified as procyanidin dimer with a B-type interflavan linkage (Figure 6), based on similar fragmentation pattern reported in literature (124), and was found in all the cowpea varieties except in the red IT82D889, IT84S-2246 (golden brown), TX2028-1-3-1 (green) and Early Acre (white) varieties. It had a $[\mathrm{M}-\mathrm{H}]^{-}$at $m / z$ 577, with main MS/MS fragments at $m / z$ 425, 407 and 289 (Table 6). The procyanidins B1-B4, usually characterized by the $\mathrm{C} 4 \rightarrow \mathrm{C} 8$ linkage, are the most common dimers, occasionally accompanied by corresponding $\rightarrow \mathbf{C A}$ linked isomers (B5-B8) (Figure 6) (138). The ion at m/z 425 resulted from Retro-DielsAlder (RDA) fission of the heterocyclic ring (Figure 7), a characteristic pattern for dimeric procyanidins $(139,140)$. The product of the subsequent water elimination $(\mathrm{m} / \mathrm{z}$ 407) was also detected in significant amounts. The ion at $\mathrm{m} / \mathrm{z} 289$ was produced from interflavanoid bond cleavage of dimeric procyanidins through the quinone-methine (QM) mechanism, particularly when the base unit is a flavan-3-ol (139); whereas the ion at $m / z 125$ is the heterocyclic ring fission (HRF) product (Figure 7). 
A

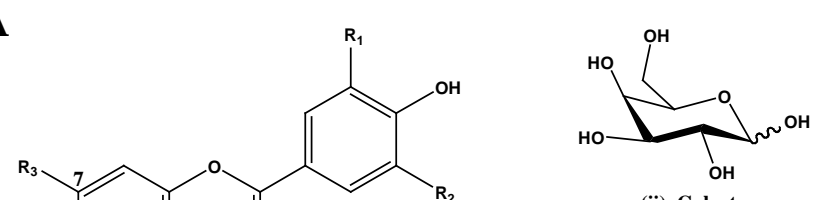

(ii) Galactose

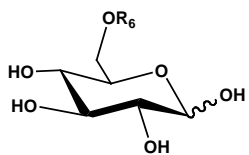

(iii) Glucose

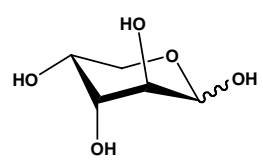

(iv) Arabinose

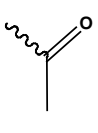

(v) Acetoyl

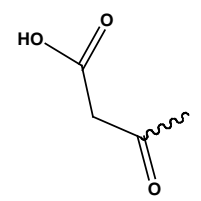

(vi) Malonoyl<smiles>O=C(O)/C=C/c1ccc(O)c(O)c1</smiles>

(vii) Caffeoyl<smiles>COc1cc(/C=C/C(C)=O)ccc1O</smiles>

(viii) Feruloyl<smiles>COc1cc(/C=C/C(=O)O)cc(OC)c1O</smiles>

(ix) Sinapoyl<smiles>O=C1c2c(O)cc(O)cc2OC(c2ccc(O)c(O)c2)C1O</smiles>

(i) Taxifolin<smiles>O=C(O)c1ccc(O)c(O)c1</smiles>

(iii) Protocatechuic acid<smiles>O=C1C[C@H](c2ccc(O)c(O)c2)Oc2cc(O)cc(O)c21</smiles>

(ii) Eriodictyol<smiles>O=Cc1ccc(O)c(O)c1</smiles>

(iv) Protocatechuic aldehyde

Figure 4. Chemical structures of flavonols and their glycosyl and acyl derivatives, (A); and flavanonol (taxifolin), flavanone (eriodictyol), protocatechuic acid and protocatechuic aldehyde identified in cowpea seeds $(\mathbf{B})$. 

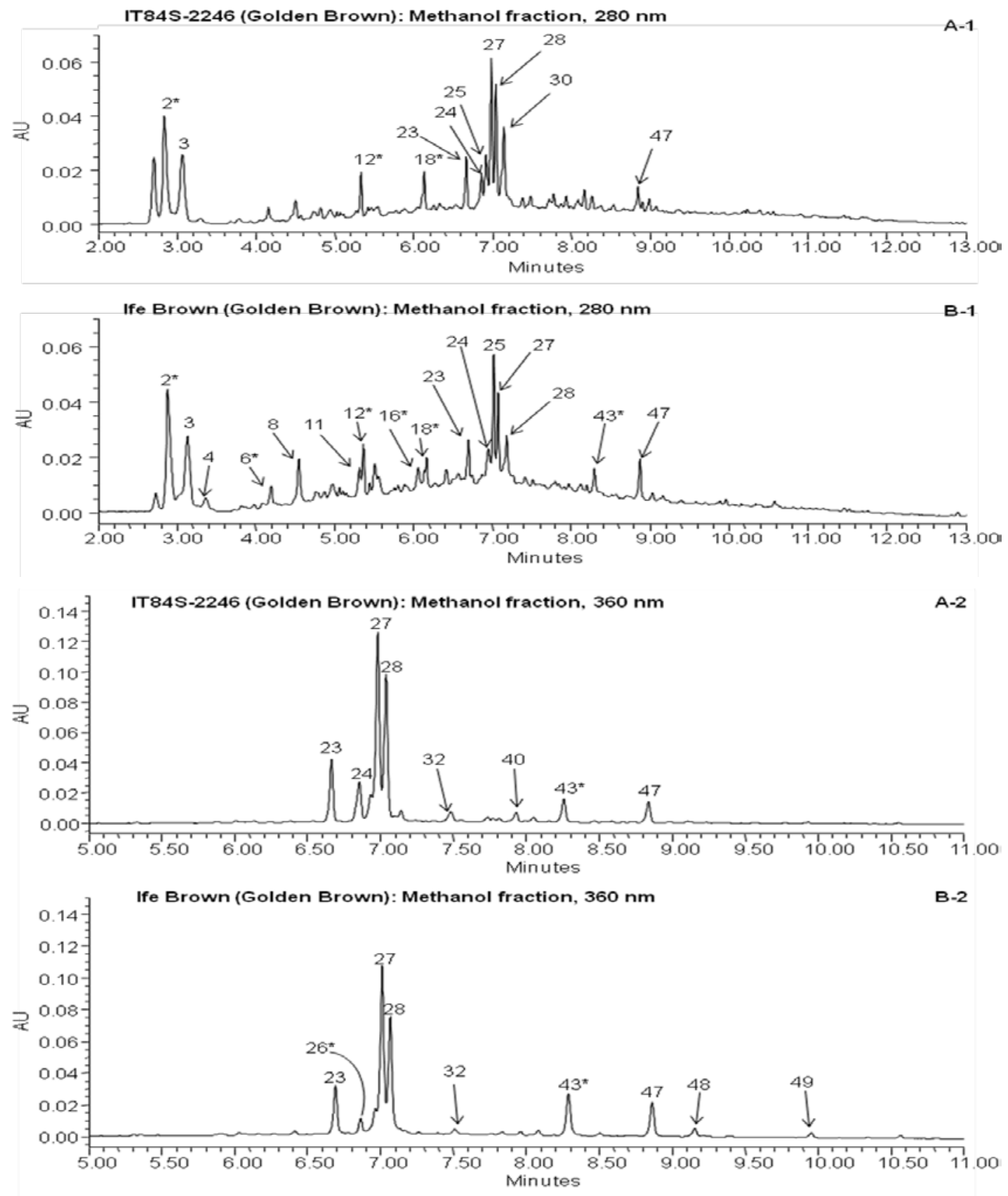

Figure 5. Reverse-phase UPLC chromatogram of phenolic extracts from methanol fractions of golden brown cowpea varieties; IT84S-2246 at $280 \mathrm{~nm}$ (A-1) and $360 \mathrm{~nm}$ (A-2); and Ife Brown at $280 \mathrm{~nm}(\mathbf{B}-\mathbf{- 1})$ and $360 \mathrm{~nm}(\mathbf{B}-2)$. Peaks marked (*) are unidentified. Peak numbers are referenced to Tables 7 and 8. 

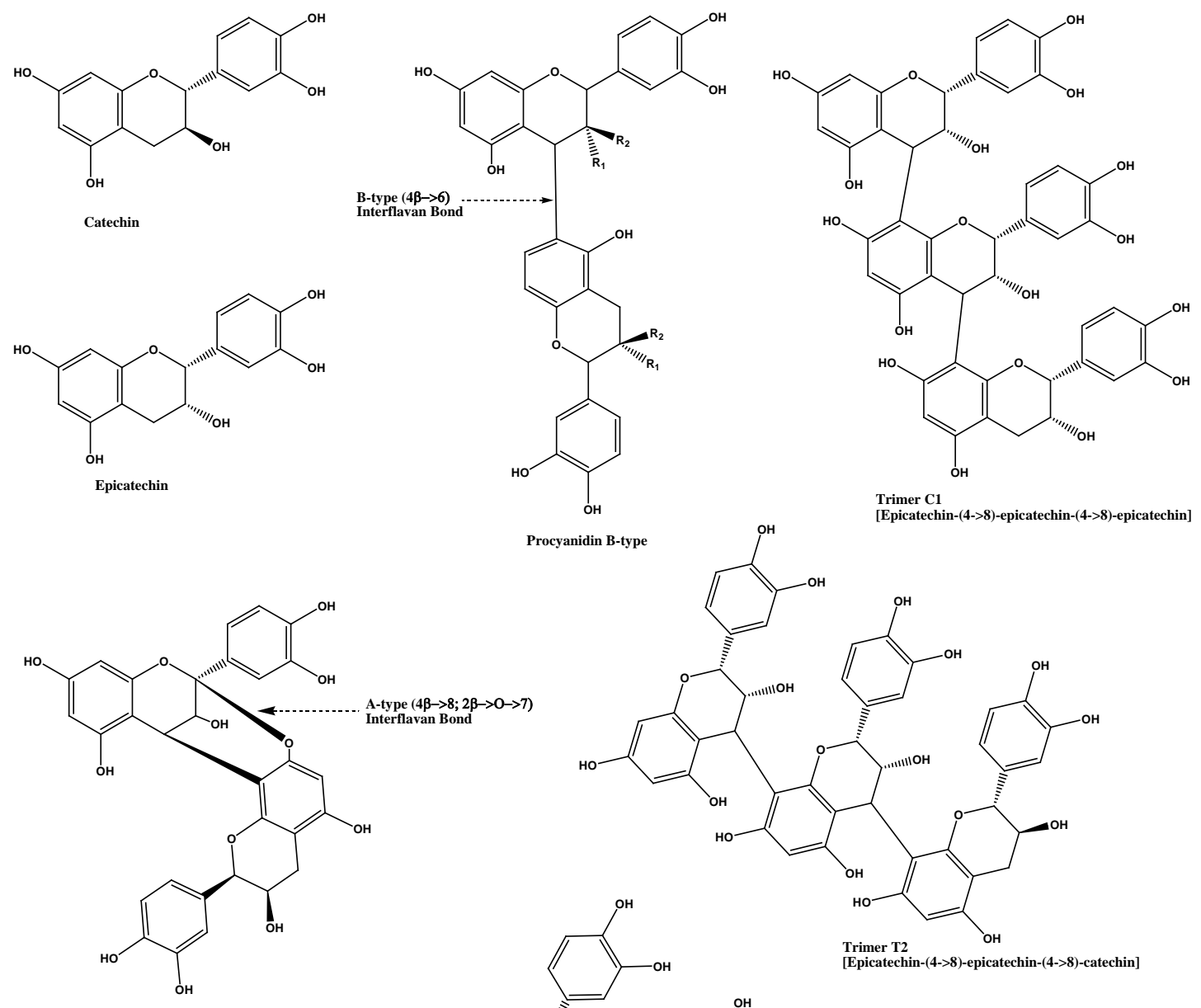

Trimer $\mathrm{C}$

[Epicatechin-(4->8)-epicatechin-(4->8)-epicatechin]
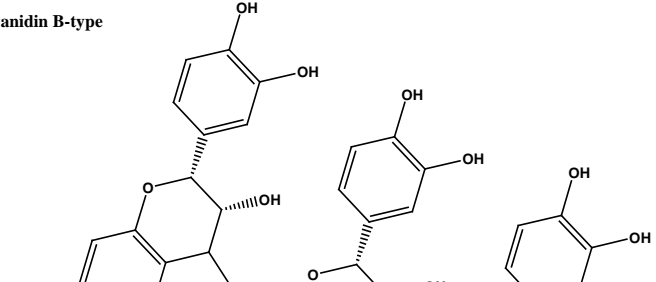

Procyanidin A-type
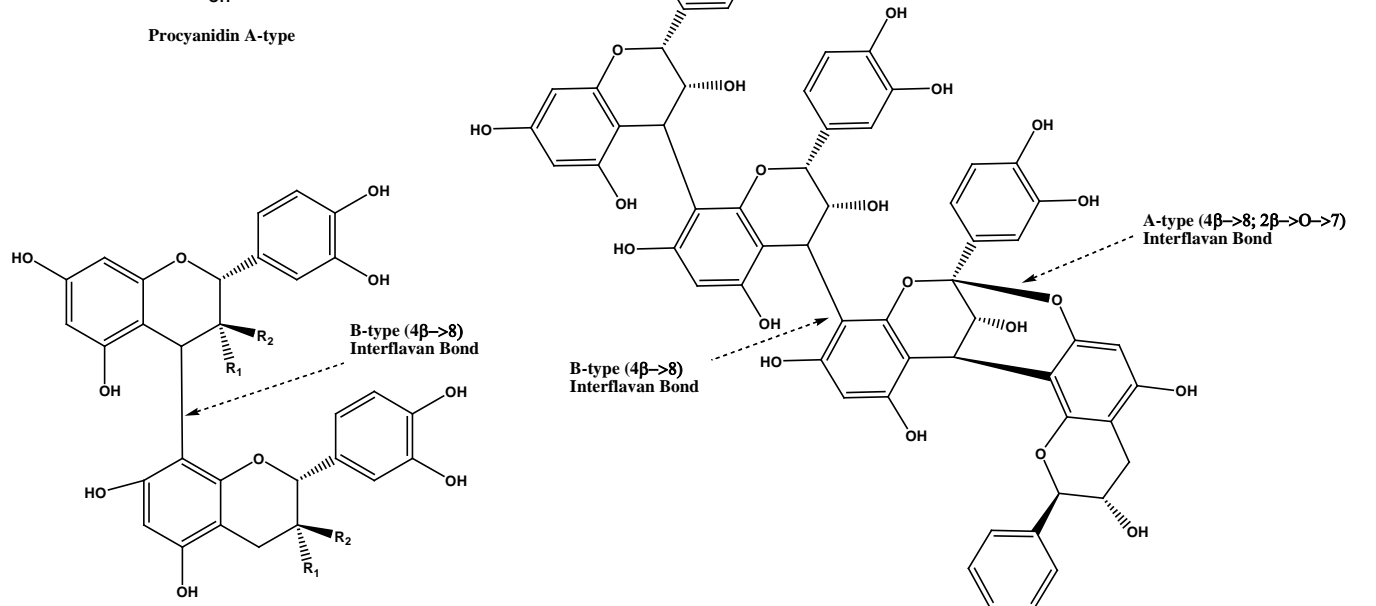

Procyanidin B-type

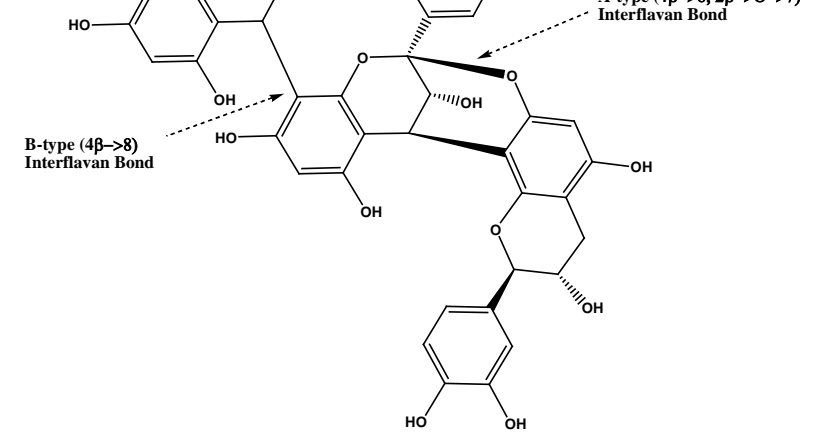

Procyanidin Tetramer

Figure 6. Chemical structures of the most common flavanol monomers, procyanidin dimers and trimers identified in cowpea. $\mathbf{R}_{\mathbf{1}}=\mathbf{H} ; \mathbf{R}_{\mathbf{2}}=\mathbf{O H}$. 
Peak $10\left(\mathrm{t}_{\mathrm{R}}=4.82 \mathrm{~min}, \lambda_{\max }=279 \mathrm{~nm}\right)$, which had a $[\mathrm{M}-\mathrm{H}]^{-}$at $\mathrm{m} / \mathrm{z} 289$ was elucidated as a procyanidin monomer (either a catechin or epicatechin unit) (Table 7) based on standards. It was only found in the red IT97K-1042-3, black (IT95K-1105-5 and IT98K-1092-1) and light brown (IAR-48 and 09FCV-CC-27M) cowpea varieties. These samples also contained the B-type procyanidin dimer (peak 8).

Both peak 11 and 21 had similar $[\mathrm{M}-\mathrm{H}]^{-}$at $\mathrm{m} / \mathrm{z} 865$ and absorption maxima at $\lambda_{\max }=279 \mathrm{~nm}$, and were both established as trimers from literature data (124). However, based on differences in elution times of these trimeric procyanidins, peak $11\left(\mathrm{t}_{\mathrm{R}}=5.29\right.$ min) was established as procyanidin trimer $\mathrm{T} 2$ while peak $21\left(t_{R}=6.39 \mathrm{~min}\right)$ was procyanidin trimer C1 (Figure 6). The interflavan fragmentation resulted in signals at $\mathrm{m} / \mathrm{z} 577$ corresponding to $\left[\mathrm{M}_{\text {middle-base }}-\mathrm{H}\right]^{-}$and $\mathrm{m} / \mathrm{z} 289$ (catechin or epicatechin units) (Table 7) (124), one of which must be B-type unit, regardless of its position in the sequence (141). Procyanidin trimer T2 was only found in the IT97K-1042-3 (red) (Figure 3A-1), Ife Brown (golden brown) (Figure 5A-2), IAR-48 (light brown) and 09FCV-CC27M (light brown) varieties (Figure 8); while procyanidin trimer C1 was only found in the 09FCV-CC27M variety (Figure 8A-1).

Peak $13\left(\mathrm{t}_{\mathrm{R}}=5.46 \mathrm{~min}, \lambda_{\max }=278 \mathrm{~nm}\right)$, which had a $[\mathrm{M}-\mathrm{H}]^{-}$at $\mathrm{m} / \mathrm{z} 1154$ was elucidated as a procyanidin tetramer (four catechin or epicatechin units). This is supported by the MS/MS major products at $\mathrm{m} / \mathrm{z} 575$ (two catechin or epicatechin units) and at $\mathrm{m} / \mathrm{z} 287$ (a catechin or epicatechin unit), as well as absorption maxima identical to that of catechin (Table 7). The ion at $\mathrm{m} / \mathrm{z} 575$ suggests the presence of an A-type interflavanoid linkage $(4 \beta-8,2 \beta-O-7)(142)$; while the fragment at $\mathrm{m} / \mathrm{z} 287$ corresponds 
to interflavanoid bond cleavage of dimeric procyanidins via the quinone-methine (QM) mechanism, particularly when the methylene-quinone is the top unit (Figure 7) (124). IAR-48, a light brown phenotype, was the only cowpea variety in which the tetramer was detected (Figure 8B-1). This is the first report of A-type procyanidin tetramers in cowpeas.

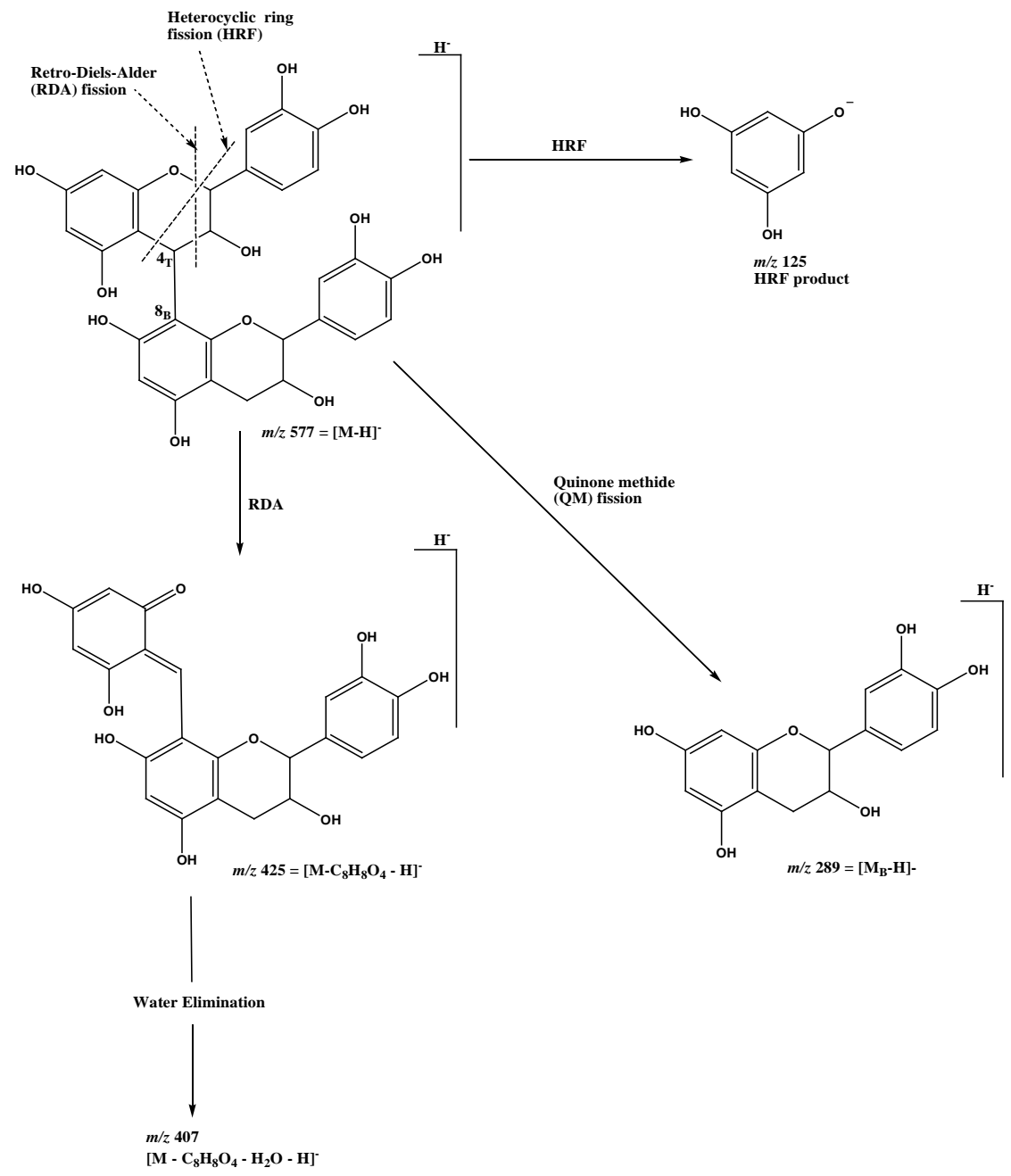

Figure 7. General schematic diagram showing fragmentation of dimeric procyanidins in negative mode following fragmentation mechanism postulated by Friedrich et al. (140). 

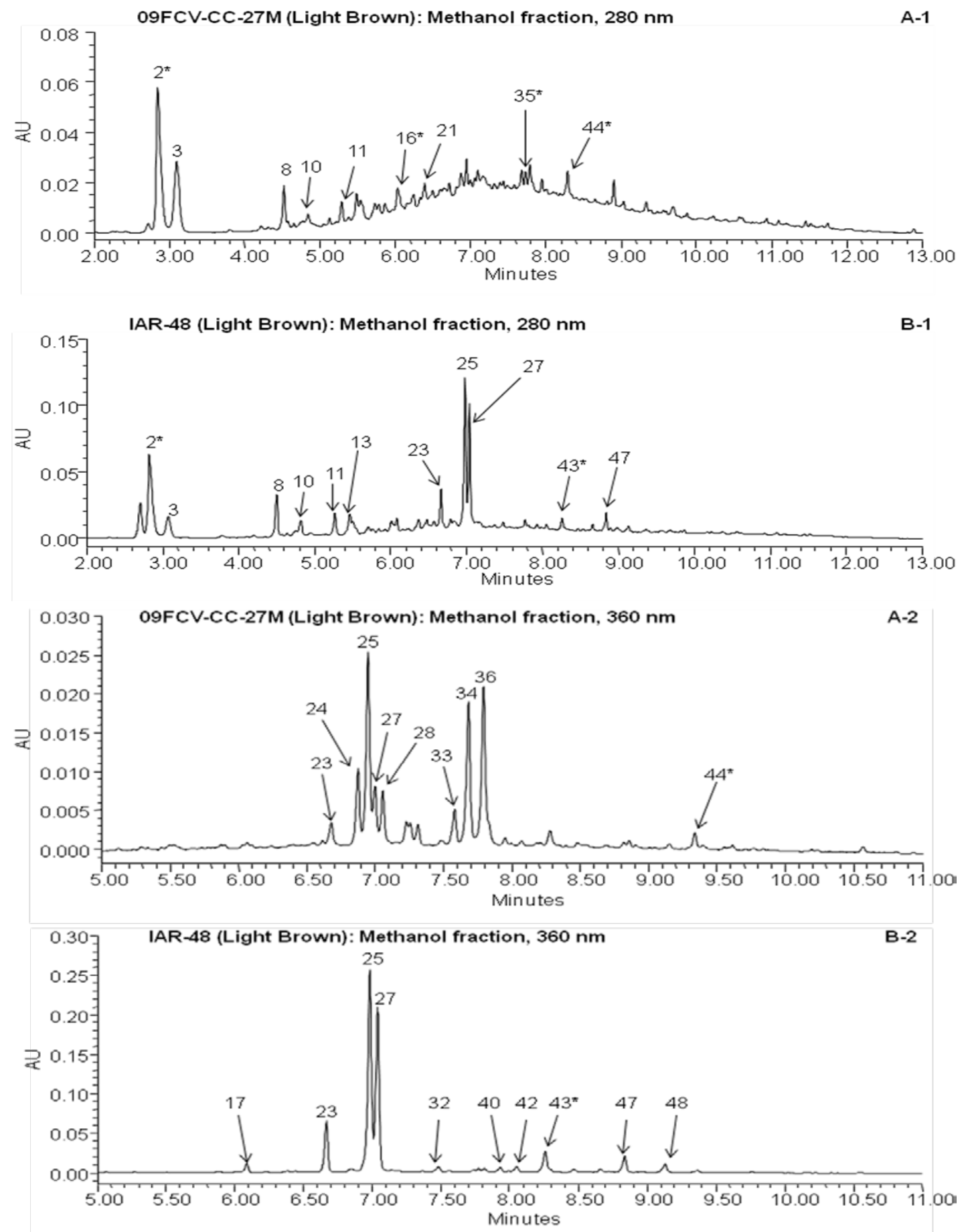

Figure 8. Reverse-phase UPLC chromatogram of phenolic extracts from methanol fractions of light brown cowpea varieties; 09FCV-CC27M at $280 \mathrm{~nm}$ (A-1) and $360 \mathrm{~nm}$ (A-2); and IAR-48 at $280 \mathrm{~nm}$ (B-1) and $360 \mathrm{~nm}$ (B-2). Peaks marked (*) are unidentified. Peak numbers are referenced to Tables 7 and $\mathbf{8}$. 
IT95K-1105-5 (Black): Methanol fraction, $360 \mathrm{~nm}$

A

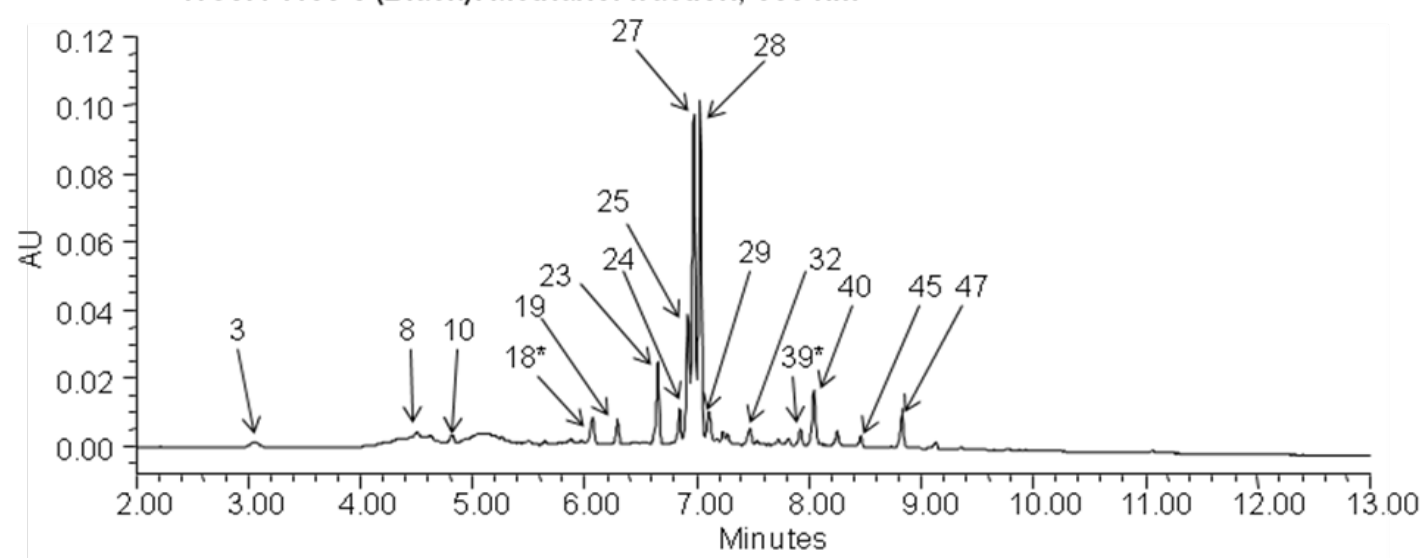

IT98K-1092-1 (Black): Methanol fraction, $360 \mathrm{~nm}$

B

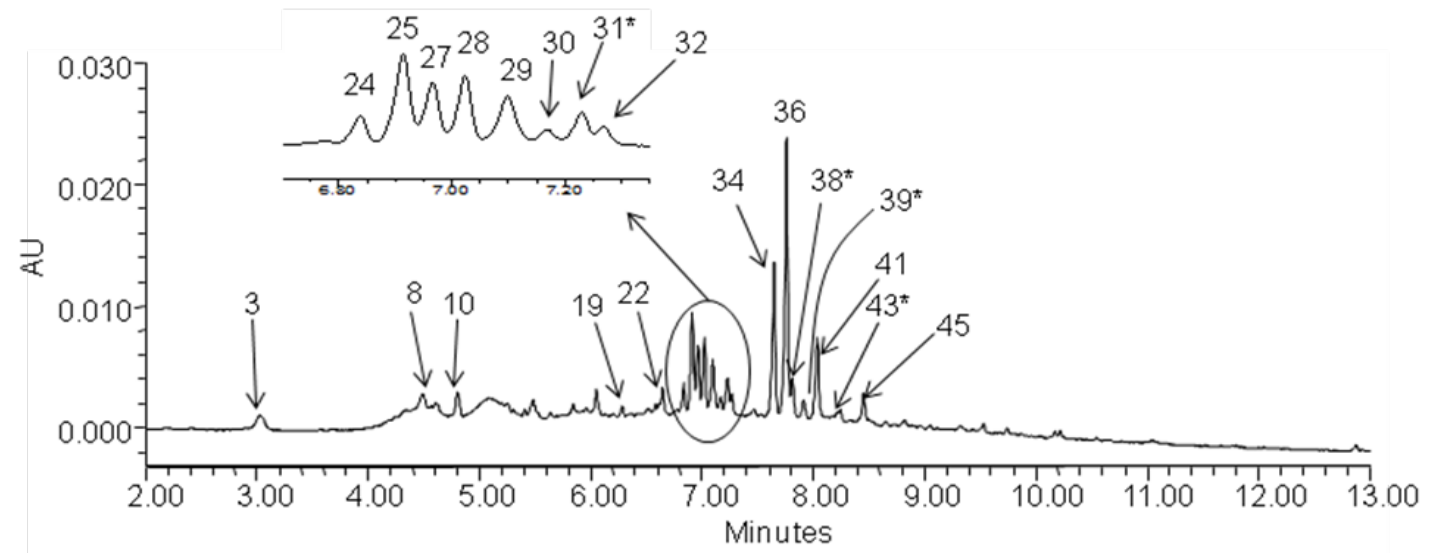

Figure 9. Reverse-phase UPLC chromatogram of phenolic extracts from methanol fractions of black cowpea varieties at $360 \mathrm{~nm}$; IT95K-1105-5 (A); and IT98K-1092-1 (B). Peaks marked (*) are unidentified. Peak numbers are referenced to Tables $\mathbf{7}$ and $\mathbf{8}$.

\subsubsection{Flavonols}

Peak $14\left(\mathrm{t}_{\mathrm{R}}=5.80 \mathrm{~min}, \lambda_{\max }=354 \mathrm{~nm}\right)$ was only present in the white Early Acre variety (Figure 10) variety and had a $[\mathrm{M}-\mathrm{H}]^{-}$at $\mathrm{m} / \mathrm{z}$ 787. The MS/MS products included $\mathrm{m} / \mathrm{z} 301(\mathrm{M}-486)$, suggesting loss of 3 glycosyl units $(3 \times 162 \mathrm{amu})$ that were attached at the same position (Table 8). The absorption $\lambda_{\max }$ and other MS/MS products 
at $\mathrm{m} / \mathrm{z} 179$ and 151 matches fragmentation pattern for quercetin (143). Because MS/MS cleaves glycosyl units at the glucosidic bonds between the flavylium ring and the sugars directly attached to it (144), we propose the identity of this compound as quercetin-3-Otriglucoside, since the most common glycosylation position is usually C-3 (126).
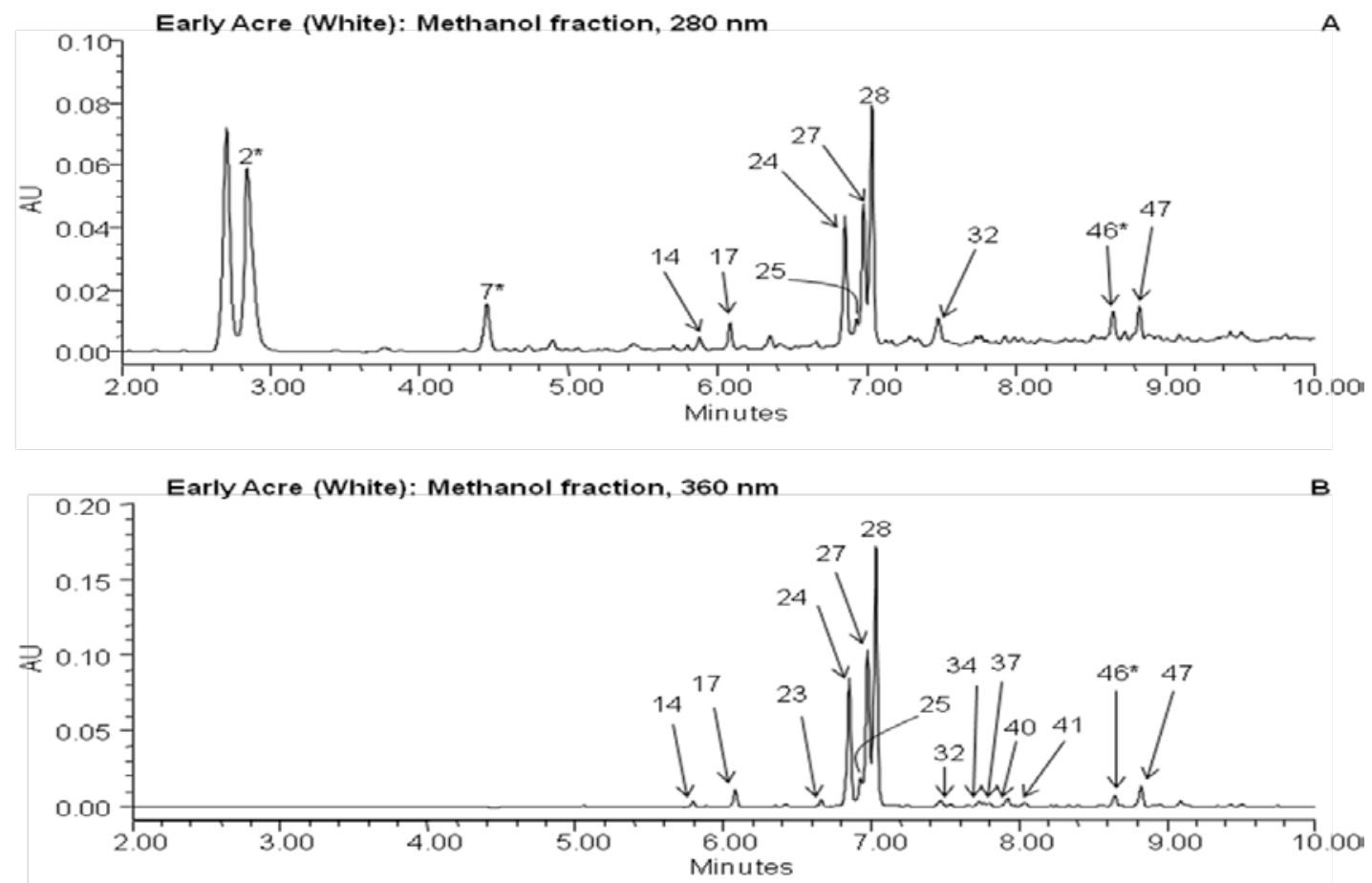

Figure 10. Reverse-phase UPLC chromatogram of phenolic extracts from methanol fraction of white cowpea variety, Early Acre at $280 \mathrm{~nm}$ (A) and $360 \mathrm{~nm}$ (B). Peaks marked with (*) are unidentified. Peak numbers are referenced to Tables 7 and 8. 
Table 8. Identification of dihydrochalcones (at $320 \mathrm{~nm}$ ) and flavonols (at $360 \mathrm{~nm}$ ) in methanolic fraction of 10 cowpea varieties based on UPLC retention time $\left(t_{r}\right)$, UV-vis spectroscopic characteristics $\left(\lambda_{\max }\right)$, and MS-MS/MS spectroscopic pattern. Ionization was performed in the negative mode. Peaks marked $(*)$ were unidentified.

\begin{tabular}{|c|c|c|c|c|c|}
\hline $\begin{array}{l}\text { Peak } \\
\text { no. }\end{array}$ & $\begin{array}{l}\mathbf{t}_{\mathrm{R}} \\
(\mathrm{min})\end{array}$ & $\begin{array}{l}\lambda_{\max } \\
(\mathrm{nm})\end{array}$ & Proposed identifications & $\begin{array}{l}\mathrm{M}-\mathrm{H}]^{-} \\
(\mathrm{m} / \mathrm{z})\end{array}$ & MS/MS fragments $(m / z)$ \\
\hline 14 & 5.80 & 354 & Quercetin-3-O-triglucoside & 787 & $301,179,151$ \\
\hline 17 & 6.08 & 345 & $\begin{array}{l}\text { Quercetin-3-O-glucoside-4'-O- } \\
\text { diglucoside }\end{array}$ & 787 & $625,301,300$ \\
\hline 19 & 6.29 & 357 & Myricetin-3-O-diglucoside & 641 & $317,316,271$ \\
\hline 22 & 6.60 & 351 & Quercetin-3-O-arabinosyl-diglucoside & 757 & 301 \\
\hline 23 & 6.65 & 346 & $\begin{array}{l}\text { Quercetin-3-O-arabinoside-7-O- } \\
\text { diglucoside }\end{array}$ & 757 & 625,301 \\
\hline 24 & 6.80 & 353 & Quercetin-3-O-digalactoside & 625 & $301,271,179,151$ \\
\hline 25 & 6.84 & 352 & Quercetin-3,7-diglucoside & 625 & 463, 301, 271 \\
\hline $26^{*}$ & 6.86 & 376 & Unknown & 899 & 737, 585, 556, 539, 407 \\
\hline 27 & 6.90 & 354 & Quercetin-3-O-galactosylglucoside & 625 & 300,151 \\
\hline $\mathbf{2 8}^{\dagger}$ & 6.97 & 355 & Quercetin-3-O-diglucoside & 625 & $301,179,151$ \\
\hline $29^{\dagger}$ & 7.10 & 357 & Myricetin-3-O-glucoside & 479 & $317,287,271,179,151$ \\
\hline 30 & 7.14 & 325 & Phlorizin (Phloretin-2'-glucoside) & 435 & $273,137,135,125$ \\
\hline 32 & 7.48 & 352 & Kaempferol-3-O-diglucoside & 609 & 285, 255, 169 \\
\hline 33 & 7.58 & 353 & Quercetin-3-O-arabinosylglucoside & 595 & 301 \\
\hline 34 & 7.65 & 355 & Quercetin-3-O-galactosylrhamnoside & 609 & 301 \\
\hline 36 & 7.76 & 354 & Quercetin-3-O-glucosylrhamnoside & 609 & 301 \\
\hline $37^{*}$ & 7.81 & 359 & Unknown & 467 & 323, 305, 203, 189, 161 \\
\hline $38^{*}$ & 7.85 & 325 & Unknown & 467 & 323, 305, 203, 189, 161 \\
\hline $39 *$ & 7.90 & 350 & Unknown & 597 & $\begin{array}{l}\text { 455, 387, 357, 273, 229, 221, } \\
209,167\end{array}$ \\
\hline $40^{\dagger}$ & 7.93 & 353 & Quercetin-3-O-galactoside & 463 & $301,271,179,151$ \\
\hline 41 & 8.04 & 354 & Quercetin-7-O-glucoside & 463 & $301,271,179,151$ \\
\hline 42 & 8.10 & 357 & Quercetin-3-O-glucoside & 463 & $301,271,179,151$ \\
\hline $43^{*}$ & 8.29 & 376 & Unknown & 737 & $\begin{array}{l}407,394,287,271,229,189, \\
165,161,125\end{array}$ \\
\hline 45 & 8.48 & 353 & Quercetin-3-(6"-malonoyl)-glucoside & 549 & $301,271,179,151$ \\
\hline $46^{*}$ & 8.65 & 364 & Unknown & 867 & 517, 349, 331, 317 \\
\hline 47 & 8.82 & 334 & Quercetin-3-(6"-feruloyl)-diglucoside & 801 & 625,301 \\
\hline 48 & 9.16 & 363 & $\begin{array}{l}\text { Quercetin-3-(6"-diacetoyl)- } \\
\text { diglucoside }\end{array}$ & 709 & 625,301 \\
\hline 49 & 9.96 & 332 & Quercetin-3-(6"-sinapoyl)-rutinoside & 815 & 301 \\
\hline $50^{\dagger}$ & 11.05 & 370 & Quercetin & 301 & $301,179,151$ \\
\hline
\end{tabular}

*Unidentified peak; ${ }^{\dagger}$ Previously identified in cowpea $(51,54)$. 
Peak $17\left(\lambda_{\max }=345 \mathrm{~nm}\right)$ had $[\mathrm{M}-\mathrm{H}]^{-}$at $m / z 787$, and was only present in five varieties including IT97K-1042-3 (red) and IT82D-889 (red) (Figure 3), IAR-48 (light brown) (Figure 8B-2), Early Acre (white) (Figure 10) and TX2028-1-3-1 (green) (Figure 11). Since its pseudo-molecular ion is similar to that of peak 14, these two compounds are likely related. However, its fragmentation pattern was different from that of peak 14, in that the first MS/MS ion at m/z 625 (M - 162 amu) corresponded to loss of one glucosyl moiety possibly conjugated at C-3 (the most common position for glycosylation) $(54,126)$, while the subsequent ion at $m / z 301(\mathrm{M}-162-324 \mathrm{amu})$ corresponded to a further loss of two glucosyl moieties possibly from C-4' position based on UV-vis $(145,146)$. The fact that the glucosyl units were attached at different positions is evident from sequential loss of the glucosyl fragments, as well as the large hypsochromic shift in $\lambda_{\max }(9 \mathrm{~nm})$ relative to the quercetin-3-O-triglucoside (peak 14) (Table 8). Based on the MS/MS data and $\lambda_{\max }$, we propose peak 17 to correspond to quercetin-3-O-glucoside-4'-O-diglucoside, a new compound first identified in this study.

Peak $19\left(\mathrm{t}_{\mathrm{R}}=6.29 \mathrm{~min}, \lambda_{\max }=357 \mathrm{~nm}\right)$ had $[\mathrm{M}-\mathrm{H}]^{-}$at $\mathrm{m} / \mathrm{z} 641$, which gave a fragment at $m / z 317(\mathrm{M}-324 \mathrm{amu})$ corresponding to loss of 2 glycosyl units (Table 8). Based on its UV-vis profile, elution time and MS data, peak 19 was identified as myricetin-3-O-diglucoside. 3-O-Diglycosylated flavonols have been reported in cowpea (54, 147). In this study, this peak was found in the black (i.e. IT98K-1092-1 and IT95K1105-5) and red (i.e. IT1042-3 and IT82D-889) cowpea phenotypes only.

Peaks 22 and 23 had the same MS profile $\left([\mathrm{M}-\mathrm{H}]^{-}\right.$at $\mathrm{m} / \mathrm{z}$ 757) but slightly different retention times $\left(t_{R}=6.60\right.$ and $6.65 \mathrm{~min}$, respectively). The MS/MS data 
indicated that both peaks contained quercetin $(\mathrm{m} / \mathrm{z}$ 301) (Table 8). However, peaks 22 MS/MS data showed only one fragment at $\mathrm{m} / \mathrm{z} 301$ (M - $456 \mathrm{amu})$, corresponding to loss of 2 hexoses $(2 \times 162 \mathrm{amu})$ and a pentose (132 amu) linked together and bonded to the aglycone at one position. The general term pentose is used due to the difficulty in detection of stereochemical structures of glycosyl residues based on MS data alone. It could be either arabinose or xylose, with the former usually preferred (148). Thus, based on retention time and MS data, peak 22 was identified as quercetin-3-O-arabinosyldiglucoside (Table 8). This compound was only present in the black IT98K-1092-1 (Figure 9B) and green TX2028-1-3-1 varieties (Figure 11). On the other hand, peak 23 MS/MS showed a fragment at $\mathrm{m} / \mathrm{z} 625(\mathrm{M}-132 \mathrm{amu})$, as well as another fragment at m/z 301 (M - 132 - 324 amu) suggesting a further loss of two glycosyl units (Table 8). Thus, based on sequential loss of a pentose group followed by a diglucosyl moiety, peak 23 was designated as quercetin-3-O-arabinoside-7-O-diglucoside. It was present in all the cowpea varieties except in the black IT98K-1092-1, green TX2028-1-3-1 and red IT82D-889 varieties. This is the first time that pentose-substituted flavonols has been found in cowpea.

It was also observed that peaks 24, 25, 27 and 28 had similar MS profiles ([M $\mathrm{H}]^{-}$at $m / z$ 625). The appearance of an MS/MS fragment corresponding to the loss of 324 amu is observed for both peaks (Table 8). This corresponds to a loss of a dihexose group to give a fragment at $\mathrm{m} / \mathrm{z} 301$ which corresponds to quercetin. Based on MS data, peak $24\left(\mathrm{t}_{\mathrm{R}}=6.80 \mathrm{~min}, \lambda_{\max }=353 \mathrm{~nm}\right)$ and $28\left(\mathrm{t}_{\mathrm{R}}=6.97 \mathrm{~min}, \lambda_{\max }=355 \mathrm{~nm}\right)$ were both assigned quercetin-3-O-dihexoside. Based on retention times, it is logical to assume that 
one of the sugar moieties for peak 24 is a galactose unit (which causes slightly shorter retention times and absorption at a lower wavelength), and that both sugars for peak 28 are glucose units (149). Among all the cowpea samples studied, only the light brown IAR-48 and red IT97K-1042-3 varieties did not contain quercetin-3-O-digalactoside; while only IAR-48 variety did not contain quercetin-3-O-diglucoside. In fact, quercetin 3-O-glucoside and quercetin 3-O-diglucoside are the two common flavonol glycosides identified in cowpeas $(51,54)$. This compound was found in all the varieties studied except in the red IT97K-1042-3 variety. On the other hand, peak $27\left(\mathrm{t}_{\mathrm{R}}=6.90 \mathrm{~min}, \lambda_{\max }\right.$ $=354 \mathrm{~nm}$ ) was designated as quercetin-3-O-galactosylglucoside based on retention time relative to peaks 24 and 28, and was found in all the cowpea phenotypes studied. In the case of peak $25\left(\mathrm{t}_{\mathrm{R}}=6.84 \mathrm{~min}, \lambda_{\max }=352 \mathrm{~nm}\right)$, the cleavage of the glycosyl units appear to follow a different pattern. Two sequential losses of $162 \mathrm{amu}$, indicated the hexoses are linked at different positions (Table 8), we assigned peak 25 as quercetin-3,7diglucoside.

Peak $29\left(\mathrm{t}_{\mathrm{R}}=7.10 \mathrm{~min}, \lambda_{\max }=357 \mathrm{~nm}\right)$ produced a $[\mathrm{M}-\mathrm{H}]^{-}$at $\mathrm{m} / \mathrm{z} 479$ and an MS/MS spectrum with the predominant ion at $\mathrm{m} / \mathrm{z} 317$ (M - $162 \mathrm{amu}$, loss of a glucosyl unit) (Table 8). Based on this MS spectrum and literature data, we established peak 29 as myricetin-3-O-glucoside (54). This compound was identified in only four varieties, that is, red (IT97K-1042-3) (Figure 3A-1), black (IT95K-1105-1 and IT98K-1092-1) (Figure 9), and green (IT2028-1-3-1) (Figure 11). This compound has previously been reported in Vigna species $(51,54)$. 

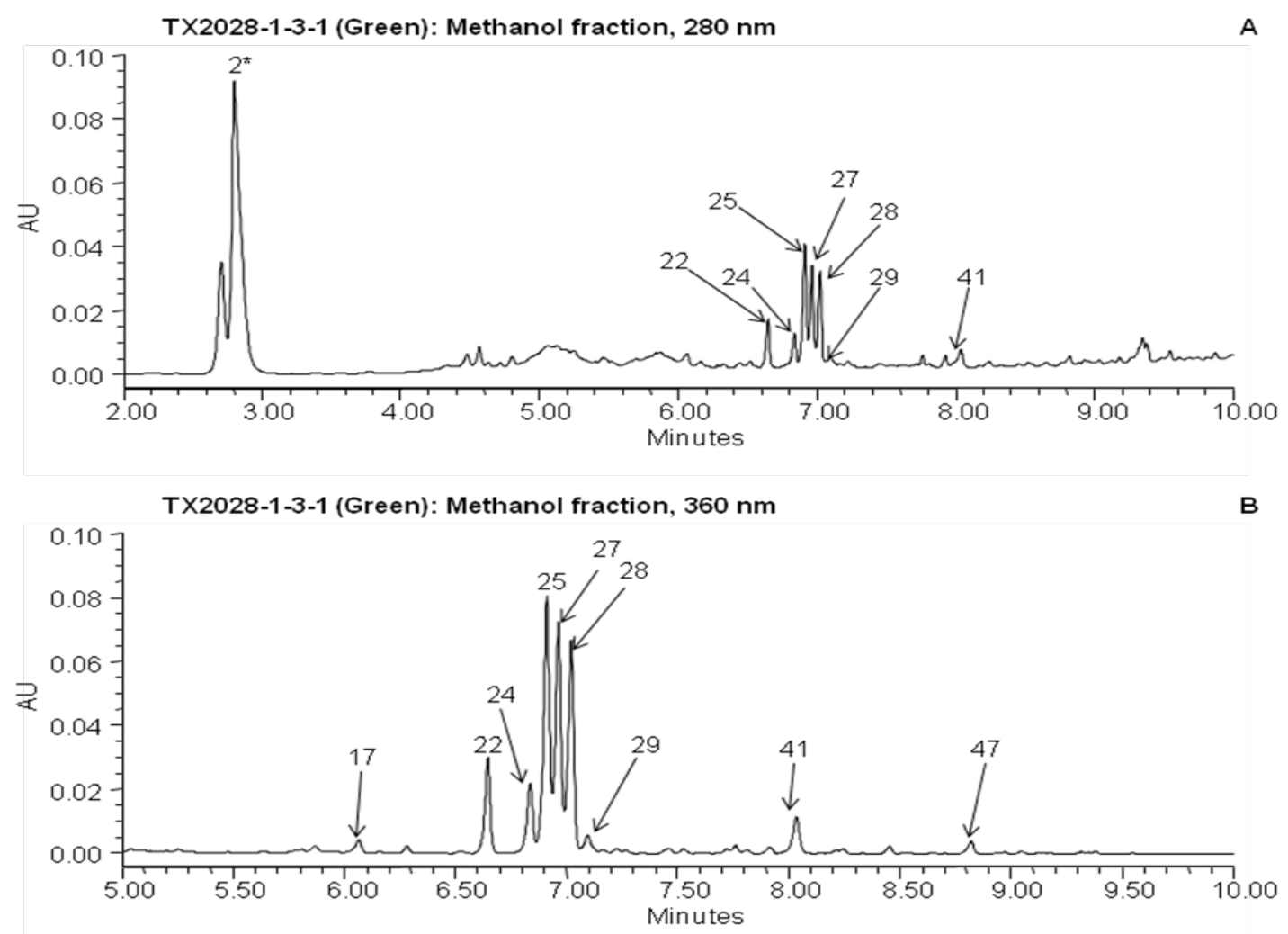

Figure 11. Reverse-phase UPLC chromatogram of phenolic extracts from methanol fraction of green cowpea variety, TX2028-1-3-1 at $280 \mathrm{~nm}$ (A) and $360 \mathrm{~nm}$ (B). Peaks marked (*) are unidentified. Peak numbers are referenced to Tables 7 and $\mathbf{8}$.

Peaks $32\left(\mathrm{t}_{\mathrm{R}}=7.48 \mathrm{~min}, \lambda_{\max }=352 \mathrm{~nm}\right), 34\left(\mathrm{t}_{\mathrm{R}}=7.65 \mathrm{~min}, \lambda_{\max }=355 \mathrm{~nm}\right)$ and 36 $\left(\mathrm{t}_{\mathrm{R}}=7.76 \mathrm{~min}, \lambda_{\max }=354 \mathrm{~nm}\right)$ had same MS profiles $[\mathrm{M}-\mathrm{H}]^{-}$at $\mathrm{m} / \mathrm{z} 609$ (Table 8). Their UV-vis spectra were also consistent with derivatives of flavonols. However, upon MS/MS fragmentation, peak 32 had signal at m/z 285 (loss of $324 \mathrm{amu}$, corresponding to the loss 2 glycosyl units attached at the same position), which corresponds to kaempferol molecule. Based on this evidence, this peak can be identified as kaempferol-3-Odiglucoside. This was found in all the varieties studied except in the red (IT82D-889 and 
IT97K-1042-3), green (TX2028-1-3-1) and light brown (09FCV-CC27M) varieties. Kaempferol 3-O-glucoside has been reported in some pulses (150). As far as we know, this is the first report of diglycosylated kaempferol in pulses.

On the other hand, peak 34 had a major loss of $308 \mathrm{amu}$, corresponding to loss of a hexose (162 amu) + rhamnose (146 amu) attached at the same position, indicated by product ion at $\mathrm{m} / \mathrm{z} 301$ corresponding to that of quercetin molecule. Peak 36 had similar fragmentation pattern as peak 34, and thus are assumed to be structurally related. The nature of the sugar moiety was proposed based on their relative retention times. Since peak 34 eluted earlier than peak 36, peak 34 was elucidated as quercetin-3-Ogalactosylrhamnoside, while peak 36 was quercetin-3-O-glucosylrhamnoside. In this study, we found peaks corresponding to quercetin-3-O-galactosylrhamnoside only in IT97K-1042-3 (red) (Figure 3B-2), 09FCV-CC27M (light brown) (Figure 8A-2) and Early Acre (white) (Figure 10) varieties; while peaks corresponding to quercetin-3-Oglucosylrhamnoside were found only in the red (IT82D-889 and IT97K-1042-3) (Figure 3) and light brown (09FCV-CC27M) (Figure 8A-2) varieties.

Peak $33\left(\mathrm{t}_{\mathrm{R}}=7.58 \mathrm{~min}, \lambda_{\max }=353 \mathrm{~nm}\right)$ was only present in the light brown 09FCV-CC27M variety (Figure 8A-2) and had $[\mathrm{M}-\mathrm{H}]^{-}$at $\mathrm{m} / \mathrm{z}$ 595. The major signal in MS/MS was m/z 301 (M - 294), corresponding to loss of pentose (132 amu) + hexose (162 amu) attached at the same position on the aglycone. Since arabinose is the most common pentose (148), peak 33 was designated as quercetin-3-O-arabinosylglucoside (Table 8). This is the first time that this compound has been reported in cowpea. 
Peaks $40\left(t_{\mathrm{R}}=7.93 \mathrm{~min}\right), 41\left(t_{\mathrm{R}}=8.04 \mathrm{~min}\right)$ and $42\left(t_{\mathrm{R}}=8.10 \mathrm{~min}\right)$ showed $[\mathrm{M}-$ $\mathrm{H}]^{-}$at $\mathrm{m} / \mathrm{z}$ 463. The fragment ion at $\mathrm{m} / \mathrm{z} 301$ was derived by losing a hexose unit from the parent ion (i.e. quercetin), joined by an $O$-glycosidic linkage (Table 8). Thus, all these peaks are proposed to be $O$-glycosyl derivatives of quercetin. Since type and position of glycosylation has been shown to affect the elution characteristics of flavonoids, we used retention time to elucidate the identities of these three peaks. The order of elution of the glycosides on C18 column is galactoside before glucoside, followed by arabinoside (123). Therefore, we proposed peak 40 as quercetin-3-Ogalactoside based on its shorter retention time and lower UV absorption maximum $\left(\lambda_{\max }\right.$ $=353 \mathrm{~nm}$ ), compared to peaks 41 and 42. This compound has previously been reported in cowpea (51). In this study, quercetin-3-O-galactoside was found in five varieties only, that is, IT95K-1105-5 (black) (Figure 9A), IT82D-889 (red) (Figure 3), IT84S-2246 (golden brown) (Figure 5A-2), IAR-48 (light brown) (Figure 8) and Early Acre (white) (Figure 10). Conjugation of the sugar at 7-position has been shown to increase polarity of quercetin through the C18 column, thus 7-O-glucosides are known to elute before 3O-glucosides (54). Thus, based on the elution order, peak 41 was designated as quercetin-7-O-glucoside, and peak 42 as quercetin-3-O-glucoside. Both quercetin-7-Oglucoside and quercetin-3-O-glucoside have been reported in a black seed cultivar of cowpea (54). In this study, quercetin-7-O-glucoside was found in five cowpea varieties including red (IT97K-1042-3 and IT82D-889) (Figure 3), black IT98K-1092-1 (Figure 9B), white Early Acre (Figure 10) and green TX2028-1-3-1 (Figure 11); while 
quercetin-3-O-glucoside was only present in the light brown IAR-48 variety (Figure 8B2).

Peak $45\left(t_{\mathrm{R}}=8.48 \mathrm{~min}, \lambda_{\max }=357 \mathrm{~nm}\right)$ had $[\mathrm{M}-\mathrm{H}]^{-}$at $\mathrm{m} / \mathrm{z} 549$, and was only present in two phenotypes, that is red IT97K-1042-3 (Figure 3) and black (TX95K1105-5 and TX98K-10921-1) (Figure 9). It showed MS/MS fragment at $\mathrm{m} / \mathrm{z} 301$, corresponding to loss of $248 \mathrm{amu}$. This indicated loss of hexose (162 amu) + malonic acid (86 amu). The most common positions for acylation are C-3" and C-6"; however, C-6" is most preferred position for acylation (129). The ions at $\mathrm{m} / \mathrm{z} 301,179$ and 151 , coupled with the maximum UV absorption for this peak is typical of flavonol quercetin and its derivatives (Table 8). Moreover, acyl groups such as acetyl or malonyl usually occur as 6 -O-acetylglucoside or 6 -O-malonylglucoside (151). Thus, peak 45 was tentatively identified as quercetin-3-(6"-malonoyl)-glucoside (Figure 4A). Flavonoids containing $6^{\prime}$-malonoyl-glucoside groups have been identified in eggplants and red onions (129). To our knowledge, this is the first time that this quercetin derivative is identified in cowpea, and thus far, in pulses.

Peak $47\left(\mathrm{t}_{\mathrm{R}}=8.82 \mathrm{~min}, \lambda_{\max }=334 \mathrm{~nm}\right)$ had precursor ion $[\mathrm{M}-\mathrm{H}]^{-}$at $m / z 801$. The MS/MS spectrum showed product ions at $\mathrm{m} / \mathrm{z} 625$ and at 301, an indication of sequential cleavage of two groups (Table 8). The ion at $\mathrm{m} / \mathrm{z} 625$ corresponded to a diglucosyl residue (loss of $324 \mathrm{amu}$ ) while the ion at $\mathrm{m} / \mathrm{z} 301$ corresponded to a terminal feruloyl derivative (loss of $176 \mathrm{amu}$ ) in the 3-position of the quercetin aglycone (152). Therefore, this compound was proposed as quercetin-3-(6"-feruloyl)-diglucoside (Figure 4A). In this study, we found peaks corresponding to quercetin-3-feruloyl- 
diglucoside in the black IT95K-1105-5, golden brown (IT84S-2246 and Ife Brown), light brown IAR-48 and green TX2028-1-3-1 varieties. This compound has previously been identified in cowpea (51).

Peak $48\left(t_{\mathrm{R}}=9.16 \mathrm{~min}\right)$ showed $[\mathrm{M}-\mathrm{H}]^{-}$at $\mathrm{m} / \mathrm{z} 709$ and UV-spectrum with maximum at $363 \mathrm{~nm}$. Fragmentation of this compound produced ions at $\mathrm{m} / \mathrm{z} 625(\mathrm{M}-84$ amu) and $301(\mathrm{M}-84-324 \mathrm{amu})$. This indicates the presence of a terminal di-acetoyl group $(2 \times 42 \mathrm{amu})$ and di-glucosyl moiety $(2 \times 162 \mathrm{amu})$. The MS/MS spectral pattern (Table 8) showed that the di-acetoyl and the glycosyl groups were sequentially cleaved off the quercetin backbone $(\mathrm{m} / \mathrm{z}$ 301) (Table 8). Therefore, this compound was designated as quercetin-3-(6"-diacetoyl)-diglucoside (Figure 4A) and also showed much longer retention time compared to its non acylated counterparts. Among all the samples studied, peaks corresponding to quercetin-3-di-acetoyl-diglucoside were only found in the Ife Brown (golden brown) (Figure 5B-2) and IAR-48 (light brown) varieties (Figure 8B-2).

Peak $49\left(t_{\mathrm{R}}=9.96 \mathrm{~min}, \lambda_{\max }=332 \mathrm{~nm}\right)$ had $[\mathrm{M}-\mathrm{H}]^{-}$at $\mathrm{m} / \mathrm{z} 815$. The fragment at $m / z 301(\mathrm{M}-514 a m u)$ was attributed to the loss of rutinose (6-O- $\alpha$-L-rhamnosyl- $D$ glucose; $308 \mathrm{amu}$ ) with the rutinose acylated with sinapic acid (206 amu) and finally joined to the aglycone by an $O$-glycosidic bond. The aglycone was revealed by the ions at $m / z$ 301, 179 and 151 to be quercetin (Table 8). Peak 49, which was only found in Ife Brown variety (Figure 5B-2), was tentatively designated as quercetin-3-(6"-sinapoyl)rutinoside (Figure 4A) (129). 
Peak $50\left(t_{\mathrm{R}}=11.05 \mathrm{~min}\right)$ had $[\mathrm{M}-\mathrm{H}]^{-}$at $\mathrm{m} / \mathrm{z} 301$ corresponding to quasi molecular ion of quercetin in negative ionization mode (Table 8). This compound also showed characteristics both in the UV-vis spectra $\left(\lambda_{\max }=370 \mathrm{~nm}\right)$ and in the MS/MS spectrum (ions at $\mathrm{m} / \mathrm{z} 179$ and 151), coupled with a much longer retention time which are consistent with literature information on properties of quercetin (54). In this study, we observed derivatives of quercetin flavonol in these cowpea extracts; thus, the occurrence of quercetin was also expected. However, this peak was only present in the IT82D-889 (red) variety (Figure 3B-2). Based on our observations throughout this study, it means that flavonols basically occur in cowpea as glycosides and acylglycosides. We found that glycosides of quercetin are predominant in cowpea. Previous studies reported high levels of quercetin (412.5 $\mu \mathrm{g} / \mathrm{g})$ and myricetin (51.3 $\mu \mathrm{g} / \mathrm{g})$ in black cowpea hydrosylates (56).

\subsubsection{Dihydrochalcones}

Peak $30\left(\mathrm{t}_{\mathrm{R}}=7.14 \mathrm{~min}, \lambda_{\max }=325 \mathrm{~nm}\right)$, which was only present in IT98K-1092-1 (black) (Figure 9B) and golden brown (IT84S-2246 and Ife Brown) varieties (Figure 5A-1) produced a $[\mathrm{M}-\mathrm{H}]^{-}$at $m / \mathrm{z}$ 435. In the MS/MS spectrum, the majority ion at $\mathrm{m} / \mathrm{z}$ $273(\mathrm{M}-162 \mathrm{amu})$ corresponds to loss of a glycosyl unit. The fragment at $\mathrm{m} / \mathrm{z} 273$ and $\lambda_{\max }$ at $325 \mathrm{~nm}$ (Table 7) matches that of dihydrochalcone phloretin (Figure 13) known to contribute to the flavor, color and health benefits of apple fruit $(153,154)$. Based on the MS spectrum and literature evidence (154), peak 30 can be identified as phlorizin (phloretin 2 -glucoside), also known to competitively inhibit renal glucose transport 
(155) and facilitate memory storage in mice (156). Until recently, phlorizin and its derivatives were believed to exist only in Malus species, primarily in the young shoots, roots, leaves and bark of apple trees (154). The presence of phlorizin in legumes has not been reported before.

\subsubsection{Phenolic acids}

Peaks 55, 56 and 59 all had $[\mathrm{M}-\mathrm{H}]^{-}$at $\mathrm{m} / \mathrm{z}$ 399. The fragment at $\mathrm{m} / \mathrm{z} 193$ corresponded to cleavage of the aldaric acid moiety. Based on literature data and fragmentation pattern (Table 9), we propose the peaks as trans-feruloylmethylaldaric acids (Figure 12) (51). Based on the $t_{\mathrm{R}}$ of peak $59\left(t_{\mathrm{R}}=7.23 \mathrm{~min}\right)>56\left(t_{\mathrm{R}}=6.66 \mathrm{~min}\right)>$ $55\left(t_{\mathrm{R}}=6.53 \mathrm{~min}\right)$ we suspect that there is a single substituent on the structure of this compound that only differs in the position (ortho-, para- and meta-) at which it is substituted, which may affect their polarity. In this study, we found peaks corresponding to trans-feruloylmethylaldaric acid in the red IT82D-889 (Figure 14), golden brown (Ife Brown and IT84S 2246) (Figure 15), light brown (IAR-48 and 09FCV-CC27M) (Figure 17), and white (Early Acre) (Figure 18) cowpea varieties. Previous studies have also reported trans-feruloylaldaric acid and its methyl derivatives in cowpea (51). 


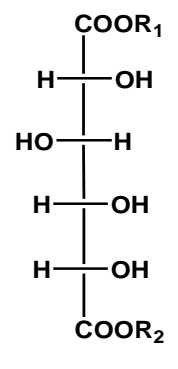

$\mathbf{R}_{\mathbf{1}}=\mathbf{R}_{\mathbf{2}}=\mathbf{H}$

D-Glucaric acid

(A)

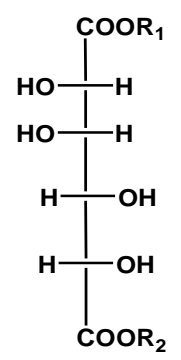

$\mathbf{R}_{1}=\mathbf{R}_{2}=\mathbf{H}$

D-Mannaric acid

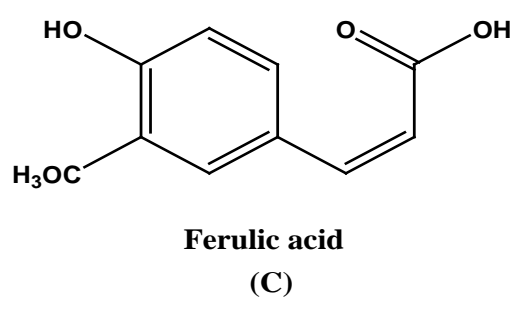

(C)

(B)

Figure 12. Representative aldaric acid derivatives. Aldaric acid, $\mathbf{R}_{\mathbf{1}}=\mathbf{R}_{\mathbf{2}}=\mathbf{H} . \mathbf{C H}_{\mathbf{3}}$ and ferulic acid may bond at $\mathbf{R}_{\mathbf{1}}$ and $\mathbf{R}_{\mathbf{2}}$ to $\mathbf{A}$ and $\mathbf{B}$.

\subsection{Flavonoids in the ethyl-acetate fractions}

The elution with ethyl acetate on C18 Sep-Pak cartridges as described under materials and methods isolates catechins and oligomeric proanthocyanidin from anthocyanins and flavonols. However, some oligomers and polymeric forms of proanthocyanidins are more strongly associated with the stationary phase, thus, are eluted with stronger solvents, such as methanol. Thus, it is not surprising to find some of these compounds in both methanolic and ethyl-acetate fractions. Moreover, non-polar compounds are highly soluble in ethyl acetate, thus would be found in the ethyl acetate extract fractions. The detected peaks (Figures 14 - 20), and a summary of their MS and MS/MS data, as well as $\lambda_{\max }$ and retention times $\left(t_{\mathrm{R}}\right)$, are presented in Table 8. Identification and peak assignments were primarily based on comparison of their retention time and mass spectrometric data with literature guidelines. 
Table 9. Identification of flavonoids in ethyl-acetate fraction of 10 cowpea varieties based on UPLC retention time $\left(t_{R}\right)$, UV-vis spectroscopic characteristics $\left(\lambda_{\max }\right)$, and MS-MS/MS spectroscopic pattern. Ionization was performed in the negative mode. Peaks marked $\left(^{*}\right)$ were unidentified.

\begin{tabular}{|c|c|c|c|c|c|}
\hline $\begin{array}{l}\text { Peak } \\
\text { no. }\end{array}$ & $\begin{array}{l}t_{R} \\
(\min )\end{array}$ & $\begin{array}{l}\lambda_{\max } \\
(\mathrm{nm})\end{array}$ & Proposed identifications & $\begin{array}{l}{[\mathbf{M}-\mathbf{H}]^{-}} \\
(\boldsymbol{m} / \mathbf{z})\end{array}$ & MS/MS fragments $(\mathrm{m} / \mathrm{z})$ \\
\hline 51 & 4.73 & 284 & Taxifolin-7-O- $\beta$-glucoside & 465 & $303,285,275,125$ \\
\hline $52 *$ & 5.28 & 325 & Unknown & 865 & $\begin{array}{l}713,577,561,425,407, \\
289\end{array}$ \\
\hline 53 & 6.06 & 299 & Eriodictyol-7-O- $\beta$-galactoside & 449 & $287,151,135$ \\
\hline $54 *$ & 6.11 & 266 & Unknown & 281 & 281, 237, 201, 189, 171 \\
\hline 55 & 6.53 & 325 & trans-Feruloylmethylaldaric acid & 399 & $193,147,85$ \\
\hline 56 & 6.66 & 326 & trans-Feruloylmethylaldaric acid & 399 & $193,147,85$ \\
\hline 57 & 6.79 & 279 & Procyanidin tetramer & $1154(577)$ & 451, 425, 407, 289 \\
\hline 58 & 7.14 & 278 & Di-phlorizin & $871(435)$ & 299, 273, 137, 135 \\
\hline 59 & 7.23 & 327 & trans-Feruloylmethylaldaric acid & 399 & 193, 147, 85 \\
\hline 60* & 7.26 & 492 & Unknown & 341 & 295, 267, 241, 160, 153 \\
\hline 61* & 7.43 & 283 & Unknown & 521 & 359, 344, 119, 101 \\
\hline 62 & 7.71 & 283 & Eriodictyol-7-O- $\beta$-glucoside & 449 & $287,151,135$ \\
\hline 63* & 8.05 & 353 & Unknown & 985 & $521,477,463,341,161$ \\
\hline $64^{*}$ & 8.08 & 283 & Unknown & $1043(521)$ & 359, 344, 119, 101 \\
\hline 65* & 8.27 & 381 & Unknown & 561 & 409, 273, 125 \\
\hline 66 & 8.74 & 354 & Catechin-kaempferol dimer & 575 & 449, 289, 285, 125 \\
\hline 67* & 8.75 & 269 & Unknown & 849 & $\begin{array}{l}561,409,367,299,287, \\
273,243\end{array}$ \\
\hline 68 & 9.06 & 287 & Eriodictyol-5- $O$ - $\beta$-glucoside & 449 & $287,151,135$ \\
\hline $69 *$ & 9.38 & 352 & Unknown & 493 & $181,167,123$ \\
\hline 70 & 9.51 & 355 & $\begin{array}{l}\text { Quercetin-3-(6"-succinoyl)- } \\
\text { glucoside }\end{array}$ & 563 & $463,301,300,151$ \\
\hline 71* & 9.85 & 260 & Unknown & 553 & $385,241,167$ \\
\hline $72 *$ & 10.38 & 274 & Unknown & 579 & 385, 325, 283, 241, 197 \\
\hline
\end{tabular}

\subsubsection{Flavanonols}

Peak $51\left(t_{\mathrm{R}}=4.73 \mathrm{~min}, \lambda_{\max }=284 \mathrm{~nm}\right)[\mathrm{M}-\mathrm{H}]^{-}$at $\mathrm{m} / \mathrm{z} 465$ was identified as taxifolin-7-O- $\beta$-glucoside (157). The fragment corresponding to the loss of glucose at m/z 303 (M - 162 amu) gave the molecular weight of taxifolin aglycone (Table 9), and 
the UV-vis matched that of its standard. Taxifolin (a dihydroquercetin) is categorized as a flavanonol (Figure 4B). In this study, we found peaks corresponding to taxifolin-7-O$\beta$-glucoside only in the red cowpea varieties, i.e. red IT82D-889 and IT97K-1042-3 varieties (Figure 14). Taxifolin and its glycosides have not been reported in cowpeas or other pulses before.

\subsubsection{Flavanones}

The golden brown varieties had peaks 53, 62 and 68 (Figure 15) with $[\mathrm{M}-\mathrm{H}]^{-}$ at $m / z$ 449. These peaks were identified as eriodictyol derivatives by comparison of their fragmentation pattern with literature data (157) and UV spectra with external standard. The loss of 162 amu ([M - 287]) indicated presence of a hexose moiety. The most commonly reported hexose conjugated with eriodictyol is glucose $(134,157)$. Moreover, the position and type of the glucose moiety can be used to discriminate between the three peaks based on their retention times (Table 9). Flavanone glycosylation mainly occurs at the C-7 position (158); however, both 7-O- $\beta$-glucosylated and 5-O- $\beta$-glucosylated derivatives of eriodictyol have been reported in nature, especially in sorghum grains (134, 157). Glycosylation at C-7 increases polarity of compounds, thus, 7-O-glycosides would elute early (54). Based on this evidence, peaks $53\left(t_{\mathrm{R}}=6.06 \mathrm{~min}\right), 62\left(t_{\mathrm{R}}=7.71\right.$ $\min )$ and $68\left(t_{\mathrm{R}}=9.06 \mathrm{~min}\right)$ were identified as eriodictyol-7- $O$ - $\beta$-galactoside, eriodictyol-7-O- $\beta$-glucoside and eriodictyol-5-O- $\beta$-glucoside, respectively. In this study, a peak corresponding to eriodictyol-7-O- $\beta$-galactoside was only found in the Ife Brown (golden brown) variety; while two peaks corresponding to eriodictyol-7-O- $\beta$-glucoside 
and eriodictyol-5-O- $\beta$-glucoside were found in the golden brown (i.e. IT84S-2246 and Ife Brown) varieties (Figure 15). As far as we know, these compounds are reported for the first time in cowpea seeds.

\subsubsection{Dihydrochalcones}

Peak $58\left(t_{\mathrm{R}}=7.14 \mathrm{~min}, \lambda_{\max }=278 \mathrm{~nm}\right)$ is tentatively identified as phlorizin dimer (Figure 13), and was only present in the golden brown IT84S-2246 (Figure 15A-1) and light brown 09FCV-CC27M cowpea varieties (Figure 17A-1). It has $[\mathrm{M}-\mathrm{H}]^{-}$at $\mathrm{m} / \mathrm{z}$ 871, suggesting presence of two units of $435 \mathrm{amu}$. On fragmentation, the ion at $\mathrm{m} / \mathrm{z} 435$ produced similar products as those observed for peak 30 (i.e. phlorizin aglycone) (Table 9). As previously discussed, the monomeric form of phlorizin (peak 30) was only found in the golden brown IT84S-2246 (Figure 5A-1) and black IT98K-1092-1 varieties (Figure 9B). From our observations, it seems therefore, that the black IT98K-1092-1 variety contained the phlorizin only in its monomeric form; while the light brown 09FCV-CC27M only contained the dimeric but not the monomeric form. However, the golden brown IT84S-2246 variety contained both phlorizin and its dimeric form (Figures 5A-1 and 15A-1). 
<smiles>O=C(CCc1ccc(O)cc1)c1c(O)cc(O)cc1O</smiles>

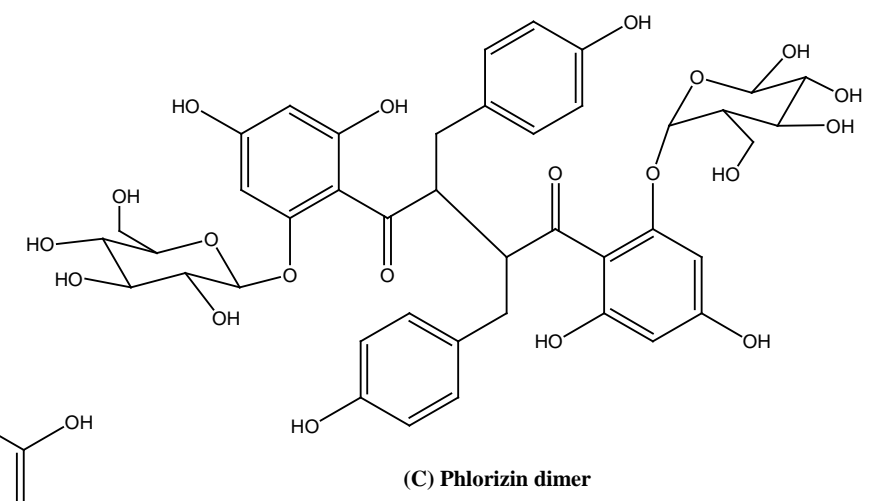<smiles>O=C(CCc1ccc(O)cc1)c1c(O)cc(O)cc1OC1OCC(O)C(O)C1O</smiles>

(C) Phlorizin dimer

(B) Phlorizin

Figure 13. Hydroxychalcones identified in cowpea. Phloretin, (A); phlorizin, (B), and phlorizin dimer, (C). The structure of the dimer is proposed following postulated mechanism for the production of dimeric flavonones from chalcones substituted at C-4 (159).

\subsubsection{Flavan-3-ols}

Among the varieties studied, only 09FCV-CC27M (light brown) (Figure 16A-1) and Ife Brown (light brown) varieties (Figures 16B-1 and 16B-2) had peak $57\left(t_{\mathrm{R}}=6.79\right.$ $\min , \lambda_{\max }=279 \mathrm{~nm}$ ) which is identified as a procyanidin tetramer. This peak has $[\mathrm{M}-$ $\mathrm{H}]^{-}$at $\mathrm{m} / \mathrm{z}$ 1154, suggesting presence of four catechin units, with major MS/MS fragments at $m / z$ 577, suggesting loss of a dimer, and 289, confirming presence of catechin units (136). It also showed UV-vis absorption maximum of $279 \mathrm{~nm}$, which is typical of proanthocyanidins (Table 9). This is the first report indicating that cowpea contains procyanidin tetramers. 
Peak $66\left(t_{\mathrm{R}}=8.74 \mathrm{~min}, \lambda_{\max }=354 \mathrm{~nm}\right)$ which had $[\mathrm{M}-\mathrm{H}]^{-}$at $\mathrm{m} / \mathrm{z} 575$ was designated as catechin-kaempferol dimer (Figure 16). Its fragmentation pattern included major ions at $\mathrm{m} / \mathrm{z}$ 449, 289, 285 and 125 (Table 9). The ion at $\mathrm{m} / \mathrm{z} 449$ corresponds to HRF of the top unit, causing a loss of 126 amu. This fragmentation path leads to the loss of B-ring in the top unit. The ion at $\mathrm{m} / \mathrm{z} 289$ characterizes catechin as the base unit, following the cleavage of the interflavanoid linkage (140), while the ion at $\mathrm{m} / \mathrm{z} 285$, as well as $\lambda_{\max }=354 \mathrm{~nm}$ gives the identity of the flavonol, that is, kaempferol, which forms the terminal (bottom) unit. The strong signal at $\mathrm{m} / \mathrm{z} 125$ is phloroglucinol (product of HRF) in negative mode $(140,160)$. The proposed fragmentation pathway of this flavonol-flavan-3-ol dimer is shown in Figure 16. In this study, we found a peak corresponding to catechin-kaempferol dimer only in the red IT97K-1042-3 variety (Figures 14A-1 and 2). This is the first report of the presence of flavanol-flavonol condensed pigment in cowpea, and thus far, in pulses. As far as we know, only the presence of flavanol-anthocyanin condensed pigments in different species of beans (Phaseolus vulgaris) has been described by other authors (161). 

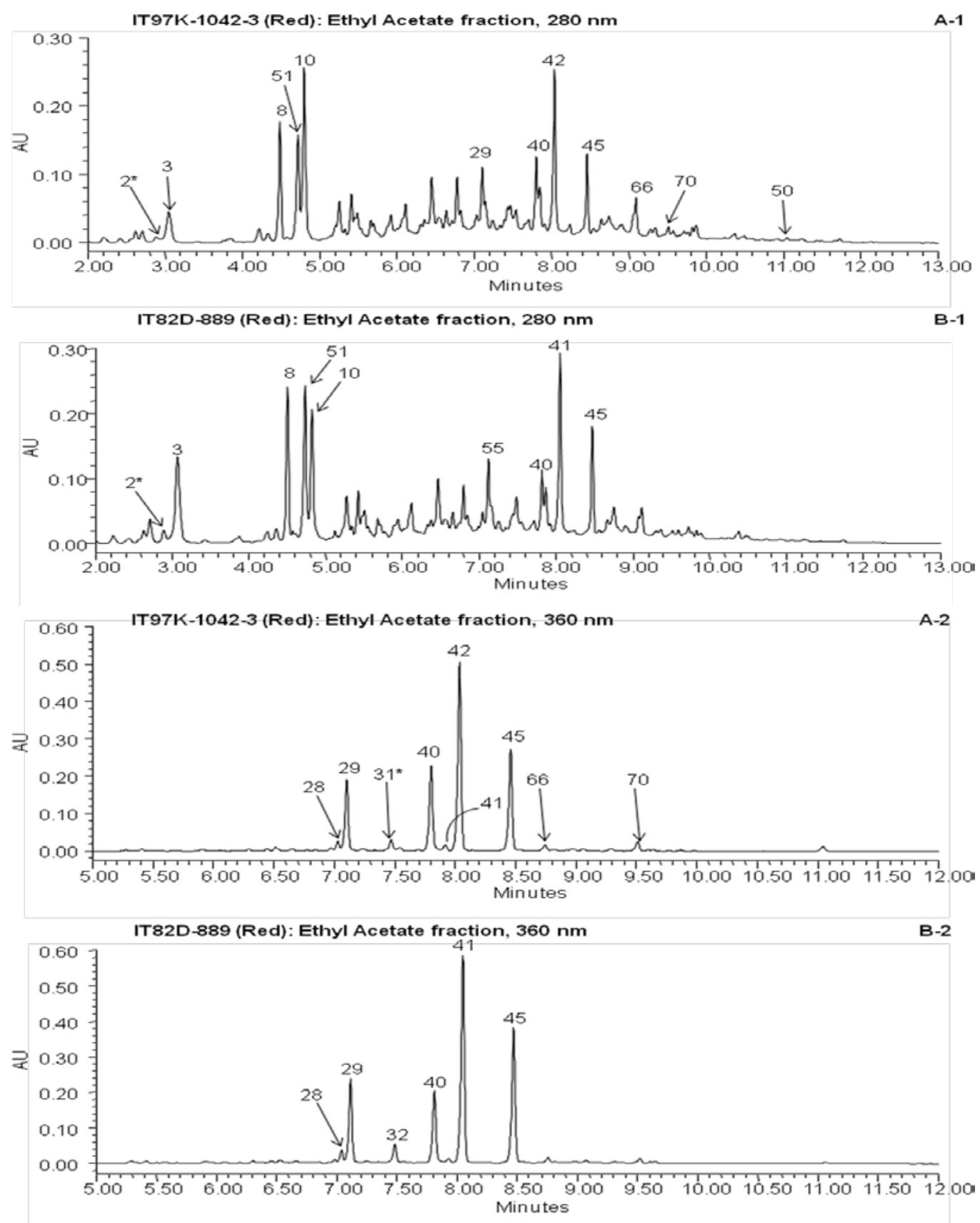

Figure 14. Reverse-phase UPLC chromatogram of phenolic extracts from ethyl-acetate fractions of red cowpea varieties; IT97K-1042-3 at $280 \mathrm{~nm}$ (A-1) and $360 \mathrm{~nm}$ (A-2); and IT82D-889 at $280 \mathrm{~nm}$ (B-1) and $360 \mathrm{~nm}$ (B-2). Peaks marked (*) are unidentified. Peak numbers are referenced to Tables 6 - 9 . 

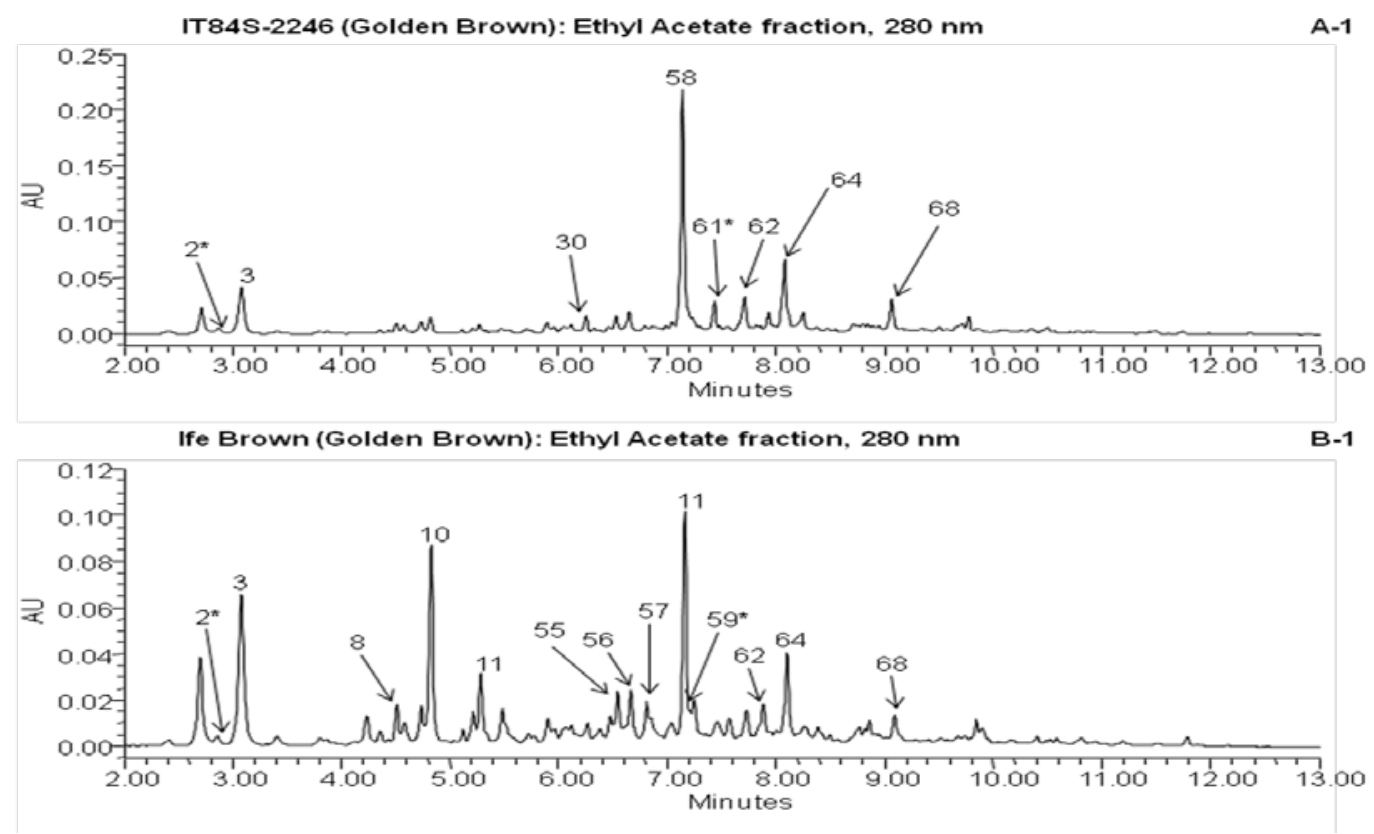

IT84S-2246 (Golden Brown): Ethyl Acetate fraction, $360 \mathrm{~nm}$

A-2
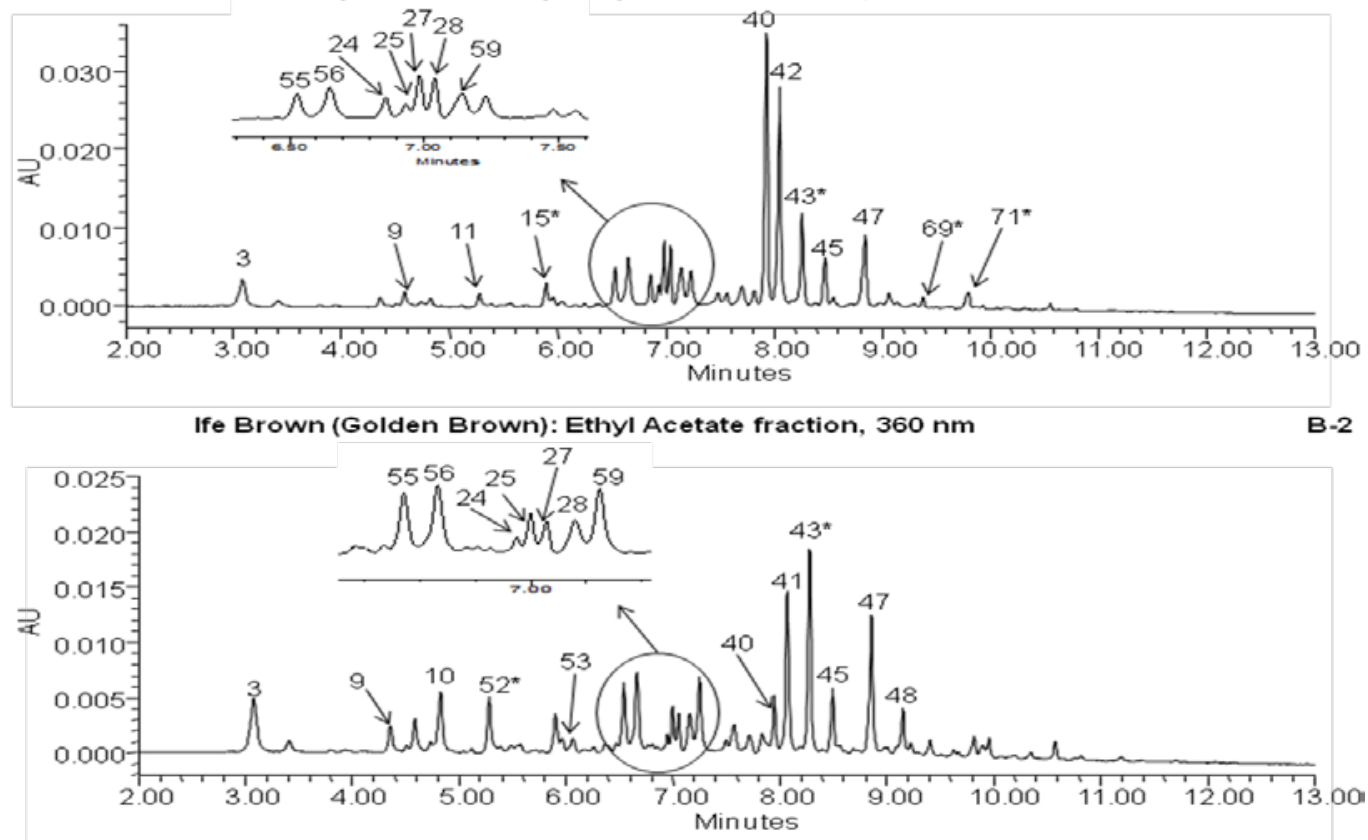

Figure 15. Reverse-phase UPLC chromatogram of phenolic extracts from ethyl-acetate fractions of golden brown cowpea varieties; IT84S-2246 at $280 \mathrm{~nm}$ (A-1) and $360 \mathrm{~nm}$ (A-2); and Ife Brown at $280 \mathrm{~nm}(\mathbf{B}-\mathbf{1})$ and $360 \mathrm{~nm}(\mathbf{B}-2)$. Peaks marked (*) are unidentified. Peak numbers are referenced to Tables 6 - 9 . 


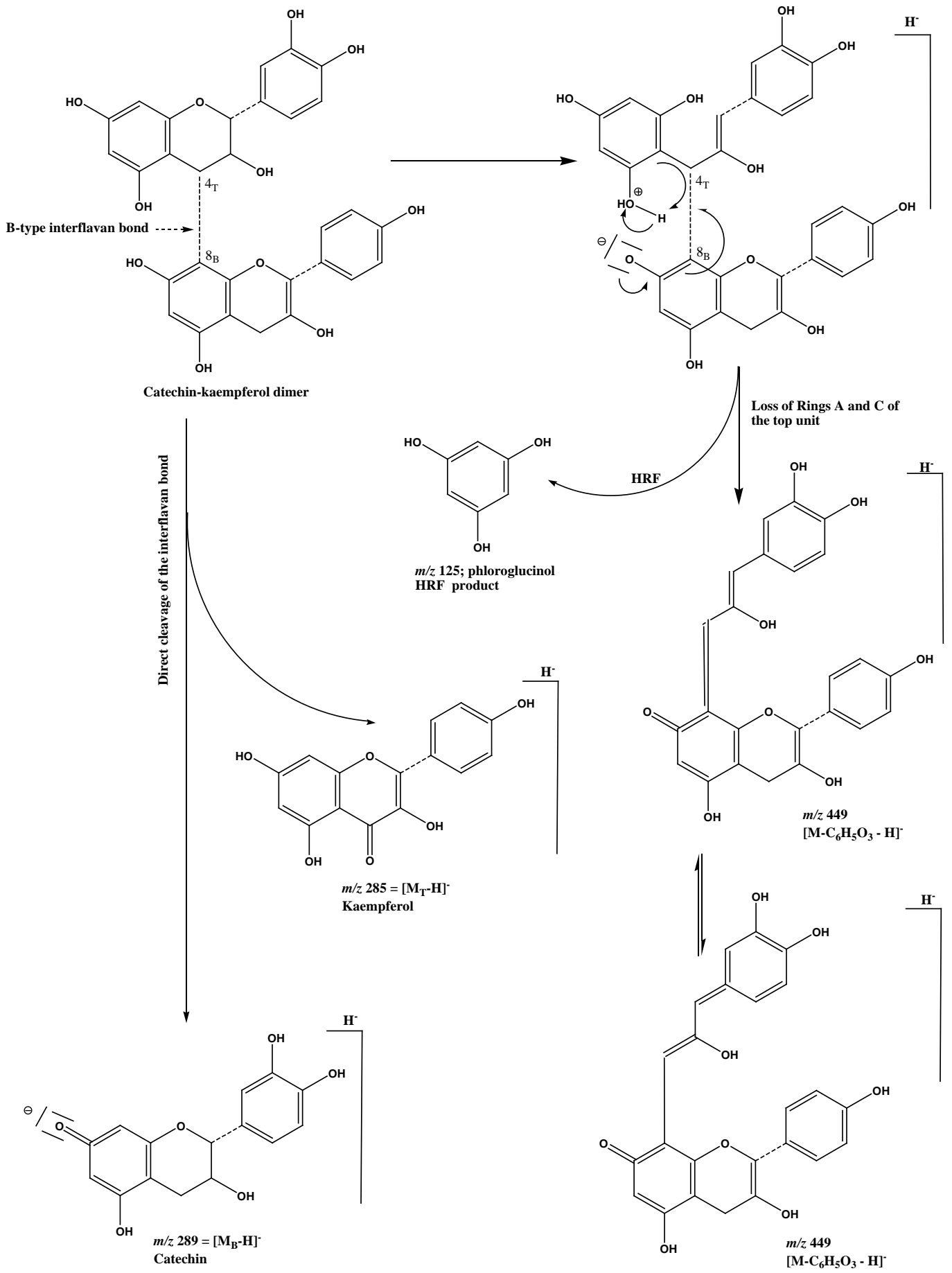

Figure 16. Fragmentation mechanism of flavanol-flavan-3-ol dimer found in cowpea (in negative mode) following general scheme proposed by Friedrich et al. (140). 

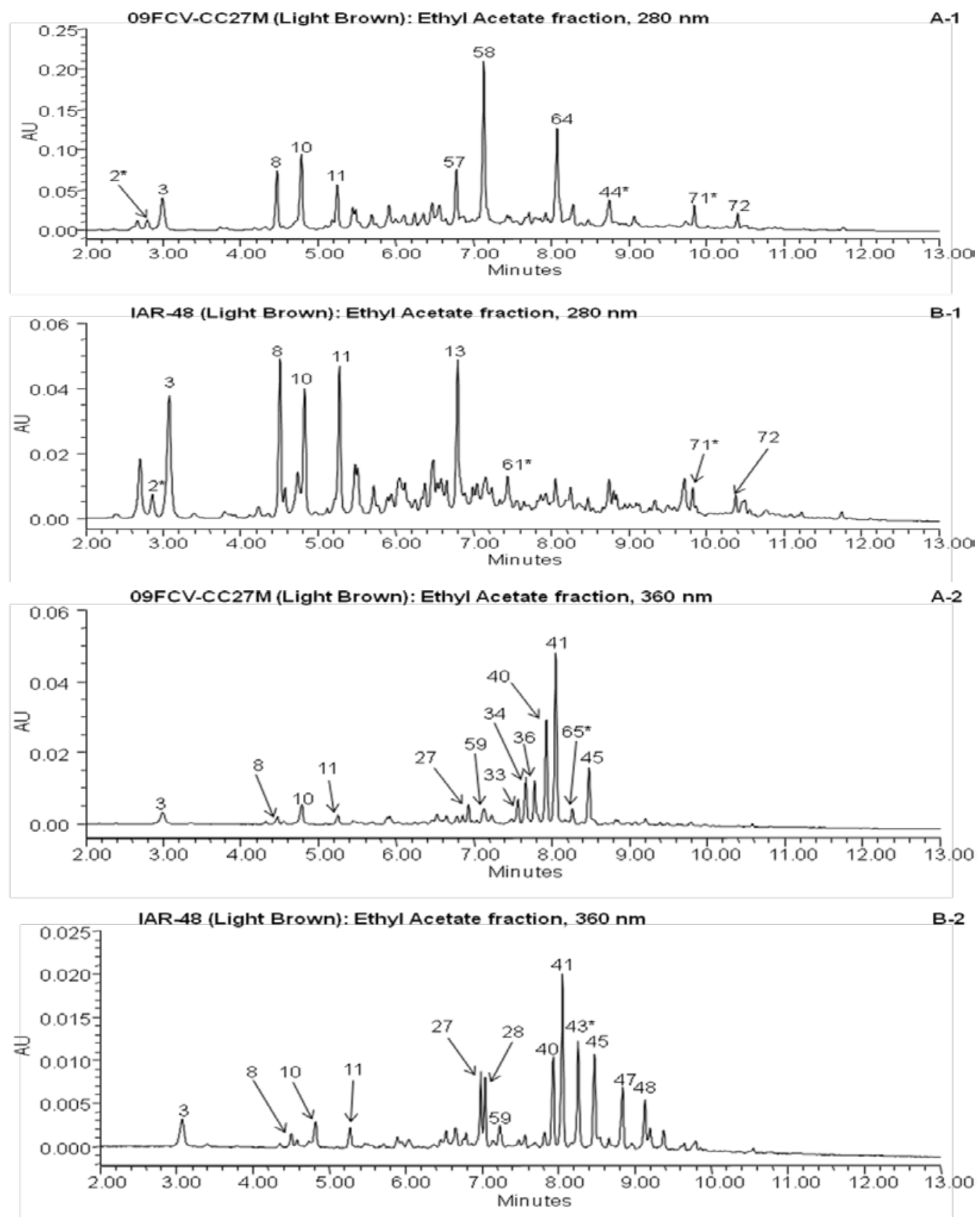

Figure 17. Reverse-phase UPLC chromatogram of phenolic extracts from ethyl-acetate fractions of light brown cowpea varieties; 09FCV-CC27M at $280 \mathrm{~nm}$ (A-1) and $360 \mathrm{~nm}$ (A-2); and IAR48 at $280 \mathrm{~nm}$ (B-1) and $360 \mathrm{~nm}(\mathbf{B}-2)$. Peaks marked (*) are unidentified. Peak numbers are referenced to Tables 6 - 9 . 

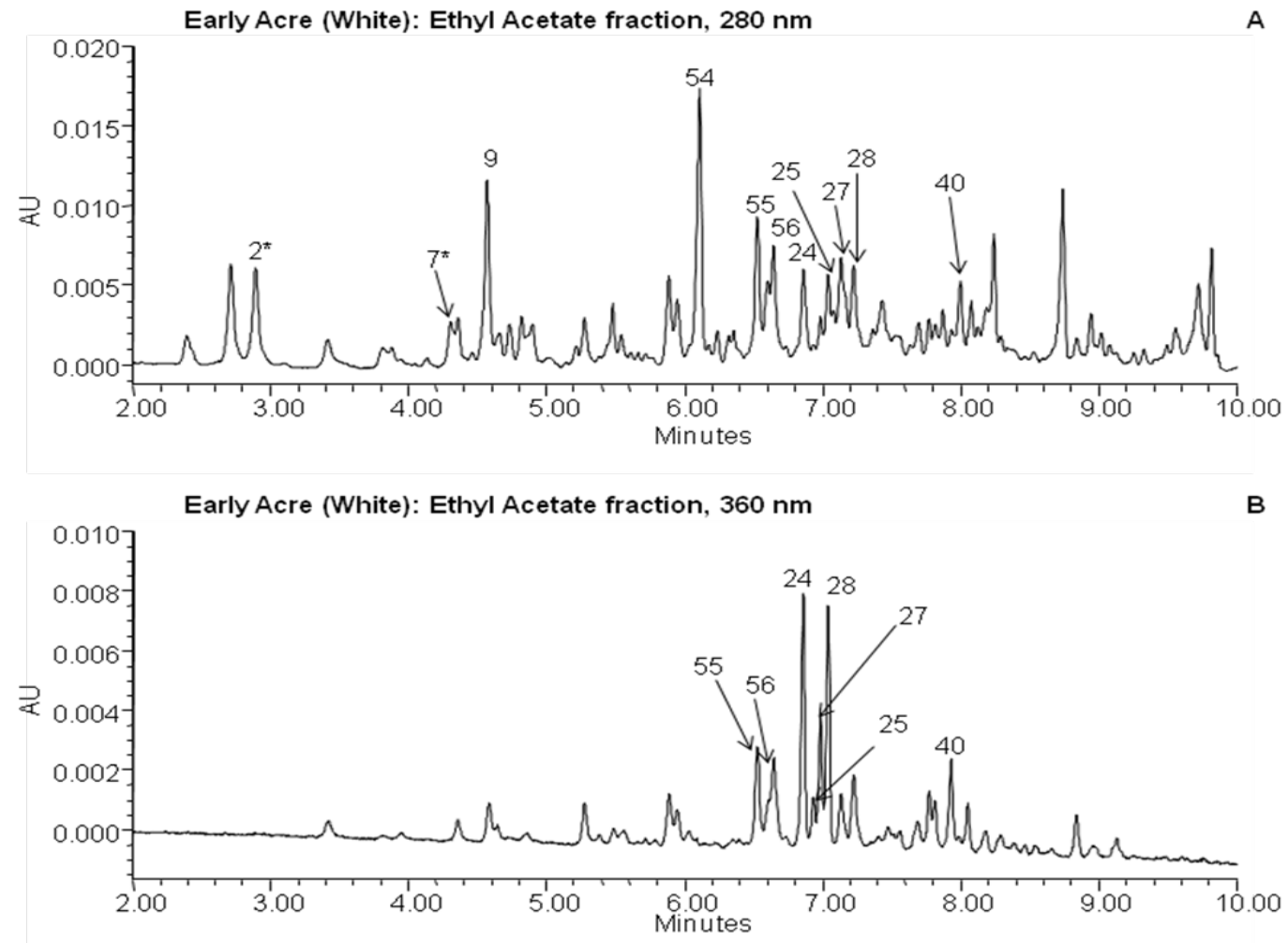

Figure 18. Reverse-phase UPLC chromatogram of phenolic extracts from ethyl-acetate fractions of white cowpea variety, Early Acre at $280 \mathrm{~nm}$ (A) and $360 \mathrm{~nm}$ (B). Peaks marked (*) are unidentified. Peak numbers are referenced to Tables 6 - 9 . 

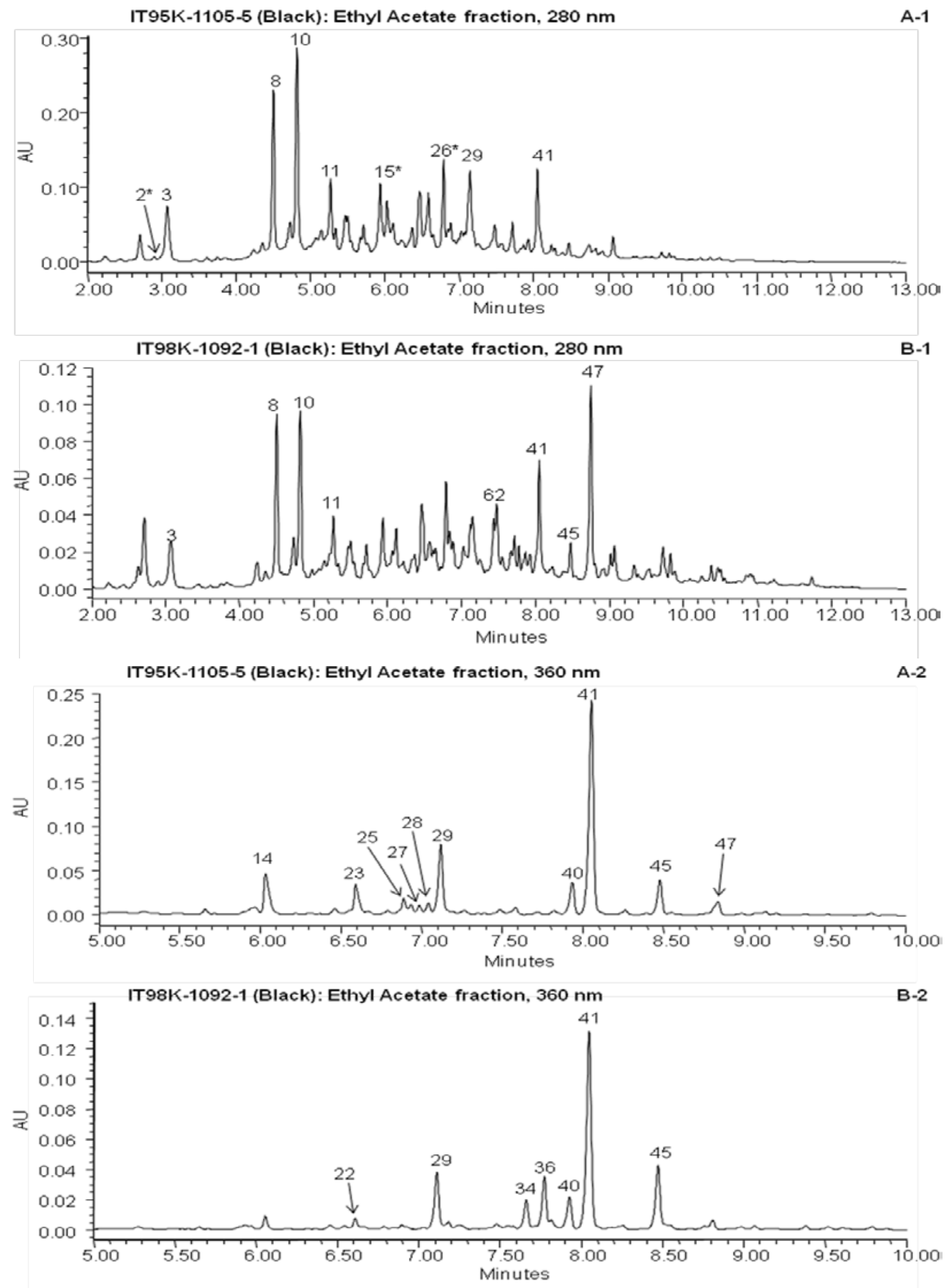

Figure 19. Reverse-phase UPLC chromatogram of phenolic extracts from ethyl-acetate fractions of black cowpea varieties; IT95K-1105-5 at $280 \mathrm{~nm}$ (A-1) and $360 \mathrm{~nm}$ (A-2); and IT98K-1092-1 at $280 \mathrm{~nm}$ (B-1) and $360 \mathrm{~nm}$ (B-2). Peaks marked (*) are unidentified. Peak numbers are referenced to Tables 6 - 9 . 


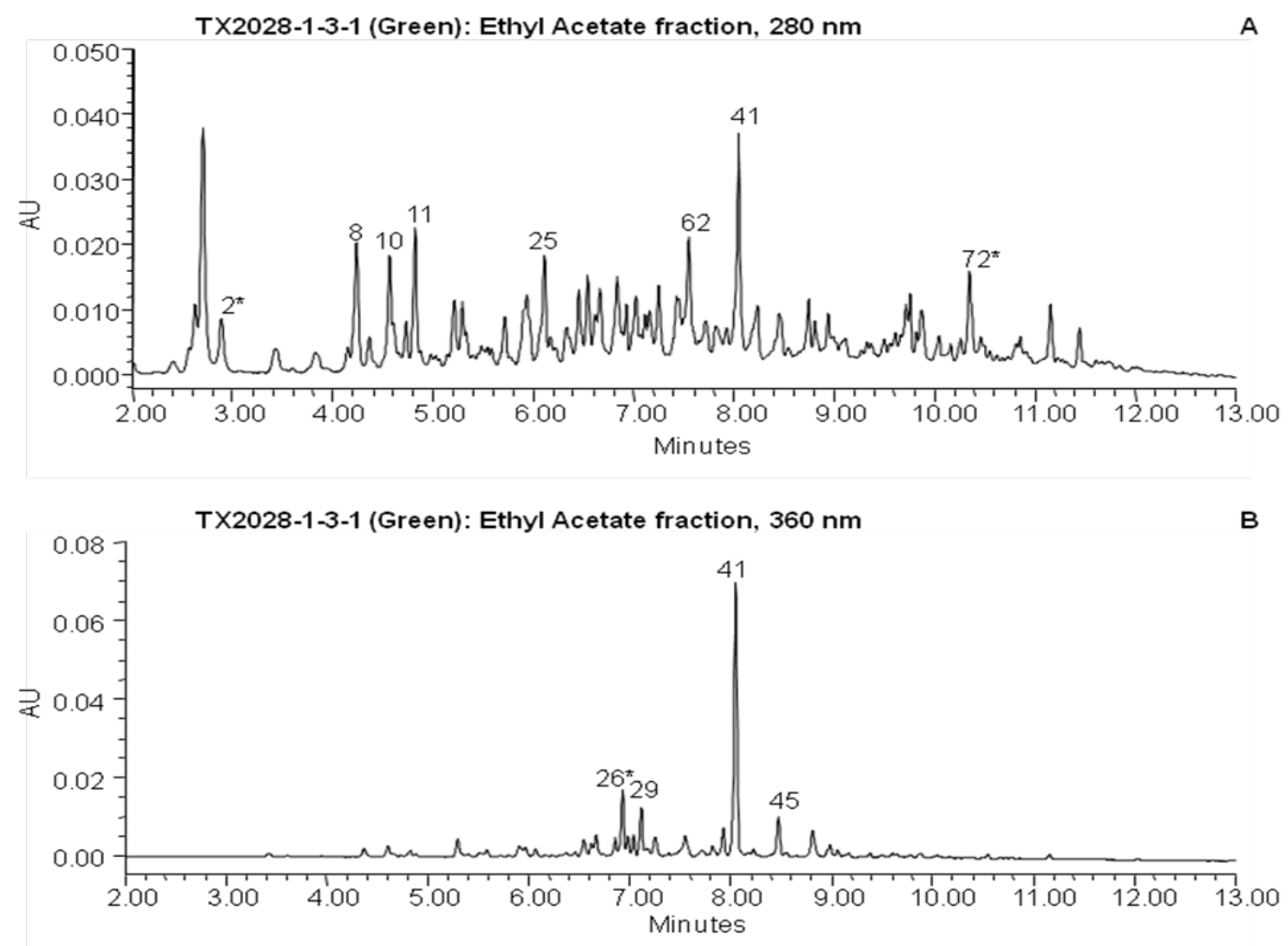

Figure 20. Reverse-phase UPLC chromatogram of phenolic extracts from ethyl-acetate fractions of green cowpea variety, TX2028-1-3-1 at $280 \mathrm{~nm}$ (A) and $360 \mathrm{~nm}$ (B). Peaks marked (*) are unidentified. Peak numbers are referenced to Tables 6 - 9.

\subsubsection{Flavonols}

Peak $70\left(t_{\mathrm{R}}=9.51 \mathrm{~min}, \lambda_{\max }=355 \mathrm{~nm}\right)$ had $[\mathrm{M}-\mathrm{H}]^{-}$at $m / \mathrm{z}$ 563. The MS/MS fragment at $\mathrm{m} / \mathrm{z} 301$ corresponds to quercetin. Upon fragmentation, the ion at $\mathrm{m} / \mathrm{z} 463$ (loss of $100 \mathrm{amu}$ ) occurred, suggesting the compound is acylated with succinic acid; while the ion at $\mathrm{m} / \mathrm{z} 301(\mathrm{M}-100-162 \mathrm{amu})$, indicated there was a subsequent fragmentation of a glucose moiety. This peak is thus designated as quercetin-3-(6"- 
succinoyl)-glucoside, and was only found in the red IT97K-1042-3 variety (Figures 14A-1 and 2; Table 8).

\subsection{Flavonol content in cowpeas}

With regard to general flavonol content in pulses, most studies focus on common bean, and very limited information is available on other pulses $(47,54)$. The individual (quercetin, myricetin and kaempferol derivatives) and total flavonol contents of the raw and boiled cowpeas are presented in Tables 10 - 14 .

Overall, twenty nine (29) flavonol compounds were isolated in the cowpea varieties, six of which were unidentified (Tables 8 and 9). From this study, a total of twenty three (23) flavonols were newly identified in cowpea. The majority (20 compounds) were quercetin derivatives. Myricetin derivatives were only found in black (IT95K-1105-1 and IT98K-1092-1), red (IT82D-889 and IT97K-1042-3) and green TX2028-1-3-1 varieties. Only one kaempferol derivative (kaempferol-3-O-diglucoside) was detected and was only found in the black (IT95K-1105-1 and IT98K-1092-1), golden brown (Ife Brown and IT84S-2246), light brown IAR-48 and white Early Acre varieties. Average flavonol content was significantly higher in the red phenotype (1799 $\pm 64.9 \mu \mathrm{g} / \mathrm{g})$, than the other phenotypes (Tables $10-\mathbf{1 4})$. 
Table 10. Compositions ( $\mu \mathrm{g} / \mathrm{g}$ of cowpea flour) and effect of boiling on flavonols and flavan-3ols in black cowpea varieties ${ }^{a}$

\begin{tabular}{|c|c|c|c|c|c|c|}
\hline \multirow[b]{4}{*}{ Compound } & \multicolumn{6}{|c|}{ Black cowpea varieties } \\
\hline & \multicolumn{3}{|c|}{$\underline{\text { IT95K-1105-5 }}$} & \multicolumn{3}{|c|}{$\underline{\text { IT98K-1092-1 }}$} \\
\hline & \multicolumn{6}{|c|}{ Flavonol content ( $\mu \mathrm{g} / \mathrm{g}$ cowpea flour) } \\
\hline & Raw & Boiled & $\begin{array}{c}\% \\
\text { change }\end{array}$ & Raw & Boiled & $\begin{array}{c}\% \\
\text { change }\end{array}$ \\
\hline $\begin{array}{l}\text { Quercetin-3-O-glucoside-4'-O- } \\
\text { diglucoside }\end{array}$ & $34.1 \pm 1.14$ & $\mathrm{ND}^{b}$ & - & $30.5 \pm 3.14$ & $\mathrm{ND}$ & - \\
\hline Quercetin-3-O-arabinosyldiglucoside & $44.2 \pm 0.73$ & $38.8 \pm 1.30$ & 12.2 & $13.9 \pm 0.23$ & ND & - \\
\hline Quercetin-3-O-digalactoside & $17.8 \pm 0.29$ & $15.6 \pm 0.52$ & 12.4 & $12.6 \pm 0.28$ & ND & - \\
\hline Quercetin-3,7-diglucoside & $12.3 \pm 0.55$ & ND & - & $8.54 \pm 1.28$ & ND & - \\
\hline Quercetin-3-O-galactosylglucoside & $55.4 \pm 1.41$ & ND & - & $12.5 \pm 2.81$ & ND & - \\
\hline Quercetin-3-O-diglucoside & $59.0 \pm 2.97$ & ND & - & $6.13 \pm 1.04$ & ND & - \\
\hline Quercetin-7-O-glucoside & $76.9 \pm 2.97$ & $19.8 \pm 1.46$ & 74.3 & $23.3 \pm 7.75$ & $12.4 \pm 1.21$ & 46.8 \\
\hline Quercetin-3-(6"-malonyl)-glucoside & $20.8 \pm 0.24$ & $8.36 \pm 1.12$ & 59.8 & $15.4 \pm 0.70$ & $7.11 \pm 2.65$ & 53.8 \\
\hline Quercetin-3-(6"-feruloyl)-diglucoside & $18.8 \pm 0.21$ & $8.75 \pm 0.15$ & 53.5 & ND & ND & - \\
\hline Quercetin-3-O-galactosylrhamnoside & ND & ND & - & $53.8 \pm 3.37$ & $28.3 \pm 1.53$ & 47.4 \\
\hline Quercetin-3-O-glucosylrhamnoside & ND & ND & - & $67.1 \pm 3.57$ & $25.7 \pm 0.97$ & 61.7 \\
\hline Subtotal quercetin & $339 \pm 7.5$ & $91.3 \pm 4.55$ & 73.1 & $244 \pm 24.2$ & $73.5 \pm 6.36$ & 69.9 \\
\hline Myricetin-3-O-diglucoside & $23.8 \pm 1.39$ & ND & - & $19.3 \pm 0.88$ & ND & - \\
\hline Myricetin-3-O-glucoside & $23.2 \pm 1.00$ & ND & - & $26.1 \pm 1.77$ & ND & - \\
\hline Subtotal myricetin & $47.0 \pm 2.39$ & - & - & $45.4 \pm 2.65$ & - & - \\
\hline Kaempferol-3-O-diglucoside & $13.6 \pm 2.44$ & ND & - & $187 \pm 9.4$ & $177 \pm 5.4$ & 5.28 \\
\hline Subtotal kaempferol & $13.6 \pm 2.44$ & ND & - & $187 \pm 9.4$ & $177 \pm 5.4$ & 5.28 \\
\hline \multirow[t]{2}{*}{ Total flavonols } & $399 \pm 12.3$ & $91.3 \pm 4.55$ & 77.3 & $476 \pm 36.3$ & $251 \pm 11.8$ & 47.3 \\
\hline & \multicolumn{6}{|c|}{ Flavan-3-ols content ( $\mu \mathrm{g} / \mathrm{g}$ cowpea flour) } \\
\hline Catechin-3-O-glucoside & $2288 \pm 40.9$ & $571 \pm 9.6$ & 75.0 & $1811 \pm 8.3$ & $896 \pm 8.6$ & 50.5 \\
\hline Procyanidin dimer B-type & $3862 \pm 102.8$ & $1770 \pm 52.5$ & 54.1 & $2084 \pm 62.7$ & ND & - \\
\hline Catechin/epicatechin & $272 \pm 5.9$ & $157 \pm 6.0$ & 42.4 & $64.1 \pm 3.84$ & $28.9 \pm 1.6$ & 55.0 \\
\hline Total flavan-3-ols & $6422 \pm 149.6$ & $2498 \pm 68.1$ & 61.1 & $3959 \pm 74.8$ & $924 \pm 10.2$ & 76.7 \\
\hline
\end{tabular}

${ }^{a}$ Data are expressed as mean $\pm \mathrm{SD}(n=3)$ on a dry weight basis ( $\mu \mathrm{g} / \mathrm{g}$ of cowpea flour). Concentrations of glycosides or acyl-glycosides of flavonols were calculated from the standard curve of kaempferol, myricetin, quercetin, quercetin-3-O-rutinoside and quercetin 3-Oglucopyranoside; while those for flavan-3-ols were calculated from standard curve of catechin and procyanidin B2; but were all adjusted on the basis of molecular-weight differences. ${ }^{b} \mathrm{ND}=$ not detectable. 
Table 11. Compositions ( $\mu \mathrm{g} / \mathrm{g}$ of cowpea flour) and effect of boiling on flavonols and flavan-3ols in red cowpea varieties ${ }^{a}$

\begin{tabular}{|c|c|c|c|c|c|c|}
\hline \multirow[b]{4}{*}{ Compound } & \multicolumn{6}{|c|}{ Red cowpea varieties } \\
\hline & \multicolumn{3}{|c|}{$\underline{\text { IT82D-889 }}$} & \multicolumn{3}{|c|}{$\underline{\text { IT97K-1042-3 }}$} \\
\hline & \multicolumn{6}{|c|}{ Flavonol content ( $\mu \mathrm{g} / \mathrm{g}$ cowpea flour) } \\
\hline & Raw & Boiled & $\begin{array}{c}\% \\
\text { change }\end{array}$ & Raw & Boiled & $\begin{array}{c}\% \\
\text { change }\end{array}$ \\
\hline Quercetin-3-O-glucoside-4'-O-diglucoside & $106 \pm 7.9$ & $13.9 \pm 0.78$ & 86.9 & $24.0 \pm 3.12$ & $11.9 \pm 1.45$ & 50.4 \\
\hline Quercetin-3-O-digalactoside & $12.5 \pm 1.19$ & $\mathrm{ND}^{b}$ & - & ND & ND & - \\
\hline Quercetin-3-O-arabinosyldiglucoside & ND & ND & - & $93.0 \pm 3.89$ & ND & - \\
\hline Quercetin-3,7-diglucoside & ND & ND & - & ND & ND & - \\
\hline Quercetin-3-O-galactosylglucoside & $102 \pm 7.0$ & $35.2 \pm 0.71$ & 65.5 & $70.9 \pm 2.25$ & $30.5 \pm 0.68$ & 40.4 \\
\hline Quercetin-7-O-glucoside & $144 \pm 3.1$ & $56.7 \pm 0.31$ & 60.6 & $90.0 \pm 2.48$ & $82.4 \pm 2.18$ & 8.4 \\
\hline Quercetin-3-O-diglucoside & $313 \pm 6.2$ & $118 \pm 2.2$ & 62.3 & $334 \pm 5.8$ & $123 \pm 6.16$ & 63.2 \\
\hline Quercetin & $5.71 \pm 0.56$ & ND & - & ND & ND & - \\
\hline Quercetin-3-(6"-malonoyl)-glucoside & $46.5 \pm 3.10$ & $22.2 \pm 0.68$ & 52.3 & $120 \pm 4.1$ & ND & - \\
\hline Subtotal quercetin & $729 \pm 29.1$ & $246 \pm 4.7$ & 66.3 & $732 \pm 21.6$ & $248 \pm 10.5$ & 64.2 \\
\hline Myricetin-3-O-diglucoside & $129 \pm 6.2$ & $88.6 \pm 3.22$ & 31.3 & $138 \pm 5.6$ & $93.5 \pm 6.13$ & 32.3 \\
\hline Myricetin-3-O-glucoside & ND & ND & - & $71.4 \pm 2.39$ & $68.7 \pm 4.87$ & 3.8 \\
\hline Subtotal myricetin & $129 \pm 6.2$ & $88.6 \pm 3.22$ & 31.3 & $209 \pm 7.99$ & $162 \pm 11.0$ & 22.6 \\
\hline \multirow[t]{2}{*}{ Total flavonols } & $858 \pm 35.3$ & $335 \pm 7.9$ & 61.1 & $941 \pm 29.6$ & $410 \pm 21.5$ & 56.4 \\
\hline & \multicolumn{6}{|c|}{ Flavan-3-ols content ( $\mu \mathrm{g} / \mathrm{g}$ cowpea flour) } \\
\hline Catechin-3-O-glucoside & $2199 \pm 8.3$ & $1118 \pm 7.8$ & 49.2 & $2264 \pm 10.3$ & ND & - \\
\hline Procyanidin dimer B-type & ND & ND & - & $3388 \pm 69.9$ & ND & - \\
\hline Catechin/epicatechin & ND & ND & - & $86.1 \pm 4.27$ & ND & - \\
\hline Procyanidin trimer T2 & ND & ND & - & $3833 \pm 61.9$ & ND & - \\
\hline Total flavan-3-ols & $2199 \pm 8.3$ & $1118 \pm 7.8$ & 49.2 & $9571 \pm 146.4$ & - & - \\
\hline
\end{tabular}

${ }^{a}$ Data are expressed as mean \pm SD $(n=3)$ on a dry weight basis ( $\mu \mathrm{g} / \mathrm{g}$ of cowpea flour). Concentrations of glycosides or acyl-glycosides of flavonols were calculated from the standard curve of myricetin, quercetin, quercetin-3-O-rutinoside and quercetin 3-O-glucopyranoside; while those for flavan-3-ols were calculated from standard curve of catechin and procyanidin $\mathrm{B} 2$; but were all adjusted on the basis of molecular-weight differences. ${ }^{b} \mathrm{ND}=$ not detectable. 
The three most dominant quercetin derivatives identified in the raw cowpea samples were quercetin-3,7-diglucoside, quercetin-3-O-galactosylglucoside and quercetin-3-O-diglucoside (Tables 10 - 14). The average amount of quercetin derivatives were highest in the red varieties (Table 11) and lowest in the light brown 09FCV-CC27M variety (Table 12). However, the average amounts of the acylated quercetin derivatives were generally low, ranging from $9.1 \mu \mathrm{g} / \mathrm{g}$ of quercetin-3-(6"diacetoyl)-diglucoside found in golden brown IT84S 2246 variety to $120 \mu \mathrm{g} / \mathrm{g}$ of quercetin-3-(6"-malonoyl)-glucoside in the red IT97K-1042-3 cowpea variety. How growth environment affects synthesis and accumulation of these flavonols is unknown.

Myricetin derivatives (mainly myricetin-3-O-glucoside and myricetin-3-Odiglucoside) were only detected in the black, red and green cowpea varieties (Tables 10 - 14). The average myricetin content was highest in the red IT97K-1042-3 (210 $\mu \mathrm{g} / \mathrm{g})$ variety (Table 11), and lowest in the green TX2028-1-3-1 variety (24.8 $\mu \mathrm{g} / \mathrm{g})$ (Table 14). From a quantitative point of view, the average myricetin content in raw cowpea varieties studied were higher than those reported in raw cool season food legumes such as green pea (36.2 $\mu \mathrm{g} / \mathrm{g})$, yellow pea (36.7 $\mu \mathrm{g} / \mathrm{g})$, chick pea (32.1 $\mu \mathrm{g} / \mathrm{g})$ and lentils (33.3 $\mu \mathrm{g} / \mathrm{g})(71)$.

In conclusion, flavonol compounds of the 10 cowpea varieties studied were found to be dominated by quercetin derivatives, followed by myricetin derivatives. The red phenotype seems to synthesize higher levels of flavonols compared to the other varieties. Five acyl derivatives of quercetin were also identified and were present in small quantities. From this study, we found that the different concentrations of the 
identified flavonols and the diversity in peak distribution on chromatograms of the 10 cowpea samples suggest that the identities of the varieties can be described by the flavonol profiles. Total flavonol contents for all the cowpea varieties ranged from 270 to $941 \mu \mathrm{g} / \mathrm{g}$ of flour, suggesting cowpea is a significant source of flavonols in the diet.

\subsection{Effect of boiling on flavonol content in cowpea}

Boiling significantly reduced total flavonol content in all the cowpea varieties. The greatest loss in total flavonol content was observed in the black IT95K-1105-5 (77.3\% reduction) (Table 10). Our results are different from earlier report on green beans, which was not much affected by thermal processing (162). The differences may be attributed to the difference between dry cowpea seeds in our study and fresh beans used in the literature. Boiling was found to significantly reduce the concentrations of individual flavonols in cowpeas, and in some cases reduced their concentrations to undetectable levels (Tables 10 - 14). The changes, however, depended upon the variety of cowpea, as well as the levels of individual flavonols in the raw samples. Thermal processing has also been shown to reduce levels of myricetin in green peas, yellow pea and chick pea (71); and kaempferol-3-glucoside and kaempferol-3-acetylglucoside in pinto beans (130).

In general, the flavonols were more stable than anthocyanins after boiling. This suggests that the flavonol aglycones are not readily transformed into their intermediate 
thermolabile chalcones which permit cleavage into phloroglucinaldehyde, protocatechuic acid and 4-hydroxybenzoic acid.

\subsection{Flavan-3-ol content in cowpeas}

On average, the light brown phenotype had the highest total flavan-3-ol content, followed by the red, black and then golden brown phenotypes (Tables $10-13)$. The green TX2028-1-3-1 and white Early Acre did not contain detectable levels of flavan-3ols (Table 14). In terms of varieties, the light brown 09FCV-CC27M had the highest flavan-3-ols content $(13,664 \pm 184.5 \mu \mathrm{g} / \mathrm{g})$, followed by golden brown Ife Brown $(9,877$ $\pm 152.8 \mu \mathrm{g} / \mathrm{g})$ and red IT97K-1092-1 (9,571 $\pm 146.4 \mu \mathrm{g} / \mathrm{g})$. Moderate levels of flavan-3ols were found in the black (IT95K-1105-5 and IT98K-1092-1) (Table 10) and light brown IAR-48 cowpea varieties (Table 12).

Catechin-3-O-glucoside was the most dominant flavan-3-ol compound detected, and was particularly higher in the golden brown IT84S-2246 (Table 13), red (IT82D889 and IT97K-1042-3) (Table 11) and black IT95K-1105-5 cowpea varieties (Table 10). However, proanthocyanidins polymers with a mean degree of polymerization (mDP) of 7 - 9 were reportedly predominant in lentil seed coat followed by oligomers (mDP of $4-5)(136)$. We also observed that polymerization (mDP of 3) was a common feature in most of the flavan-3-ol compounds detected in this study, particularly procyanidin trimers T2 and C1 (Figure 6). Our method did not allow for detection of DP

$>$ 4.0. The highest amounts of trimer T2 was found in the light brown 09FCV-CC27M 
cowpea variety $(3,950 \pm 69.2 \mu \mathrm{g} / \mathrm{g})$ (Table 12), followed by golden brown Ife Brown, red IT97K-1092-1 and light brown IAR-48 varieties. On the other hand, procyanidin trimer C1 content in the light brown 09FCV-CC27M and IAR-48 varieties were 1,187 and 2,613 $\mu \mathrm{g} / \mathrm{g}$, respectively (Table 12). These are the only two cowpea varieties in which trimer C1 was found. Black beans have also been reported to contain procyanidin trimers C1 and C2, as well as B2 dimer (62). Proanthocyanidin oligomers containing (epi)gallocatechin have also been reported in black beans (163). Procyanidin dimers and trimers in adzuki beans reportedly ranges from 15.9 to $213 \mathrm{mg} / \mathrm{g}$ dry weight basis (135). Seed coats of lentils have also been shown to contain highly polymerized flavan-3-ols $(65-75 \%)$ and very little in monomeric forms $(<2 \%)(136)$. The levels of procyanidin B2, B3 and procyanidin tetramer in lentils have been reported to range from 0.1 to 0.5 mg/100 g dry weight basis (60). In this study, we also found B-type procyanidin dimer, which was particularly higher in the light brown 09FCV-CC27M sample compared to the other cowpea varieties (Table 12).

Catechin was also reported as a major flavan-3-ol in the raw cool season food legumes (71). The levels of catechin in green pea, yellow pea, chickpea and lentils were found as 205, 281, 1,509 and $696 \mu \mathrm{g} / \mathrm{g}$, respectively; whereas epicatechin was only found in chickpea (146 $\mu \mathrm{g} / \mathrm{g})$ and lentils $(3,819 \mu \mathrm{g} / \mathrm{g})$. Chickpea and lentils also contained high levels of epigallocatechin and epigallocatechin-gallate (10.1 - 3,819 $\mu \mathrm{g} / \mathrm{g})$. In our study, the highest concentration of catechin/epicatechin was found in the light brown 09FCV-CC27M variety (1090 $\mu \mathrm{g} / \mathrm{g}$ ) (Table 12) and the least in the black IT98K-1092-1 variety (64.1 $\mu \mathrm{g} / \mathrm{g})$ (Table 10). 
Table 12. Compositions ( $\mu \mathrm{g} / \mathrm{g}$ of cowpea flour) and effect of boiling on flavonols and flavan-3ols in light brown cowpea varieties ${ }^{a}$

\begin{tabular}{|c|c|c|c|c|c|c|}
\hline \multirow[b]{4}{*}{ Compound } & \multicolumn{6}{|c|}{ Light Brown cowpea varieties } \\
\hline & \multicolumn{3}{|c|}{$\underline{\text { IAR-48 }}$} & \multicolumn{3}{|c|}{ 09FCV-CC-27M } \\
\hline & \multicolumn{6}{|c|}{ Flavonol content ( $\mu \mathrm{g} / \mathrm{g}$ cowpea flour) } \\
\hline & Raw & Boiled & $\begin{array}{c}\% \\
\text { change }\end{array}$ & Raw & Boiled & $\begin{array}{c}\% \\
\text { change }\end{array}$ \\
\hline $\begin{array}{l}\text { Quercetin-3- } O \text {-glucoside-4'-O- } \\
\text { diglucoside }\end{array}$ & $27.5 \pm 1.74$ & $\mathrm{ND}^{b}$ & - & ND & ND & - \\
\hline Quercetin-3-O-arabinosyldiglucoside & $75.4 \pm 4.88$ & $28.1 \pm 0.12$ & 62.7 & $23.7 \pm 2.90$ & $18.5 \pm 1.31$ & 21.9 \\
\hline Quercetin-3,7-diglucoside & $314 \pm 3.2$ & $180 \pm 3.9$ & 42.6 & $90.7 \pm 2.83$ & $36.1 \pm 0.75$ & 60.2 \\
\hline Quercetin-3-O-galactosylglucoside & ND & ND & - & $83.0 \pm 8.70$ & $64.8 \pm 4.59$ & 21.9 \\
\hline Quercetin-3-O-galactoside & $17.7 \pm 1.91$ & ND & - & ND & ND & - \\
\hline Quercetin-3-O-glucoside & $6.8 \pm 0.32$ & ND & - & ND & ND & - \\
\hline Quercetin-3-O-diglucoside & $212 \pm 5.0$ & $102 \pm 7.0$ & 51.8 & $16.1 \pm 2.77$ & $11.4 \pm 0.50$ & 29.2 \\
\hline Quercetin-3-O-arabinosylglucoside & ND & ND & - & $24.0 \pm 3.06$ & $10.7 \pm 1.48$ & 55.4 \\
\hline Quercetin-3-(6"-feruloyl)-diglucoside & $21.5 \pm 1.57$ & ND & - & ND & ND & - \\
\hline Quercetin-3-(6"-diacetoyl)-diglucoside & $20.0 \pm 0.32$ & $11.9 \pm 1.07$ & 40.6 & ND & ND & - \\
\hline Quercetin-3-O-glucosylrhamnoside & ND & ND & - & $88.0 \pm 3.38$ & $48.2 \pm 1.24$ & 45.2 \\
\hline Quercetin-3-O-galactosylrhamnoside & ND & ND & - & $96.0 \pm 4.73$ & $42.8 \pm 1.64$ & 55.4 \\
\hline Subtotal quercetin & $695 \pm 18.9$ & $322 \pm 12.1$ & 53.7 & $422 \pm 28.4$ & $233 \pm 11.5$ & 44.8 \\
\hline Kaempferol-3-O-diglucoside & $13.75 \pm 0.87$ & ND & - & ND & ND & - \\
\hline Subtotal kaempferol & $13.75 \pm 0.87$ & ND & - & ND & ND & - \\
\hline \multirow[t]{2}{*}{ Total flavonols } & $709 \pm 19.8$ & $322 \pm 12.09$ & 54.5 & $422 \pm 28.4$ & $233 \pm 11.5$ & 44.8 \\
\hline & \multicolumn{6}{|c|}{ Flavan-3-ols content ( $\mu \mathrm{g} / \mathrm{g}$ cowpea flour) } \\
\hline Catechin-3-O-glucoside & $1977 \pm 10.6$ & $1188 \pm 6.3$ & 39.9 & $2023 \pm 2.7$ & $497 \pm 4.5$ & 75.4 \\
\hline Procyanidin dimer B-type & $919 \pm 45.2$ & $425 \pm 59.0$ & 53.8 & $3788 \pm 69.2$ & $1727 \pm 69.9$ & 54.4 \\
\hline Catechin/epicatechin & $703 \pm 1.67$ & $521 \pm 9.2$ & 25.8 & $1090 \pm 9.9$ & $917 \pm 7.4$ & 15.9 \\
\hline Procyanidin trimer T2 & $1443 \pm 43.7$ & $1080 \pm 16.0$ & 25.2 & $3950 \pm 69.2$ & $2801 \pm 32.8$ & 16.4 \\
\hline Procyanidin trimer $\mathrm{C} 1$ & $1187 \pm 53.2$ & ND & - & $2613 \pm 33.5$ & $2008 \pm 37.9$ & 44.4 \\
\hline Procyanidin tetramer A-type & $601 \pm 48.9$ & ND & - & ND & ND & - \\
\hline Total flavan-3-ols & $6830 \pm 203.3$ & $2214 \pm 90.5$ & 71.7 & $13464 \pm 184.5$ & $8950 \pm 152.5$ & 35.4 \\
\hline
\end{tabular}

${ }^{a}$ Data are expressed as mean \pm SD $(n=3)$ on a dry weight basis ( $\mu \mathrm{g} / \mathrm{g}$ of cowpea flour). Concentrations of glycosides or acyl-glycosides of flavonols were calculated from the standard curve of kaempferol, myricetin, quercetin, quercetin-3-O-rutinoside and quercetin 3-Oglucopyranoside; while those for flavan-3-ols were calculated from standard curve of catechin and procyanidin B2; but were all adjusted on the basis of molecular-weight differences. ${ }^{b} \mathrm{ND}=$ not detectable. 
Table 13. Compositions ( $\mu \mathrm{g} / \mathrm{g}$ of cowpea flour) and effect of boiling on flavonols and flavan-3ols in golden brown cowpea varieties ${ }^{a}$

\begin{tabular}{|c|c|c|c|c|c|c|}
\hline \multirow[b]{4}{*}{ Compound } & \multicolumn{6}{|c|}{ Golden Brown cowpea varieties } \\
\hline & \multicolumn{3}{|c|}{ IFE BROWN } & \multicolumn{3}{|c|}{$\underline{\text { IT84S } 2246}$} \\
\hline & \multicolumn{6}{|c|}{ Flavonol content ( $\mu \mathrm{g} / \mathrm{g}$ cowpea flour) } \\
\hline & Raw & Boiled & $\begin{array}{c}\% \\
\text { change }\end{array}$ & Raw & Boiled & $\begin{array}{c}\% \\
\text { change }\end{array}$ \\
\hline $\begin{array}{l}\text { Quercetin-3-O-glucoside-4'- } \\
\text { diglucoside }\end{array}$ & $\mathrm{ND}$ & $\mathrm{ND}^{b}$ & - & $14.9 \pm 2.24$ & $14.3 \pm 0.17$ & 4.03 \\
\hline Quercetin-3-O-arabinosyldiglucoside & $40.9 \pm 8.24$ & ND & - & $91.9 \pm 4.67$ & $46.6 \pm 2.40$ & 49.2 \\
\hline Quercetin-3-O-digalactoside & $32.4 \pm 6.25$ & ND & - & $16.1 \pm 1.27$ & ND & - \\
\hline Quercetin-3,7-diglucoside & ND & ND & - & $21.6 \pm 2.86$ & $11.3 \pm 0.86$ & 47.7 \\
\hline Quercetin-3-O-galactosylglucoside & $177 \pm 4.5$ & $31.2 \pm 1.04$ & 82.4 & $188 \pm 4.12$ & $88.3 \pm 3.87$ & 53.0 \\
\hline Quercetin-3-O-diglucoside & $148 \pm 2.1$ & $102 \pm 0.20$ & 31.1 & $157 \pm 5.65$ & $10.3 \pm 0.05$ & 93.4 \\
\hline Quercetin-3-(6"-feruloyl)-diglucoside & $30.4 \pm 4.66$ & $14.4 \pm 4.43$ & 52.7 & ND & ND & - \\
\hline $\begin{array}{l}\text { Quercetin-3-(6"-diacetoyl)- } \\
\text { diglucoside }\end{array}$ & $20.2 \pm 2.76$ & $11.4 \pm 2.01$ & 43.3 & $9.1 \pm 1.31$ & ND & - \\
\hline $\begin{array}{l}\text { Quercetin-3-(6"-sinapoyl)- } \\
\text { diglucoside }\end{array}$ & $10.1 \pm 1.86$ & ND & - & ND & ND & - \\
\hline Subtotal quercetin & $459 \pm 30.4$ & $159 \pm 7.68$ & 65.4 & $499 \pm 22.1$ & $171 \pm 7.4$ & 67.6 \\
\hline Kaempferol-3-O-diglucoside & $12.2 \pm 1.86$ & $5.76 \pm 1.77$ & 52.8 & $12.9 \pm 2.50$ & ND & - \\
\hline Subtotal kaempferol & $12.2 \pm 1.86$ & $5.76 \pm 1.77$ & 52.8 & $12.9 \pm 2.50$ & ND & - \\
\hline \multirow[t]{2}{*}{ Total flavonols } & $471 \pm 32.3$ & $165 \pm 9.5$ & 64.9 & $512 \pm 24.6$ & $171 \pm 7.4$ & 66.6 \\
\hline & \multicolumn{6}{|c|}{ Flavan-3-ols content ( $\mu \mathrm{g} / \mathrm{g}$ cowpea flour) } \\
\hline Catechin-3-O-glucoside & $877 \pm 7.0$ & $550 \pm 7.3$ & 37.3 & $\begin{array}{c}1610 \pm \\
13.9\end{array}$ & $80.5 \pm 5.70$ & 95.0 \\
\hline Procyanidin dimer B-type & $1855 \pm 59.0$ & $1550 \pm 48.1$ & 16.4 & ND & ND & - \\
\hline Procyanidin trimer T2 & $2948 \pm 37.2$ & $1665 \pm 52.5$ & 43.5 & ND & ND & - \\
\hline $\begin{array}{l}\text { Procyanidin dimer-3-diglucoside-7- } \\
\text { glucoside }\end{array}$ & $4197 \pm 49.6$ & $2783 \pm 72.2$ & 33.7 & ND & ND & - \\
\hline Total flavan-3-ols & $9877 \pm 152.8$ & $6548 \pm 180.1$ & 33.7 & $\begin{array}{l}1610 \pm \\
13.9\end{array}$ & $80.5 \pm 5.70$ & 95.0 \\
\hline
\end{tabular}

${ }^{a}$ Data are expressed as mean \pm SD $(n=3)$ on a dry weight basis ( $\mu \mathrm{g} / \mathrm{g}$ of cowpea flour). Concentrations of glycosides or acyl-glycosides of flavonols were calculated from the standard curve of kaempferol, myricetin, quercetin, quercetin-3-O-rutinoside and quercetin 3-Oglucopyranoside; while those for flavan-3-ols were calculated from standard curve of catechin and procyanidin B2; but were all adjusted on the basis of molecular-weight differences. ${ }^{b} \mathrm{ND}=$ not detectable. 
The identification and quantification of detected flavan-3-ol derivatives in cowpeas, such as catechin-3-O-glucoside and procyanidin dimer-3,7-diglucoside, in addition to procyanidin trimer $\mathrm{C} 1$, procyanidin trimer $\mathrm{T} 2$ and procyanidin tetramer Atype provide new insight on the qualitative flavonoid composition in cowpea that may have health promoting effects in humans. Further characterization of flavan-3-ols in cowpea is still needed. Although the UPLC reversed phase C18 column used in this study had the ability to separate flavan-3-ol monomers and oligomers of equivalent MW into their isomers, the isolation and quantification of heterogeneous flavan-3-ol oligomers (e.g. hexamers; $\mathrm{mDP} \geq 5$ ) was not feasible. Because of possible overlapping of the isomers with different mean degrees of polymerization or stereochemistry, it is likely that the oligomeric proanthocyanidins co-eluted in some of the large unresolved peak (Figures 14A-1 and 14B-1; 19A-1 and 19B-1).

\subsection{Effect of boiling on flavan-3-ol content in cowpea}

Boiling was found to significantly reduce flavan-3-ol compounds in cowpeas (Tables 10 - 13). The greatest impact of processing on total flavan-3-ols was found in the golden brown IT84S-2246 (Table 13) and red IT97K-1042-3 (Table 11) cowpea varieties, in which boiling reduced most of their flavan-3-ol compounds to undetectable levels. A likely reason for lower flavan-3-ols contents in the boiled cowpea samples is that proanthocyanidins bind with peptides during cooking, forming insoluble complexes held together by hydrogen and/or hydrophobic bonding, thus decreasing their 
extractability. Similar interactions between proanthocyanidin and protein have been associated with haze formation in beer and apple juice (164).

Table 14. Compositions ( $\mu \mathrm{g} / \mathrm{g}$ of cowpea flour) and effect of boiling on flavonols in green (TX2028-1-3-1) and white (Early Acre) cowpea varieties ${ }^{a}$

\begin{tabular}{|c|c|c|c|c|c|c|}
\hline \multirow[b]{4}{*}{ Compound } & \multicolumn{6}{|c|}{ Green and White cowpea varieties } \\
\hline & \multicolumn{3}{|c|}{ TX2028-1-3-1 (GREEN) } & \multicolumn{2}{|c|}{ EARLY ACRE (WHITE) } & \multirow[b]{3}{*}{$\begin{array}{c}\% \\
\text { change }\end{array}$} \\
\hline & \multicolumn{5}{|c|}{ Flavonol content ( $\mu \mathrm{g} / \mathrm{g}$ cowpea flour) } & \\
\hline & Raw & Boiled & $\begin{array}{c}\% \\
\text { change }\end{array}$ & Raw & Boiled & \\
\hline Quercetin-3-O-triglucoside & $\mathrm{ND}^{b}$ & ND & - & $14.9 \pm 2.24$ & $14.3 \pm 0.17$ & 4.02 \\
\hline $\begin{array}{l}\text { Quercetin-3-O-glucoside-4'-O- } \\
\text { diglucoside }\end{array}$ & $35.2 \pm 2.82$ & ND & - & $17.4 \pm 1.57$ & $11.7 \pm 0.53$ & 32.8 \\
\hline $\begin{array}{l}\text { Quercetin-3-O- } \\
\text { arabinosyldiglucoside }\end{array}$ & $60.4 \pm 4.50$ & $52.4 \pm 2.19$ & 13.2 & $11.4 \pm 0.91$ & ND & - \\
\hline Quercetin-3-O-digalactoside & $22.9 \pm 1.56$ & $11.9 \pm 0.23$ & 48.0 & $48.5 \pm 6.25$ & $21.1 \pm 0.23$ & 56.6 \\
\hline Quercetin-3,7-diglucoside & $91.8 \pm 7.82$ & $59.4 \pm 1.13$ & 35.3 & $31.4 \pm 9.22$ & $20.3 \pm 0.33$ & 35.4 \\
\hline Quercetin-3-O-galactosylglucoside & $34.6 \pm 3.14$ & ND & - & $33.7 \pm 1.12$ & ND & - \\
\hline Quercetin-3-O-galactoside & ND & ND & - & $5.0 \pm 0.70$ & ND & - \\
\hline Quercetin-7-O-glucoside & $28.7 \pm 3.37$ & $9.5 \pm 0.74$ & 66.8 & ND & ND & - \\
\hline Quercetin-3-O-diglucoside & $42.1 \pm 1.39$ & $21.0 \pm 1.06$ & 50.1 & $77.2 \pm 2.80$ & $37.1 \pm 0.42$ & 51.9 \\
\hline $\begin{array}{l}\text { Quercetin-3-(6"-feruloyl)- } \\
\text { diglucoside }\end{array}$ & $11.5 \pm 1.27$ & ND & - & $14.5 \pm 1.64$ & ND & - \\
\hline Subtotal quercetin & $327 \pm 25.9$ & $154 \pm 5.4$ & 53.2 & $254 \pm 26.5$ & $105 \pm 1.7$ & 52.8 \\
\hline Myricetin-3-O-glucoside & $24.8 \pm 0.92$ & ND & - & ND & ND & - \\
\hline Subtotal myricetin & $24.8 \pm 0.92$ & ND & - & ND & ND & - \\
\hline Kaempferol-3-O-diglucoside & ND & ND & - & $15.8 \pm 2.3$ & $13.5 \pm 0.7$ & 14.6 \\
\hline Subtotal kaempferol & ND & ND & - & $15.8 \pm 2.3$ & $13.5 \pm 0.7$ & 14.6 \\
\hline Total flavonols & $352 \pm 26.8$ & $154 \pm 5.4$ & 56.3 & $270 \pm 28.8$ & $119 \pm 2.4$ & 55.9 \\
\hline
\end{tabular}

${ }^{a}$ Data are expressed as mean $\pm \mathrm{SD}(n=3)$ on a dry weight basis ( $\mu \mathrm{g} / \mathrm{g}$ of cowpea flour). Concentrations of glycosides or acyl-glycosides of flavonols were calculated from the standard curve of kaempferol, myricetin, quercetin, quercetin-3-O-rutinoside and quercetin-3-Oglucopyranoside; while those for flavan-3-ols were calculated from standard curve of catechin and procyanidin B2; but were all adjusted on the basis of molecular-weight differences. ${ }^{b} \mathrm{ND}=$ not detectable. 
In general, changes in flavan-3-ols content in cowpea after boiling depended on cowpea variety. Since cowpea must be cooked before consumption, these observations suggest that proper cooking methods should be chosen to preserve these flavonoids and improve health-promoting potential of processed cowpea foods. The deleterious effect of heat on flavan-3-ols was also observed by Xu and Chang (130) who reported that regular boiling significantly $(p<0.05)$ decreased flavan-3-ols (catechin, epicatechin and epicatechin-gallate) contents in black beans as compared to the raw black beans.

\subsection{Flavonoid content in cowpeas}

Among all the samples, the light brown phenotype had the highest average flavonoid content, followed by the black, red, golden brown, green and then the white varieties (Table 15). The phenotypic differences in total flavonoid content indicate that seed coat color affect synthesis and/or accumulation of certain groups of flavonoids (Tables 10 - 14). For example, the predominant group in the light brown 09FCVCC27M variety was the flavan-3-ols, contributing $97 \%$ of the total flavonoid content (Tables 12 and 15); anthocyanins contributed 23.5\% of the total flavonoid content in the black IT95K-1105-5 variety (Tables 4 and 15); and flavonols contributed 30.8\% of the total flavonoid content in the red IT97K-1042-3 variety (Tables 11 and 15). However, there were also significant differences in the total flavonoid content between two varieties having the same seed coat color, especially in the light brown IAR-48 and 09FCV-CC-27M (Table 15). In general, the light brown 09FCV-CC-27M contained the 
highest flavonoid content; followed by the black IT95K-1105-5 and red IT97K-1042-3 variety (Table 15).

Table 15. Flavonoid content of raw cowpea samples. See appendix A for photos of the cowpea phenotypes studied.

\begin{tabular}{lcll}
\hline & $\begin{array}{c}\text { Seed weight } \\
(\boldsymbol{g} / \mathbf{1 0 0 g} \text { seeds) }\end{array}$ & Phenotype & ${\text { Flavonoid content }(\boldsymbol{\mu g} / \mathbf{g})^{\ddagger}}^{\dagger}$ \\
& $23.4 \pm 0.37$ & Black & $8915 \pm 197.4$ \\
IT95K-1105-5 $^{a}$ & $11.6 \pm 035$ & Black & $6111 \pm 138.9$ \\
IT98K-1092-1 $^{a}$ & $11.3 \pm 0.17$ & Red & $1227 \pm 55.3$ \\
IT82D-889 $^{b}$ & $13.1 \pm 0.20$ & Red & $3057 \pm 43.6$ \\
IT97K-1042-3 $^{b}$ & $21.6 \pm 0.45$ & Green & $10512 \pm 176.0$ \\
TX2028-1-3-1 $^{a}$ & $22.6 \pm 0.22$ & Light brown & $8539 \pm 223.1$ \\
IAR-48 $^{b}$ & $14.9 \pm 0.40$ & Light brown & $13886 \pm 232.9$ \\
09FCV-CC27M $^{b}$ & $15.8 \pm 0.16$ & Golden brown & $10348 \pm 185.1$ \\
IFE BROWN $^{b}$ & $17.5 \pm 0.08$ & Golden brown & $2122 \pm 38.5$ \\
IT84S-2246 $^{b}$ & $11.6 \pm 0.16$ & White & $270 \pm 28.8$ \\
EARLY ACRE $^{c}$ & & &
\end{tabular}

${ }^{\dagger}$ Seed weight expressed as mean \pm SD of triplicate weights of 100 seeds. ${ }^{*}$ Sum of HPLC quantified anthocyanins, flavonols and flavan-3-ols (up to tetramers). ${ }^{a}$ Contain anthocyanins, flavonols and flavan-3-ols; ${ }^{b}$ Contain flavonols and flavan-3-ols; ${ }^{c}$ Contain flavonols only.

\subsection{Conclusions}

From this study, seed-coat color may be a good indicator of the accumulation of flavonoids in cowpeas. Cowpea with dark-colored seed coats, especially the black varieties contain high levels of anthocyanins, whereas the red seed-coated varieties contain high levels of flavonols. The red, black, light brown and golden brown varieties were also found to contain high concentration of flavan-3-ols. Levels of individual phenolic compounds were variety-dependent rather than phenotype-dependent. 
Eight anthocyanins and 72 other phenolic compounds in cowpea seeds were identified and characterized using LC coupled with Tandem Quadrupole e $\lambda$ Detector (TQD). We found, for the first time, petunidin-3-O-galactoside in black and green cowpea phenotypes. The concentrations of the anthocyanins identified in the black and green cowpea varieties were in the following order: delphinidin-3-O-glucoside > cyanidin-3-O-glucoside $>$ petunidin-3-O-glucoside $>$ malvidin-3-O-glucoside $>$ delphinidin-3-O-galactoside > cyanidin-3-O-galactoside > peonidin-3-O-glucoside > petunidin-3-O-galactoside. Relatively higher amounts of these compounds were found in the black IT95K-1105-1, followed by black IT98K-1092-1 and then green TX2028-1-31. There were no detectable levels of pelargonidin and its derivatives in all cowpea samples analyzed.

In the case of flavonols, quercetin and its derivatives were the major constituents, followed by myricetin derivatives. The highest amount of quercetin derivatives was found in the red varieties. The three most dominant quercetin derivatives identified in the raw cowpea samples were quercetin-3,7-diglucoside, quercetin-3-Ogalactosylglucoside and quercetin-3-O-diglucoside. The light brown 09FCV-CC27M variety contained the least amount of quercetin compounds. On the other hand, myricetin was only detected in the black, red and green cowpea varieties. Myricetin in cowpeas was mainly in the form of myricetin-3-O-glucoside and myricetin-3-O-diglucoside; and were highest in red IT97K-1042-3 sample.

In the case of flavan-3-ols, the highest amounts were detected in the light brown 09FCV-CC27M cowpea variety compared to the other samples. Within the light brown 
phenotype, the 09FCV-CC27M sample contained twice as much flavan-3-ols as IAR-48 variety, whereas the later had four times as much flavonols than the former; suggesting one synthetic pathway is sacrificed for the other in light-brown phenotypes. The green TX2028-1-3-1 and white Early Acre cowpea varieties did not contain detectable levels of flavan-3-ols. Catechin-3-O-glucoside was found as the major flavan-3-ol monomer in cowpea. Polymeric procyanidins made up a large proportion of the cowpea phenolics.

We found, for the first time, acylated derivatives of flavonols in cowpea, specifically malonoyl-, sinapoyl-, feruloyl-, acetoyl- and succinoyl- derivatives of quercetin glycosides, as well as flavononols (taxifolin derivatives), flavanones (eriodictyol derivatives), dihydrochalcones (phloretin derivatives), phenolic acids and phenolic aldehyde. The presence of these compounds in the seeds may contribute to the high antioxidant activity observed for cowpea seeds. The unidentified peaks and information on the position, type and stereochemistry of their substituent groups would require the use of NMR technology. However, this would require extensive sample purification as well as several orders of magnitude more analyte than the low concentrations used in HPLC-MS analysis.

Boiling significantly reduced the levels of individual and total flavonoid contents in cowpea. The decrease in flavonoid content after boiling is related to the losses of individual phenolic compounds, which could be resulting in the formation of other phenolics such as protocatechuic acid, 4-hydroxybenzoic acid and phloroglucinaldehyde. Since these heat-induced degradation products are structurally different from their precursor aglycones, they cannot compensate for the bioactivity of their precursors, 
which may lead to lower antioxidant activity in the boiled samples even though these compounds would still be biologically potent. Thus, proper cooking methods should be chosen to preserve flavonoids in cowpea in order to improve health-promoting potential of processed cowpea foods.

In summary, cowpea is a good source of flavonoids; however, great variability in flavonoid content exists within and among cowpea phenotypes. In this study, we show that when specific flavonoids are required in cowpea diets, the black seed-coated cowpea is a good source of anthocyanins; red seed-coated cowpea is a good source of quercetin; and, light brown seed-coated 09FCV-CC27M variety is a good source of flavan-3-ols. Therefore, we recommend that the use of cowpea as a source of flavonoids in diets should consider the differences in flavonoid levels among different cowpea varieties. Since variety has an impact on important traits such as types of flavonoids synthesized, flavonoid content should be incorporated into cowpea breeding programs as a new trait for selection. Further studies are needed to address the effect of growth conditions on synthesis of individual flavonoids identified in this study and to validate the observed relationship between cowpea seed-coat color and their reported flavonoid profiles. 


\section{EFFECT OF BOILING ON THE ANTIOXIDANT PROPERTIES OF DIFFERENT COWPEA PHENOTYPES}

\subsection{Introduction}

Accumulation of flavonoids in legume seeds is restricted to the seed coat, and affects their antioxidant capacity (65). The phenolic compositions of beans comprise condensed tannins, anthocyanins, flavonols, as well as phenolic acids. Of these, condensed tannins are the predominant phenolic compounds found in legume seeds $(113,165)$. The importance of legume seed coat on antioxidant activity of legumes has been reported by several authors, and has been associated with high levels of tannins in dark colored species (114). Tannins are considered anti-nutritional since they negatively affect protein digestibility and Fe availability. Tannins are also superior at quenching free radicals than other flavonoids (166), suggesting that dehulling or decorticating of cowpeas (legumes) during processing for human consumption may lead to lower tannin content and improved protein digestibility but lower antioxidant activity. In addition, dark colored species of pulses such as beans (Phaseolus vulgaris L.) has also been associated with higher antioxidant activity than the white beans due to the presence of anthocyanins in the seed coat of the colored varieties (167).

The importance of polyphenolic antioxidants in the maintenance of health and protection from cardiovascular diseases, coronary heart disease and cancer is also raising interest among scientists, food manufacturers and consumers (168). 
Various processing methods have been shown to significantly reduce the health promoting phenolic compounds and antioxidant activities of legumes (131). Soaking and boiling of cowpeas are some of the traditional methods for preparing cowpeas for human consumption in the developing countries, whereas pressure cooking and steaming methods are mostly utilized in the developed countries. Such thermal processes improve flavor and palatability of cowpeas, and increase the bioavailability of nutrients by eliminating or inactivating antinutritional factors (e.g. trypsin inhibitor, saponins, agglutinins, lectins, flatulence causing oligosaccharides, etc) (119). However, thermal processing is detrimental to the phenolic composition of legumes. For example, the boiling process destroyed $40-60 \%$ of total phenol content in green peas, yellow peas and chickpeas; and $60 \%$ in lentils (71). The overall negative effect of thermal processing on antioxidant properties of polyphenols could be due to leaching of the water-soluble antioxidants, degradation of anthocyanins and other antioxidant components (75), interactions between natural and heat-induced antioxidants, and the combined effect of other oxidative reactions during cooking (169). The reduction in antioxidant activity by processing caused lower antiproliferation capacities of cool season food legumes against cancer cells compared to the raw samples (71).

Cowpea has many nutritional qualities that make it attractive as a functional food. However, even though processed cowpea is useful as human food, the effect of processing on their health-promoting properties such as total phenol content and antioxidant activities remain unexplored. Since antioxidant activity is a fundamental property associated with anti-inflammatory and anti-carcinogenic property of plant 
polyphenols, retention of antioxidant activity after commonly used processing methods for cowpea preparation such as boiling becomes important in ensuring that processed cowpea can still prevent inflammatory-related diseases. Therefore, to continue our investigation on thermal processing effects on cowpea phytochemicals, the present study was undertaken to further elucidate how boiling affects bioactive properties such as total phenol content, condensed tannin content and antioxidant activities of cowpea and correlate of these properties to cowpea variety and/or phenotype.

\subsection{Materials and methods}

\subsubsection{Cowpea samples}

The cowpeas presented in Table 2 were used in this investigation. Broken and damaged seeds, as well as foreign materials were removed from the samples. Cooking was conducted by soaking $100 \mathrm{~g}$ raw seeds in $450 \mathrm{~mL}$ distilled water for 12 hours at room temperature, and then boiling for 15 min [the average time adequate tactile texture (resistance to pressure between the fingers) was achieved] (122). Cooking time commenced when the cook-water started boiling. Both the boiled seeds and the soup were then frozen to $-80^{\circ} \mathrm{C}$ and then freeze-dried. Both raw and cooked freeze-dried cowpea seeds were ground using a coffee grinder (Cuisinart, Model DCG-20N series) to pass through a 60-mesh sieve. To determine the moisture content, triplicate samples were dried in an air circulated oven at $110^{\circ} \mathrm{C}$ until a constant weight was obtained. 


\subsubsection{Chemicals and reagents}

Folin-Ciocalteu reagent, ethanolamine, gallic acid monohydrate, vanillin reagent, (+)-catechin hydrate, fluorescein disodium, ABTS '(2,2 -azino-bis(3ethylbenzothiazoline-6-sulfonic acid), potassium persulfate, sodium fluorescein and 6hydroxy-2,5,7,8-tetramethylchroman-2-carboxylic acid (Trolox) were purchased from Sigma-Aldrich Chemical Co. (St. Louis, MO). AAPH (2,2 -Azobis(2-amidinopropane) dihydrochloride) were purchased from Wako Chemicals USA (Richmond, VA). All other chemicals were analytical grade.

\subsubsection{Determination of total phenols content (TPC)}

The total phenols content (TPC) was determined by a Folin-Ciocalteu assay described by Kaluza et al. (170) using gallic acid (GA) as the standard. Briefly, 0.1g of the raw and cooked ground cowpea samples were separately extracted with $10 \mathrm{~mL}$ of aqueous $70 \%$ acetone by continuously shaking on a Standard Analog Shaker (VWR, USA) at ambient temperature for 8 hours, centrifuged (10000 $g$-force for $10 \mathrm{~min}$ ) and the supernatants collected. The extractions were performed in triplicates for each individual cowpea variety.

The extracted aqueous samples $(0.1 \mathrm{~mL})$ were added into $1.1 \mathrm{~mL}$ distilled water then reacted with $0.4 \mathrm{~mL}$ Folin reagent and $0.9 \mathrm{~mL} 0.5 \mathrm{M}$ ethanolamine for $20 \mathrm{~min}$ at room temperature. The absorbances were measured using a UV-visible spectrophotometer (UV-2450, Shimadzu, Kyoto, Japan) at $600 \mathrm{~nm}$ against a reagent 
blank. The TPC values were expressed as micrograms of gallic acid equivalent per gram of cowpeas ( $\mu \mathrm{g} \mathrm{GAE/g)} \mathrm{on} \mathrm{dry} \mathrm{weight} \mathrm{basis} \mathrm{through} \mathrm{the} \mathrm{calibration} \mathrm{curve} \mathrm{of} \mathrm{gallic} \mathrm{acid.}$

\subsubsection{Determination of condensed tannins content (CTC)}

The condensed tannin content analysis were performed according to the method of Broadhurst and Jones (171) with slight modification. Approximately $200 \mathrm{mg}$ of the raw and cooked ground cowpea materials were separately weighed into capped centrifuge tubes and extracted with $8 \mathrm{~mL}$ of aqueous $70 \%$ acetone in $30^{\circ} \mathrm{C}$ water bath for 20 minutes. Triplicate extractions were perfomed for each cowpea variety. The tubes were vortexed at 5 min intervals during the incubation period, and were then centrifuged at $10000 \mathrm{~g}$-force for $10 \mathrm{~min}$. Two 1 -mL aliquots of the respective supernatants were transferred into clean test tubes and placed into the water bath. The absorption was measured using a UV-visible spectrophotometer (UV-2450, Shimadzu, Tokyo, Japan) at $500 \mathrm{~nm}$ against a methanol blank. The tannin content was expressed as milligrams of catechin equivalent per gram of cowpeas (mg CAE/g) on dry weight basis using the calibration curve of (+)-catechin.

\subsubsection{Determination of scavenging activity on 2,2'-azino-bis(3- ethylbenzothiazoline-6-sulphonic acid) radical cation (ABTS ${ }^{*+}$ )}

Three replicates of $0.1 \mathrm{~g}$ of the raw and cooked ground cowpea samples were separately extracted with $10 \mathrm{~mL}$ of aqueous $70 \%$ acetone by continuously shaking on a 
Standard Analog Shaker (VWR, USA) at room temperature for 4 hours and centrifuged (10000 $\mathrm{g}$-force for $10 \mathrm{~min}$ ). The supernatants were used to determine the scavenging activity of $\mathrm{ABTS}^{\cdot+}$ (172). A mixture of ABTS $(8 \mathrm{mM})$ and potassium persulfate $(3 \mathrm{mM})$ in distilled water was prepared and reacted at room temperature for 12 hours in the dark.

The ABTS working solution was prepared prior to the assay by diluting $10 \mathrm{~mL}$ ABTS stock solution with $290 \mathrm{~mL}$ of $\mathrm{pH} 7.4$ PBS buffer to an absorbance of 1.5 at 734 $\mathrm{nm}$. The aqueous sample solutions $(0.1 \mathrm{~mL})$ was added to the diluted ABTS working solution (2.9 mL) and reacted at ambient temperature for $30 \mathrm{~min}$. These were conducted in triplicates. The standards consisted of a series dilution of Trolox $(0,100,200,300$, $400,500,600,700,800,1000 \mu \mathrm{M}$ in methanol; $\mathrm{r}=0.99)$. The radical scavenging activity was expressed as $\mu \mathrm{mol}$ Trolox equivalent/g sample on dry weight basis [ $\mu$ molTE/g (db)].

\subsubsection{Oxygen Radical Absorbing Capacity (ORAC) Assay}

The ORAC assay was performed using a Biotek Synergy HT plate reader with automatic dispenser (Biotek, Winooski, VT) according to the method described by Talcott and Lee (173) with slight modifications. Approximately $100 \mathrm{mg}$ of raw and cooked ground cowpea samples were separately soaked in $10 \mathrm{~mL}$ of $70 \%$ aqueous acetone in triplicates for 3 hours at $4^{\circ} \mathrm{C}$ and then shaken for 3 hours at ambient temperature. After centrifuging, $4 \mathrm{~mL}$ aliquots of the supernatants were transferred into clean test tubes and stored at $4^{\circ} \mathrm{C}$ until analyzed. Prior to the analysis, the extracts were properly diluted with distilled water to fit within the linearity range of the Trolox standards. The diluted aqueous cowpea extracts (25 $\mu \mathrm{L})$ and Trolox standards (25 $\mu \mathrm{L})$ 
were analyzed in triplicates on a solid black 96 -well plate. The Trolox standards $(0,6.25$, 12.5, 25, 50 and $100 \mu \mathrm{M})$ and sodium fluorescein working solution $\left(4 \times 10^{-3} \mu \mathrm{M}\right)$ and 2,2'-azobis-2-methyl-propanimidamide dihydrochloride AAPH (153 mM) were prepared using PBS buffer (pH 7.4). Prior to incubation, $150 \mu \mathrm{L}$ of sodium fluorescein working solution was added to each well and the microplate (sealed with film) was incubated for $30 \mathrm{~min}$ in the plate reader set at $37^{\circ} \mathrm{C}$. After the incubation period, $25 \mu \mathrm{L}$ of the peroxyl generator (153 mM AAPH) was automatically dispensed into appointed wells according to the layout to initiate the oxidation reaction.

After shaking the microplate for 15 seconds, the plate reader begun taking the kinetic readings of the fluorescence changes at 1 min intervals for $90 \mathrm{~min}$. The area under the fluorescence decay curve (AUC) (excitation $485 \mathrm{~nm}$, emission $528 \mathrm{~nm}$ ) was used to calculate the antioxidant capacity; AUC $=0.5+(\mathrm{R} 2 / \mathrm{R} 1)+(\mathrm{R} 3 / \mathrm{R} 1)+(\mathrm{R} 4 / \mathrm{R} 1)+$ $\ldots+(\mathrm{Rn} / \mathrm{R} 1)$, where $\mathrm{R} 1$ corresponded to the fluorescence reading at the initiation of the reaction and $\mathrm{R} n$ was the fluorescence reading at the $n$th minute. The net AUC was determined by subtracting the AUC of the blank from that of a sample or standard. A standard curve for the Trolox was then obtained by plotting the net AUC of the series of Trolox standards versus their concentrations $(r=0.99)$. Trolox equivalent $(\mathrm{TE})$ of each sample was calculated by interpolating the net AUC of sample against the Trolox standard curve. The ORAC values of the cowpea extracts, analyzed in triplicates, were averaged and expressed as $\mu \mathrm{mol} \mathrm{TE/g} \mathrm{db.}$ 


\subsection{Statistical Analysis}

Data are reported as means \pm SD of 3 replicates; and analyzed using 2005 SAS (Version 9.1, SAS Inst. Inc., Cary, N.C., U.S.A.) with one-way Analysis of Variance (ANOVA). Post Hoc test (Fisher's LSD and Tukey-Kramer HSD) after ANOVA was used to compare treatments means. Significant levels were defined using $p<0.05$. Correlations between variables were performed using Pearson correlation tests.

\subsection{Results and discussion}

\subsubsection{Effect of seed coat color on total phenolic composition of cowpea}

The total phenolic content (TPC) and condensed tannin content (CTC) of the extracts from different varieties of cowpeas (raw and cooked) are presented in Table 16. Significant differences $(p<0.05)$ in TPC and CTC were found among the raw cowpea phenotypes as well as among the varieties.

Among all the samples, the black, red and light brown phenotypes had the highest TPC values (Table 16). This could be due to high amounts of anthocyanins, flavonols and flavan-3-ols in the black (Table 4), red (Table 11) and light brown varieties (Table 12), respectively. Specifically, the light brown 09FCV-CC27M variety had the highest TPC (14.9 mg GAE/g), followed by black and red varieties. The high TPC also correlated with high total flavonoid content reported for these varieties (Table 15). The Early Acre (white) and green TX2028-1-3-1 varieties had the lowest TPC (2.6 - $2.9 \mathrm{mg} \mathrm{GAE} / \mathrm{g}$ ) (Table 16); this could be due to the much lower levels of flavonol and 
no detectable flavan-3-ols in the white and green varieties compared to the other samples

(Table 14). In general, the CTC values also followed the same trend (Table 16).

Table 16. Levels of Total Phenolic Content (TPC) and Condensed Tannin Content (CTC) of raw and boiled cowpeas.* See appendix $\boldsymbol{A}$ for the photos of the cowpea phenotypes studied.

\begin{tabular}{llllllll}
\hline Cowpea variety & Phenotype & $\begin{array}{l}\text { TPC (raw) } \\
\text { (mg } \\
\text { GAE/g) }\end{array}$ & $\begin{array}{l}\text { TPC } \\
\text { (boiled) } \\
\text { (mg GAE/g) }\end{array}$ & $\begin{array}{l}\text { TPC } \\
\text { change }\end{array}$ & $\begin{array}{l}\text { CTC (raw) } \\
\text { (mg } \\
\text { CAE/g) }\end{array}$ & $\begin{array}{l}\text { CTC } \\
\text { (boiled) } \\
\text { (mg CAE/g) }\end{array}$ & $\begin{array}{l}\text { CTC } \\
\% \\
\text { change }\end{array}$ \\
\hline IT 98K-1092-1 & Black & $10.6 \mathrm{~b}$ & $6.7 \mathrm{~b}$ & 36.9 & $8.9 \mathrm{~b}$ & $3.1 \mathrm{c}$ & 65.5 \\
IT 95K-1105-5 & Black & $14.4 \mathrm{a}$ & $8.2 \mathrm{~b}$ & 43.5 & $11.8 \mathrm{a}$ & $4.2 \mathrm{~b}$ & 64.1 \\
IT 82D-889 & Red & $9.8 \mathrm{~b}$ & $6.7 \mathrm{~b}$ & 31.7 & $7.2 \mathrm{~b}, \mathrm{c}$ & $3.1 \mathrm{c}$ & 56.3 \\
IT 97K -1042-3 & Red & $10.3 \mathrm{~b}$ & $7.2 \mathrm{~b}$ & 30.4 & $6.5 \mathrm{c}$ & $3.0 \mathrm{c}$ & 54.2 \\
TX 2028-1-3-1 & Green & $2.9 \mathrm{~d}$ & $2.5 \mathrm{~d}$ & 13.7 & $0.9 \mathrm{~d}$ & $0.7 \mathrm{e}, \mathrm{d}$ & 27.0 \\
EARLY ACRE & White & $2.6 \mathrm{~d}$ & $2.7 \mathrm{~d}$ & +5.0 & $0.3 \mathrm{~d}$ & $0.5 \mathrm{e}$ & $+60.9 \dagger$ \\
IAR-48 & Light & $4.8 \mathrm{c}, \mathrm{d}$ & $4.0 \mathrm{c}, \mathrm{d}$ & 16.4 & $1.7 \mathrm{~d}$ & $0.9 \mathrm{e}, \mathrm{d}$ & 44.6 \\
09FCV-CC-27M & $\begin{array}{l}\text { Light } \\
\text { brown }\end{array}$ & $14.9 \mathrm{a}$ & $10.2 \mathrm{a}$ & 31.6 & $12.6 \mathrm{a}$ & $5.0 \mathrm{a}$ & 60.4 \\
IFE BROWN & $\begin{array}{l}\text { Golden } \\
\text { brown }\end{array}$ & $6.3 \mathrm{c}$ & $4.8 \mathrm{c}$ & 23.9 & $1.9 \mathrm{~d}$ & $1.0 \mathrm{~d}$ & 45.4 \\
IT 84S-2246 & $\begin{array}{l}\text { Golden } \\
\text { brown }\end{array}$ & $6.2 \mathrm{c}$ & $4.2 \mathrm{c}, \mathrm{d}$ & 32.4 & $1.7 \mathrm{~d}$ & $0.9 \mathrm{e}, \mathrm{d}$ & 45.9 \\
\hline
\end{tabular}

*Data are expressed as means of triplicate experiments on dry weight basis. †Values determined from measurements falling within margin of error. Values marked by the same letter in each column are not significantly different $(p<0.05)$.

The difference in TPC and CTC values within phenotypes were generally small; except light brown varieties (Table 16). This could be due to the significantly high levels of flavan-3-ol compounds in the light brown 09FCV-CC27M variety than in IAR48 sample (Table 12), suggesting that in cowpea, the association of dark-colors with higher phenolic content may be misleading since the 09FCV-CC27M variety is not dark- 
colored yet it contained the highest concentrations of total phenolics compared to the black and red seed coated varieties.

The average TPC and CTC values for the cowpea varieties analyzed appear to have the following trend: light brown $>$ black $>$ red $>$ golden brown $>$ green and white (Table 16), suggesting cowpea phenolic content and composition may be highly influenced by seed coat color. These observations appear to indicate that in cowpea, dark colored seed coat does not necessarily translate to higher total phenolic compositions.

\subsubsection{Effects of boiling on total phenolic composition of cowpeas}

Previous literature (174) reported that about 26 to 52\% of TPC could be lost with the soak water if discarded - a common practice in preparation of legumes for human consumption. Bressani and Elias (175) also observed that cooking and discarding the cooking water removes about 30 to $40 \%$ of phenolics from common beans. In this study, the soak water was eventually used to cook the seeds, and the remaining water after cooking were freeze-dried to avoid losing water soluble polyphenolics which may have leached into the cook water. As presented in Table 16, the TPC and CTC of cooked cowpea samples were significantly reduced $(p<0.05)$ compared to the respective original uncooked seeds, except for the Early Acre (white) variety.

Among all the phenotypes studied, the black cowpea seeds showed the greatest decrease in TPC and CTC as a result of boiling. In fact, about $36.9-43.5 \%$ of measurable TPC and 65.5 - 64.1\% of CTC for the black cowpea varieties (IT 98K-10921 and IT 95K-1105-5) were lost due to boiling (Table 16). Since these varieties also 
contained greater concentrations of anthocyanins (Table 4), it is possible that the reduction in polyphenolic compositions may be due to significant degradation of the heat labile anthocyanin pigments.

In general, the observed losses in TPC and CTC of cowpea polyphenolic composition following boiling (Table 16) could be due to instability of phenolic compounds to heat treatment causing extensive structural breakdown and transformations of the polyphenolics. Our results showed trends similar to those reported by $\mathrm{Xu}$ and Chang $(72,174)$ who demonstrated that thermal treatment decreased TPC in peas and black common beans (P. vulgaris) by $50-70 \%$ and $70-80 \%$, respectively; as well as by Xu and Chang (131) who reported that about $43-62 \%$ of TPC and $28-36 \%$ of CTC were decreased in cooked black soybean.

However, processing can also induce freeing of phenolics from their bound forms, cause formation of new compounds $(176,177)$, as well as alter extractability of phenolic compounds which may affect TPC. Turkmen et al. (70) reported that conventional cooking methods (boiling and steaming) significantly $(p<0.05)$ increased the TPC for pepper, broccoli and green beans. Steam cooking was also reported to increase the TPC for sweet potatoes by 2 - 13 times (178). In our study, we observed approximately 5\% increase in the TPC for boiled white cowpea (Table 16). Though this increase was not significant $(p<0.05)$, it confirms the ability of the thermal energy to enhance extractability of phenolics by releasing them from their bound forms. Earlier reports (131) also showed that thermal processing of yellow soybean, such as pressure steaming increased TPC by about 35\%; and that regular boiling, regular steaming and 
pressure boiling increased the total flavonoid content of soybeans by $60-90 \%$ and their CTC by $20-60 \%$. The increase in TPC could be due to the freeing of bound phenolic or release of phenolic-like substances from polymeric substances present in the cell wall upon thermal processing; which may also react with Folin-Ciocalteu reagent.

In summary, boiling significantly affected the TPC (14 - 44\% reduction) and CTC (27 - 66\% reduction) in cowpeas. This effect was variety-dependent. The final TPC and CTC after boiling depended on the initial distributions and compositions of individual compounds in the cowpea samples studied (Tables $4 ; 10$ - 14; 16).

\subsubsection{Antioxidant capacity of cowpeas with different seed coat colors}

Antioxidant activity assays are reaction-mechanism-dependent. The ORAC method uses the hydrogen atom transfer (HAT) mechanism based on how competitive an antioxidant is to trap free radicals; while ABTS uses the electron transfer (ET) mechanism involving non-competitive redox reaction between the antioxidant and oxidant $(179,180)$. These methods have different sensitivity and specificity properties, thus one method may not completely account for all the antioxidants in the extracts. Thus, the use of both HAT and ET assays provides a more reliable determination of the antioxidant activity profiles of the cowpea samples. The antioxidant activities of the raw and cooked cowpeas, based on ABTS and ORAC assays are presented in Figure 21. 

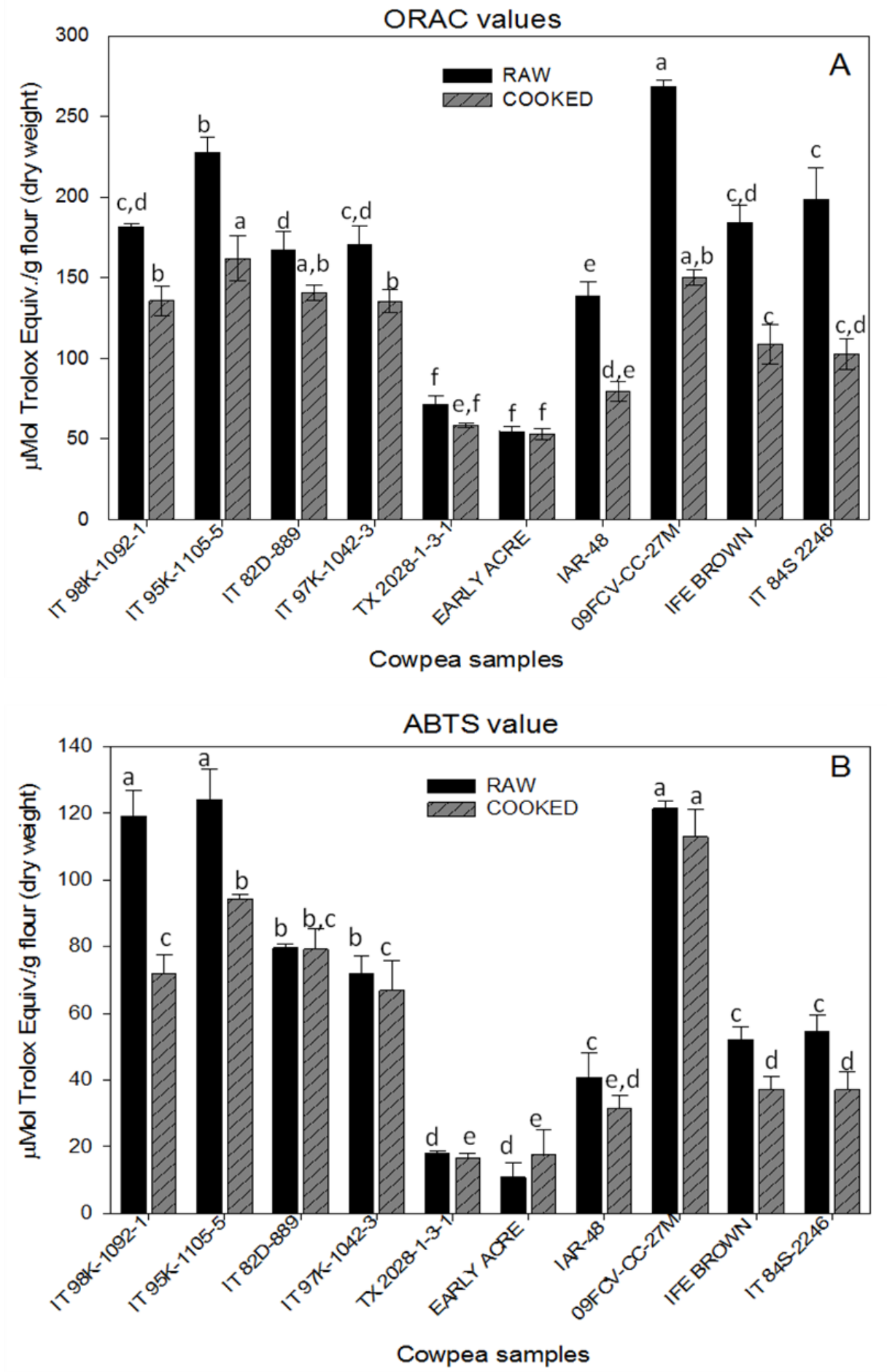

Figure 21. Antioxidant activities of various raw and cooked cowpeas varieties: ORAC values, A; and ABTS values, B. Bar data are expressed as mean \pm standard deviation $(n=3)$ on dry weight basis. Values marked above the same color bars with the same letter are not significantly different $(p<0.05)$. 
In general, the black, red and light brown cowpeas had the highest antioxidant activity determined by both ORAC and ABTS methods, whereas the white and green varieties had the lowest antioxidant activity (Figure 21). The presence of high levels of anthocyanins in the black (Table 4), flavonols in the red (Table 11) and tannincompounds in the light brown phenotypes (Table 12) contributed to their strong ability to quench free radicals. This indicated a positive correlation existed between levels of phenolic compounds and antioxidant activity of cowpea. Xu and Chang (57) also found high antioxidant activity of red and black varieties of Phaseolus vulgaris than those of their white counterparts. Warrington et al. (181) also reported significant differences in radical scavenging activity among Vigna spp; those with pigmented seed coats, especially black and red varieties had the highest antioxidant capacity values, followed by pinkeye and black-eye types, and then the cream and white types were the lowest.

Our studies show that the average antioxidant activity of the six raw cowpea phenotypes investigated is in decreasing order: black $>$ light brown $>$ red $>$ golden brown $>$ green $>$ white. The relatively higher antioxidant activities of the black, light brown and red phenotypes could be due to their higher TPC and CTC (Table 16), as well as their flavonoid compositions. Thus, in addition to their traditional role of preventing protein malnutrition, intake of black, light brown and red cowpea varieties may prevent degenerative diseases associated with oxidative damage. 


\subsubsection{Effect of boiling on antioxidant activities of cowpeas}

Figure 21 shows the effect of boiling on antioxidant activity of different cowpea phenotypes. All phenotypes showed reduction in antioxidant activity after boiling. On average, the greatest losses occurred in the black phenotypes (IT98K-1092-1 and IT95K1105-5), which showed $25.4-28.8 \%$ and $24.1-39.7 \%$ reduction in ORAC and ABTS values, respectively (Figure 21); followed by the golden brown, light brown and red phenotypes assayed by the ORAC method (Figure 21A). This effect could be due to significant losses in TPC and CTC observed in these phenotypes after boiling (Table 16). The overall reduction in antioxidant activity of boiled cowpeas can be attributed to the synergistic effects of heat induced oxidative reactions, breakdown of heat-labile antioxidant compounds and possibly polymerization reactions which reduce extractability of the phenolic components resulting in lower TPC and CTC. Boiling significantly reduced antioxidant activity of other pulses such as pinto beans and black beans (130); green pea, yellow pea, chickpea and lentils losses were also attributed to thermal degradation of the antioxidants (71).

The reduction in overall antioxidant properties of boiled cowpeas is attributed to the degradation of the phenolic compounds, and heat-induced interactions between the antioxidants and other plant components like starch.

A significant (61.4\%) increase in antioxidant activity by boiling was found in the white Early Acre variety (Figure 21B). This increase in antioxidant activity of the Early Acre extract was likely due, at least in part, to the release of bound phenolic acids such as feruloylaldaric acid derivatives that were detected in this variety (Figures 12 and 18). 
Heat treatment has been shown to improve extractability and liberation of low molecular weight phenolic acids (182). The presence of protocatechuic acid and protocatechuic aldehyde in the red phenotype (Figure 3) may also explain why red cowpea varieties had the least losses of ORAC and ABTS values despite containing higher levels of heatlabile flavonols. Thus, the presence of lower molecular weight phenolic compounds in cowpea may indicate of greater retention of antioxidant activity after heat treatment.

\subsubsection{Conclusions}

Boiling significantly affected the TPC and CTC of all cowpea varieties analyzed, as well as antioxidant activity associated with these compounds. The net reduction in antioxidant activity after boiling was less than the net TPC reduction, which suggested that phenolic degradation products may contribute to antioxidant activity. It is believed that beneficial plant components are significantly lost through food preparation processes such as sterilization and home-cooking. Exploring processing methods that improve retention of the heat labile antioxidants and phenolic components is recommended. 


\section{ANTI-INFLAMMATORY PROPERTIES OF COWPEA PHENOTYPES WITH DIFFERENT PHENOLIC PROFILES IN INTESTINAL MYOFIBROBLAST CCD18Co CELLS}

\subsection{Introduction}

Inflammation is generally a protective response induced by microbial infection or tissue injury. The main purpose of inflammation is elimination of disease causing pathogens, healing injured tissues at both cellular and molecular levels and maintenance of homeostasis equilibrium (14). Maintenance of this equilibrium is important since the inflammatory response in certain chronic inflammatory diseases such as CVDs and cancers have been shown to cause more damage to the host than the microbe (183). Since chronic inflammation can lead to extensive destruction of other neighboring tissues, an ideal inflammatory response should be rapid, destructive and specific, yet self-limiting (183). For example, malignant conversion of normal colonic cells following sustained chronic inflammation causes colorectal cancer, the second leading cause of cancer-related deaths worldwide $(184,185)$.

Malnutrition also causes inflammation, and has been one of the main leading causes of mortality and morbidity among the poor and children in developing countries who have limited access to adequate medical care and nutritious foods (25). Overreliance on maize (poor source of tryptophan and lysine) and other cereal grains, especially in sub-Saharan Africa results in malnutrition. These regions are characterized by inadequate rainfall and sandy soils which limit types of crops that may be cultivated. 
Cowpea is a heat and drought tolerant legume. It is a nutritious crop that is also highly adaptable to different soil conditions, thus, may be suitable in mitigating malnutrition in such regions. Moreover, the phenolic compounds such as anthocyanins (46), flavonols and isoflavonols $(51)$ and phenolic acids $(47,51)$ previously identified in cowpeas have been shown to have both anti-inflammatory effects and chemopreventive properties in colon cancer $(186,187)$ as well as ability to reduce risk of coronary heart disease (110). Thus, cowpea has great potential for controlling chronic inflammatory states.

Polyphenolic compounds in raw common bean seed coats have antitumor (188) antimutagenic (189) anti-inflammatory (190) and hepatoprotective effects (191). Previous studies showed that these positive health effects were probably due to the antioxidative effects exerted by the flavonoids present in the bean seed coat (191), suggesting bean antioxidants may be responsible for their physiological effects by counteracting the damages caused by reactive oxygen species (ROS) (192), increasing activity of non-enzymatic and enzymatic antioxidant defense systems (193), modulating transcription and activity of carcinogen defense and antioxidant enzymes (194, 195). ROS is generated in cells during respiration, but can also be derived from external sources. ROS significantly impact etiology of several chronic diseases, including cancer, by causing oxidative damage and DNA mutations (90). The presence of diverse groups of phenolic compounds in cowpea suggests it may also have strong ability to inhibit intracellular ROS and prevent chronic inflammatory conditions. 
During inflammation, several cytokines and target genes interact to reverse or promote the inflammatory process. For example, pro-inflammatory cytokines such as interleukins and tumor necrosis factor (TNF- $\alpha$ ) are associated with proliferative signaling. TNF- $\alpha$ (a signal that induces apoptosis) can induce transcription factors e.g. NF- $\kappa \mathrm{B}$ that eventually regulate expression of several target genes (196). Activation of NF- $\kappa$ B may lead to development of many different chronic diseases (197). Thus flavonoids which inhibit dysregulated activation of NF- $\mathrm{BB}$ are capable of suppressing inflammation, tumor cell transformation, proliferation and other chronic disorders (90, 198).

Cytokines also activate leukocytes and endothelial cells to express intercellular adhesion molecules (e.g. vascular cell adhesion molecule-1; VCAM-1) as well as their integrin ligands. This promotes leukocyte adherence to endothelial cells and their migration through tissue to the site of injury (199). VCAM-1 expression is regulated primarily at the level of transcription, especially by transcription factors such as NF- $\mathrm{B}$ (200). Endothelial cells also express microRNAs (miRs), such as miR-126, which regulates VCAM-1 expression and controls vascular inflammation upon bacterial infection. Thus, miRNAs serve as a potential link between inflammation and cancer for their role as potent post-transcriptional regulators of target genes and critical biological processes, including cell differentiation and disease (201).

Chronic inflammation of the intestinal tract is a risk factor for colorectal cancer. Previous epidemiological studies have suggested that regular legume intake reduce the risk of colorectal cancer (202). In vitro and in vivo assays have also demonstrated that 
legumes such as black soybean can prevent colonic inflammation and cell proliferation, and was associated with antioxidant properties of anthocyanins, proanthocyanidins and isoflavones present in this cultivar (203). A recent report, however, show that the evidence associating legumes with reduced risk of inflammatory disorders such as cancer are still inconclusive (204), suggesting that more studies are required. Therefore, the aim of this study was to investigate how polyphenolic compounds in different cowpea varieties affect ROS quenching and anti-inflammatory properties on nonmalignant intestinal myofribroblast CCD-18Co cells.

\subsection{Materials and methods}

\subsubsection{Chemicals and reagents}

The Folin-Ciocalteu reagent, dichlorofluorescein diacetate (DCFH-DA), and lipopolysaccharide (LPS) were purchased from Fisher Scientific (Pittsburgh, PA). Dimethyl sulfoxide (DMSO) was obtained from Sigma (St. Louis, MO). Bradford reagent was obtained from Bio-Rad (Hercules, CA) and VCAM-1 was obtained from Santa Cruz Biotechnology, Inc. (Santa Cruz, CA). TaqMan ${ }^{\circledR}$ MicroRNA Assay kit for miR-126 was obtained from Applied Biosystems (Carlsbad, CA). All other chemicals were analytical grade from VWR International (Bristol, CT).

\subsubsection{Plant materials and extraction}

Five cowpea varieties, namely, black IT95K-1105-5, red IT97K-1042-3, green TX2028-1-3-1, light brown 09FCV-CC-27M and white Early Acre were used in this 
study (Table 2). These varieties, representing five major phenotypes, were chosen based on their distinct differences in phenolic profiles and total phenol content. These samples were separately soaked in water (1:4.5 w/v) in triplicates for 12 hours, and boiled for 15 minutes. After boiling, the seeds (including the soup) were chilled and frozen to $-80^{\circ} \mathrm{C}$, freeze-dried and ground to pass through 60-mesh screen. The powders were then extracted with aqueous $70 \%$ acetone, roto-evaporated and the extracts freeze-dried. The freeze-dried extracts were stored at $-20^{\circ} \mathrm{C}$ until used.

\subsubsection{Total soluble phenolics}

Total soluble phenolic (TSP) levels (measure of total metal ion reducing capacity) of the freeze-dried boiled cowpea extracts was determined by a slightly modified Folin-Ciocalteu assay using gallic acid (GA) as the standard (205).

\subsubsection{Cell culture assays}

\subsubsection{Cell line}

Non-malignant colon CCD18Co cell line was purchased from the American Type Culture Collection (Manassas, VA, USA) and cultured using high glucose Dulbecco’s Modified Eagle Medium, supplemented with 1\% penicillin/streptomycin solution, $1 \%$ non-essential amino acids $(10 \mathrm{mM}), 1 \%$ sodium pyruvate $(100 \mathrm{mM})$ and 20\% Fetal Bovine Serum (Invitrogen, Carlsbad, CA). The cells were maintained at $37^{\circ} \mathrm{C}$ in a humidified $5 \% \mathrm{CO}_{2}$ atmosphere. 


\subsubsection{Cell proliferation assay}

Cells were seeded (1.5 x $10^{4}$ onto a 24-well plate) and incubated for $24 \mathrm{hr}$ (at $37^{\circ} \mathrm{C}$ /humidified $5 \% \mathrm{CO}_{2}$ atmosphere) to allow cells to stabilize and attach onto the bottom of the wells. The freeze-dried cowpea extracts were re-dissolved in DMSO, and then diluted with media to known concentrations of total soluble polyphenolics ranging from 0 - $80 \mathrm{mg}$ GAE/L (205). The cells were then exposed to the various concentrations of each cowpea phenolic extract for 48 hrs and then quantified with an electronic cell counter (Z1 ${ }^{\mathrm{TM}}$ Series, Beckman Coulter, Inc).

\subsubsection{Generation of reactive oxygen species (ROS) assay}

Intracellular ROS was assessed using',2' -dichlorofluorescin diacetate (DCFDA) (Molecular Probes, Eugene, OR) as a probe as described by Meng et al. (206) but with slight modifications. Cell were seeded in a black 96-well plate (3,000 cells/well) for 24 hrs to allow cell attachment, followed by incubation with cowpea phenolic extracts (2 - $20 \mathrm{mg} \mathrm{GAE} / \mathrm{L}$ ) for 24 hrs. The cells were then stimulated with $2 \mu \mathrm{g} / \mathrm{mL}$ LPS (in 100 $\mu \mathrm{L}$ media) to generate ROS for 2 hrs, followed by washing out the spent media using PBS buffer. The cells were then stained in situ with $100 \mu \mathrm{L}$ of $10 \mu \mathrm{M}$ DCFH, incubated at $37^{\circ} \mathrm{C}$ and the fluorescence signal was monitored after $15 \mathrm{~min}$ at $520 \mathrm{~nm}$ emission and $480 \mathrm{~nm}$ excitation with a FLUOstar Omega plate reader (BMG Labtech Inc, Durhan, NC). Relative fluorescence units (RFU) were analyzed using Omega Microplate Data Analyse Software and normalized to control cells not treated with cowpea extracts. 


\subsubsection{LPS-induced inflammation assay}

Cells were seeded in a 12 -well plate (80,000 cells/well) for $24 \mathrm{hrs}\left(37^{\circ} \mathrm{C} / 5 \%\right.$ $\mathrm{CO}_{2}$ ) to allow cell attachment. Cowpea extracts pre-dissolved in DMSO were then diluted to known concentrations of total polyphenolics (2, 5, 10 and $20 \mathrm{mg}$ GAE/L) and normalized to $<0.2 \%$ DMSO in the culture medium. The cells were then pre-treated with the extracts for 3 hrs, and then stimulated with $2 \mu \mathrm{g} / \mathrm{mL}$ LPS for 6 hrs, after which messenger RNA (mRNA) and micro-RNA (miRs) were extracted from the lysated cells and analyzed.

\subsubsection{RNA extraction and real-time PCR analysis of mRNAs and miRNAs}

\subsection{Total RNA extraction}

Total RNA was extracted according to the manufacturer's protocol using the Qiagen extraction kit (Qiagen Inc. Valencia, CA) for mRNA analysis; and using mirVana ${ }^{\mathrm{TM}}$ miRNA isolation kit (Applied Biosystems, Foster City, CA) for micro-RNA analysis. The quality and quantity of the isolated RNA were assessed using the NanoDrop ${ }^{\circledR}$ ND-1000 spectrophotometer (NanoDrop Technologies, Wilmington, DE).

\subsubsection{2 mRNA analysis}

Complementary DNA (cDNA) was synthesized from the isolated RNA using a Reverse Transcription Kit (Invitrogen Corp., Grand Island, NY) according to the manufacturer's protocol. Real Time PCR (qRT-PCR) was carried out with the SYBR 
Green PCR Master Mix (Applied Biosystems Inc, Foster City, CA) on an ABI Prism 7900 Sequence Detection System (Applied Biosystems Inc, Foster City, CA). The pairs of forward and reverse primers were obtained from Integrated DNA Technologies, Inc., San Diego, CA.

\subsection{Primer sequences used for mRNA analysis}

The sequences of the primers used were:

\begin{tabular}{|c|c|c|}
\hline IL-8: & $\mathrm{F}:$ & 5'-CACCGGAAGGAACCATCTCA-3' \\
\hline IL-8: & $\mathrm{R}:$ & 5'-AGAGCCACGGCCAGCTT-3' \\
\hline TNF- $\alpha$ : & $\mathrm{F}:$ & 5'-TGTGTGGCTGCAGGAAGAAC-3' \\
\hline TNF- $\alpha$ : & $\mathrm{R}:$ & 5'-GCAATTGAAGCACTGGAAAAGG-3' \\
\hline VCAM-1: & $\mathrm{F}:$ & 5'-ACAGAAGAAGTGGCCCTCCAT-3' \\
\hline VCAM-1: & $\mathrm{R}:$ & 5'-TGGCATCCGTCAGGAAGTG-3' \\
\hline NF- $\kappa B:$ & $\mathrm{F}:$ & 5'-TGGGAATGGTGAGGTCACTCT-3' \\
\hline$N F-\kappa B:$ & $\mathrm{R}:$ & 5'-TCCTGAACTCCAGCACTCTCTTC-3' \\
\hline
\end{tabular}

\subsubsection{4 miRNA analysis}

The RNA Reverse Transcription (RT) reactions and quantitative real time PCR (qRT-PCR) amplification were performed following TaqMan ${ }^{\circledR}$ MicroRNA Reverse Transcription Kit protocol (Applied Biosystems, Foster City, CA). Briefly, for RT analysis of miR-NU6B and miR-126, $8 \mu \mathrm{L}$ of the master mix and $5 \mu \mathrm{L}$ of isolated mRNA containing $7 \mathrm{ng} / \mu \mathrm{L}$ mRNA was used to make the cDNA. The primers for miR- 
126 and miR-NU6B were obtained from Life Technologies Corp., Applied Biosystems, Carlsbad, CA. For qRT-PCR analysis of miR-126, the RT product was diluted 1:15 and

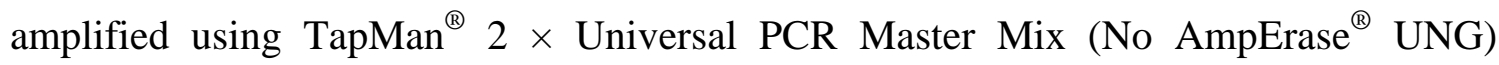
(Applied Biosystems, Foster City, CA) on a 384-well plate following the manufacturer's recommendations. The miR-NU6B small nuclear RNA was used as an endogenous control.

\subsubsection{Protein expression}

\subsection{Enzyme-Linked Immunosorbent Assay (ELISA)}

Cells seeded in $10 \mathrm{~cm}$ plates $\left(1 \times 10^{6}\right)$ were allowed to attach and stabilize for 24 hrs before subjecting them to treatment with cowpea extracts $(0,2,5,10$ and $20 \mathrm{mg}$ GAE/L) for 3 hrs followed by LPS stimulation (2 $\mu \mathrm{g} / \mathrm{mL}$ ) for 6 hrs. Cell culture supernatants were collected and analyzed by ELISA assay for VCAM-1 (Human sVCAM-1 Immunoassay Kit, Invitrogen Corp., Camarillo, CA) according to the manufacturer's protocol. The protein concentration was quantified using Bradford reagent (Bio-Rad) from which the final VCAM-1 ( $\mu \mathrm{g} / \mathrm{g}$ protein) was calculated according to the manufacturer's protocol and normalized to untreated control cells.

\subsection{Transfection assay}

Cells seeded in 6 -well ( $35 \mathrm{~mm}$ diameter) cluster plates $\left(3 \times 10^{5}\right.$ cells/well) were allowed to attach for 24 hrs to $80 \%$ confluency and then transfected with $100 \mathrm{pmol} / \mathrm{mL}$ 
of anti-sense oligonucleotide (miR-126 inhibitor) (Dharmacon Inc., Lafayette, CO) using Neon $^{\mathrm{TM}}$ Transfection System and Lipofectamine ${ }^{\circledR} 2000$ Reagent kit (Invitrogen, Carlsbad, CA) following the recommendations provided by the manufacturer. For targeted knockdown of miR-126, cells were transfected with a mock siRNA (negative control, NC) in full media according to manufacturer's recommendations. After transfection, the cells were treated with $10 \mathrm{mg}$ GAE/L cowpea extract for $24 \mathrm{hrs}$ followed by LPS ( $2 \mu \mathrm{g} / \mathrm{mL}$ ) stimulation for 24 hrs. Total RNA was then extracted using mirVana ${ }^{\mathrm{TM}}$ miRNA isolation kit (Applied Biosystems, Foster City, CA) following manufacturer's protocol and analyzed for miR-126 and VCAM-1 gene expression using

qRT-PCR on the Applied Biosystems 7900HT. The cell culture supernatants were also analyzed for VCAM-1 protein expression using ELISA assay kit (Invitrogen, Camarillo, CA).

\subsection{Statistical analysis}

Data are reported as means \pm SD for ROS and protein quantification; and means \pm SE for gene expression, of 3 replicates; and analyzed using 2005 SAS (Version 9.1, SAS Inst. Inc., Cary, N.C., U.S.A.) with one-way Analysis of Variance (ANOVA). Post Hoc test (Fisher's LSD and Tukey-Kramer HSD) after ANOVA was used to compare treatments means. Significant levels were defined using $p<0.05$. 


\subsection{Results and discussion}

\subsubsection{Cell proliferation assay}

It was important to first investigate cell proliferation property of the cowpea extracts since a chemopreventive agent should have protective effects against cancer without damaging non-cancer cells (207). Overall, the maximum concentration of cowpea extracts that supported CCD18Co cell growth after 48 hrs of incubation was 20 mg GAE/L (> 85\% cells surviving) (Figure 22). Therefore, extract concentrations within a dose range of $2-20 \mathrm{mg} \mathrm{GAE} / \mathrm{L}$ were used in the subsequent assays to assess the antiinflammatory properties of cowpea.

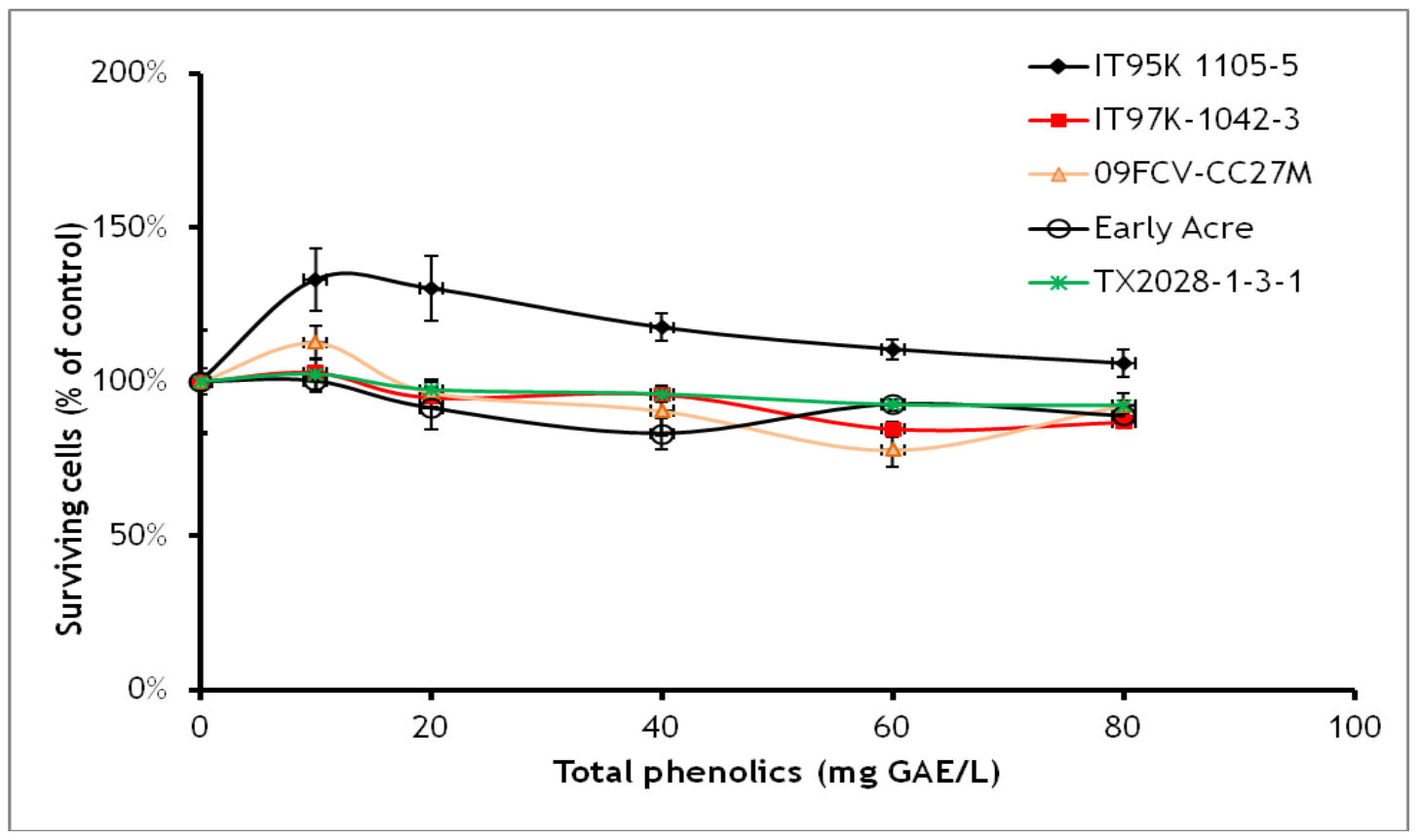

Figure 22. Cell proliferation assay on CCD18Co cells treated with various concentrations of extracts from different cowpea varieties; and assessed after 48 hrs incubation. Values are means $\pm \operatorname{SD}(n=3)$. 


\subsubsection{Cell protection against production of reactive oxygen species}

The intracellular reactive oxygen species (ROS) assay was performed to screen for cowpea varieties with greater potency in protecting the non-malignant CCD18Co cells from LPS-induced ROS generation. Results showed that the protection of CCD18Co cells against ROS by the black IT95K-1105-5, red IT97K-1042-3 and light brown 09FCV-CC27M cowpea varieties was achieved in a dose-dependent manner (within 2 to $20 \mathrm{mg} \mathrm{GAE} / \mathrm{L}$ ) (Figure 23). At the lowest concentration (2 mg GAE/L), the flavonol-rich red IT97K-1042-3 and anthocyanin-rich black IT95K-1105-5 had the highest inhibitory effect on ROS (37.2 - 39.8\% reduction), followed by the light brown 09FCV-CC27M (28.4\% reduction) compared to the positive control (Figure 23). At highest concentration tested (20 mg GAE/L), the black IT95K-1105-5 had the highest effect on ROS inhibition (55.7\%), followed by red IT97K-1042-3 (46.6\%) and light brown 09FCV-CC27M (35.0\%) compared to the positive control (Figure 23). On the other hand, the white Early Acre variety had no significant $(p<0.05)$ effect on ROS inhibition at all concentrations tested (Figure 23).

Generation of ROS in cells causes oxidative stress which may lead to cardiovascular disease or promotion of tumor progression which eventually causes cancer (208). Therefore, the ability of cowpea extracts to inhibit ROS generation may contribute to delaying or blocking tumor progression. The differences in major types of flavonoid present in these cowpea varieties have a significant effect on their capacity to mitigate generation of ROS in non-cancer cells. 


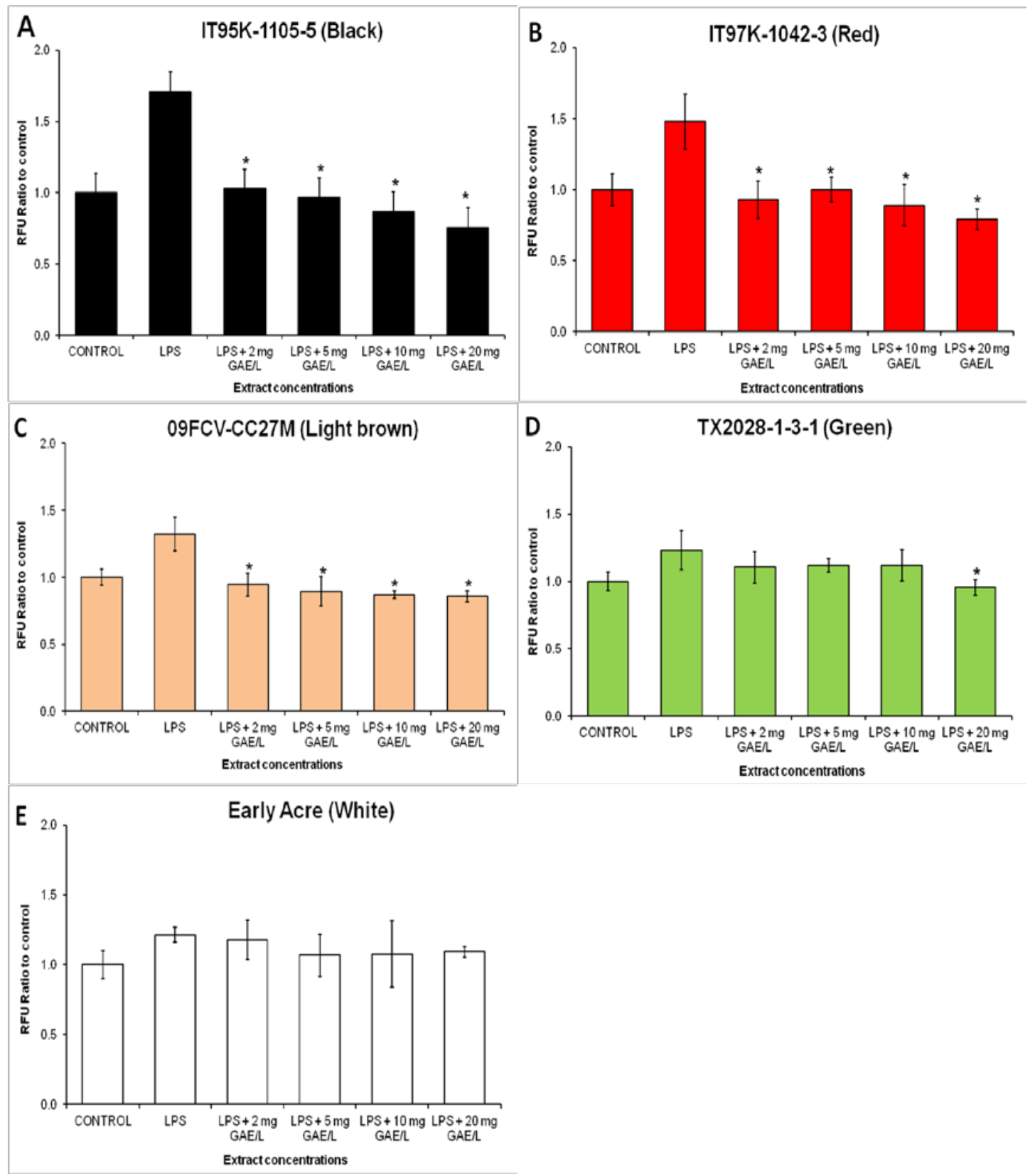

Figure 23. Effect of cowpea extracts on generation of ROS after LPS-induced oxidative damage in non-cancer CCD-18Co cells. Cells were pretreated with extracts (2 - $20 \mathrm{mg} \mathrm{GAE} / \mathrm{L})$ from black IT95K-1105-5 (A), red IT97K-1042-3 (B), light brown 09FCV-CC27M (C), green TX2028-1-3-1 (D), and white Early Acre (E) cowpea varieties for 24 hrs. Values are normalized to control cells not treated with cowpea extracts and presented as means $\pm \mathrm{SD}, n=3$; (*) indicate significance at $p<0.05$. 
Results from this study suggest that cowpea polyphenolics may protect cellular components (e.g. DNA, etc) from oxidative damage or release of proinflammatory cytokines due to their ROS scavenging property, thus, may have a role in treatment of pathological conditions in which ROS production plays an important role.

No previous studies have reported the protection of endothelial cells by cowpea polyphenolics. Other studies showed that flavonols, especially quercetin and kaempferol, had favorable inhibition of TNF- $\alpha$-induced ROS generation in non-cancer human embryonic kidney HEK-293 cells (209). Another study demonstrated differential protective effect of quercetin and kaempferol against oxidative stress induced by proinflammatory stimuli in human hepatocyte-derived cell line (Chang Liver cells) possibly through modulation of some antioxidant enzymes (210), suggesting protective effects by flavonols against liver diseases in which prevention of oxidative stress is critical. Cowpea polyphenols may have exerted their cardioprotective property through interference with ROS generation on CCD18Co cells.

\subsubsection{Effects of cowpea extracts on proinflammatory cytokines}

The mRNA expressions of chemoattractant cytokine IL-8 was significantly upregulated upon LPS stimulation (Figure 24). LPS induced IL-8 gene expression after 6 hrs of stimulation by 2.22-fold compared to untreated control cells (no LPS stimulation). However, all cowpea extracts dose-dependently decreased IL-8 (Figure 24). The effect of phenotype and phenolic composition on IL-8 inhibition was also observed even at low extract concentration (2 mg GAE/L). For example, the black IT95K-1105-5 and red 
IT97K-1042-3 cowpea varieties significantly $(p<0.01)$ reversed the IL-8 mRNA by 1.95- and 2.22-fold, respectively, compared to untreated control cells; whereas the white Early Acre only decreased IL-8 mRNA by 1.47-fold at 2 mg GAE/L (Figure 24). The red variety contained flavonols and flavan-3-ols (Table 11) while the black contained anthocyanins in addition to flavonols and flavan-3-ols (Tables 4 and 10). The white variety had no detectable levels of anthocyanins or flavan-3-ols (Table 14), suggesting the phenolic compounds in the red, black and light brown varieties synergistically contributed to greater IL-8 inhibition. Flavonols (kaempferol and quercetin) have been shown to significantly inhibit IL-8 gene expression (209); IL-8 promotes phagocytosis of neutrophils (211), an event that causes secretion of ROS which has been implicated in the etiology of several chronic disorders such as colon cancer and IBD (212). Since IL-8 are chemokines mostly secreted by endothelial cells under oxidative stress, the inhibition of IL-8 by cowpea extracts containing ROS scavengers (anthocyanins, flavonols, flavan3-ols, etc) suggest ROS inhibition could be one mechanism by which cowpea may protect endothelial cells from inflammation.

LPS also up-regulated TNF- $\alpha$ mRNA expression by 3.08-fold relative to untreated control cells (Figure 25). In this study, all phenotypes showed significant inhibition of TNF- $\alpha$ gene expression even at the lowest concentration tested (2 mg GAE/L), an important step in cancer prevention; except the white Early Acre. 

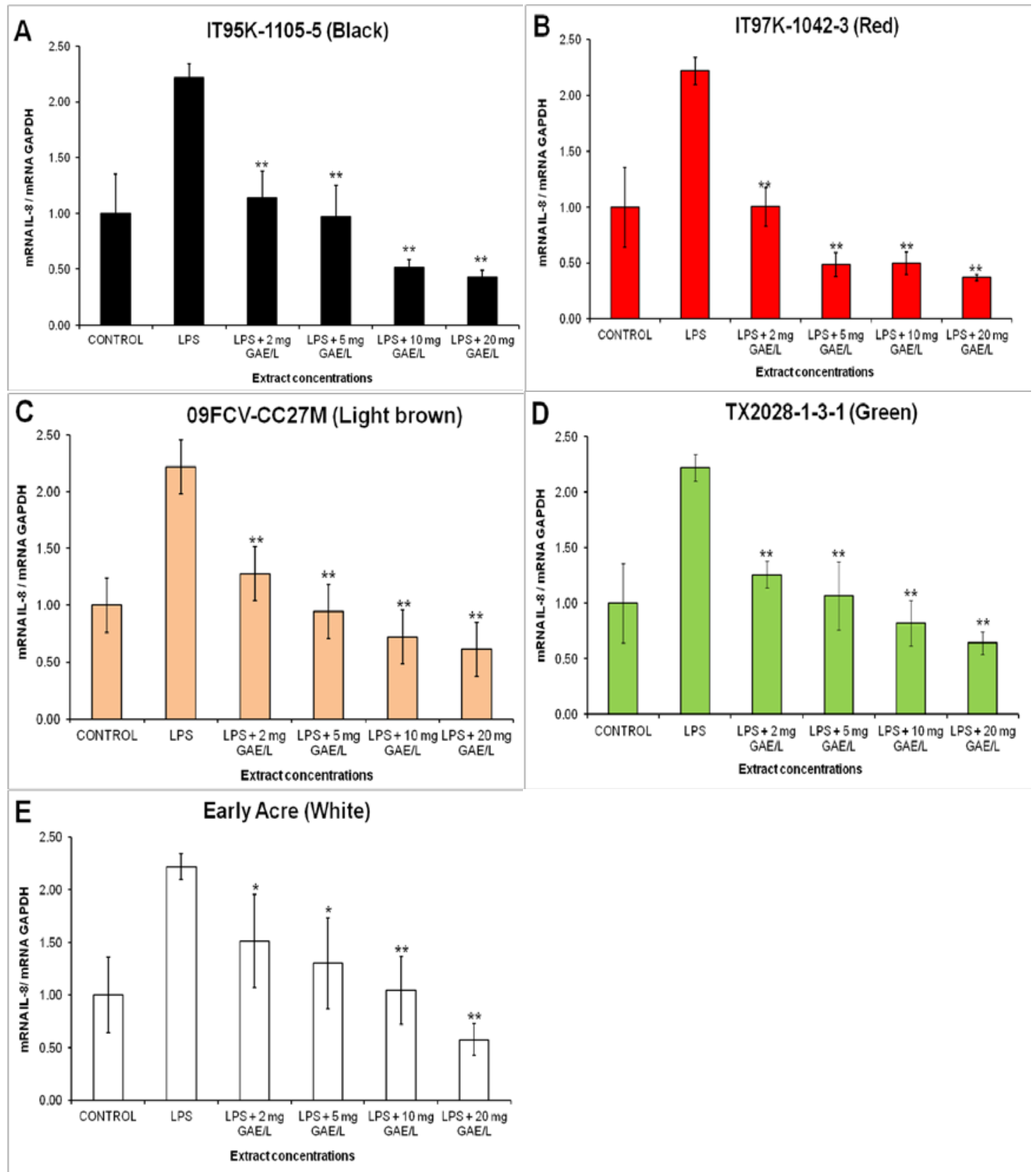

Figure 24. CCD-18Co gene expression of IL-8. Cells were pre-treated for 3 hrs with extracts (2 - 20 mg GAE/L) from black IT95K-1105-5 (A), red IT97K-1042-3 (B), light brown 09FCVCC27M (C), green TX2028-1-3-1 (D), and white Early Acre (E) cowpea varieties, then stimulated with LPS for 6 hrs; and analyzed by real time qRT-PCR as ratio to GAPDH mRNA. Values are means \pm SE $(n=3) ;(*) p<0.05,(* *) p<0.01$. 

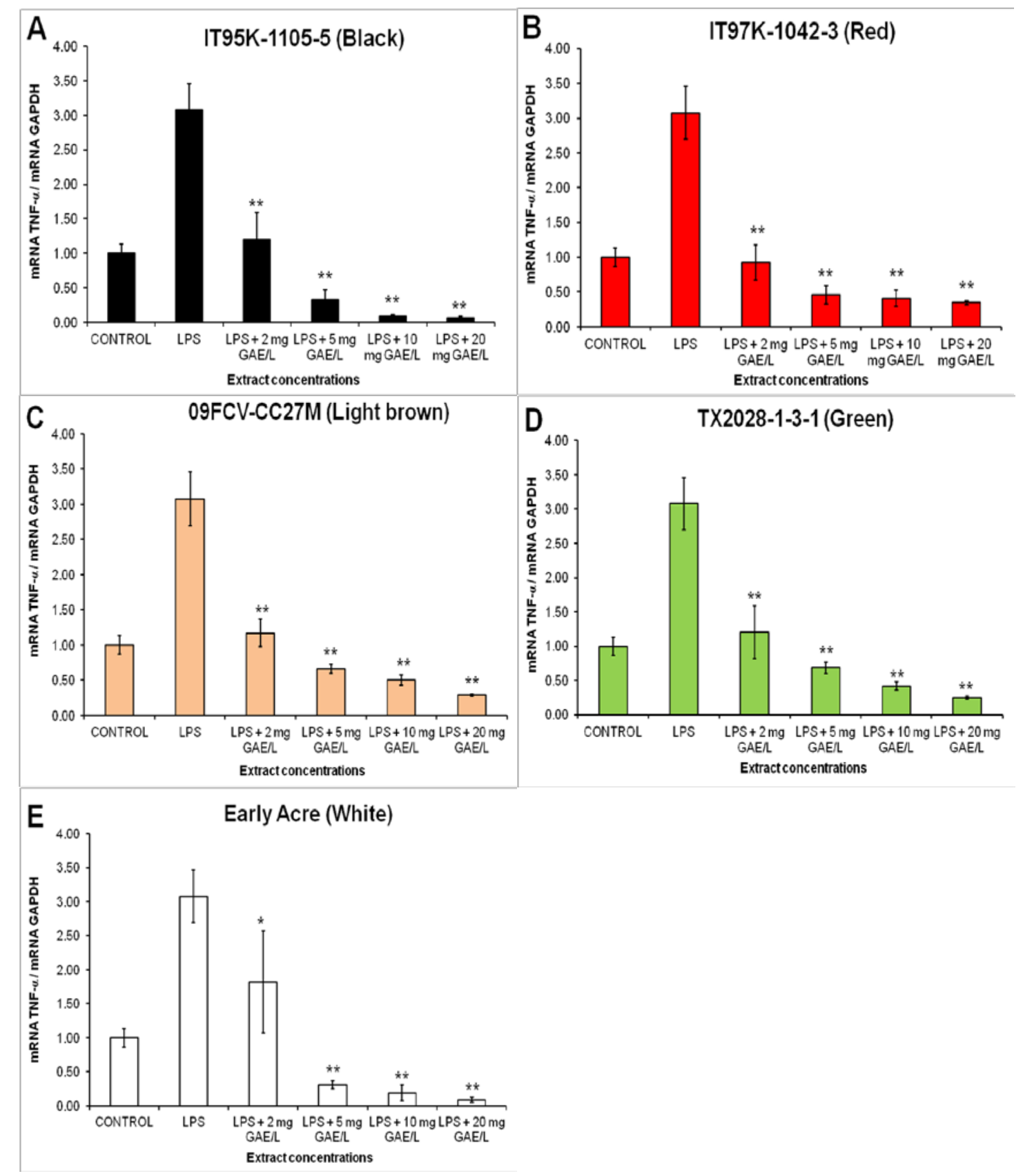

Figure 25. CCD-18Co gene expression of TNF- $\alpha$. Cells were pre-treated for 3 hrs with extracts (2 - 20 mg GAE/L) from black IT95K-1105-5 (A), red IT97K-1042-3 (B), light brown 09FCVCC27M (C), green TX2028-1-3-1 (D), and white Early Acre (E) cowpea varieties, then challenged with LPS for $6 \mathrm{hrs}$; and analyzed by real time qRT-PCR as ratio to GAPDH mRNA. Values are means $\pm \mathrm{SE}(n=3) ;(*) p<0.05,(* *) p<0.01$. 
At $2 \mathrm{mg}$ GAE/L, the flavonol-rich red IT97K-1042-3 variety had the highest inhibition of TNF- $\alpha$ (by 3.35-fold relative to untreated control cells), followed by the anthocyanin-rich black IT95K-1105-5 variety compared to the white Early Acre variety which only reduced TNF- $\alpha$ by 1.68 -fold relative to untreated control cells at this concentration (Figure 25). This suggests that cowpea flavonoid profiles strongly influenced inhibition of TNF- $\alpha$. However, all cowpea extracts down-regulated TNF- $\alpha$ secretion dose-dependently (Figure 25). The red cowpea phenotype contained significant levels of quercetin, kaempferol and myricetin derivatives (Tables 10 - 14), which may explain why the red IT97K-1042-3 cowpea variety had higher inhibitory effect against IL-8 and TNF- $\alpha$ even at low phenolic concentrations, followed by the anthocyanin-rich black IT95K-1105-5 variety (Figures 24 and 25). Down-regulation of proinflammatory cytokines such as TNF- $\alpha$ by flavonoids is generally linked to prevention of chronic diseases such as ulcerative colitis (213) and inhibiting tumor growth and angiogenesis, therefore such strategies of down-regulating them has been suggested as therapeutic for colorectal carcinoma $(198,214)$.

This study also investigated the effects of cowpea extracts on expression of transcription factor NF- $\kappa \mathrm{B}$ (Figure 26). NF- $\kappa \mathrm{B}$ induces several pro-inflammatory cytokines including IL-8 and TNF- $\alpha$ in addition to other activities and is activated through phosphorylation. mRNA expression of NF- $\kappa \mathrm{B}$ increased by 2.11 -fold relative to untreated control cells after LPS challenge (Figure 26). This effect was dosedependently reduced by polyphenolics from all cowpea phenotypes tested. However, our result showed that flavonoid profiles amongst the varieties may influence cowpea's 
ability to down-regulate NF- $\kappa$ B genes. For example, whereas the black, red, green and white varieties significantly $(p<0.01)$ inhibited NF- $\mathrm{kB}$ at $2 \mathrm{mg} \mathrm{GAE} / \mathrm{L}$, the light brown variety only had similar inhibitory effect at $10 \mathrm{mg}$ GAE/L (Figure 26). The light brown 09FCV-CC27M contains high levels of polymeric flavan-3-ols which may affect their

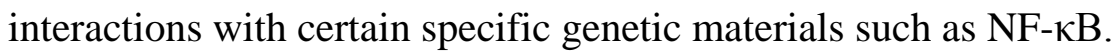

In general, higher inhibition of NF-אB was exhibited by the flavonol-rich red IT97K-1042-3 variety at $20 \mathrm{mg}$ GAE/L (Figure 26). Flavonols (quercetin and kaempferol) have been reported to inhibit the activation of NF- $\kappa \mathrm{B}$ induced by cytokines in parenchymal liver cells, probably via protecting cells against oxidative species,

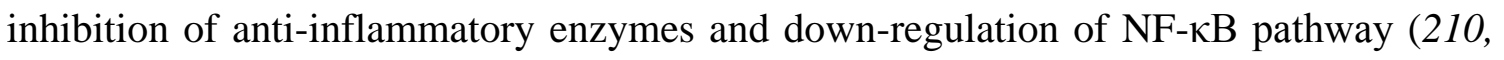
215). Our results strongly suggest cowpea may play a critical role on regulating inflammation linked to dysregulated NF- $\mathrm{B}$ gene expression, in the initiation and progression of chronic disorders (216).

Since vascular cell adhesion molecule VCAM-1 is a target gene for NF- $\mathrm{BB}$, we also investigated whether cowpea polyphenolics might regulate VCAM-1 as an additional model to assess cowpea's potential protective effects in vascular inflammation. LPS up-regulated VCAM-1 mRNA by 3.55-fold relative to untreated control cells (Figure 27). Cell adhesion molecules (CAMs) are known to regulate leukocyte transendothelial migration and cause inflammation (217). 


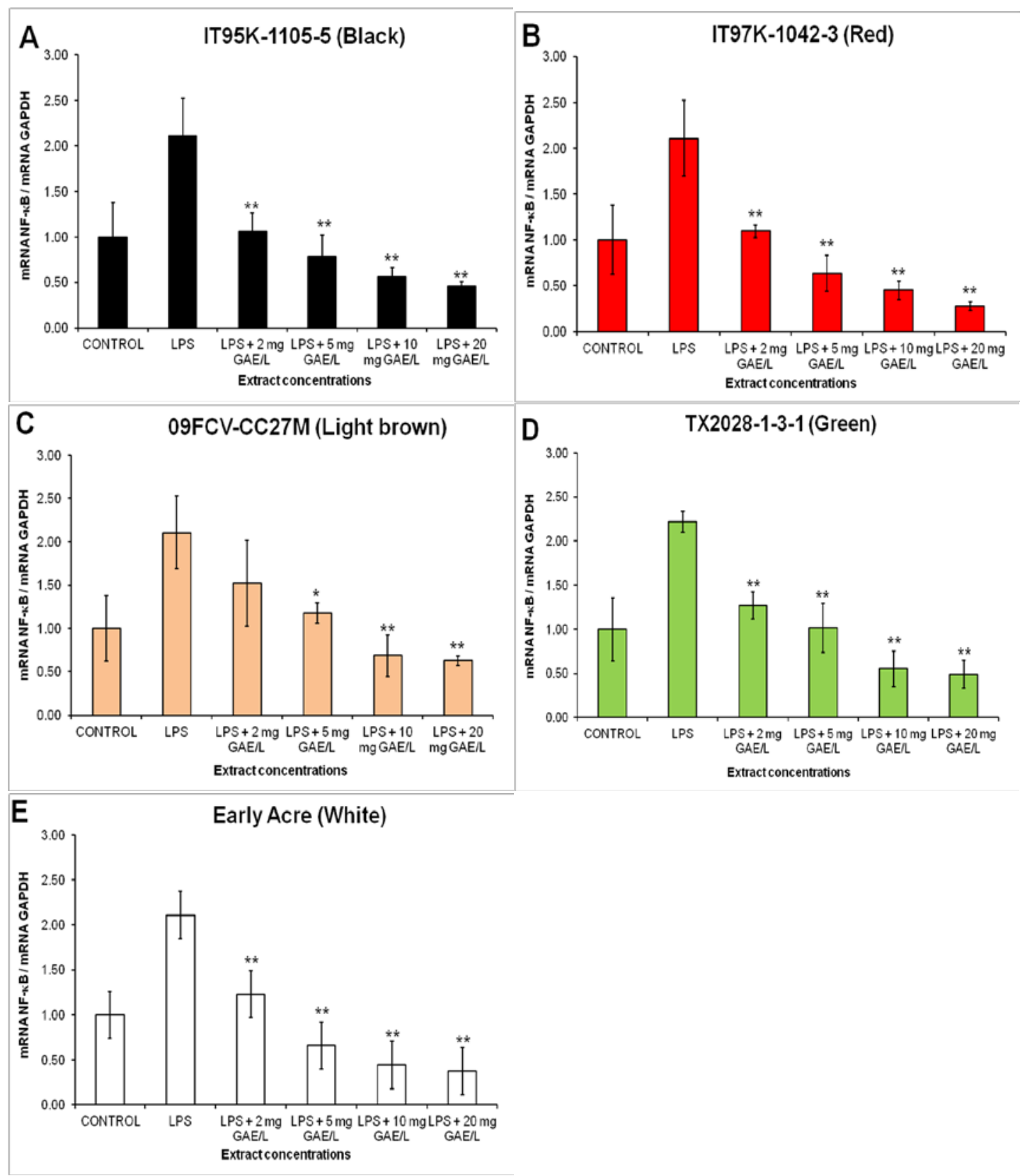

Figure 26. CCD-18Co gene expression of NF- $\mathrm{kB}$. Cells were pre-treated for 3 hrs with extracts (2 - 20 mg GAE/L) from black IT95K-1105-5 (A), red IT97K-1042-3 (B), light brown 09FCVCC27M (C), green TX2028-1-3-1 (D), and white Early Acre (E) cowpea varieties, then challenged with LPS for $6 \mathrm{hrs}$; and analyzed by real time qRT-PCR as ratio to GAPDH mRNA. Values are means $\pm \mathrm{SE}(n=3) ;(*) p<0.05,(* *) p<0.01$. 
All cowpea extracts had significant dose-dependent reduction of VCAM-1 gene expression on CCD18Co cells (Figure 27), demonstrating that cowpea polyphenolics have protective effects in endothelial cells stimulated by LPS. Similar results were also reported regarding acaí and red muscadine grape polyphenolics on NF-kB target genes VCAM-1, ICAM-1, and E-selectin (218).

The effect of different cowpea phenotypes on VCAM-1 mRNA was also observed (Figure 27). Polyphenolics from the anthocyanin-rich IT95K-1105-5 (black), procyanidin-rich 09FCV-CC27M (light brown) and Early Acre (white) varieties seemed to be more effective at down-regulating VCAM-1 gene expression compared to those from red and green at a low concentration of $2 \mathrm{mg} \mathrm{GAE} / \mathrm{L}$. This suggests that specific flavonoid profiles modulate different molecular pathways, thus, different cowpea phenotypes may prevent endothelial dysfunction and cardiovascular complications through different mechanisms. Already, proanthocyanidins have been shown to exert inhibitory effect on the expression of CAMs via several mechanisms, including reduction of ROS generation (219), inhibition of the AngII-induced MAPK (220), downregulation of NF-KB inflammatory cascade and regulation of TRAF6 - IRAK1 axis (218), thus might help prevent development of atherosclerosis. 

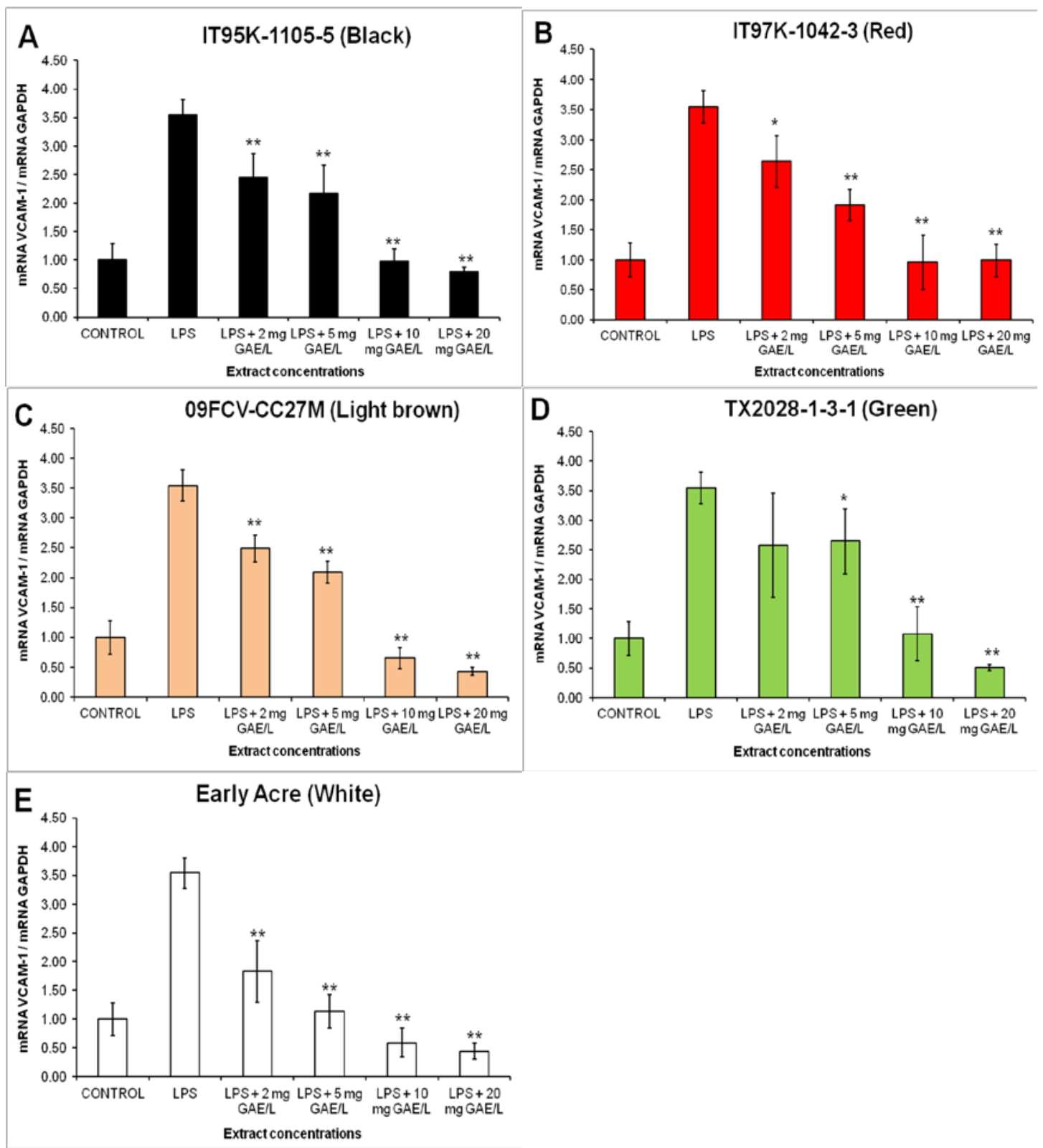

Figure 27. CCD-18Co gene expression of VCAM-1. Cells were pre-treated for 3 hrs with extracts (2 - 20 mg GAE/L) from black IT95K-1105-5 (A), red IT97K-1042-3 (B), light brown 09FCV-CC27M (C), green TX2028-1-3-1 (D), and white Early Acre (E) cowpea varieties, then challenged with LPS for 6 hrs; and analyzed by qRT-PCR as ratio to GAPDH mRNA. Values are means $\pm \operatorname{SE}(n=3) ;\left({ }^{*}\right) p<0.05,(* *) p<0.01$. 
Our study reveals important differences among cowpea varieties in their capacity to protect the colonic myofibroblast against NF- $\mathrm{B}$ activation and transcription of proinflammatory genes in LPS-induced inflammation at the mRNA level. The flavonol-rich red IT97K-1042-3 cowpea variety had superior capacity to down-regulate expression of cytokines/chemokines and NF- $\mathrm{B}$, followed by the anthocyanin-rich black IT95K-11055; suggesting that the modulation of proinflammatory genes by cowpeas is dependent on their phenolic profiles. The light brown phenotype had the least flavonol content. These results provide evidence on how different cowpea phenotypes and their phenolic compositions could affect the management of inflammatory conditions and potential for colon cancer prevention.

Overall, based on the positive effects of cowpea polyphenolics on endothelial function, follow-up studies in animals and humans are required to support these beneficial effects and to determine clinical relevance. Lower concentrations should also be tested to determine the minimum effective doses. Specific flavonoid fractions should also be tested to determine the class of cowpea flavonoids that has the highest potency.

\subsubsection{Effect of cowpea extracts on lipopolysaccharide-induced vascular inflammation}

LPS induces innate immune responses via cell membrane ligands that initiate the $\mathrm{NF}-\kappa \mathrm{B}$ cell signaling cascade involving expression of cellular adhesion molecules and interleukins that regulate leukocyte recruitment (210). For example, VCAM-1 play a key role in leukocyte adhesion, migration and maintenance of vascular integrity. 
Dysregulated expression of VCAM-1 may cause vascular lesions (221) via NF-кB activation which may result in atherosclerosis (222). Thus, the protective effect of extracts from different cowpea varieties in vascular inflammation was assessed in CCD18Co cells to determine the best variety with greater potential to down-regulate VCAM-1 at the protein level. The amount of VCAM-1 protein excreted to culture media after 6 hrs of LPS stimulation was increased by 6.38-fold compared to untreated control cells (Figure 28).

In general, all cowpea extracts dose-dependently reversed LPS-induced upregulation of VCAM-1 protein expression within 2 - $20 \mathrm{mg}$ GAE/L concentrations tested (Figure 28). At $2 \mathrm{mg}$ GAE/L, the greatest decrease in VCAM-1 protein expression was observed with the black and red cowpea phenotypes (Figure 28). The black and red cowpea varieties had higher amounts of anthocyanins and flavonols, respectively. At $20 \mathrm{mg}$ GAE/L, all cowpea extracts restored VCAM-1 basal protein excreted into the culture media, indicating that their anti-inflammatory effect on this NF$\kappa \mathrm{B}$ target gene was a response modulated by their polyphenolic profiles. However, as the extract concentration increased, the light brown 09FCV-CC27M cowpea variety seemed to be more efficacious compared to the other varieties; it showed a marked decrease in VCAM-1 protein secretion at $10 \mathrm{mg}$ GAE/L (Figure 28C), compared to the other samples at this concentration (Figure 28). This suggests that the high levels of procyanidins in 09FCV-CC27M variety may be providing superior protection against adhesion molecules expression than the flavonols and anthocyanins in IT97K-1042-3 and IT95K-1105-5 varieties, respectively. This could be because procyanidins mainly 
exert their anti-inflammatory effects through interference with ROS generation and their anti-apoptotic effects (219); whereas flavonols mainly provide their anti-inflammatory effects by acting on signaling cascades and their downstream substrates, as well as by inhibiting critical enzymes and membrane proteins often required for cellular specific functions (223). Polyphenolics from açai and red Muscadine grape seeds, mainly composed of proanthocyanidins, had a reducing effect on intercellular cell adhesion molecules, namely ICAM-1, VCAM-1 and E-selectin, as well as intracellular platelet endothelial cell adhesion molecule (PECAM-1) by decreasing generation of ROS (218).

Overall, in this study, cowpea extracts were effective at decreasing VCAM-1 expression both at mRNA (Figure 27) and protein levels (Figure 28), suggesting cowpea polyphenolics may prevent dysregulated expression of adhesion molecules on the cell surface of endothelial cells and circulating polymorphonuclear cells and thus may reduce risk of tumors and cardiovascular diseases (224). Follow-up studies using in vivo models such as rats are therefore required to support these findings. 


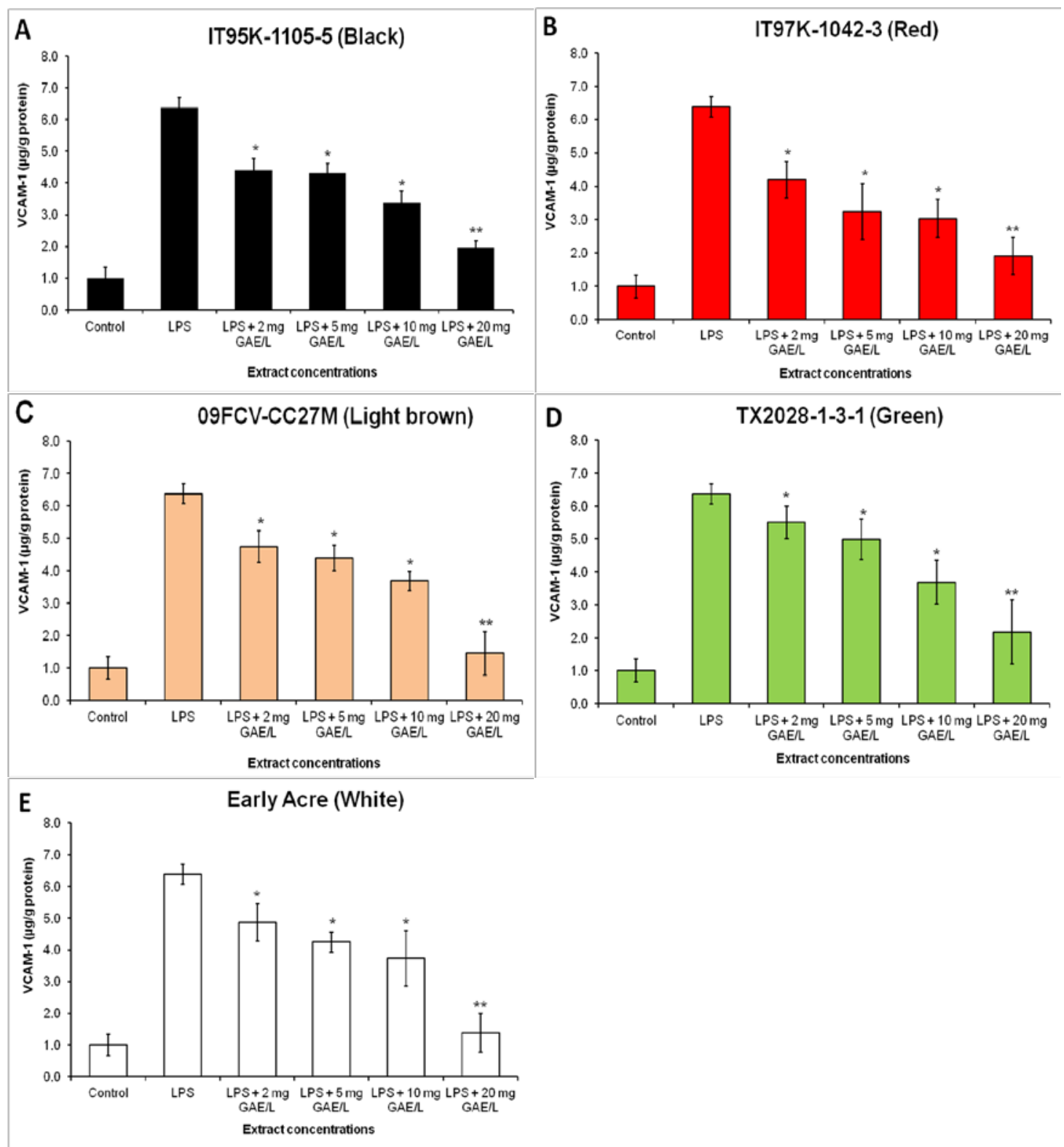

Figure 28. Relative amount of VCAM-1 protein excreted to culture media. Cell culture supernatants from cells pretreated for 3 hrs with solvent (DMSO) or different extract concentrations (2 - 20 mg GAE/L) from black IT95K-1105-5 (A), red IT97K-1042-3 (B), light brown 09FCV-CC27M (C), green TX2028-1-3-1 (D), and white Early Acre (E) cowpea varieties, and challenged with LPS $(2 \mu \mathrm{g} / \mathrm{mL})$ for 6 hrs were analyzed by ELISA. Values were normalized to protein concentrations relative to untreated control cells. Values are means \pm SD $(n=3) ;(*) p<0.05,(* *) p<0.01$. 


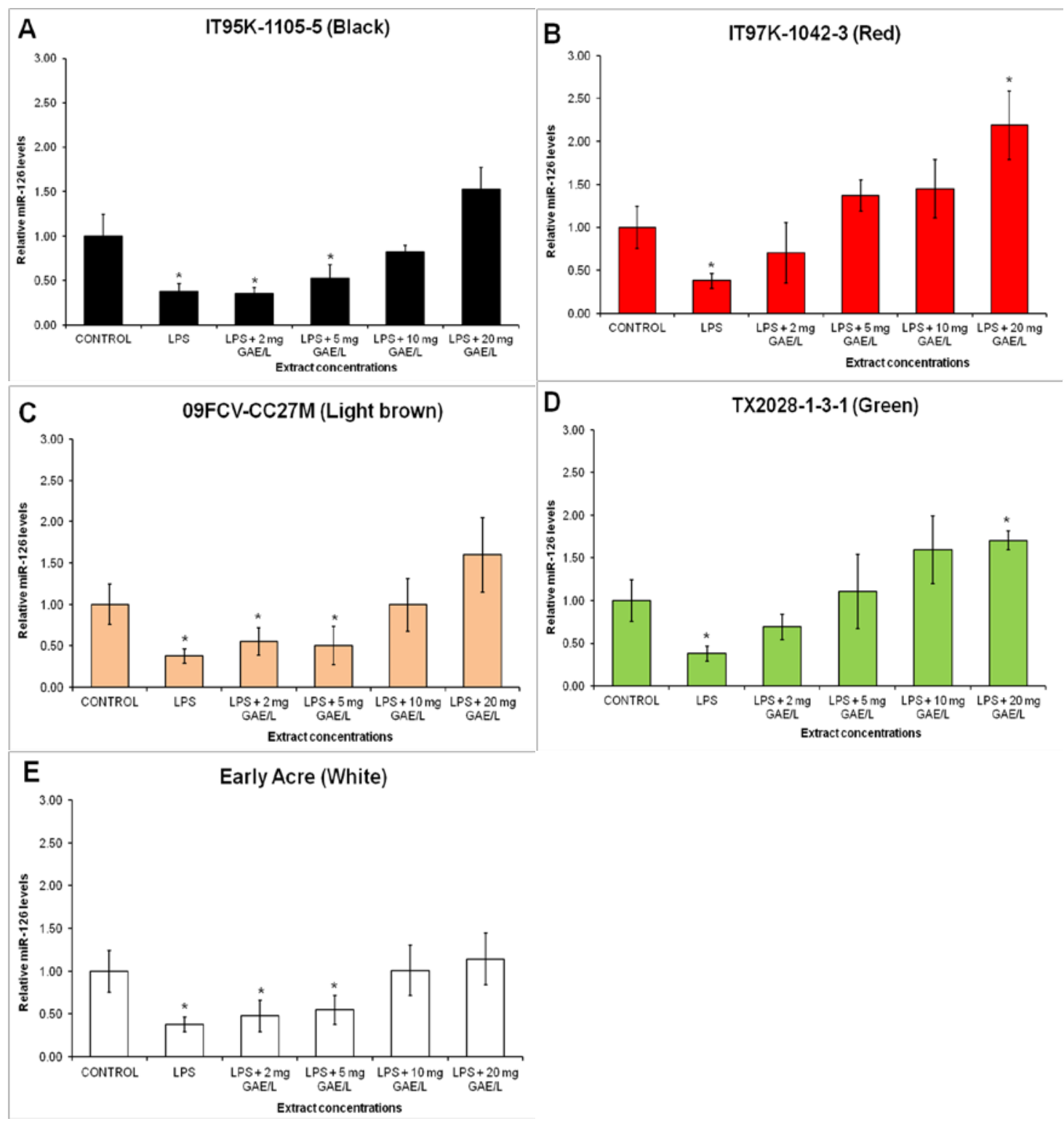

Figure 29. Modulation of miR-126 by cowpea extracts on LPS-challenged CCD18Co cells. Cells were pretreated for $3 \mathrm{hrs}$ with solvent (DMSO) or different extract concentrations $(2-20$ mg GAE/L) from black IT95K-1105-5 (A), red IT97K-1042-3 (B), light brown 09FCV-CC27M (C), green TX2028-1-3-1 (D), and white Early Acre (E) cowpea varieties, and then stimulated with LPS $(2 \mu \mathrm{g} / \mathrm{mL})$ for 6 hrs. Values are means \pm SE $(n=3)$. $\left(^{*}\right)$ within each sample indicate significant difference at $p<0.05$ compared to control. 


\subsubsection{Effect of cowpea extracts on miR-126}

Resting endothelial cells usually do not express adhesion molecules; however, upon activation by cytokines such as IL-8 and TNF- $\alpha$, cell adhesion molecules such as VCAM-1 and ICAM-1 may be expressed which eventually mediate leukocyte adherence to endothelial cells (97). Such crucial biological processes have been shown to be highly regulated by miRNAs during immune response. For example, miR-126 has been shown to play a key role in regulation of VCAM-1 in vascular endothelial cells (97).

In this study, the expression of miR-126 in CCD18Co cells was found to be inversely correlated to VCAM-1 expression at both gene and protein levels, suggesting its participation in the control of vascular inflammation (Figures 27 - 29). Results showed that LPS significantly decreased miR-126 expression by $64 \%$ relative to untreated control cells (Figure 29), and this response was inversely correlated to the expression of VCAM-1 at gene (Figure 27) and protein levels (Figure 28). However, cowpea extracts (2 - $20 \mathrm{mg}$ GAE/L) exerted a dose-response increase of miR-126 expression (Figure 29), which showed corresponding down-regulation of VCAM-1 at both gene and protein levels (Figures 27 and 28). Polyphenolics from açai and red Muscadine grape seeds (5 - 20 mg GAE/L) were also reported to induce a dose-response increase of miR-126 expression in LPS-challenged HUVEC cells, and this response was inversely correlated to the expression of adhesion molecules (VCAM-1, ICAM-1, Eselectin and PECAM-1) at both gene and protein expression levels (218). This indicates miR-126 is normally involved in inhibiting VCAM-1 expression, confirming VCAM-1 regulation is mediated through miR-126. 
To understand the mechanisms by which phenolic compounds in cowpea and miR-126 regulate endothelial biology, we quantified mRNA expression of VCAM-1 (a potential miR-126 target) by qRT-PCR in CCD18Co cells that had been transfected with specific miR-126 inhibitor in the presence of black IT95K-1105-5 cowpea extract at 10 mg GAE/L (Figure 30). This sample was chosen since it contained significant amounts of the major flavonoid compounds (anthocyanins, flavonols and flavan-3-ols) identified in cowpea (Tables 4 and 10). Upon miR-126 inhibition, LPS increased VCAM-1 mRNA levels by 2.45 -fold relative to the negative control (NC)-treated cells, and the black IT95K-1105-5 cowpea extract reversed this effect by 37\% (Figure 30A). This suggested that cowpea extract were involved in regulation of VCAM-1 genes.

We also assessed the expression of VCAM-1 protein in the cell culture supernatants collected from the control or miR-126-transfected CCD18Co cells using ELISA, but we did not detect significant levels of VCAM-1 protein in these samples. This does not mean that the antibody was ineffective; since VCAM-1 protein was readily detectible in LPS-treated endothelial cells (Figure 28); rather it showed that miRNA may regulate stability or translation of target mRNAs as had been demonstrated by other authors (225).

Transfection with miR-126 inhibitor significantly $(p<0.05)$ decreased miR-126 levels by $62 \%$ of negative control (NC)-treated cells (Figure 30B). However, when transfected cells were treated with 10 mg GAE/L black IT95K-1105-5 cowpea extract, the miR-126 levels increased by 1.92-fold of NC-treated (Figure 30B). 

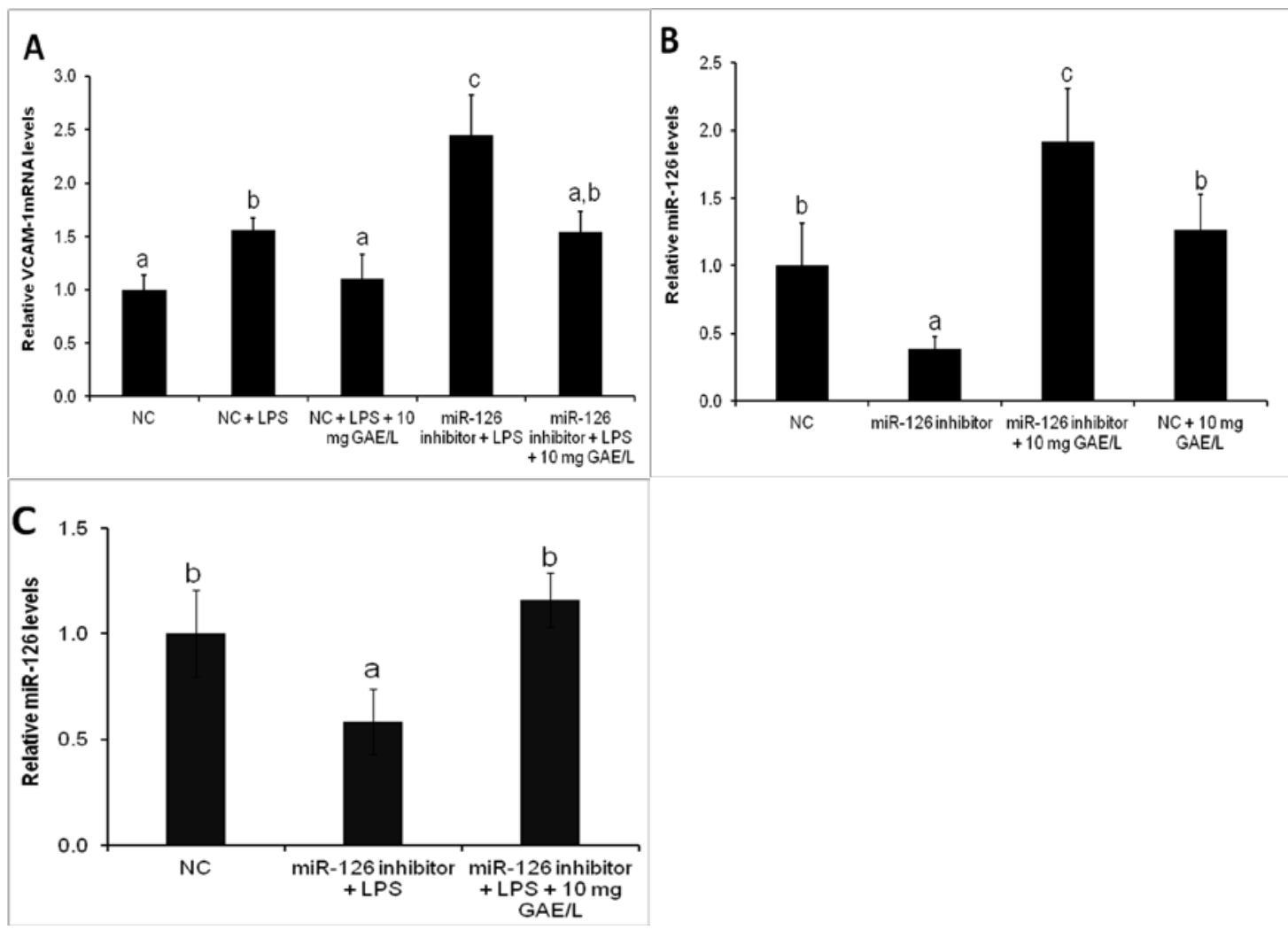

Figure 30. Effect of $10 \mathrm{mg}$ GAE/L polyphenolic extracts from black IT95K-1105-5 cowpea variety on VCAM-1 mRNA levels on LPS-treated transfected cells (A); miR-126 levels on transfected cells (B); and miR-126 levels on LPS-treated transfected cells (C). Cells were pretreated with solvent (DMSO) or the extract for 24 hrs followed by stimulation with LPS (2 $\mu \mathrm{g} / \mathrm{mL}$ ) for 24 hrs. Using qRT-PCR, relative VCAM-1 and miR-126 levels were analyzed as a ratio to the GAPDH and miR-NU6B endogenous controls, respectively. NC, negative control; LPS, lipopolysaccharide. Data are expressed as mean \pm SE $(n=3)$. Different letters within each assay indicate significant difference at $p<0.05$.

Upon LPS stimulation, the miR-126 levels on cells transfected with miR-126 inhibitor decreased by $41 \%$ relative to NC-treated cells, and the cowpea extract reversed this effect (Figure 30C). These results suggest that phenolic compounds in cowpea modulate the expression of endothelial cell-specific miR-126 as one of the underlying mechanisms that protect endothelial cells from inflammation. miR-126 is known to 
regulate endothelial expression of VCAM-1 (97), thus induction of miR-126 by cowpea polyphenolics following LPS challenge (Figure 30B) demonstrates cowpea may protect endothelial cells against atherosclerotic risk factors by decreasing VCAM-1 expression through miR-126 induction as one of the underlying mechanisms. This is supported by the fact that miR-126 expression was inversely correlated to the decreased VCAM-1 gene (Figure 27) and protein expression (Figure 28). These positive health effects of cowpea associated with regulation of miR-126 is critical since miR-126 expression has been correlated with lung (226) and breast (227) cancer survival as well as tumor suppression (228).

In previous studies, miR-126 was reported to target VCAM-1 in TNF- $\alpha$ treated (97) and LPS-treated (218) endothelial cells. Additionally, other authors $(97,229)$ also showed that the 3'-UTR transcript for human VCAM-1 is perfectly complimentary to the nucleotides $604-625$ of miR-126, which is responsible for decreasing cell adhesion and inflammation in endothelial cells, indicating involvement of miR-126 in modulating VCAM-1 expression during immune response.

\subsubsection{Conclusions}

Cowpeas contain phenolic compounds which may provide protective effects against NF-кB-linked risk factors associated with cancer and cardiovascular diseases by decreasing levels of VCAM-1 both at the gene and protein expression levels through induction of miR-126 as the underlying mechanism (Figure 30). This was further demonstrated when the overall effect of miR-126 inhibitor on VCAM-1 gene and protein 
expressions in transfected cells were reversed by polyphenolics from the black IT95K1105-5 cowpea extract (Figure 30).

The molecular pathways targeted by cowpea polyphenolics in the maintenance of cellular homeostasis may be complex, but these results show that their anti-inflammatory effects, ROS inhibition and induction of miR-126 may contribute to their overall prevention of endothelial dysfunction and cardiovascular complications. From these results, cowpea has great potential in prevention of CVDs and cancers. Considering the importance of miR-126 in regulating endothelial biology, further in vivo investigations on mechanistic and translational aspects of these positive health effects shown by cowpea extracts would be essential in validating their relevance to human health. 


\section{CONCLUSIONS AND RECOMMENDATIONS}

\subsection{Conclusions}

From this study, seed-coat color may be a good indicator of the accumulation of flavonoids in cowpeas. Overall, levels of individual phenolic compounds were varietydependent rather than phenotype-dependent. Boiling significantly decreased the levels of individual and total flavonoid contents in cowpea. The initial antioxidant capacity of the cowpea varieties was influenced by their phenolic profiles; but was significantly impacted by boiling.

The ability of cowpea phenolic compounds to regulate proinflammatory genes and modulate miR-126 and its target gene VCAM-1 was variety-dependent. This indicated that cowpea's ability to protect the colonic myofibroblast cells from chronic inflammation was strongly influenced by the phenolic profiles. This effect was via inhibition of ROS and down-regulation of transcription factors NF- $\kappa$ B. These studies emphasize the importance of cancer inhibitory potential of phenolic compounds from cowpea and their role in preventing anti-inflammatory disorders. Specifically, the black and red cowpea phenotypes were more efficient than green or white phenotypes in antioxidant cellular protection and in in vitro inhibition of inflammatory genes. Taken together, these studies demonstrate that the preventive effect of phenolic compounds from cowpea against inflammatory conditions is variety dependent and, for the first time, demonstrate the potential role of cowpea in prevention of chronic diseases. 


\subsection{Recommendations for further research}

Based upon findings of the study, the following recommendations are relevant:

1. Focus should be placed on isolating, identifying and quantifying heterogeneous flavan-3-ol oligomers (e.g. hexamers; mDI 5) which could be present in cowpea.

2. Determine the type of flavonoid adducts produced by boiling from cowpea polyphenols, since these compounds may contribute to the overall antioxidant activity and anti-inflammatory properties of boiled cowpea samples.

3. Determine the ability of cooked cowpea extracts to regulate and modulate other microRNAs, cell adhesion molecules such as PECAM-1 and E-selectin in noncancer cell lines, in addition to using various cancerous cell lines would be essential in validating their relevance to human health.

4. Follow-up studies using in vivo animal models and human intervention studies using cowpea diets is required to support these findings.

5. Exploration of processing technologies that permit greater retention of phenolics should be considered. 


\section{LITERATURE CITED}

(1) Mathers, J. C. Pulses and carcinogenesis: potential for the prevention of colon, breast and other cancers. Brit. J. Nutr. 2002, 88 (Suppl.) 3, 273S279S.

(2) Kushi, L. H.; Meyer, K. A.; Jacobs, D. R., Jr. Cereals, legumes, and chronic disease risk reduction: evidence from epidemiologic studies. Am. J. .Clin. Nutr. 1999, 70, S451-S458.

(3) Venn, B. J.; Mann, J. I. Cereal grains, legumes and diabetes. Eur. J. Clin. Nutr. 2004, 58, 1443-1461.

(4) Finley, J. W.; Burrell, J. B.; Reeves, P. G. Pinto bean consumption changes SCFA profiles in fecal fermentations, bacterial populations of the lower bowel, and lipid profiles in blood of humans. J. Nutr. 2007, 137, 23912398.

(5) Duane, W. C. Effects of legume consumption on serum cholesterol, biliary lipids, and sterol metabolism in humans. J. Lipid Res. 1997, 38, 1120-1128.

(6) Kim, J. M.; Kim, J. S.; Yoo, H.; Choung, M. G.; Sung, M. K. Effects of black soybean [Glycine max (L.) Merr.] seed coats and its anthocyanidins on colonic inflammation and cell proliferation in vitro and in vivo. J. Agric. Food Chem. 2008, 56, 8427-8433.

(7) Janssen-Heininger, Y. M. W.; Poynter, M. E.; Baeuerle, P. A. Recent advances towards understanding redox mechanisms in the activation of nuclear factor $\kappa$ B. Free Rad. Biol. Med. 2000, 28, 1317-1327.

(8) Schwenger, P.; Alpert, D.; Skolnik, E. Y.; Vilček, J. Activation of p38 mitogen-activated protein kinase by sodium salicylate leads to inhibition of tumor necrosis factor-induced IкB $\alpha$ phosphorylation and degradation. Mol. Cell. Biol. 1998, 18, 78-84.

(9) Foster-Powell, K.; Miller, J. B. International tables of glycemic index. Am. J. Clin. Nutr. 1995, 62, S871-S890.

(10) Phillips, R. D.; McWatters, K. H. Contribution of cowpeas to nutrition and health. Food Technol. 1991, 45, 127-130.

(11) Collier, G. R.; Giudici, S.; Kalmusky, J. Low glycemic index starchy foods improve glucose control and lower serum cholesterol in diabetic children. Diab. Nutr. Metab. 1988, 1, 11-19.

(12) Rochfort, S.; Panozzo, J. Phytochemicals for health, the role of pulses. $J$. Agric. Food Chem. 2007, 55, 7981-7994. 
(13) Balkwill, F.; Mantovani, A. Inflammation and cancer: back to Virchow? Lancet 2001, 357, 539-45.

(14) Kutuk, O.; Basaga, H. Inflammation meets oxidation: NF-kappa B as a mediator of initial lesion development in atherosclerosis. Trends Mol. Med. 2003, 9, 549-57.

(15) Fresco, P.; Borges, F.; Diniz, C.; Marques, M. P. M. New insights on the anticancer properties of dietary polyphenols. Med. Res. Rev. 2006, 26, 747766.

(16) Langyintuo, A. S.; Lowenberg-DeBoer, J.; Faye, M.; Lambert, D.; Ibro, G.; Moussa, B.; Kergna, A.; Kushwaha, S.; Musa, S.; Ntoukam, G. Cowpea supply and demand in West and Central Africa. Field Crops Res.2003, 82, 215-231.

(17) Faris, D. G. The origin and evolution of the cultivated forms of Vigna sinensis. C. J. Gen. Cyt. 1965, 7, 433-452.

(18) FAO 2009 Food and Agriculture commodities production - Cowpeas, dry. http://faostat.fao.org/ (Accessed online on December 3, 2011).

(19) Ehlers, J. D.; Fery, R. L.; Hall, A. E. Cowpea breeding in the USA: New varieties and improved germplasm. In Challenges and opportunities for enhancing sustainable cowpea production, C. A. Fatokun; S.A. Tarwali; B.B. Singh; P.M. Kormawa; Tamo, M., Eds. International Institute of Tropical Agriculture (IITA): Ibadan, Nigeria, 2002; pp 62-77.

(20) Thomas Jefferson Agricultural Institute Columbia, MO. Cowpea: A versatile legume for hot, dry conditions. www.jeffersoninstitute.org/ (Accessed online on June 20, 2011).

(21) Bagnall, D. J.; King, R. W. Temperature and irradiance effects on yield in Cowpea (Vigna unguiculata). Field Crops Res. 1987, 16, 217-229.

(22) Quin, F. M. Introduction. In Advances in cowpea research. Copublication of International Institute of Tropical Agriculture (IITA) and Japan International Research Center for Agricultural Sciences (JIRCAS), B.B. Singh; D.R. Mohan Raj; K.E. Dushiell; Jackai, L. E. N., Eds. IITA: Ibadan, Nigeria., 1997; pp ix-Xv.

(23) Fageria, N. K.; Baligar, V. C.; Jones, C. A. Growth and mineral nutrition of field crops. CRC Press, Taylor and Francis Group: Boca Raton, FL, 2011.

(24) Wheeler, W. A. Forage and pasture crops: a handbook of information about the grasses and legumes grown for forage in the United States. New York: Van Nostrand, 1950. 
(25) Pelletier, D. L.; Frongillo, J., E. A.; Schroeder, D. G.; Habicht, J. P. The effects of malnutrition on child mortality in developing countries. Bull. World Health Org. 1995, 73, 443-448.

(26) Pelletier, D. L.; Frongillo, E. A. Changes in child survival are strongly associated with changes in malnutrition in developing countries. J. Nutr. 2003, 133, 107-119.

(27) Feed the Future (FTF) FY 2010 implementation plans. In feedthefuture.gov: 2010; pp 1-45. (Accessed online on June 20, 2011).

(28) Maina, W. K. Times Publication: http://www.corporate-africa.com/. NonCommunicable Diseases Control in Kenya: Past, Present and Future. (Accessed online on June 20, 2011).

(29) Savethechildren.org. Child Malnutrition in Zimbabwe increasing as emergency aid pipeline falters. http://www.savethechildren.org/. (Accessed on June 6, 2011).

(30) Worldvision.org. Child malnutrition soaring in eastern Congo. http://www.worldvision.org. (Accessed on June 20, 2011).

(31) WHOSIS World Health Organization Statistical Information System. World Health Statistics 2008: Geneva Switzerland. http://www.who.int/whosis/whostat/2008/en/index.html. (Accessed on December 3, 2011).

(32) Iqbal, A.; Khalil, I. A.; Ateeq, N.; Sayyar Khan, M. Nutritional quality of important food legumes. Food Chem. 2006, 97, 331-335.

(33) El Faki, H. A.; Venkatarama, L. V.; Desikachar, H. S. R. Effect of processing on the in vitro digestibility of proteins and carbohydrates in some Indian legumes. Plant Foods Human Nutr. 1984, 34, 127-133.

(34) Vartak, H. G.; Bodhe, A. M.; Paranjpe, S. V.; Jagannathan, V. Proteinase inhibitors from Vigna unguiculata subsp. cylindrica. II. Inhibitors of subtilisin and trypsin. Arch. Biochem. Biophy. 1980, 204, 129-133.

(35) Chavan, J. K.; Hejgaard, J. Detection and partial characterisation of subtilisin inhibitors in legume seeds by isoelectric focusing. J. Sci. Food Agric. 1981, 32, 857-862.

(36) Bressani, R.; Elias, L. G.; Braham, J. E. Reduction of digestibility of legume proteins by tannins. J. Plant Foods 1982, 4, 43-45. 
(37) Reyes-Moreno, C.; Paredes-López, O.; Gonzalez, E. Hard-to-cook phenomenon in common beans - A review. Crit. Rev. Food Sci. Nutr. 1993, 33, 227-286.

(38) Uzogara, S. G.; Ofuya, Z. M. Processing and utilization of cowpeas in developing countries: A review. J. Food Proc. Pres. 1992, 16, 105-147.

(39) Akinyele, I. O. Effects of traditional methods of processing on the nutrient content and some antinutritional factors in cowpeas (Vigna unguiculata). Food Chem. 1989, 33, 291-299.

(40) Kachare, D. P.; Chavan, J. K.; Kadam, S. S. Nutritional quality of some improved cultivars of cowpea. Plant Foods Human Nutr. 1988, 38, 155162.

(41) Fery, R. L. The cowpea: production, utilization, and research in the United States. In Horticultural Reviews, John Wiley \& Sons, Inc.: 1990; pp 197222.

(42) Nielsen, S. S.; Ohler, T. A.; Mitchell, C. A. Cowpea leaves for human consumption: production, utilization and nutrient composition. In Advances in cowpea research, Singh, B. B., Ed. International Institute of Tropical Agriculture: Ibadan, Nigeria, 1997; pp 326-332.

(43) Coyne, D. P.; Steadman, J. R.; Godoy-Lutz, G.; Gilbertson, R.; ArnaudSantana, E.; Beaver, J. S.; Myers, J. R. Contributions of the Bean/Cowpea CRSP to management of bean diseases. Field Crops Res. 2003, 82, 155168.

(44) Kelly, J. D.; Gepts, P.; Miklas, P. N.; Coyne, D. P. Tagging and mapping of genes and QTL and molecular marker-assisted selection for traits of economic importance in bean and cowpea. Field Crops Res. 2003, 82, 135154.

(45) Postel, S., L. Entering an era of water scarcity: The challenges ahead. Ecol. Applic. 2000, 10, 941-948.

(46) Ha, T. J.; Lee, M.-H.; Jeong, Y. N.; Lee, J. H.; Han, S.-I.; Park, C.-H.; Pae, S.-B.; Hwang, C.-D.; Baek, I.-Y.; Park, K.-Y. Anthocyanins in cowpeas [Vigna unguiculata (L.) Walp. ssp. unguiculata]. Food Science Biotech. 2010, 19, 821-826.

(47) Cai, R.; Hettiarachchy, N. S.; Jalaluddin, A. High-performance liquid chromatography determination of phenolic constituents in 17 varieties of cowpeas. J. Agric. Food Chem. 2003, 51, 1623-1627. 
(48) Garavello, W.; Rossi, M.; McLaughlin, J. K.; Bosetti, C.; Negri, E.; Lagiou, P.; Talamini, R.; Franceschi, S.; Parpinel, M.; Dal Maso, L.; La Vecchia, C. Flavonoids and laryngeal cancer risk in Italy. Ann. Onco. 2007, 18, 11041109.

(49) McCue, P.; Shetty, K. Health benefits of soy isoflavonoids and strategies for enhancement: A review. Crit. Rev. Food Sci. Nutr. 2004, 44, 361-367.

(50) Prinyawiwatkul, W.; McWatters, K. H.; Beuchat, L. R.; Phillips, R. D.; Uebersak, M. A. Cowpea flour: A potential ingredient in food products. Crit. Rev. Food Sci. Nutr. 1996, 36, 413-436.

(51) Dueñas, M.; Fernández, D.; Hernández, T.; Estrella, I.; Muñoz, R. Bioactive phenolic compounds of cowpeas (Vigna sinensis L). Modifications by fermentation with natural microflora and with Lactobacillus plantarum ATCC 14917. J. Sci. Food Agric. 2005, 85, 297304.

(52) Luthria, D. L.; Pastor-Corrales, M. A. Phenolic acids content of fifteen dry edible bean (Phaseolus vulgaris L.) varieties. J. Food Compos. Anal. 19, 205-211.

(53) Takeoka, G. R.; Dao, L. T.; Tamura, H.; Harden, L. A. Delphinidin 3-O-(2O-beta-D-Glucopyranosyl-alpha-l-arabinopyranoside): a novel anthocyanin identified in Beluga black lentils. J. Agric. Food Chem. 2005, 53, 49324937.

(54) Chang, Q.; Wong, Y.-S. Identification of flavonoids in Hakmeitau beans (Vigna sinensis) by High-Performance Liquid Chromatography-Electrospray Mass Spectrometry (LC-ESI/MS). J. Agric. Food Chem. 2004, 52, 6694--6699.

(55) Pandey, K. B.; Rizvi, S. I. Current understanding of dietary polyphenols and their role in health and disease. Current Nutr. Food Sci. 2009, 5, 249263.

(56) Wang, M. L.; Gillaspie, A. G.; Morris, J. B.; Pittman, R. N.; Davis, J.; Pederson, G. A. Flavonoid content in different legume germplasm seeds quantified by HPLC. Plant Gen. Res.: Characterization and Utilization 2008, 6, 62-69.

(57) Xu, B. J.; Chang, S. K. C. A comparative study on phenolic profiles and antioxidant activities of legumes as affected by extraction solvents. J. Food Sci. 2007, 72, S159-S166.

(58) Madhujith, T.; Naczk, M.; Shahidi, F. Antioxidant activity of common beans (Phaseolus vulgaris L.). J. Food Lipids 2004, 11, 220-233. 
(59) Price, M. L.; Hagerman, A. E.; Butler, L. G. Tannin content of cowpeas, chickpeas, pigeon peas, and mung beans. J. Agric. Food Chem. 1980, 28, 459-461.

(60) López-Amorós, M. L.; Hernández, T.; Estrella, I. Effect of germination on legume phenolic compounds and their antioxidant activity. J. Food Compos. Anal. 2006, 19, 277-283.

(61) Amarowicz, R.; Estrella, I.; Hernandez, T.; Troszynska, A. Antioxidant activity of extract of adzuki bean and its fractions. J. Food Lipids 2008, 15, 119-136.

(62) Madhujith, T.; Amarowicz, R.; Shahidi, F. Phenolic antioxidants in beans and their effects on inhibition of radical-induced DNA damage. J. Am. Oil Chem. Soc. 2004, 81, 691-696.

(63) Santos-Buelga, C.; Scalbert, A. Proanthocyanidins and tannin-like compounds - nature, occurrence, dietary intake and effects on nutrition and health. J. Sci. Food Agric. 2000, 80, 1094-1117.

(64) Kaneda, H.; Kano, Y.; Osawa, T.; Kawakishi, S.; Kamimura, M. Effect of free radicals on haze formation in beer. J. Agric. Food Chem. 1990, 38, 1909-1912.

(65) Nzaramba, M. N.; Hale, A. L.; Scheuring, D. C.; Miller Jr, J. C. Inheritance of antioxidant activity and its association with seedcoat color in cowpea. $J$. Am. Soc. Hort. Sci. 2005, 130, 386-391.

(66) Tsuda, T.; Makino, Y.; Kato, H.; Osawa, T.; Kawakishi, S. Screening for antioxidantive activity of edible pulses. Biosci. Biotechnol. Biochem. 1993, $57,1606-1608$.

(67) Siddhuraju, P.; Becker, K. The antioxidant and free radical scavenging activities of processed cowpea (Vigna unguiculata (L.) Walp.) seed extracts. Food Chem. 2007, 101, 10-19.

(68) Xu, B. J.; Yuan, S. H.; Chang, S. K. C. Comparative studies on the antioxidant activities of nine common food legumes against copper-induced human low-density lipoprotein oxidation in vitro. J. Food Science 2007, 72, S522-S527.

(69) Rocha-Guzmán, N. E.; González-Laredo, R. F.; Ibarra-Pérez, F. J.; NavaBerúmen, C. A.; Gallegos-Infante, J.-A. Effect of pressure cooking on the antioxidant activity of extracts from three common bean (Phaseolus vulgaris L.) cultivars. Food Chem. 2007, 100, 31-35. 
(70) Turkmen, N.; Sari, F.; Velioglu, Y. S. The effect of cooking methods on total phenolics and antioxidant activity of selected green vegetables. Food Chem. 2005, 93, 713-718.

(71) Xu, B. J.; Chang, S. K. C. Phytochemical profiles and health-promoting effects of cool-season food legumes as influenced by thermal processing. $J$. Agric. Food Chem. 2009, 57, 10718-10731.

(72) Xu, B. J.; Chang, S. K. C. Effect of soaking, boiling, and steaming on total phenolic content and antioxidant activities of cool season food legumes. Food Chem. 2008, 110, 1-13.

(73) Han, H.; Baik, B. K. Antioxidant activity and phenolic content of lentils (Lens culinaris), chickpeas (Cicer arietinum L.), peas (Pisum sativum L.) and soybeans (Glycine max), and their quantitative changes during processing. Int. J. Food Sci. Technol. 2008, 43, 1971-1978.

(74) Laurena, A. C.; Garcia, V. V.; Mendoza, E. M. T. Effects of heat on the removal of polyphenols and in vitro protein digestibility of cowpea (Vigna Unguiculata (L) Walp). Plant Foods Human Nutr. 1987, 37, 183-192.

(75) Zhang, D.; Hamauzu, Y. Phenolics, ascorbic acid, carotenoids and antioxidant activity of broccoli and their changes during conventional and microwave cooking. Food Chem. 2004, 88, 503-509.

(76) Kavey, R.-E. W.; Daniels, S. R.; Lauer, R. M.; Atkins, D. L.; Hayman, L. L.; Taubert, K. American Heart Association guidelines for primary prevention of atherosclerotic cardiovascular disease beginning in childhood. Circulation 2003, 107, 1562-1566.

(77) Brown, L.; Rosner, B.; Willett, W. W.; Sacks, F. M. Cholesterol-lowering effects of dietary fiber: a meta-analysis. The Am. J. Clin. Nutr. 1999, 69, $30-42$.

(78) Milgate, J.; Roberts, D. C. K. The nutritional and biological significance of saponins. Nutr. Res. 1995, 15, 1223-1249.

(79) Sathe, S. K.; Deshpande, S. S.; Salunkhe, D. K.; Rackis, J. J. Dry beans of phaseolus. A review. Part 2. Chemical composition: Carbohydrates, fiber, minerals, vitamins, and lipids. C R C Crit. Rev. Food Sci. Nutr. 1984, 21, 41-93.

(80) Ascherio, A.; Rimm, E. B.; Hernán, M. A.; Giovannucci, E. L.; Kawachi, I.; Stampfer, M. J.; Willett, W. C. Intake of potassium, magnesium, calcium, and fiber and risk of stroke among US men. Circulation 1998, 98, 1198-1204. 
(81) Anderson, J. W.; Hanna, T. J. Impact of non-digestible carbohydrates on serum lipoproteins and risk for cardiovascular disease. J. Nutr. 1999, 129, 1457S-1466S.

(82) Bazzano, L. A.; He, J.; Ogden, L. G.; Loria, C.; Vupputuri, S.; Myers, L.; Whelton, P. K. Legume consumption and risk of coronary heart disease in US men and women: NHANES I Epidemiologic follow-up study. Arch. Int. Med. 2001, 161, 2573-2578.

(83) Velie, E. M.; Schairer, C.; Flood, A.; He, J.-P.; Khattree, R.; Schatzkin, A. Empirically derived dietary patterns and risk of postmenopausal breast cancer in a large prospective cohort study. The Am. J. Clin. Nutr. 2005, 82, 1308-1319.

(84) Takezaki, T.; Gao, C. M.; Ding, J. H.; Liu, T. K.; Li, M. S.; Tajima, K. Comparative study of lifestyles of residents in high and low risk areas for gastric cancer in Jiangsu Province, China; with special reference to allium vegetables. J. Epid. 1999, 9, 297-305.

(85) Franceschi, S. Nutrients and food groups and large bowel cancer in Europe. Eur. J. Cancer Prev. 1999, 8, S49-S52.

(86) Schuurman, A. G.; Goldbohm, R. A.; Dorant, E.; Van Den Brandt, P. A. Vegetable and fruit consumption and prostate cancer risk: A cohort study in the Netherlands. Cancer Epid. Biom. Prev. 1998, 7, 673-680.

(87) Fraser, G. E. Associations between diet and cancer, ischemic heart disease, and all- cause mortality in non-Hispanic white California Seventh-day Adventists. Am. J. Clin. Nutr. 1999, 70, S532-S538.

(88) Agurs-Collins, T.; Smoot, D.; Afful, J.; Makambi, K.; Adams-Campbell, L. Legume intake and reduced colorectal adenoma risk in African-Americans. J. National Black Nurses Assoc. 2006, 17, 6-12.

(89) Rao, B. N. Bioactive phytochemicals in Indian foods and their potential in health promotion and disease prevention. Asia Pacific J. Clin. Nutr. 2003, 12, 9-22.

(90) Prasad, S.; Phromnoi, K.; Yadav, V. R.; Chaturvedi, M. M.; Aggarwal, B. B. Targeting inflammatory pathways by flavonoids for prevention and treatment of cancer. Planta Medica 2010, 76, 1044-1063.

(91) Hussain, S. P.; Hofseth, L. J.; Harris, C. C. Radical causes of cancer. Nature Rev. Cancer 2003, 3, 276-85.

(92) Pollard, J. W. Tumor-educated macrophages promote tumour progression and metastasis. Nature Rev. Cancer 2004, 4, 71-78. 
(93) Comalada, M.; Ballester, I.; Bailón, E.; Sierra, S.; Xaus, J.; Gálvez, J.; Medina, F. S. D.; Zarzuelo, A. Inhibition of pro-inflammatory markers in primary bone marrow-derived mouse macrophages by naturally occurring flavonoids: Analysis of the structure-activity relationship. Biochem. Pharm. 2006, 72, 1010-1021.

(94) Calixto, J. B.; Campos, M. M.; Otuki, M. F.; Santos, A. R. S. Antiinflammatory compounds of plant origin. Part II. Modulation of proinflammatory cytokines, chemokines and adhesion molecules. Planta Medica 2004, 70, 93-103.

(95) Santangelo, C.; Vari, R.; Scazzocchio, B.; Di Benedetto, R.; Filesi, C.; Masella, R. Polyphenols, intracellular signalling and inflammation. Ann Ist Super Sanita 2007, 43, 394-405.

(96) Karin, M.; Yamamoto, Y.; Wang, Q. M. The IKK NF-[kappa]B system: a treasure trove for drug development. Nature Rev. Drug Disc. 2004, 3, 1726.

(97) Harris, T. A.; Yamakuchi, M.; Ferlito, M.; Mendell, J. T.; Lowenstein, C. J. MicroRNA-126 regulates endothelial expression of vascular cell adhesion molecule 1. Proc. National Academy of Sci. 2008, 105, 1516-1521.

(98) Kang, J. S.; Yoon, Y. D.; Han, M. H.; Han, S.-B.; Lee, K.; Lee, K. H.; Park, S.-K.; Kim, H. M. Glabridin suppresses intercellular adhesion molecule-1 expression in tumor necrosis factor- $\alpha$-stimulated human umbilical vein endothelial cells by blocking sphingosine kinase pathway: Implications of Akt, extracellular signal-regulated kinase, and nuclear factor- $\kappa \mathrm{B} / \mathrm{Rel}$ signaling pathways. Mol. Pharm. 2006, 69, 941-949.

(99) De Stefano, D.; Maiuri, M. C.; Simeon, V.; Grassia, G.; Soscia, A.; Cinelli, M. P.; Carnuccio, R. Lycopene, quercetin and tyrosol prevent macrophage activation induced by gliadin and IFN-[gamma]. Eur. J. Pharm. 2007, 566, 192-199.

(100) Min, Y. D.; Choi, C. H.; Bark, H.; Son, H. Y.; Park, H. H.; Lee, S.; Park, J. W.; Park, E. K.; Shin, H. I.; Kim, S. H. Quercetin inhibits expression of inflammatory cytokines through attenuation of NF- $\kappa \mathrm{B}$ and p38 MAPK in HMC-1 human mast cell line. Inflammation Res. 2007, 56, 210-215.

(101) Gerritsen, M. E.; Carley, W. W.; Ranges, G. E.; Shen, C. P.; Phan, S. A.; Ligon, G. F.; Perry, C. A. Flavonoids inhibit cytokine-induced endothelial cell adhesion protein gene expression. Am. J. Pathology 1995, 147, 278-92.

(102) Phillips, R. D.; McWaters, K. H. Contribution of cowpeas to nutrition and health. Food Technol. 1991, 45, 127-130. 
(103) Aremu, M. O.; Olaofe, O.; Akintayo, T. E. A comparative study on the chemical and amino acid composition of some Nigerian under-utilized legume flours. Pakistan J. Nutr. 2006, 5, 34-38.

(104) Trinidad, T. P.; Wolever, T. M. S.; Thompson, L. U. Availability of calcium for absorption in the small intestine and colon from diets containing available and unavailable carbohydrates: An in vitro assessment. Int. J. Food Sci. Nutr. 1996, 47, 83-88.

(105) Frota, K. M. G.; Mendonça, S.; Saldiva, P. H. N.; Cruz, R. J.; Arêas, J. A. G. Cholesterol-lowering properties of whole cowpea seed and its protein isolate in hamsters. J. Food Sci. 2008, 73, H235-H240.

(106) Oboh, G. Antioxidant properties of some commonly consumed and underutilized tropical legumes. Eur. Food Res. Technol. 2006, 224, 61-65.

(107) Sunday Y, G. Compositional and nutritional properties of selected newly developed lines of cowpea (Vigna unguiculata L.Walp). J. Food Compos. Anal. 2005, 18, 665-673.

(108) Macz-Pop, G. A.; Rivas-Gonzalo, J. C.; Pérez-Alonso, J. J.; GonzálezParamás, A. M. Natural occurrence of free anthocyanin aglycones in beans (Phaseolus vulgaris L.). Food Chem. 2006, 94, 448-456.

(109) Hakimuddin, F.; Paliyath, G.; Meckling, K. Selective cytotoxicity of a red grape wine flavonoid fraction against MCF-7 Cells. Breast Cancer Res. Treatment 2004, 85, 65-79.

(110) Sumner, M. D.; Elliott-Eller, M.; Weidner, G.; Daubenmier, J. J.; Chew, M. H.; Marlin, R.; Raisin, C. J.; Ornish, D. Effects of pomegranate juice consumption on myocardial perfusion in patients with coronary heart disease. The Am. J. Cardiology 2005, 96, 810-814.

(111) Brune, M.; Rossander, L.; Halberg, L. Iron absorption and phenolic compounds: Importance of different phenolic structures. Eur. J. Clin. Nutr. 1989, 43, 547-558.

(112) Baloyi, J. J.; Ngongoni, N. T.; Topps, J. H.; Acamovic, T.; Hamudikuwanda, H. Condensed tannin and saponin content of Vigna unguiculata (L.) Walp, Desmodium uncinatum, Stylosanthes guianensis and Stylosanthes scabra grown in Zimbabwe. Trop. Animal Health Prod. 2001, 33, 57-66.

(113) Elias, L. G.; Defernandez, D. G.; Bressani, R. Possible effects of seed coat polyphenolics on the nutritional quality of bean protein. J. Food Sci. 1979, 44, 524-527. 
(114) Troszynska, A.; Honke, J.; Kozlowska, H. Antioxidant properties of legumes. In Cost 916 Action on Bioactive Plant Cell Wall Components in Nutrition and Health., Amado, R.; Lairon, D.; Gerber, M.; Maiani, G., Eds. European Communications: Luxembourg, 2001; pp. 59-61.

(115) Troszynska, A.; Kubicka, E. Superoxide scavenging activity of seed coat extracts from legume seeds. Pol. J. Food Nutr. Sci. 2001, 51, 55-59.

(116) Onyenekwe, P. C.; Njoku, G. C.; Ameh, D. A. Effect of cowpea (Vigna unguiculata) processing methods on flatus causing oligosaccharides. Nutr. Res. 2000, 20, 349-358.

(117) Taiwo, K. A. The potential of cowpea as human food in Nigeria. Food Rev. International 1998, 14, 351-370.

(118) Oboh, H. A.; Muzquiz, M.; Burbano, C.; Cuadrado, C.; Pedrosa, M. M.; Ayet, G.; Osagie, A. U. Effect of soaking, cooking and germination on the oligosaccharide content of selected Nigerian legume seeds. Plant Foods for Human Nutr. 2000, 55, 97-110.

(119) Udensi, E. A.; Ekwu, F. C.; Isinguzo, J. N. Antinutrient factors of vegetable cowpea (Sesquipedalis) seeds during thermal processing. Pak. J. Nutr. 2007, 6, 194-197.

(120) Liener, I. E. Phytohemagglutinins (Phytolectins). Annual Rev. Plant Phys. Plant Mol. Bio. 1976, 27, 291-319.

(121) AOAC Method 925.10 (air oven method) for moisture in flour. In Official Methods of Analysis, 17th ed.; Gaithersburg, MD, 2000.

(122) Yeung, H.; Ehlers, J. D.; Waniska, R. D.; Alviola, J. N.; Rooney, L. W. Rapid screening methods to evaluate cowpea cooking characteristics. Field Crops Res. 2009, 112, 245-252.

(123) Prior, R. L.; Lazarus, S. A.; Cao, G.; Muccitelli, H.; Hammerstone, J. F. Identification of procyanidins and anthocyanins in blueberries and cranberries (Vaccinium Spp.) using High-Performance Liquid Chromatography/Mass Spectrometry. J. Agric. Food Chem. 2001, 49, $1270-1276$.

(124) Monagas, M.; Gómez-Cordovés, C.; Bartolomé, B.; Laureano, O.; Ricardo da Silva, J. M. Monomeric, oligomeric, and polymeric flavan-3-ol composition of wines and grapes from Vitis vinifera L. Cv. Graciano, Tempranillo, and Cabernet Sauvignon. J. Agric. Food Chem. 2003, 51, 6475-6481. 
(125) Ju, Z. Y.; Howard, L. R. Effects of solvent and temperature on pressurized liquid extraction of anthocyanins and total phenolics from dried red grape skin. J. Agric. Food Chem. 2003, 51, 5207-5213.

(126) Hollman, P. C. H.; Arts, I. C. W. Flavonols, flavones and flavanols nature, occurrence and dietary burden. J. Sci. Food Agric. 2000, 80, 10811093.

(127) Lee, J. H.; Kang, N. S.; Shin, S.-O.; Shin, S.-H.; Lim, S.-G.; Suh, D.-Y.; Baek, I.-Y.; Park, K.-Y.; Ha, T. J. Characterisation of anthocyanins in the black soybean (Glycine max L.) by HPLC-DAD-ESI/MS analysis. Food Chem. 2009, 112, 226-231.

(128) Takeoka, G. R.; Dao, L. T.; Full, G. H.; Wong, R. Y.; Harden, L. A.; Edwards, R. H.; Berrios, J. D. J. Characterization of black bean (Phaseolus vulgaris L.) Anthocyanins. J. Agric. Food Chem. 1997, 45, 3395-3400.

(129) Wu, X.; Prior, R. L. Identification and characterization of anthocyanins by High-Performance Liquid Chromatography - electrospray ionization tandem mass spectrometry in common foods in the United States: Vegetables, nuts, and grains. J. Agric. Food Chem. 2005, 53, 3101-3113.

(130) Xu, B.; Chang, S. K. C. Total phenolic, phenolic acid, anthocyanin, flavan3-ol, and flavonol profiles and antioxidant properties of pinto and black beans (Phaseolus vulgaris L.) as affected by thermal processing. J. Agric. Food Chem. 2009, 57, 4754-4764.

(131) Xu, B.; Chang, S. K. C. Total phenolics, phenolic acids, isoflavones, and anthocyanins and antioxidant properties of yellow and black soybeans as affected by thermal processing. J. Agric. Food Chem. 2008, 56, 7165-7175.

(132) Mercadante, A. Z.; Bobbio, F. O. Anthocyanins in foods: occurance and physiochemical properties. In Food Colorants: Chemical and Functional Properties, Socaciu, C., Ed. CRC Press: New York, 2007; pp 261.

(133) Sadilova, E.; Carle, R.; Stintzing, F. C. Thermal degradation of anthocyanins and its impact on color and in vitro antioxidant capacity. Mol. Nutr. Food Res. 2007, 51, 1461-1471.

(134) Svensson, L.; Sekwati-Monang, B.; Lutz, D. L.; Schieber, A.; Gänzle, M. G. Phenolic acids and flavonoids in nonfermented and fermented red sorghum (Sorghum bicolor (L.) Moench). J. Agric. Food Chem. 2010, 58, 9214-9220.

(135) Amarowicz, R.; Estrella, I.; Hernandez, T.; Troszynska, A. Antioxidant activity of extract of adzuki bean and its fractions. J. Food Lipids 2008, 15, 119-136. 
(136) Dueñas, M.; Sun, B.; Hernández, T.; Estrella, I.; Spranger, M. I. Proanthocyanidin composition in the seed coat of lentils (Lens culinaris L.). J. Agric. Food Chem. 2003, 51, 7999-8004.

(137) Schieber, A.; Berardini, N.; Carle, R. Identification of flavonol and xanthone glycosides from mango (Mangifera indica L. Cv. "Tommy Atkins”) peels by High-Performance Liquid Chromatography-Electrospray Ionization Mass Spectrometry. J. Agric. Food Chem. 2003, 51, 5006-5011.

(138) Bombardelli, E.; Morazzoni, P. Vitis vinifera L. Fitoterapia 1995, 66, 291317.

(139) Barofsky, D. F. FAB-MS applications in the elucidation of proanthocyanidin structures. In Chemistry and Significance of Condensed Tannins, Hemingway, R. W.; Karchesy, J. J., Eds. Plenum Press: New York, 1989; pp 175-195.

(140) Friedrich, W.; Eberhardt, A.; Galensa, R. Investigation of proanthocyanidins by HPLC with electrospray ionization mass spectrometry. Eur. Food Res. Technol. 2000, 211, 56-64.

(141) Li, H.-J.; Deinzer, M. L. The mass spectral analysis of isolated hops A-type proanthocyanidins by electrospray ionization tandem mass spectrometry. $J$. Mass Spec. 2008, 43, 1353-1363.

(142) Krueger, C. G.; Vestling, M. M.; Reed, J. D. Matrix-assisted laser desorption / ionization time-of-flight mass spectrometry of heteropolyflavan-3-ols and glucosylated heteropolyflavans in sorghum [Sorghum bicolor (L.) Moench]. J. Agric. Food Chem. 2003, 51, 538-543.

(143) Mullen, W.; Yokota, T.; Lean, M. E. J.; Crozier, A. Analysis of ellagitannins and conjugates of ellagic acid and quercetin in raspberry fruits by LC-MSn. Phytochemistry 2003, 64, 617-624.

(144) Giusti, M. M.; Rodríguez-Saona, L. E.; Griffin, D.; Wrolstad, R. E. Electrospray and Tandem Mass Spectroscopy as tools for anthocyanin characterization. J. Agric. Food Chem. 1999, 47, 4657-4664.

(145) Bonaccorsi, P.; Caristi, C.; Gargiulli, C.; Leuzzi, U. Flavonol glucoside profile of southern Italian red onion (Allium cepa L.). J. Agric. Food Chem. 2005, 53, 2733-2740.

(146) Hedin, P. A.; Iii, P. L. L.; Thompson, A. C.; Minyard, J. P. Isolation and structural determination of 13 flavonoid glycosides in Hibiscus Besculentus (Okra). Am. J. Bot. 1968, 55, 431-437. 
(147) Wang, M. L.; Morris, J. B. Flavonoid content of seeds of guar germplasm by HPLC. Plant Gen. Resources: Characterization and Utilization 2007, 5, 96-99.

(148) Cuyckens, F.; Claeys, M. Mass spectrometry in the structural analysis of flavonoids. J. Mass Spec. 2004, 39, 1-15.

(149) Wu, X.; Prior, R. L. Systematic identification and characterization of anthocyanins by HPLC-ESI-MS/MS in common foods in the United States: Fruits and berries. J. Agric. Food Chem. 2005, 53, 2589-2599.

(150) Beninger, C. W.; Hosfield, G. L.; Nair, M. G. Flavonol glycosides from the seed coat of a new Manteca-type dry bean (Phaseolus vulgaris L.). J. Agric. Food Chem. 1998, 46, 2906-2910.

(151) Lin, L.-Z.; He, X.-G.; Lindenmaier, M.; Yang, J.; Cleary, M.; Qiu, S.-X.; Cordell, G. A. LC-ESI-MS Study of the flavonoid glycoside malonates of red clover (Trifolium pratense). J. Agric. Food Chem. 2000, 48, 354-365.

(152) Olsen, H.; Aaby, K.; Borge, G. I. A. Characterization and quantification of flavonoids and hydroxycinnamic acids in curly kale (Brassica oleracea L. Convar. acephala Var. sabellica) by HPLC-DAD-ESI-MSn. J. Agric. Food Chem. 2009, 57, 2816-2825.

(153) Picinelli, A.; Dapena, E.; Mangas, J. J. Polyphenolic pattern in apple tree leaves in relation to scab resistance. A preliminary study. J. Agric. Food Chem. 1995, 43, 2273-2278.

(154) Jugdé, H.; Nguy, D.; Moller, I.; Cooney, J. M.; Atkinson, R. G. Isolation and characterization of a novel glycosyltransferase that converts phloretin to phlorizin, a potent antioxidant in apple. The FEBS Journal 2008, 275, 3804-3814.

(155) Rossetti, L.; Smith, D.; Shulman, I.; Papachristou, D.; Defronzo, A. Correction of hyperglycemia with phlorizin normalizes tissue sensitivity to insulin in diabetic rats. The J. Clin. Invest. 1987, 79, 1510-1515.

(156) Boccia, M. M.; Kopf, S. R.; Baratti, C. M. Phlorizin, a competitive inhibitor of glucose transport, facilitates memory storage in mice. Neur. Learning Mem. 1999, 71, 104-112.

(157) Gujer, R.; Magnolato, D.; Self, R. Glucosylated flavonoids and other phenolic compounds from sorghum. Phytochemistry 1986, 25, 1431-1436.

(158) Tomás-Barberán, F. A.; Clifford, M. N. Flavanones, chalcones and dihydrochalcones - nature, occurrence and dietary burden. J. Sci. Food Agric. 2000, 80, 1073-1080. 
(159) Farag, M. A.; Deavours, B. E.; de Fátima, Â.; Naoumkina, M.; Dixon, R. A.; Sumner, L. W. Integrated metabolite and transcript profiling identify a biosynthetic mechanism for hispidol in Medicago truncatula cell cultures. Plant Physiology 2009, 151, 1096-1113.

(160) Stevens, J. F.; Ivancic, M.; Hsu, V. L.; Deinzer, M. L. Prenylflavonoids from Humulus lupulus. Phytochemistry 1997, 44, 1575-1585.

(161) Macz-Pop, G. A.; González-Paramás, A. M.; Pérez-Alonso, J. J.; RivasGonzalo, J. C. New FlavanotAnthocyanin condensed pigments and anthocyanin composition in Guatemalan beans (Phaseolus spp.). J. Agric. Food Chem. 2005, 54, 536-542.

(162) Ewald, C.; Fjelkner-Modig, S.; Johansson, K.; Sjöholm, I.; Åkesson, B. Effect of processing on major flavonoids in processed onions, green beans, and peas. Food Chem. 1999, 64, 231-235.

(163) Aparicio-Fernandez, X.; Yousef, G. G.; Loarca-Pina, G.; de Mejia, E.; Lila, M. A. Characterization of polyphenolics in the seed coat of black Jamapa bean (Phaseolus vulgaris L.). J. Agric. Food Chem. 2005, 53, 4615-4622.

(164) Siebert, K. J.; Carrasco, A.; Lynn, P. Y. Formation of protein-polyphenol haze in beverages. J. Agric. Food Chem. 1996, 44, 1997-2005.

(165) Deshpande, S. S.; Cheryan, M. Evaluation of vanillin assay for tannin analysis of dry beans. J. Food Sci. 1985, 50, 905-910.

(166) Hagerman, A. E.; Riedl, K. M.; Jones, G. A.; Sovik, K. N.; Ritchard, N. T.; Hartzfeld, P. W.; Riechel, T. L. High molecular weight plant polyphenolics (tannins) as biological antioxidants. J. Agric. Food Chem. 1998, 46, 18871892.

(167) Tsuda, T.; Osawa, T.; Nakayama, T.; Kawakishi, S.; Ohshima, K. Antioxidant activity of pea bean (Phaseolus vulgaris L.) extract. J. Am. Oil Chem. Soc. 1993, 70, 909-913.

(168) Velioglu, Y. S.; Mazza, G.; Gao, L.; Oomah, B. D. Antioxidant activity and total phenolics in selected fruits, vegetables, and grain products. J. Agric. Food Chem. 1998, 46, 4113-4117.

(169) Adebooye, O. C.; Singh, V. Effect of cooking on the profile of phenolics, tannins, phytate, amino acid, fatty acid and mineral nutrients of whole-grain and decorticated vegetable cowpea (Vigna unguiculata L. Walp). J. Food Qual. 2007, 30, 1101-1120. 
(170) Kaluza, W. Z.; McGrath, R. M.; Roberts, T. C.; SchroÌder, H. H. Separation of phenolics of Sorghum bicolor (L.) moench grain. J. Agric. Food Chem. 1980, 28, 1191-1196.

(171) Broadhurst, R. B.; Jones, W. T. Analysis of condensed tannins using acidified vanillin. J. Sci. Food Agric. 1978, 29, 788-794.

(172) Re, R.; Pellegrini, N.; Proteggente, A.; Pannala, A.; Yang, M.; Rice-Evans, C. Antioxidant activity applying an improved ABTS radical cation decolorization assay. Free Rad. Bio. Med. 1999, 26, 1231-1237.

(173) Talcott, S. T.; Lee, J. H. Ellagic acid and flavonoid antioxidant content of muscadine wine and juice. J. Agric. Food Chem. 2002, 50, 3186-3192.

(174) Xu, B. J.; Chang, S. K. C. Total phenolic content and antioxidant properties of eclipse black beans (Phaseolus vulgaris L.) as affected by processing methods. J. Food Sci. 2008, 73, H19-H27.

(175) Bressani, A.; Elias, L. G. The nutritional role of polyphenols in beans. In Polyphenols in cereal and legumes, Hulse, J. H., Ed. Ottawa, 1980; pp 6168.

(176) Manzocco, L.; Anese, M.; Nicoli, M. C. Antioxidant properties of tea extracts as affected by processing. LWT - Food Sci. Technol. 1998, 31, 694-698.

(177) Nicoli, M. C.; Anese, M.; Parpinel, M. T.; Franceschi, S.; Lerici, C. R. Loss and/or formation of antioxidants during food processing and storage. Cancer Lett. 1997, 114, 71-74.

(178) Huang, Y.-C.; Chang, Y.-H.; Shao, Y.-Y. Effects of genotype and treatment on the antioxidant activity of sweet potato in Taiwan. Food Chem. 2006, 98, 529-538.

(179) Huang, D.; Ou, B.; Prior, R. L. The chemistry behind antioxidant capacity assays. J. Agric. Food Chem. 2005, 53, 1841-1856.

(180) Prior, R. L.; Cao, G. In vivo total antioxidant capacity: comparison of different analytical methods1. Free Rad. Bio. Med. 1999, 27, 1173-1181.

(181) Warrington, R. T.; Hale, A. L.; Scheuring, D. C.; Whitaker, D. W.; Blessington, T.; Miller Jr, J. C. Variability for antioxidant activity in cowpea (Vigna unguiculata (L.) Walp.) as influenced by genotype and post-harvest rehydration. HortScience 2002, 37, 738. 
(182) Xu, G.; Ye, X.; Chen, J.; Liu, D. Effect of Heat Treatment on the Phenolic compounds and antioxidant capacity of citrus peel extract. J. Agric. Food Chem. 2006, 55, 330-335.

(183) Barton, G. M. A calculated response: Control of inflammation by the innate immune system. J. Clin. Investigation 2008, 118, 413-420.

(184) W. H. O. World Health Statistics 2008; World Health Organization: Geneva Switzerland, 2008.

(185) Triantafillidis, J. K.; Nasioulas, G.; Kosmidis, P. A. Colorectal cancer and inflammatory bowel disease: epidemiology, risk factors, mechanisms of carcinogenesis and prevention strategies. Anticancer Res. 2009, 29, 27272737.

(186) Rathee, P.; Chaudhary, H.; Rathee, S.; Rathee, D.; Kumar, V.; Kohli, K. Mechanism of action of flavonoids as anti-inflammatory agents: A Review. Inflamm. Allergy - Drug Targets 2009, 8, 229-235.

(187) Kim, H. P.; Son, K. H.; Chang, H. W.; Kang, S. S. Anti-inflammatory plant flavonoids and cellular action mechanisms. J. Pharm. Sci. 2004, 96, 229245.

(188) Koide, T.; Hashimoto, Y.; Kamei, H.; Kojima, T.; Hasegawa, M.; Terabe, $\mathrm{K}$. Antitumor effect of anthocyanin fractions extracted from red soybeans and red beans in vitro and in vivo. Cancer Biotherapy Radiopharm. 1997, 12, 277-280.

(189) Aparicio-Fernández, X.; Manzo-Bonilla, L.; Loarca-Piña, G. F. Comparison of antimutagenic activity of phenolic compounds in newly harvested and stored common beans Phaseolus vulgaris against aflatoxin B1. J. Food Sci. 2005, 70, S73-S78.

(190) Oomah, B. D.; Corbé, A. l.; Balasubramanian, P. Antioxidant and antiinflammatory activities of bean (Phaseolus vulgaris L.) Hulls. J. Agric. Food Chem. 2010, 58, 8225-8230.

(191) Han, K. H.; Fukushima, M.; Ohba, K.; Shimada, K.; Sekikawa, M.; Chiji, H.; Lee, C. H.; Nakano, M. Hepatoprotective effects of the water extract from adzuki bean hulls on acetaminophen-induced damage in rat liver. $J$. Nutr. Sci. Vitam. 2004, 50, 380-383.

(192) Rice-Evans, C. A.; Miller, N. J.; Paganga, G. Antioxidant properties of phenolic compounds. Trends Plant Sci. 1997, 2, 152-159.

(193) Singh, B. N.; Singh, B. R.; Sarma, B. K.; Singh, H. B. Potential chemoprevention of $\mathrm{N}$-nitrosodiethylamine-induced hepatocarcinogenesis 
by polyphenolics from Acacia nilotica bark. Chemico-Bio. Interactions 2009, 181, 20-28.

(194) Yang, L.; Browning, J. D.; Awika, J. M. Sorghum 3-Deoxyanthocyanins Possess Strong Phase II Enzyme Inducer Activity and Cancer Cell Growth Inhibition Properties. J. Agric. Food Chem. 2009, 57, 1797-1804.

(195) Kluth, D.; Banning, A.; Paur, I.; Blomhoff, R.; Brigelius-Flohé, R. Modulation of pregnane $\mathrm{X}$ receptor-and electrophile responsive elementmediated gene expression by dietary polyphenolic compounds. Free Rad. Bio.Med. 2007, 42, 315-325.

(196) Haddad, J. J. Cytokines and related receptor-mediated signaling pathways. Biochem. Biophys. Res. Comm. 2002, 297, 700-713.

(197) Garg, A.; Aggarwal, B. B. Nuclear transcription factor-kappa B as a target for cancer drug development. Leukemia 2002, 16, 1053-1068.

(198) Havsteen, B. Flavonoids, a class of natural products of high pharmacological potency. Biochem. Pharm. 1983, 32, 1141-1148.

(199) Weber, C. Novel mechanistic concepts for the control of leukocyte transmigration: specialization of integrins, chemokines, and junctional molecules. J. Mol. Med. 2003, 81, 4-19.

(200) Collins, T.; Read, M.; Neish, A.; Whitley, M.; Thanos, D.; Maniatis, T. Transcriptional regulation of endothelial cell adhesion molecules: NFkappa B and cytokine-inducible enhancers. The FASEB Journal 1995, 9, 899-909.

(201) Gantier, M. P.; Sadler, A. J.; Williams, B. R. G. Fine-tuning of the innate immune response by microRNAs. Immunology Cell Bio. 2007, 85, 458462.

(202) Messina, M.; Barnes, S. The role of soy products in reducing the risk of cancer. J. National Cancer Inst. 1991, 83, 541-546.

(203) Kim, J. M.; Kim, J. S.; Yoo, H.; Choung, M. G.; Sung, M. K. Effects of black soybean [Glycine max (l.) merr.] seed coats and its anthocyanidins on colonic inflammation and cell proliferation in vitro and in vivo. J. Agric. Food Chem. 2008, 56, 8427-8433.

(204) World Cancer Research Fund/American Institute for Cancer Research (AICR). Food, nutrition, physical activity and the prevention of cancer: A global perspective; Washington, D.C., 2007. 
(205) Swain, T.; Hillis, W. E. The phenolic constituents of Prunus domestica. I. The quantitative analysis of phenolic constituents. J. Sci. Food Agric. 1959, 10, 63-68.

(206) Meng, Q.; Velalar, C. N.; Ruan, R. Effects of epigallocatechin-3-gallate on mitochondrial integrity and antioxidative enzyme activity in the aging process of human fibroblast. Free Rad. Bio. Med. 2008, 44, 1032-1041.

(207) Gian Luigi, R. Ins and outs of dietary phytochemicals in cancer chemoprevention. Biochem. Pharm. 2007, 74, 533-544.

(208) Paul T, S. Reactive oxygen species in cancer cells: Live by the sword, die by the sword. Cancer Cell 2006, 10, 175-176.

(209) Soohyoung, L.; Young-Jin, K.; Sanghoon, K.; Younghee, L.; Soo, Y. C.; Jinseu, P.; Hyung-Joo, K. Inhibitory effects of flavonoids on TNF- $\alpha-$ induced IL-8 gene expression in HEK 293 cells. BMB Report 2009, 42, 265-270.

(210) Crespo, I.; García-Mediavilla, M. V.; Almar, M.; González, P.; Tuñón, M. J.; Sánchez-Campos, S.; González-Gallego, J. Differential effects of dietary flavonoids on reactive oxygen and nitrogen species generation and changes in antioxidant enzyme expression induced by proinflammatory cytokines in Chang Liver cells. Food Chem. Toxicol. 2008, 46, 1555-1569.

(211) Kowalski, J.; Samojedny, A.; Paul, M.; Pietsz, G.; Wilczok, T. Effect of kaempferol on the production and gene expression of monocyte chemoattractant protein-1 in J774.2 macrophages. Pharm. Report 2005, 57, 107-112.

(212) Grimm, M.; Elsbury, S.; Pavli, P.; Doe, W. Enhanced expression and production of monocyte chemoattractant protein-1 in inflammatory bowel disease mucosa. J. Leukocyte Bio. 1996, 59, 804-812.

(213) Matsuda, R.; Koide, T.; Tokoro, C.; Yamamoto, T.; Godai, T. i.; Morohashi, T.; Fujita, Y.; Takahashi, D.; Kawana, I.; Suzuki, S.; Umemura, S. Quantitive cytokine mRNA expression profiles in the colonic mucosa of patients with steroid naïve ulcerative colitis during active and quiescent disease. Inflamm. Bowel Dis. 2009, 15, 328-334.

(214) Baier, P. K.; Eggstein, S.; Wolff-Vorbeck, G.; Baumgartner, U.; Hopt, U. T. Chemokines in human colorectal carcinoma. Anticancer Res. 2005, 25, 3581-3584.

(215) García-Mediavilla, V.; Crespo, I.; Collado, P. S.; Esteller, A.; SánchezCampos, S.; Tuñón, M. J.; González-Gallego, J. The anti-inflammatory flavones quercetin and kaempferol cause inhibition of inducible nitric oxide 
synthase, cyclooxygenase-2 and reactive C-protein, and down-regulation of the nuclear factor kappaB pathway in Chang Liver cells. Eur. J. Pharm. 2007, 557, 221-229.

(216) Chen, F.; Castranova, V.; Shi, X.; Demers, L. M. New insights into the role of Nuclear Factor-kappa B, a ubiquitous transcription factor in the initiation of diseases. Clin. Chem. 1999, 45, 7-17.

(217) Privratsky, J. R.; Newman, D. K.; Newman, P. J. PECAM-1: Conflicts of interest in inflammation. Life Sci. 2010, 87, 69-82.

(218) Noratto, G. D.; Angel-Morales, G.; Talcott, S. T.; Mertens-Talcott, S. U. Polyphenolics from açaí (Euterpe oleracea Mart.) and red Muscadine grape (Vitis rotundifolia) protect human umbilical vascular endothelial cells (HUVEC) from glucose- and lipopolysaccharide (LPS)-induced inflammation and target microRNA-126. J. Agric. Food Chem. 2011, 59, 7999-8012.

(219) Bagchi, D.; Sen, C. K.; Ray, S. D.; Das, D. K.; Bagchi, M.; Preuss, H. G.; Vinson, J. A. Molecular mechanisms of cardioprotection by a novel grape seed proanthocyanidin extract. Mutation Res./Fund. Mol. Mech. Mutagen. 2003, 523-524, 87-97.

(220) Naito, Y.; Yoshikawa, T. Green tea and heart health. J. Cardiovascular Pharm. 2009, 54, 385-390.

(221) Nickenig, G.; Harrison, D. G. The AT1-type angiotensin receptor in oxidative stress and atherogenesis. Circulation 2002, 105, 530-536.

(222) Tummala, P. E.; Chen, X.-L.; Sundell, C. L.; Laursen, J. B.; Hammes, C. P.; Alexander, R. W.; Harrison, D. G.; Medford, R. M. Angiotensin II induces vascular cell adhesion molecule-1 expression in rat vasculature: A potential link between the renin-angiotensin system and atherosclerosis. Circulation 1999, 100, 1223-1229.

(223) Chirumbolo, S. The role of quercetin, flavonols and flavones in modulating inflammatory cell function. Inflamm. Allergy - Drug Targets 2010, 9, 263285.

(224) Lin, F.-S.; Lin, C.-C.; Chien, C.-S.; Luo, S.-F.; Yang, C.-M. Involvement of p42/p44 MAPK, JNK, and NF- $\kappa$ B in IL-1 $\beta$-induced ICAM-1 expression in human pulmonary epithelial cells. J. Cellular Phys. 2005, 202, 464-473.

(225) Fish, J. E.; Santoro, M. M.; Morton, S. U.; Yu, S.; Yeh, R.-F.; Wythe, J. D.; Ivey, K. N.; Bruneau, B. G.; Stainier, D. Y. R.; Srivastava, D. miR-126 regulates angiogenic signaling and vascular integrity. Developmental Cell 2008, 15, 272-284. 
(226) Yu, S.-L.; Chen, H.-Y.; Chang, G.-C.; Chen, C.-Y.; Chen, H.-W.; Singh, S.; Cheng, C.-L.; Yu, C.-J.; Lee, Y.-C.; Chen, H.-S.; Su, T.-J.; Chiang, C.-C.; Li, H.-N.; Hong, Q.-S.; Su, H.-Y.; Chen, C.-C.; Chen, W.-J.; Liu, C.-C.; Chan, W.-K.; Chen, W. J.; Li, K.-C.; Chen, J. J. W.; Yang, P.-C. MicroRNA signature predicts survival and relapse in lung cancer. Cancer Cell 2008, 13, 48-57.

(227) Tavazoie, S. F.; Alarcon, C.; Oskarsson, T.; Padua, D.; Wang, Q.; Bos, P. D.; Gerald, W. L.; Massague, J. Endogenous human microRNAs that suppress breast cancer metastasis. Nature 2008, 451, 147-152.

(228) Yanaihara, N.; Caplen, N.; Bowman, E.; Seike, M.; Kumamoto, K.; Yi, M.; Stephens, R. M.; Okamoto, A.; Yokota, J.; Tanaka, T.; Calin, G. A.; Liu, C.-G.; Croce, C. M.; Harris, C. C. Unique microRNA molecular profiles in lung cancer diagnosis and prognosis. Cancer Cell 2006, 9, 189-198.

(229) Sen, C. K.; Gordillo, G. M.; Khanna, S.; Roy, S. Micromanaging vascular biology: Tiny microRNAs play big band. J. Vascular Res. 2009, 46, 527540.

(230) Karchesy, J. J.; Hemingway, R. W.; Foo, Y. L.; Barofsky, E.; Barofsky, D. F. Sequencing procyanidin oligomers by fast atom bombardment mass spectrometry. Anal. Chem. 1986, 58, 2563-2567.

(231) Es-Safi, N.-E.; Cheynier, V.; Moutounet, M. Implication of phenolic reactions in food organoleptic properties. J. Food Compos. Anal. 2003, 16, $535-553$.

(232) Salminen, J. P.; Ossipov, V.; Loponen, J.; Haukioja, E.; Pihlaja, K. Characterisation of hydrolysable tannins from leaves of Betula pubescens by high-performance liquid chromatography-mass spectrometry. $J$. Chromatogr. A 1999, 864, 283-291.

(233) Barry, K. M.; Davies, N. W.; Mohammed, C. L. Identification of hydrolysable tannins in the reaction zone of Eucalyptus nitens wood by high performance liquid chromatography-electrospray ionisation mass spectrometry. Phytochem. Analysis 2001, 12, 120-127.

(234) Aaby, K.; Skrede, G.; Wrolstad, R. E. Phenolic composition and antioxidant activities in flesh and achenes of strawberries (Fragaria ananassa). J. Agric. Food Chem. 2005, 53, 4032-4040. 


\section{APPENDIX A}

Cowpea phenotypes investigated in this study

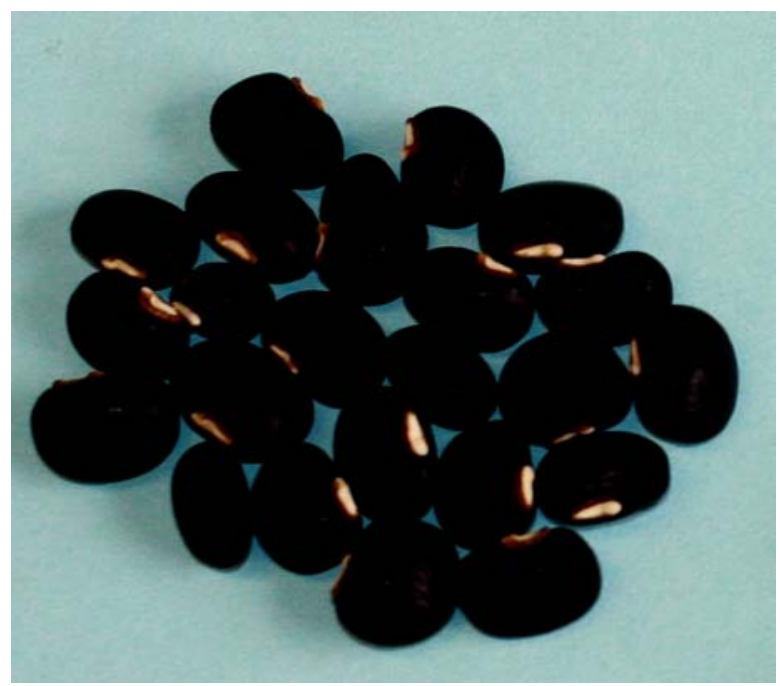

Black phenotypes

(Varieties IT95K-1105-5 and IT98K-1092-1)

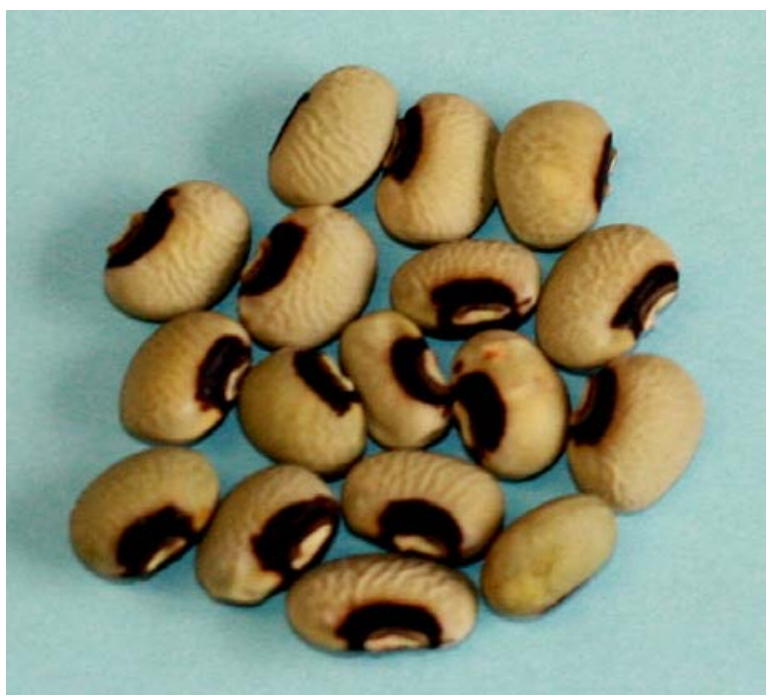

Green phenotype

(Variety TX2028-1-3-1) 


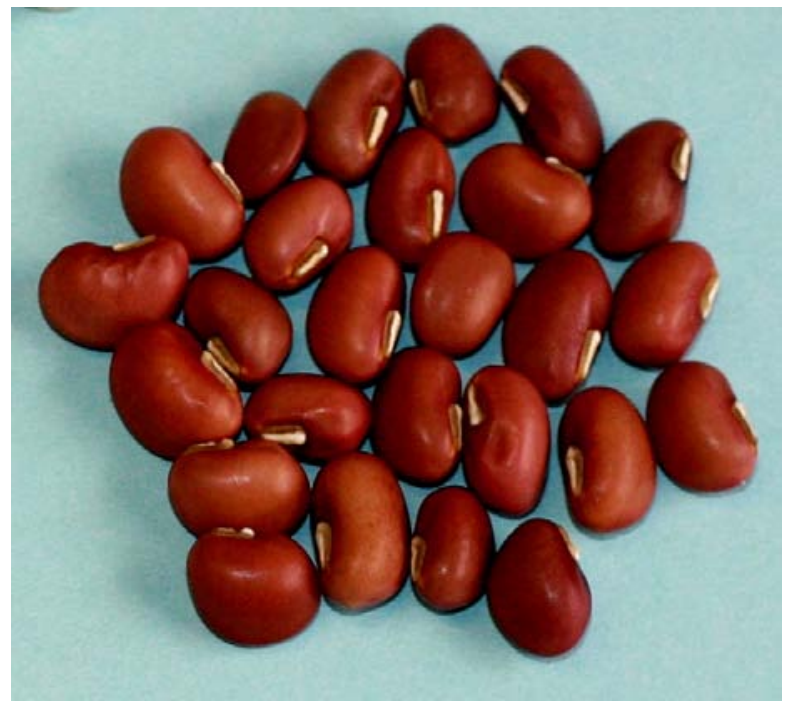

Red phenotypes

(Varieties IT97K-1042-3 and IT82D-889)

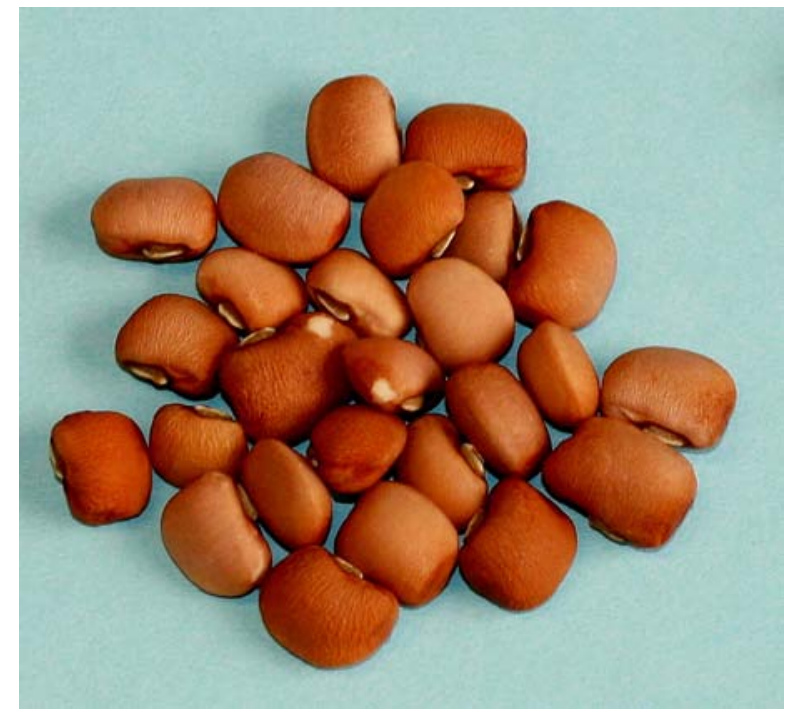

Golden Brown phenotypes

(Varieties Ife Brown and IT84S-2246) 


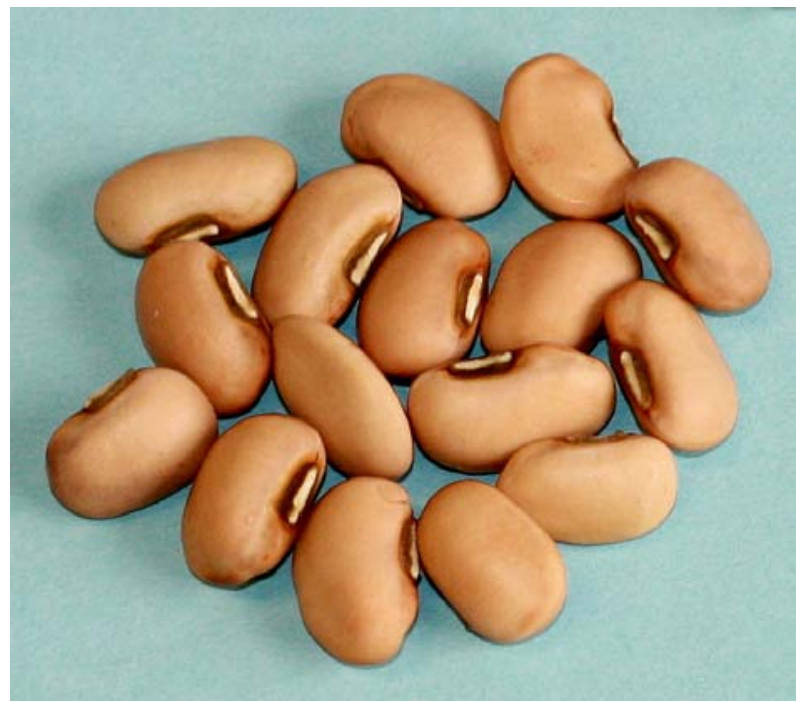

Light Brown phenotypes

(Varieties IAR-48 and 09FCV-CC27M)

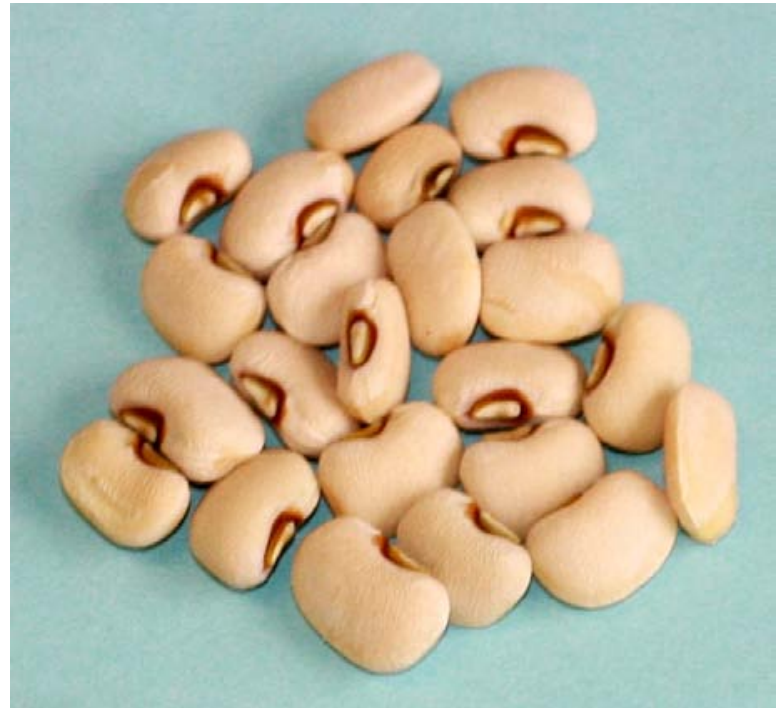

White phenotype

(Variety Early Acre) 


\section{APPENDIX B}

\section{Partly identified and non-identified compounds}

The following peaks were characterized as far as possible using the MS/MS-MS and UV-vis spectra obtained. Most of the non-identified compounds were found in the ethyl acetate fraction, indicating they are less hydrophobic. They also did not have any shared MS characteristics, suggesting each peak may be structurally different.

Peak $2\left(\mathrm{t}_{\mathrm{R}}=2.85 \mathrm{~min}, \lambda_{\max }=278 \mathrm{~nm}\right)$ had a $[\mathrm{M}-\mathrm{H}]^{-}$at $\mathrm{m} / \mathrm{z} 203$ that fragmented on MS/MS to produce ions at m/z 159 (M-44, loss of $\mathrm{CO}_{2}$ ), 142 (M-44-17 amu), 116 (M-44-17-26 amu) and $74(\mathrm{M}-44-17-26-42 \mathrm{amu})$, the fragmentation pattern suggest that it could be a simple compound with a carboxylic terminal end, non-glycosylated and may only be consisting of one benzene ring (Table 7). This peak was present in all the varieties studied, suggesting it is a major component of cowpea.

Also, the true identities of peaks 6, 12 and 18 could not be established based on the MS data alone (Table 7). All these three peaks had similar $[\mathrm{M}-\mathrm{H}]^{-}$at $\mathrm{m} / \mathrm{z} 885$ and absorption maxima $\lambda_{\max }=279 \mathrm{~nm}$. Moreover, their MS/MS fragmentation patterns were also similar. However, these peaks had significantly different retention times. The $t_{R}$ for peaks 6, 12 and 18 were 4.19, 5.36 and $6.16 \mathrm{~min}$, respectively, suggesting that the compounds were structurally related but had varying polarity which affected their elution properties. The MS/MS ion at $\mathrm{m} / \mathrm{z} 723$ suggested a loss of 162 amu, corresponding to a loss of one hexose unit. It therefore means that all these compounds are mono-glycosylated. The position of this glucose unit and the nature of the sugar (glucose or galactose) could also be responsible for the differences in elution times. 
Other major products included ions at $\mathrm{m} / \mathrm{z} 435(\mathrm{M}-162-288 \mathrm{amu})$ suggesting the presence of flavanol, which must be (epi)-catechin (161). The loss of 288 amu occurs when the (epi)catechin is situated in the upper unit; otherwise, we would expect a loss of 290 amu if the (epi)catechin is found in the terminal unit (230). In all likelihood, these compounds could be isomers of the same compound within the catechin (tannin) family.

Another unidentified compound is Peak $7\left(\mathrm{t}_{\mathrm{R}}=4.45 \mathrm{~min}, \lambda_{\max }=271 \mathrm{~nm}\right)$ which had an even numbered $[\mathrm{M}-\mathrm{H}]^{-}$ion at $\mathrm{m} / \mathrm{z}$ 508. Further, some of its main MS/MS fragments also gave even numbered ions: at m/z 328 (M - 180 amu); m/z 258 (M - 180 70 amu); and a major ion at $m / z 145(\mathrm{M}-180-70-113$ amu) (Table 7). Since the experimental conditions were optimized to provide for the best fragmentation conditions for individual compounds, this distinct fragmentation characteristic of this compound in the negative mode indicates the presence of a unique group in the its structure in addition to the usual phenolic skeletons.

Peak $15\left(\mathrm{t}_{\mathrm{R}}=5.85 \mathrm{~min}, \lambda_{\max }=278 \mathrm{~nm}\right)($ Figures 15A-2 and 19A-1) had a $[\mathrm{M}-$ $\mathrm{H}]^{-}$at $\mathrm{m} / \mathrm{z}$ 387, with MS/MS fragments at $\mathrm{m} / \mathrm{z} 207$ (M - $\left.180 \mathrm{amu}\right)$, suggesting a loss of caffeic acid (aromatic acid), and m/z 89 (M - 180 - $118 \mathrm{amu}$ ), suggesting a further loss of succinic acid (aliphatic acid) without concomitant loss of water molecule (Table 7). This could indicate the presence of these acylated groups bound to the compound. These groups may also be responsible for low $\lambda_{\max }=278 \mathrm{~nm}$ exhibited by this compound. However, the two groups may be held together by a simple phenolic compound, which could be esters or other phenolic plant constituents. 
Peak $16\left(\mathrm{t}_{\mathrm{R}}=6.03 \mathrm{~min}, \lambda_{\max }=279 \mathrm{~nm}\right)\left(\right.$ Figure 8A-1) had a $[\mathrm{M}-\mathrm{H}]^{-}$at $\mathrm{m} / \mathrm{z} 721$, with MS/MS fragments at m/z $407(\mathrm{M}-314 \mathrm{amu})$, and at $\mathrm{m} / \mathrm{z} 289(\mathrm{M}-314-117 \mathrm{amu})$. The presence of $m / z 289$ as one of the major MS/MS product ions may suggest it is from the catechin family of compounds. The ion with 314 amu is suspected to consist of two units; a galloyl (152 amu) and glycosyl (162 amu) moieties. The ion with 117 amu may be a compound(s) whose constituent(s) are still unknown (Table 7).

Peak $20\left(\mathrm{t}_{\mathrm{R}}=6.36 \mathrm{~min}, \lambda_{\max }=294 \mathrm{~nm}\right)$ showed $[\mathrm{M}-\mathrm{H}]^{-}$at $\mathrm{m} / \mathrm{z} 317$, which is similar to that of myricetin. Since flavonols have UV absorption maxima $\sim 360 \mathrm{~nm}$, this compound cannot be a myricetin (Table 7). Because it has similar fragmentation pattern as (+)-catechin, we suspect this compound could be related to the catechin family of molecules. The difference between catechin and this compound is $28 \mathrm{amu}$. Thus, it is possible that this compound consisted of a catechin unit with one aldehyde group linked to the position 6 or 8 of the aromatic A ring (231).

Peak $26\left(\mathrm{t}_{\mathrm{R}}=6.86 \mathrm{~min}, \lambda_{\max }=376 \mathrm{~nm}\right)\left(\right.$ Figure 20B) showed a $[\mathrm{M}-\mathrm{H}]^{-}$at $\mathrm{m} / \mathrm{z}$ 899. In the MS/MS spectrum different fragments are observed, the majority being the ion at $\mathrm{m} / \mathrm{z} 737(\mathrm{M}-162 \mathrm{amu})$, corresponding to loss of a glycosyl unit. The other important fragments are ions at m/z 585 (loss of $152 \mathrm{amu}$ ), m/z 557 (loss of $180 \mathrm{amu}$ ), m/z 539 (loss of $198 \mathrm{amu}$ ) and m/z 407 (loss of $330 \mathrm{amu}$ ), which arise from the cleavage of the ion at $\mathrm{m} / \mathrm{z} 73$ (Table 8). However, on the basis of the MS data, we could not establish the identity of this peak.

Peak $31\left(\mathrm{t}_{\mathrm{R}}=7.48 \mathrm{~min}, \lambda_{\max }=290 \mathrm{~nm}\right)$ had $[\mathrm{M}-\mathrm{H}]^{-}$at $\mathrm{m} / \mathrm{z} 349$, and MS/MS spectrum showed fragments at $\mathrm{m} / \mathrm{z} 331$ (M - $18 \mathrm{amu})$, corresponding to loss of water 
molecule; followed by $\mathrm{m} / \mathrm{z} 299(\mathrm{M}-18$ - $32 \mathrm{amu})$, corresponding to subsequent loss of a methoxyl group; then $\mathrm{m} / \mathrm{z} 271(\mathrm{M}-18$ - 32 - $28 \mathrm{amu}$ ), corresponding to subsequent loss of an oxo group $(\mathrm{C}=\mathrm{O})$. Peaks 31, however, had no absorbance in the visible region of the UV-vis spectra (Table 7), meaning the flavylium structure with conjugated double bonds was interrupted, thus the correct identity of this peak could not be elucidated. Peak $35\left(\mathrm{t}_{\mathrm{R}}=7.73 \mathrm{~min}, \lambda_{\max }=278 \mathrm{~nm}\right)$ had $[\mathrm{M}-\mathrm{H}]^{-}$at $\mathrm{m} / \mathrm{z}$ 723. During fragmentation, the major ions were formed at $\mathrm{m} / \mathrm{z} 434$ (loss of $289 \mathrm{amu}$, possibly catechin), $\mathrm{m} / \mathrm{z} 395$ (loss of $328 a m u$ ), m/z 287 (loss of $436 a m u$ ) and m/z 125 (loss of $598 a m u$ ). The ions with mass 328, 436 and 598 probably consist of multiple parts, the constituents of which are unknown (Table 7). This is an unusual structural pattern that, to our knowledge, has never been observed before in phenolic compounds.

According to mass spectral data, peaks 37 and 38 may have structural features similar to each other. They both consisted of $[\mathrm{M}-\mathrm{H}]^{-}$at $\mathrm{m} / \mathrm{z} 467$, and MS/MS products at 323 (loss of $144 \mathrm{amu}$ ), 305 (loss of $162 \mathrm{amu}$ ), 203 (loss of $264 \mathrm{amu}$ ), 189 (loss of 278 amu) and 161 (loss of $306 \mathrm{amu})$. However, peak $37\left(\mathrm{t}_{\mathrm{R}}=7.809 \mathrm{~min}\right.$ ) eluted shortly before peak $38\left(\mathrm{t}_{\mathrm{R}}=7.814 \mathrm{~min}\right)$, suggesting it is less polar than peak 38 ; and its $\lambda_{\max }$ (359 nm) was $34 \mathrm{~nm}$ higher than that of peak 38 (Table 8).

On the other hand, peak $39\left(t_{\mathrm{R}}=7.90 \mathrm{~min}\right)$ exhibited a maximum UV absorbance at $350 \mathrm{~nm}$. It gave rise to a precursor ion at $\mathrm{m} / \mathrm{z}$ 597. The fragmentations included ions at m/z 454 (M - 143 amu), 387 (M - 210 amu), 380 (M - 217 amu), 357 (M - 240 amu), $273(\mathrm{M}-324 a m u), 229(\mathrm{M}-368 a m u)$ and 167 (M - $430 \mathrm{amu})$ (Table 8). It is evident 
that peak 39 shows an unusual structural pattern that, to our knowledge, has not been observed in flavonols before.

Peak $43\left(t_{\mathrm{R}}=8.29 \mathrm{~min}\right)$ gave rise to $[\mathrm{M}-\mathrm{H}]^{-}$at $\mathrm{m} / \mathrm{z} 737$. Based on its retention time, it appears that this compound is very polar; while its maximum UV absorbance at $376 \mathrm{~nm}$ suggests it may be a chalcone. The major MS/MS ions were at m/z 407 (M - 330 amu) and $394(\mathrm{M}-343 \mathrm{amu})$. The intensity of the latter ion $(\mathrm{m} / \mathrm{z} 394)$ was much higher than that of the former $(\mathrm{m} / \mathrm{z} 407)$ in the MS/MS spectrum (Table 8). This fragmentation pattern is also unique in the sense that ions with 330 and $343 \mathrm{amu}$ may consist of multiple compounds, the nature of which have not been previously observed in chalcone derivatives.

Peak $44\left(t_{\mathrm{R}}=8.40 \mathrm{~min}, \lambda_{\max }=279 \mathrm{~nm}\right)$ shows $[\mathrm{M}-\mathrm{H}]^{-}$at $m / \mathrm{z} 809$, with MS/MS fragments at m/z $595(\mathrm{M}$ - $214 \mathrm{amu}), 435$ (M - 374 amu), 391 (M - 418 amu), $272(\mathrm{M}-$ $537 \mathrm{amu}$ ) and $161(\mathrm{M}-648 \mathrm{amu})$ (Table 7). This high molecular weight compound is typical of proanthocyanidins (condensed tannins), which are oligomeric and polymeric catechins. However, catechins and catechin-related compounds usually produce specific molecular ions at $m / z=289$ and 577. Our MS/MS analysis did not detect any of these signals, as well as any glycosyl ions, indicating that this peak is not related to catechins and proanthocyanidins or its glycosidated derivatives. From this evidence, there is a high likelihood that this peak may be a unique compound that has never been identified in cowpea before, thus, application of NMR techniques is suggested.

Peak $46\left(t_{\mathrm{R}}=8.65 \mathrm{~min}, \lambda_{\max }=364 \mathrm{~nm}\right)$ gave rise to $[\mathrm{M}-\mathrm{H}]^{-}$at $\mathrm{m} / \mathrm{z} 867$, which on fragmentation resulted in ions at $m / z 517(\mathrm{M}-530 \mathrm{amu}), 349(\mathrm{M}-530-12$ amu), 
$331(\mathrm{M}-530-12-6$ amu) and 317 ( $\mathrm{M}-530-12-6-2$ amu) (Table 8). The ion with mass 530 can be attributed to a rutinose (6-O- $\alpha$-L-rhamnosyl- $D$-glucose) attached to acetoyl group (42 amu). Based on the maximum UV absorbance we assume this peak may be related to a flavonol-like compound.

Peak $52\left(t_{\mathrm{R}}=5.28 \mathrm{~min}, \lambda_{\max }=325 \mathrm{~nm}\right)$ had a precursor ion at $\mathrm{m} / \mathrm{z} 865$. The MS/MS spectra showed ions at m/z 577 and 289 (Table 9), typical of high molecular weight catechin/epicatechin derivatives. We observed a major fragment at $\mathrm{m} / \mathrm{z} 713$ (loss of $152 \mathrm{amu}$ ), corresponding to loss of galloyl unit. Salminen et al. (232) reported that loss of a galloyl unit indicated that the galloyl unit most probably was bonded via a $m$ depside bond. Thus, this peak could be an m-galloyl-linked derivative. Structural properties of the compound with mass 136 (713 - $577 \mathrm{amu})$ is unknown. The ion at $\mathrm{m} / \mathrm{z}$ 425 corresponds to direct Retro Diels-Alder (RDA) cleavage of the pseudomolecular ion in the top unit, while the ion at $\mathrm{m} / \mathrm{z} 125$ corresponds to the RDA fragment in negative mode (140). The ion at $\mathrm{m} / \mathrm{z} 407$ corresponds to water elimination (425 - $18 \mathrm{amu}$ ), while the $\lambda_{\max }$ at $325 \mathrm{~nm}$ suggest that one of its units may be a flavonol. In this study, we already reported the presence of a flavonol-flavan-3-ol derivative (peak 66), thus peak 52 could also have been formed through a similar mechanism. Nevertheless our analysis did not allow us to establish the position and stereochemistry of the interflavanoid linkage.

Peak $54\left(t_{\mathrm{R}}=6.11 \mathrm{~min}, \lambda_{\max }=266 \mathrm{~nm}\right)$ had $[\mathrm{M}-\mathrm{H}]^{-}$at $\mathrm{m} / \mathrm{z} 281$, and from the MS/MS fragments, it appears that this could be a simple phenolic compound. One of the major signals in MS/MS was caused by the ion at $m / z 237$ (loss of $44 \mathrm{amu}$ ). A loss of 44 
amu is characteristic of a free carboxyl group (233). Additionally, only small molecules (80, 92 and $110 \mathrm{amu}$ ) were lost during fragmentation, with one exception; ion at $\mathrm{m} / \mathrm{z} 123$ (loss of $158 \mathrm{amu}$ ). The UV spectrum of peak 55 is consistent with a derivative of phenolic acids (Table 9).

Peak $60\left(t_{\mathrm{R}}=7.26 \mathrm{~min}\right)$ had a molecular ion $\mathrm{m} / \mathrm{z}$ 341, with a UV-vis absorption maximum of $492 \mathrm{~nm}$ - a property usually observed in some anthocyanins. However, anthocyanidins with a 3-hydroxyl group do not exist naturally in their aglycone form. Anthocyanidins are also soluble in methanol. If this pigment was an anthocyanin, we would expect to find it in greater quantities in the methanolic fraction than in the ethylacetate fraction. We did not detect it in the methanol fraction. The MS/MS spectra showed ions at m/z $295(\mathrm{M}-46 a m u), 267(\mathrm{M}-74 \mathrm{amu}), 241(\mathrm{M}-100 \mathrm{amu})$ and 153 (M - $188 \mathrm{amu})$, clearly indicating that this compound is non-glycosylated and therefore has no relationship with known anthocyanins (Table 9). The use of NMR technology may help elucidate the structural features of this compound, which to our knowledge, is identified in pulses for the first time.

Peak $61\left(t_{\mathrm{R}}=7.43 \mathrm{~min}\right)$ appear to be a monomer of peak $64\left(t_{\mathrm{R}}=8.08 \mathrm{~min}\right)$. Peak 61 has $[\mathrm{M}-\mathrm{H}]^{-}$at $m / \mathrm{z} 521$, with a major MS/MS product ion at $m / z 359(\mathrm{M}-162 \mathrm{amu})$ suggesting loss of glucose moiety. Peak 64 MS/MS spectra showed ions at $\mathrm{m} / \mathrm{z} 521$ and 1043, indicating that the compound had an aglycone with $m / z 359$ bonded to a glucose unit, and then the two compounds are linked together. For this reason, an ion with high intensity at $\mathrm{m} / \mathrm{z} 359$ occurs, possibly from breaking of the interflavanoid linkage. Other major fragments occur at $m / z 344(\mathrm{M}-162-15$ amu $)$ and $119(\mathrm{M}-162-15-225$ 
amu) (Table 9). This is an unusual structural pattern that, to our knowledge, has never been described before in phenolic compounds.

Peak $63\left(t_{\mathrm{R}}=8.05 \mathrm{~min}, \lambda_{\max }=353 \mathrm{~nm}\right)$ is a high molecular weight compound with $[\mathrm{M}-\mathrm{H}]^{-}$at $\mathrm{m} / \mathrm{z}$ 985. The major MS/MS ions upon fragmentation were at $\mathrm{m} / \mathrm{z} 521$ (M - $464 a m u)$, suggesting loss of glucose + HHDP (302 amu). The fragment at $\mathrm{m} / \mathrm{z} 477$ indicated a further loss of $44 \mathrm{amu}$, in addition to losing the HHDP-glucose group (i.e. $\mathrm{M}$ - $464-44 a m u)$. A loss of 44 amu corresponds to loss of a free carbonyl. The other ions produced were at $\mathrm{m} / \mathrm{z} 463(\mathrm{M}-464-44-12$ amu $)$ and $341(\mathrm{M}-644 \mathrm{amu})$. Thus far, we suspect that the ion with mass 644 had constituents with mass of 136 in addition to HHDP-glucose group (Table 9).

Peak $65\left(t_{\mathrm{R}}=8.27 \mathrm{~min}, \lambda_{\max }=381 \mathrm{~nm}\right)$ showed a precursor ion at $\mathrm{m} / \mathrm{z} 561$. The MS/MS spectrum gave a fragment at $\mathrm{m} / \mathrm{z} 409$ ( $\mathrm{M}-152 \mathrm{amu})$, corresponding to a loss of galloyl unit (234). Further, another major ion at $m / z 273(\mathrm{M}-152-136$ amu) suggesting possible structural relationship with peak 64 in that the ion with mass 288 $(152+136 \mathrm{amu})$ could be consisting of a galloyl unit as well as a compound with mass of 136. In addition, they both have UV-vis absorption maxima between $350-400 \mathrm{~nm}$ (Table 9).

In peak $67\left(t_{\mathrm{R}}=8.75 \mathrm{~min}, \lambda_{\max }=269 \mathrm{~nm}\right)$, the appearance of a fragment at $\mathrm{m} / \mathrm{z}$ 561, corresponding to the loss of $288 \mathrm{amu}$ is observed, and that, we believe, is due to the cleavage of flavanol (epi)-catechin (Table 9). A loss of 288 amu indicates the (epi)catechin most probably is situated in the upper unit (161). This is followed by a fragment at $m / z 409(\mathrm{M}-288-152 \mathrm{amu})$, corresponding to subsequent loss of a galloyl unit (152 
amu); and at $\mathrm{m} / \mathrm{z} 367(\mathrm{M}-288-152-42 \mathrm{amu})$, corresponding to another loss of acetoyl unit (42 amu). The presence of a strong signal at $\mathrm{m} / \mathrm{z} 287$ makes us believe that compounds with masses 288 and 287 actually came from an A-type procyanidin (575 $a m u$ ), with additional groups such as galloyl, acetoyl and another compound with a total mass of 80 amu.

Peak $69\left(t_{\mathrm{R}}=9.38 \mathrm{~min}, \lambda_{\max }=352 \mathrm{~nm}\right)$ had $[\mathrm{M}-\mathrm{H}]^{-}$at $\mathrm{m} / \mathrm{z}$ 493. The fragmentation, however, was different, with main fragments at $m / z 181$ (loss of 312 amu), 167 (loss of $326 \mathrm{amu}$ ) and 123 (loss of $370 \mathrm{amu}$ ) (Table 9). Based on this, the identity of this minor peak cannot be elucidated since the fragmentation sequence does not follow any known pattern.

Finally, peak $71\left(t_{\mathrm{R}}=9.85 \mathrm{~min}, \lambda_{\max }=260 \mathrm{~nm}\right)$ had $[\mathrm{M}-\mathrm{H}]-$ at $\mathrm{m} / \mathrm{z} 553$. Its fragmentation pattern of $\mathrm{m} / \mathrm{z} 385 \rightarrow 241 \rightarrow 167$ provided little information to help in its identification. Similarly, we could not correctly elucidate the structure of peak $72\left(t_{\mathrm{R}}=\right.$ $10.38 \mathrm{~min}, \lambda_{\max }=274 \mathrm{~nm}$ ) which had pseudo-molecular ion at $\mathrm{m} / \mathrm{z} \mathrm{579}$, and whose fragmentation followed this pattern: $m / z 385 \rightarrow 325 \rightarrow 283 \rightarrow 241 \rightarrow 193$ (Table 9). Small amounts of catechin might be present in the compounds not yet identified, and which have similar spectral characteristics or fragmentation ions as (epi)-catechin. We also believe some of these unidentified peaks might be new compounds never reported before in pulses. To adequately characterize these unidentified peaks, extensive fractionation and purification of these peaks and application of NMR technology is suggested. 


\section{VITA}

Leonnard Odhiambo Ojwang is from East-Gem location, Uranga sub-location, Siaya, Kenya. He received his Bachelor of Science degree (First Class Honors) in dairy science and technology from Egerton University, Njoro, Nakuru, Kenya in 2005. He moved to the United States in 2006 where he obtained his Master of Science degree in food science from the University of Missouri, Columbia, in 2007. His Master's Thesis focused on methods of improving the value of sorghum pigments as potential natural food colorants. He initiated his degree of Doctor of philosophy at the same university in Spring 2008 and later transferred to Texas A\&M University in Fall of the same year, where he received The Regent's Fellowship Award in recognition of outstanding achievement in 2007 - 2008. He obtained his Doctorate degree in food science and technology from Texas A\&M University at College Station, TX in 2012. He specializes in grain chemistry, biochemistry, processing, and molecular biology, with relevance to human nutrition, and his research focuses on identifying secondary plant metabolites (phytoalexins) and minor constituents that impact food quality and human health. He publishes under the name Leonnard O. Ojwang. He is currently employed at Kellogg Company, Battle Creek, MI.

Dr. Ojwang is also a co-founder of the online magazine East Africa in Focus, which is headquartered in Columbia, MO.

His permanent address is P.O. BOX 3564, Eldoret, Kenya. Dr. Ojwang may be reached at leotonado@yahoo.com or leotonado@gmail.com. 